NISTIR 6890

\title{
Fire Resistance Determination and Performance Prediction Research Needs Workshop: Proceedings
}

William Grosshandler

Editor 

NISTIR 6890

\section{Fire Resistance Determination and Performance Prediction Research Needs Workshop: Proceedings}

William Grosshandler Editor

Building and Fire Research Laboratory

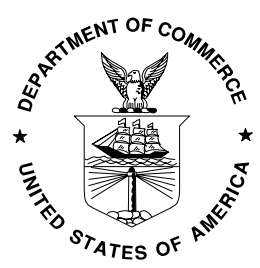

U.S. Department of Commerce Donald L. Evans, Secretary

Technology Administration Phillip J. Bond, Under Secretary of Commerce for Technology

National Institute of Standards and Technology Arden L. Bement, Jr., Director 



\begin{abstract}
The National Institute of Standards and Technology's Building and Fire Research Laboratory, as the national laboratory responsible for research into building fires, initiated a program prior to the events of September 11 to put structural fire protection on a stronger scientific footing. The first phase of this program focused on addressing the poor performance of high strength concrete (HSC) in fire, which was not yet reflected in any design codes. The catastrophic collapses of the World Trade Center underscored the need not only to accelerate but also to broaden this effort to include fire safety design of steel construction. A workshop calling upon scientific and engineering experts in materials, fire protection, and structural design was held February 19 and 20, 2002, at NIST to identify the research required to underpin meaningful test and predictive methods for use in evaluating the performance of structures subject to real fires. The specific objectives of the workshop were to review current practices for achieving fire resistance; to explore the promise of fire dynamics simulations and structural behavior predictions at elevated temperatures; to identify new fire resistance options coming from materials science; to identify opportunities and needs in advanced computational methods; and to identify applications and needs for emerging measurement, instrumentation and test methods. Commercial, academic and government experts provided background and suggestions on how best to achieve the objectives, from the perspective of the discipline they represented. This information is summarized in these Proceedings. Key recommendations include the following:

- $\quad$ to develop new experimental methods for measuring high temperature thermal and mechanical properties of structural and insulating materials;

- to develop experimental facilities and capabilities for measuring the behavior of real-scale connections and assemblies under controlled fires that permit extrapolation to total building frame behavior up to the point of failure;

- to improve the physics and speed of sophisticated numerical models, and to expand the use and acceptance of proven, simpler computational design tools;

- to establish as a goal the need to predict the performance of coupled building systems in elevated temperatures to the point of impending failure;

- to develop a strategy to effectively incorporate technological advances in structural fire resistance into engineering tools that support performance-based design alternatives;

- $\quad$ to train and improve communications between the architecture and engineering professions; and

- $\quad$ to appreciate the needs of, and better train, building code officials and regulators.
\end{abstract}




\section{ACKNOWLEDGEMENTS}

The success of any workshop is dependent upon the hard work of the individual speakers and facilitators, and the efforts of participants motivated toward a common goal. These proceedings are an assimilation of the contributions from the workshop participants, with some of the text coming directly from the presentations of the invited panelists from the following organizations:

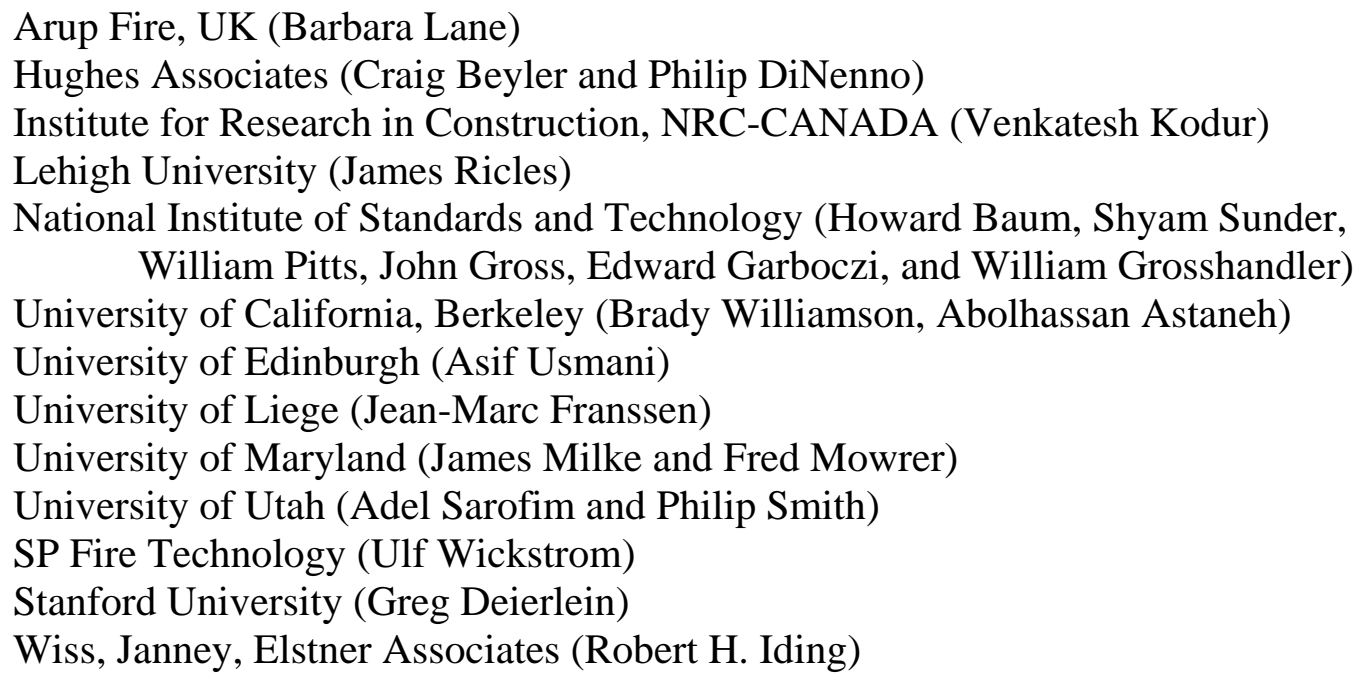

Verbatim copies of the presentations are included in the appendix. In addition, the editor wishes to acknowledge the assistance of Ms. Wanda Duffin of NIST, who helped with the planning, organizing and running of the workshop.

\section{DISCLAIMER}

Certain companies and commercial products are identified in this paper in order to specify adequately the source of information or of equipment used. Such identification does not imply endorsement or recommendation by the National Institute of Standards and Technology, nor does it imply that this source or equipment is the best available for the purpose. 
page

ABSTRACT iii

ACKNOWLEDGEMENTS

DISCLAIMER

BACKGROUND 1

WORKSHOP ORGANIZATION AND OBJECTIVES 2

HISTORY AND CURRENT PRACTICE

Craig Beyler, Philip DiNenno, and James Milke

$\begin{array}{ll}\text { FIRE TESTING AND SIMULATION } & 7\end{array}$

Howard Baum, Adel Sarofim, Philip Smith, Asif Usmani, Venkatesh Kodur, and Ulf Wickstrom

FIRE RESISTANT MATERIALS

R. Brady Williamson, Frederick Mowrer, Robert Iding, and Abdohlhassan Astaneh

STRUCTURAL PERFORMANCE

Jean-Marc Franssen, James Ricles, Greg Deierlein, and Barbara Lane

$\begin{array}{ll}\text { RECOMMENDATIONS } & 26\end{array}$

$\begin{array}{lr}\text { REFERENCES } & 29\end{array}$

\section{APPENDICES}

I. Workshop Agenda 31

II. Workshop Attendees $\quad 33$

III. Workshop Presentations 39 


\section{FIRE RESISTANCE DETERMINATION \& PERFORMANCE PREDICTION RESEARCH NEEDS}

\section{BACKGROUND}

The enormity of the loss of life and the economic impact caused by the destruction on September 11, 2001, has led the scientific and engineering community to recognize its responsibility to understand the technical issues associated with the buildings that collapsed that day. The Twin Towers, as designed, withstood the physical impact of the aircraft but succumbed to the thermal impact of the ensuing fire. WTC 7, with unknown but significantly less structural damage collapsed hours later, apparently due to the fire that burned unchecked, making it the first instance of a building of such a design to ever fail by this method. The relative amount of damage to the Pentagon due to the initial impact and due to the subsequent fire has been investigated, which is important if we are to learn the right lessons from the observed building performance, occupant behavior, and fire fighter response.

Central to all these events is the fire resistance of the structures. No one did a calculation ahead of time to predict how resistant to heat these buildings were in the event of an extreme fire. Why? Consider the following reasons:

- $\quad$ There was no code requirement to include a realistic fire scenario.

- A plane crash into a high-rise building followed by severe fire had never occurred.

- Structural engineers anticipated a possible accidental hit by an aircraft, but the architect responsible for fireproofing did no fire analysis.

- The structural elements were protected with fire resistant coatings and panels following the accepted practice of the day.

- In the late 1960s (when the buildings were designed), the engineering tools available to predict the performance of structural connections and assemblies in an actual large fire setting were primitive.

- The prevailing mindset at the time the Towers were designed was "the engineer designs the structure and the architect specifies the fire protection."

The National Institute of Standards and Technology's (NIST's) Building and Fire Research Laboratory (BFRL), as the national laboratory responsible for research into building fires, initiated a program prior to the events of September 11 to put structural fire protection on a stronger scientific footing. The first phase of this program focused on addressing the poor performance of high strength concrete (HSC) in fire, which was not yet reflected in any design codes. As a result, scientific data and knowledge related to mechanical properties of HSC at high temperature, methods for mitigating explosive spalling in fire-exposed HSC, and recommended code provisions for HSC strength-temperature relationship were developed and published [30-32]. However, the catastrophic collapses of the World Trade Center underscored the need not only to accelerate but also to broaden this effort to include fire safety design of steel construction. A workshop calling upon scientific and engineering experts in materials, fire protection, and structural dynamics was held February 19 and 20, 2002, at NIST in Gaithersburg, $\mathrm{MD}$, to identify the fundamental research required to underpin meaningful test and predictive 
methods for use in evaluating the performance of structures subject to actual fires. The agenda with the topics covered, speakers names and affiliations is shown in Appendix I. Appendix II includes a list of those who attended, and Appendix III contains the presentations.

\section{WORKSHOP ORGANIZATION AND OBJECTIVES}

The tone of the workshop was set by Sunder (see Appendix III. A) who provided an overview of the NIST strategy for advancing standards, technology and practices leading to cost-effective safety and security of buildings and critical facilities, with explicit reference to the proposed investigation of the World Trade Center disaster. In addition to the 24 month investigation, the strategy calls for sustained research and a developmental effort in structural fire protection; human behavior, emergency response and mobility; building vulnerability reduction; and an industry-led roadmap for construction and infrastructure support. As part of the structural fire protection program, research and development are proposed for methods of fire resistance determination, improved fire resistance coatings and materials, fire safety design and retrofit of structures, and mitigation of progressive collapse.

Grosshandler laid out a vision that extended beyond a direct response to the events of 9/11/01 (see Appendix III. B): Vision Scientifically-based performance predictions for the design and operation of buildings, accepted by regulators and major stakeholders, that enable a rational balance of competing demands for fire safety, function, economy, aesthetics, and environmental stewardship.

Improvements to current understanding of instrumentation development, computational methods, and measurement techniques are needed to achieve this vision. The need for performance prediction extends to building materials, products, structural elements, and systems up to the point of imminent fire-caused collapse of a significant load-bearing element. Assessment of the uncertainties in the prediction of performance, and convincing the regulators and stakeholders of the validity of the uncertainty established, will be as important as the development of the tools themselves.

The specific objectives of the workshop were laid down by Grosshandler as follows:

- $\quad$ to review current understanding of practices for achieving fire resistance;

- to explore the promise of fire dynamics simulations and structural behavior predictions;

- to identify new fire resistance options coming from materials science;

- to identify opportunities and needs in advanced computational methods; and

- to identify applications and needs for emerging measurement, instrumentation, test methods.

Commercial, academic and government experts provided background and suggestions on how best to achieve the workshop objectives, from the perspective of the discipline they represented. This information is summarized in the following sections, loosely categorized as History and Current Practice, Fire Testing and Simulations, Fire Resistant Materials, and Structural Performance. The final sections provide a summary of the workshop and list specific recommendations. 


\section{HISTORY AND CURRENT PRACTICE}

\section{P. DiNenno and C. Beyler}

DiNenno and Beyler (Appendix III. C) provided an overview of designing fire resistance for buildings. The first fire endurance tests in the U.S. were conducted in Denver on floors in 1890. The New York City Building Department adopted a code around 1900, which required floor systems to endure a five hour exposure to a furnace maintained at a temperature of $1100{ }^{\circ} \mathrm{C}$ with a mass loading of $211 \mathrm{~kg} / \mathrm{m}^{2}$, and to subsequently withstand a load four times this for $24 \mathrm{~h}$. A furnace for conducting the test was located at Columbia University. The Baltimore fire in 1904 led to the formation of an ASTM committee to develop an American standard for fire resistance. The first standards were released in 1908, with similar load requirements but the peak furnace temperature decreased from the New York code to $927^{\circ} \mathrm{C}$. Within the next ten years, testing was being conducted at Factory Mutual, the National Board of Fire Underwriters, the National Bureau of Standards and Underwriters Laboratories. Standard fire resistance tests for loaded columns began to be developed at UL around 1917. The year 1918 saw the release of ASTM C19, the first edition of the standard that is now numbered ASTM E119 [1], which contained provisions for floor and wall testing using a standard time-temperature curve and a $25 \%$ safety factor with respect to time. Ingberg [2] of the National Bureau of Standards led the efforts in the U.S. during the 1920s, examining different fuel loads and suggesting that integrating the furnace temperature over time was a way to compare performance among various fire scenarios and furnace conditions.

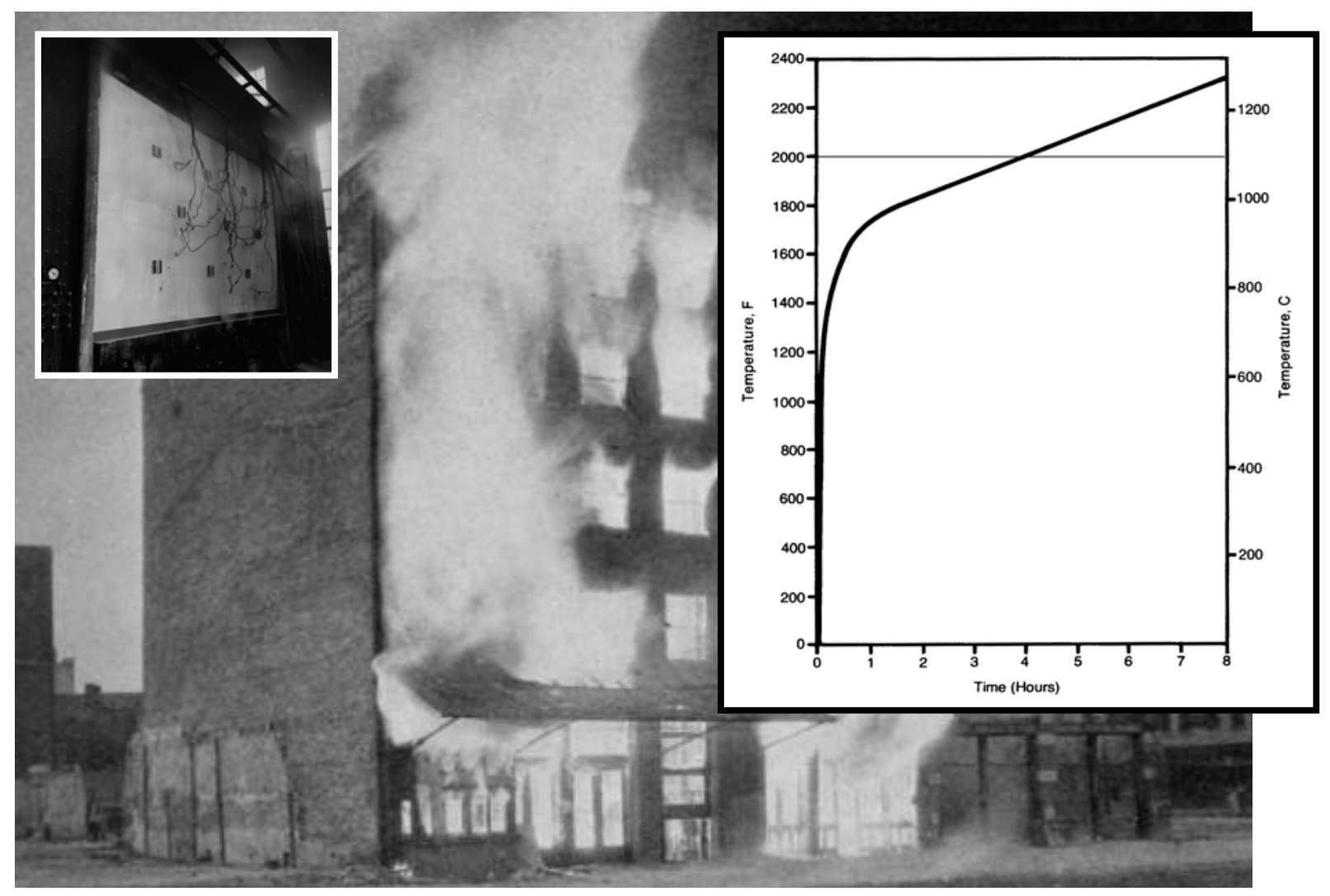

Figure 1. Photograph [3] of building fire as part of a series of tests used to develop timetemperature curve. Inset is a wall assembly ready for testing in the ASTM E119 furnace. 
The compelling needs for fire resistance are the following:

- to prevent building collapse;

- to prevent fire spread from building to building;

- to contain the fire from spreading horizontally through wall partitions and vertically through floor assemblies;

- to maintain safe means of egress;

- to control the movement of smoke; and

- to provide for fire fighter safety

Today, fire resistance requirements are established in a purely prescriptive manner by building code and are a function of occupancy, height and area of the space, and whether or not sprinklers are present. Testing is done routinely at many commercial laboratories following the procedures specified in ASTM E119, NFPA 251 [4], ISO 834 [5], or some variant developed by FM or UL. A standard time-temperature curve, based upon the work of Ingberg, is used to challenge the test specimen. Pass/fail criteria are based upon the peak temperature attained at the back of the test article and/or whether or not the test article collapses or distorts in a fashion that allows hot gases to escape (and in the case of E119, whether the wall can withstand the pressure of a hose stream). Many structural elements are tested unloaded; there is no limit on the amount of deflection that a beam can undergo and still pass the test; and connections are not tested at all. Products that are tested with these methods are assigned an equivalent fire endurance time (in hours).

The materials and systems currently used to provide fire resistance to structural members include sprayed fibers, cementitious materials, mastics, intumescent paints, suspended ceilings and drywall assemblies (membranes), concrete encasements, tiles, and plaster/lath. The adhesion and cohesion properties of spray-on fireproofing [6], and gross behavior when exposed to modest deflection and indirect impact loads are measured in standard tests $[15,16]$, but hardness and resistance to direct impact are not explicitly measured.

While a number of revisions were made to the above standards throughout the twentieth century, the prescriptive nature for these fire resistance test methods remains unaltered, in spite of changing fire loads and significant advances in our knowledge of fire and structural behavior. As early as the 1950s the engineering community was beginning to understand a number of situations that caused the fire exposure curve established by Ingberg [2] to vary significantly from reality, including post-flashover fires, ventilation controlled fires, and different insulation properties of wall linings. More was understood about the thermal response of columns and beams to changes in temperature, with new analytical, numerical, and experimental methods being developed to predict column buckling, beam deflection and truss deflection. Finite element heat transfer models, structural response models (e.g., FASBUS [7]), and models of post flashover fire conditions (e.g., COMPF [8]) were available by 1980. It is suggested by DiNenno and Beyler (Appendix III. C) that all of these tools can be brought to bear on the problem of predicting fire resistance performance of structural systems.

Figure 2 provides a framework for working these issues. Design fire exposure should be dictated by a modern fire load survey, and the knowledge gained from our capability to characterize local heat flux in a way more meaningful than provided by the well-stirred assumption. Data on the 
thermal and mechanical response of insulation systems needs to be institutionalized, and standard test methods and performance criteria developed for mechanical response, non-fire impact loading and fire exposure. The performance of fire barriers is needed along with that of load-bearing elements. The relative role for full structural models and detailed local deformation analysis needs to be assessed, especially regarding the performance of connections. A full compliment of test methods are needed to establish engineering properties. Furnace testing should be severe; e.g., ASTM E1529 [9] is a simple bounding fire exposure that provides a harsher (compared to ASTM E119) thermal test of the mechanical properties of fireproofing materials. Test methods should relate more directly to the mechanical and thermal environment likely to be experienced in a real structural fire, and should be used primarily as a validation of engineering methods. Performance criteria must be established depending upon the question being asked.

The greatest difficulty encountered in advancing fire resistance performance prediction, according to DiNenno and Beyler, is translating our increased understanding and technology into codes and standards. It is necessary to develop a broad consensus for the need to change how fire protection engineering is done. Science-based fire protection design practices need to be codified, and building codes must be formulated to accept new practices. Education of engineers, architects and authorities having jurisdiction is essential. Science-based structural fire protection is technically achievable, though it will require a total reexamination of how things are done, from product listing to design to operations (inspection, testing and maintenance). The payoff is known cost-effective performance and assured safety.

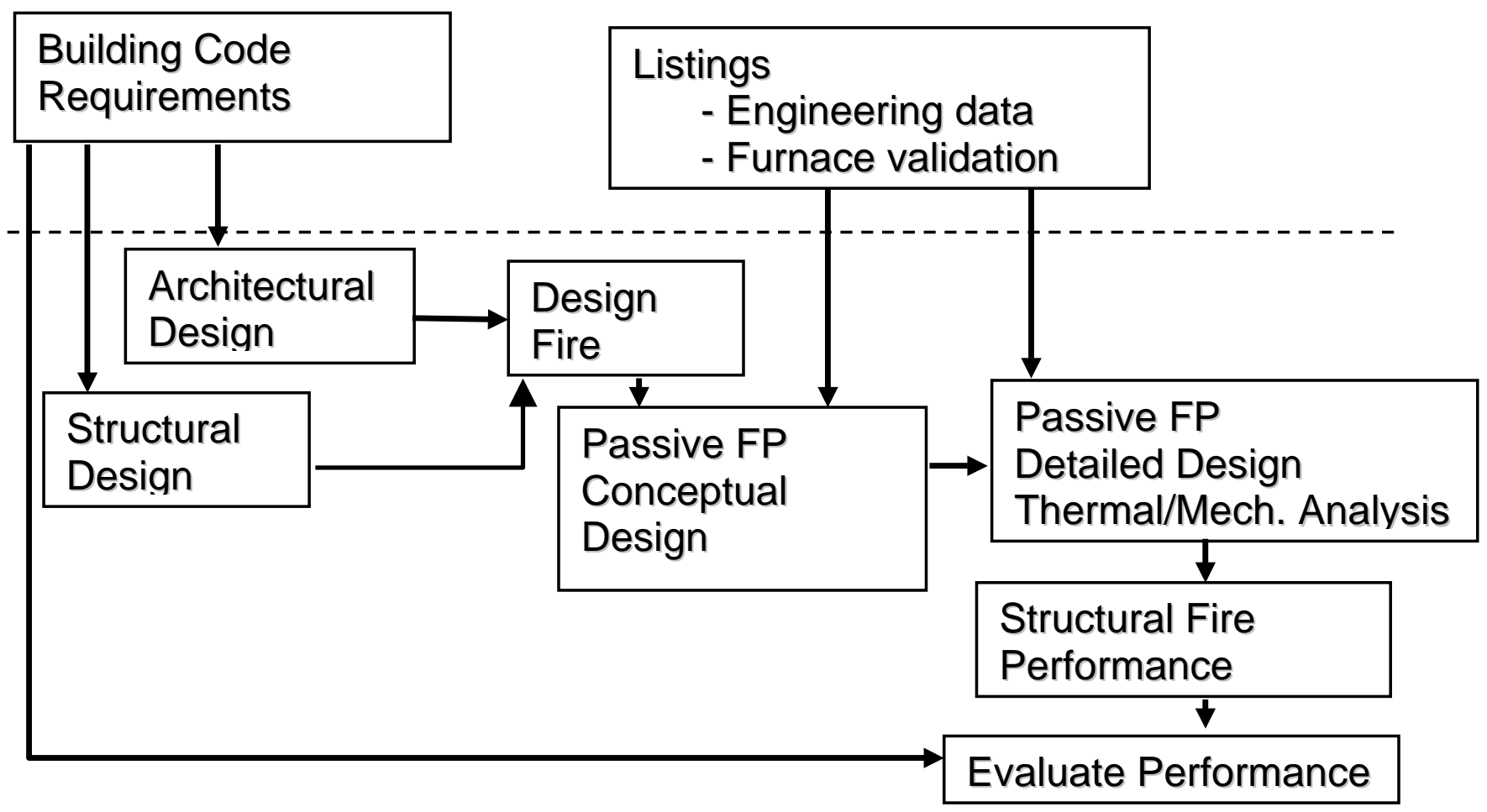

Figure 2. Science-Based Structural Fire Protection Design (DiNenno and Beyler) 


\section{$\underline{\text { J. Milke }}$}

Milke (Appendix III. D) described an effort by the American Society of Civil Engineers (ASCE) and the Society of Fire Protection Engineers (SFPE) to develop a standard on performance-based structural fire protection analyses, motivated by the difficulty in relating the current comparative tests to actual fire performance. The new standard will outline calculation procedures to link the results of tests to structural performance. Other organizations involved in the effort include the American Iron and Steel Institute (AISI), the concrete industry, the Masonry Alliance for Codes and Standards, and the American Forest and Paper Association (AFPA). The analytical framework is shown in Fig. 3. The material properties, thermal response and structural response of concrete, masonry and steel are each handled in their own section of the standard. A role will exist for simple calculations, advanced computations and experiments, all working together to determine the performance of individual structural elements, structural assemblies, and the global response of the building.

The fire exposure will be based upon heat flux (including radiative and convective contributions) as a function of time as well as temperature vs. time. Pool fires, distributed fires, and external fire exposures will be included. The thermal response of the structural elements can be followed using multi-dimensional finite element analysis with the boundary conditions provided by the (experimental and/or numerical) fire exposure. Although some material properties have been tabulated, many more, especially at higher temperature, have to be compiled. The structural response will be determined by a combination of first-order, single element analyseis (column stability, moment analysis of a slab/beam, isothermal over a range of temperatures). Computer simulations are needed to account for temperature distributions in space, variable cross-section members, complex loading, and frame analyses. Additional experimental programs are required to develop a complete material properties data base, to better characterize complex material behavior (cracking, adherence, charring and spalling), to calibrate models, and to examine interactions between component building assemblies and adjacent building assemblies within the larger structural frame.

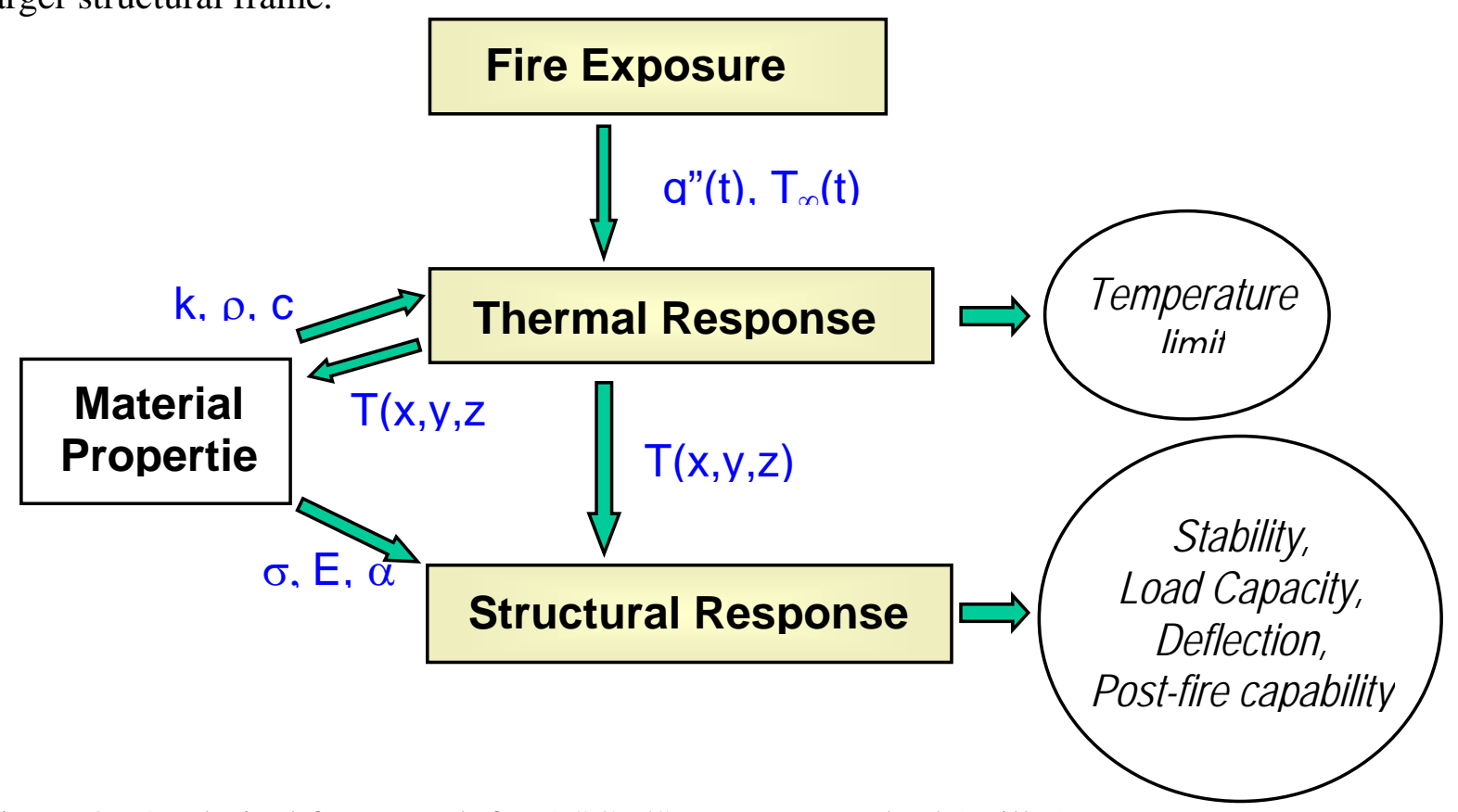

Figure 3. Analytical framework for ASCE/SFPE pre-standard (Milke) 

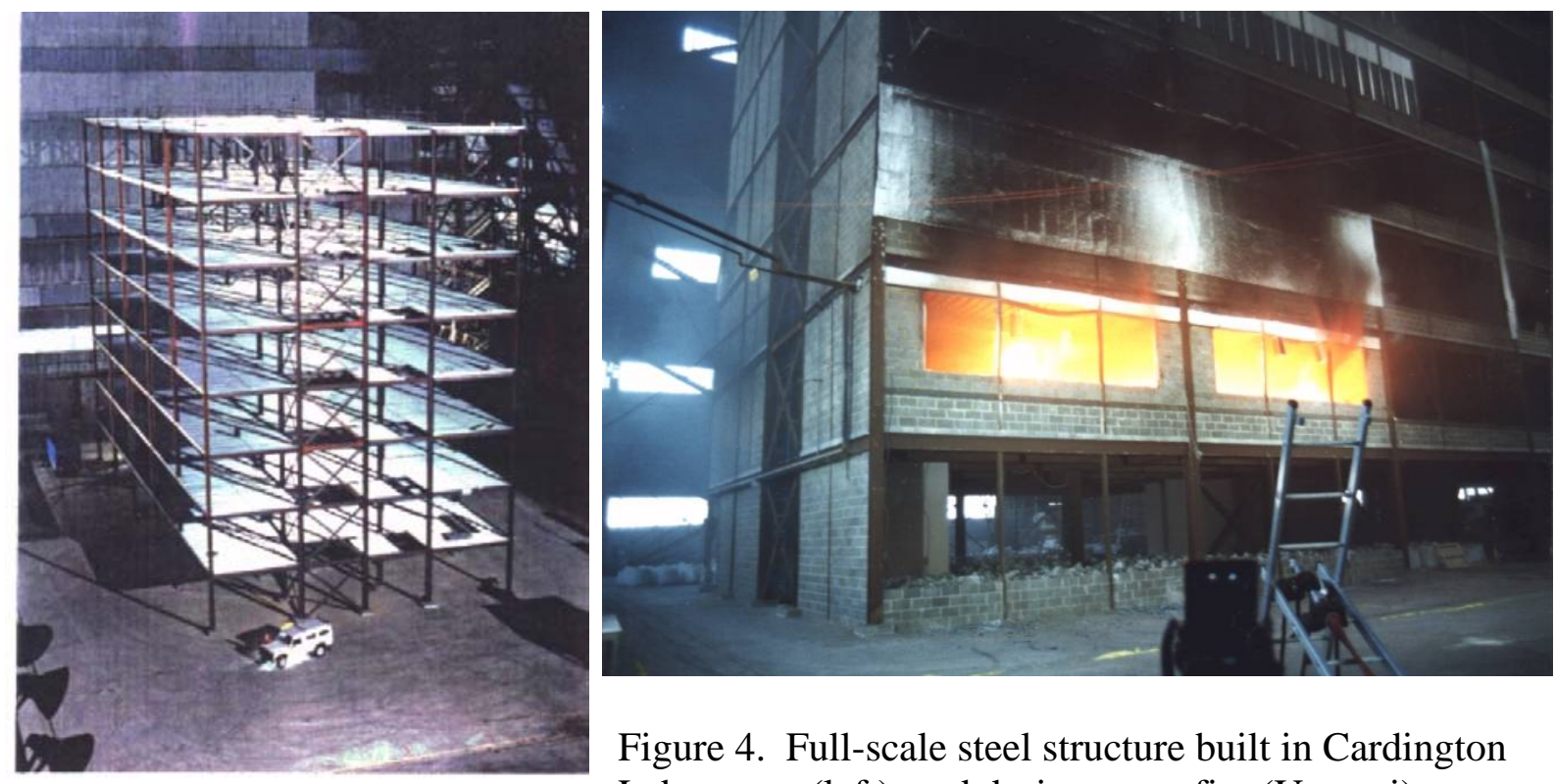

Figure 4. Full-scale steel structure built in Cardington Laboratory (left), and during a test fire (Usmani)

\section{FIRE TESTING AND SIMULATION}

\section{H. Baum}

The research needs from a fire modeler's perspective were stated succinctly by Baum. The first need is associated with defining the building. While conceptually straightforward, the large amount of data available to describe a modern building and the differing ways that these data are used for design, operations, and maintenance overwhelms the individual interested in predicting fire resistance performance, leading to great inefficiencies in the calculations and limiting their value. An efficient way to generate an electronic database that can be accessed seamlessly for multiple purposes is critical. The detail has to be sufficient to capture the location and operations of the HVAC systems, elevators and stairways. The second need is to develop a better understanding of the burning behavior of the contents of modern buildings, including complex shaped objects (e.g., real furniture), libraries and paper files. Being able to predict the occurrence of fire-induced geometry changes is the third primary need, specifically windows breaking and the warping/penetration of partitions (walls and floors).

\section{A. Sarofim and P. Smith}

An overview of the Center for the Simulation of Accidental Fires and Explosions (C-SAFE) located at the University of Utah was given by Sarofim and Smith (Appendix III. E). C-SAFE is allied with the Accelerated Strategic Computing Initiative (ASCI) to develop (unclassified) simulation science in support of the DOE defense program laboratories to safeguard the U.S. nuclear stockpile. C-SAFE is focused on the science-based tools for numerical simulation of accidental fires and explosions, within the context of handling and storing highly flammable material. The accident scenario to be simulated is a conventional high explosive material in a metal container of arbitrary shape, size and location within an arbitrary, sooting hydrocarbon pool fire. Following an assumed ignition of the liquid fuel, the calculations are made of the fire spread, the dynamics of the container, high energy transformations, and conditions that lead to 
accidental detonation. An example was provided of a calculation of a $10 \mathrm{~m}$ diameter heptane pool fire in a $(50 \mathrm{~m})^{3}$ domain. With 3.4 million computational cells and 6800 time steps, the calculation took $18 \mathrm{~h}$ to complete on the Los Alamos Nirvana computer (500 processors). The challenge for the Center is to make optimum use of the increasing number of processors to allow finer spatial resolution. Problem areas for the integrated calculation exist at the interfaces between the various phases, communication among the multiple scientific disciplines involved and with the ultimate user, and all aspects of data management (transfer, storage, mining). Lessons from Sarofim and Smith that may bear on predicting the fire resistance of structures include the encouragement to consider interdisciplinary approaches on cross-cutting issues, in particular a close collaboration with software engineers and computer scientists. "Amphibians" are needed to bridge disciplinary gaps, and the importance of communication cannot be overstated. The C-SAFE program has advanced the state of computational chemistry to predict properties, mechanisms and kinetics, and more detailed chemistry and fluid mechanics can be included in massively parallel computations. The material point methods show promise for handling large deformations and the break up of structures. Sarofim and Smith concluded by emphasizing the importance of experiments for guiding and validating the computations.

\section{$\underline{\text { A. Usmani }}$}

An eight story steel structure, shown in Figure 4, was built in Cardington, England in the mid 1990s [10] to examine the behavior of individual elements and the structural frame when exposed to various fire environments. The impetus for the full-scale testing was to demonstrate that the requirements for structural design fire safety were overly conservative. The Cardington tests have improved our understanding of structural behavior in fire, produced data for validating computer models. The new understanding of composite framed structure behavior in fire, so generated, may lead eventually to more rational design methods, and could reduce the cost of steel fire protection.

Usmani (Appendix III. G) described the challenge of numerically modeling the response of the Cardington structure to different fire loads. ABAQUS [11, 12] was used to examine a large number of structural arrangements and the details of modeling and subsequent interpretations of behavior are too voluminous to present here. However, interested readers can find many reports and other documentation containing substantial details of this work at http://www.civ.ed.ac.uk/research/fire/project/main.html.

Very briefly, this work revealed the following lessons for whole structure behavior in fire:

- restraint to thermal strain dominates behavior of the composite beam and slab system

- conventional loading contribution to overall behavior is low

- the results show low sensitivity to variations in strength and stiffness properties of steel

- at large deflections tensile membrane action in the spans and compressive membrane action near the perimeter supports of floor slabs were observed

- thermal strains automatically produce a beneficial load-carrying shape in tensile membrane action for slabs without large and damaging mechanical strains

- the load capacity can be further enhanced by thermal pre-stressing

- local buckling of the lower flange always occurred but was not found to be a detrimental mechanism 
A simple analysis will reveal that in a member restrained from lateral translation, as the mean temperature increases, compression occurs, but as the through-depth temperature gradient increases, tension occurs. The former scenario is most likely in a slow growing, protracted fire, while the latter results from a rapidly growing, short duration fire. Frames smaller than the Cardington structure may have fewer redundant paths, and the fires could extend over the entire floor. By the same token, large compartments that may be a part of a very large frame may behave quite differently because of the nature of the fire (spreading with local flashover perhaps) leading to significantly different structural response. To enable reliable tensile membrane mechanisms, it is necessary that the floor slab reinforcement is anchored at the compartment perimeter, with interior continuity provided by lapping reinforcement. Edge and corner compartments have discontinuous edges that may or may not have fire protection. Unprotected edges will provide considerably lower anchorage to tensile membrane forces, therefore protecting edge beams seems worthwhile as a means to anchor membrane forces and to protect cladding. Further 3-D modeling using DIANA was conducted to examine the impact of these variables on the structure and the results produced similar conclusions.

The key conclusions from this work are that the structural response to a fire depends upon the rate of heating as well as the temperature of the structure, and that different fires can produce very different stress/strain patterns in composite floor systems. This is because most of the prefailure response of structural members depends upon the two geometric effects produced by heating, a mean temperature increase and a mean thermal gradient. The material effects of reduction in strength and stiffness begin to dominate just before failure.

Further research was suggested by Usmani to establish the worst case fire scenario on the basis of the maximum structural damage it would inflict on the building (in addition to other life safety issues such as smoke movement and egress, the worst case scenario(s) for these may be quite different). This would require new scientifically based and practical analysis methods for reliable prediction of structural damage against a given heating regime. Research is also required to properly include (in a risk-based framework), extreme fire events as limit states, (which should be the basis of all structural designs). Tall buildings with long evacuation times require special consideration to ensure that localized collapse does not lead to overall progressive collapse. Other questions that need further research are: Are floor slab failures ductile or brittle? Can one generalize that a short and hot fire places a more severe load on the structure than a sustained, less intense fire (or vice versa)? How important is it to model connections, the cooling process, and the integrity of non-load bearing compartment boundaries? A final provocative question posed (but not answered) by Usmani is, How does one define failure?

In terms of the fundamental structural and solid mechanics research required in the context of understanding structural response to extreme events, perhaps the most important research need is as follows. Most failures in large redundant structures have roots in local "seed" events (such as a crack or fracture) that grow without being arrested and cause progressive global collapse. Many local events in a large redundant structure will occur as load redistribution mechanisms and will be self-limiting under the overall equilibrium and compatibility constraints. A thorough understanding of the development of local structural phenomena into events that threaten global structural stability/integrity should be one of the main research objectives. 


\section{Kodur}

The positive attributes of high strength concrete for buildings and columns make it an attractive material, but its high density and low porosity make it susceptible to spalling under fire conditions. Since an intended benefit of concrete is the elimination of additional fire protection, methods are required to ensure the fire safety of high strength concrete. However, there are currently no guidelines for the exposure of high strength concrete to fire. Test methods for evaluating the fire resistance of large-scale structural systems were described by Kodur (Appendix III. H), and used to highlight the differences in performance between high and normal strength concrete.

Columns of both types of concrete were examined, with size, load intensity, fiber reinforcement, fire intensity, and reinforcement configuration the independent variables. The specimens were full-scale and designed according to code, and tested according to the protocol in ASTM E119 (see Figure 5). Column temperatures, deflections and degree of spalling were the dependent variables. The primary observations during the tests were that spalling was not significant in the first 30 minutes, and that using $135^{\circ}$ (as opposed to $90^{\circ}$ ) column-ties reduces early spalling to a minimum. Within $2 \mathrm{~h}$, hair line cracks appear, widen at corners, and lead to chunks of concrete dropping off for the $90^{\circ}$ reinforcing bar ties. Failure occurs when the ties open up and the rebar buckles. The $135^{\circ}$ ties remain superior all the way through the test. The normal strength concrete, for comparison, failed only locally, the ties did not open up nor rebar buckle, and less spalling occurred.
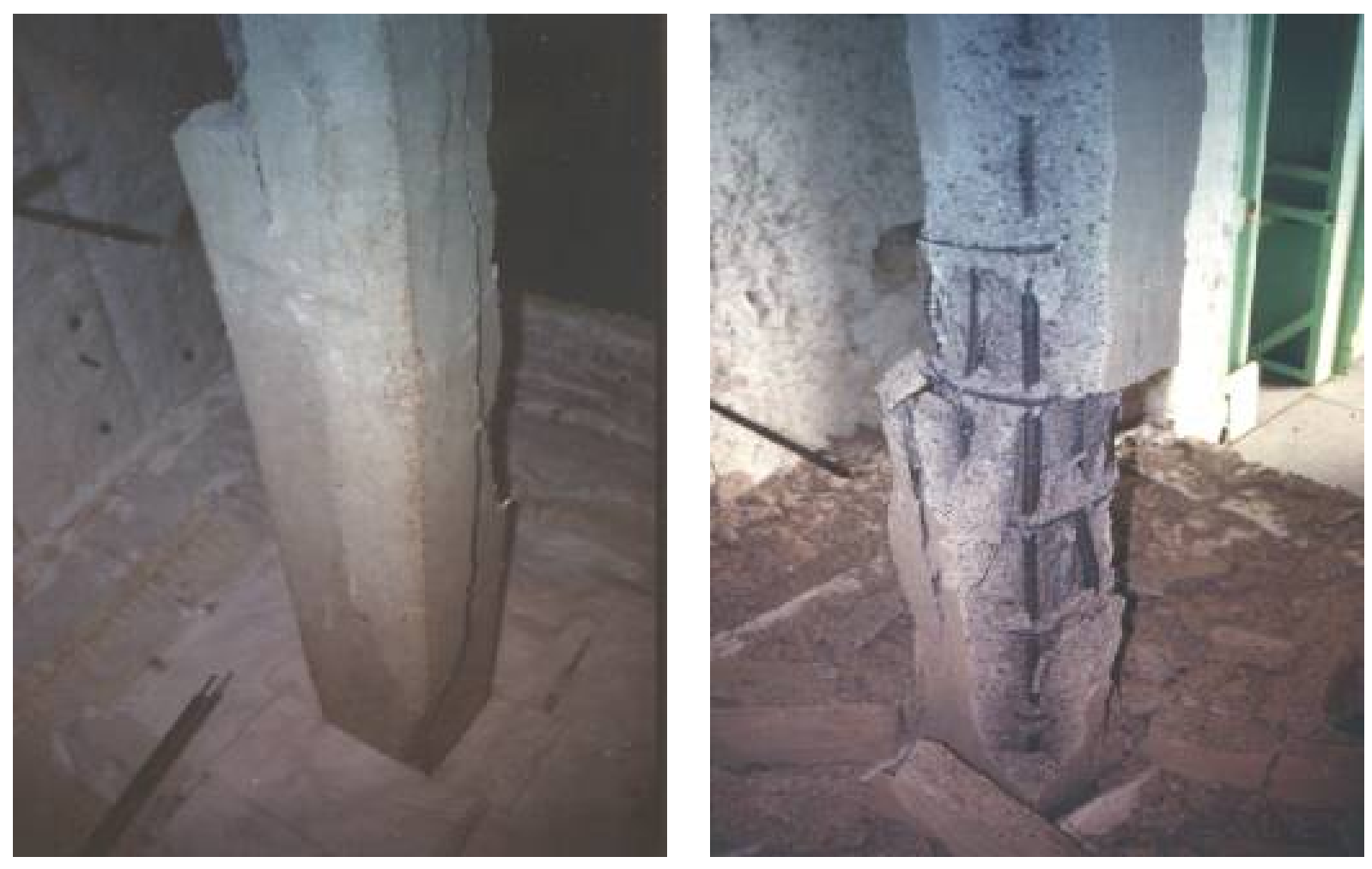

Figure 5. Comparison between normal strength concrete (left) and high strength concrete (right) after ASTM E119 column test. 


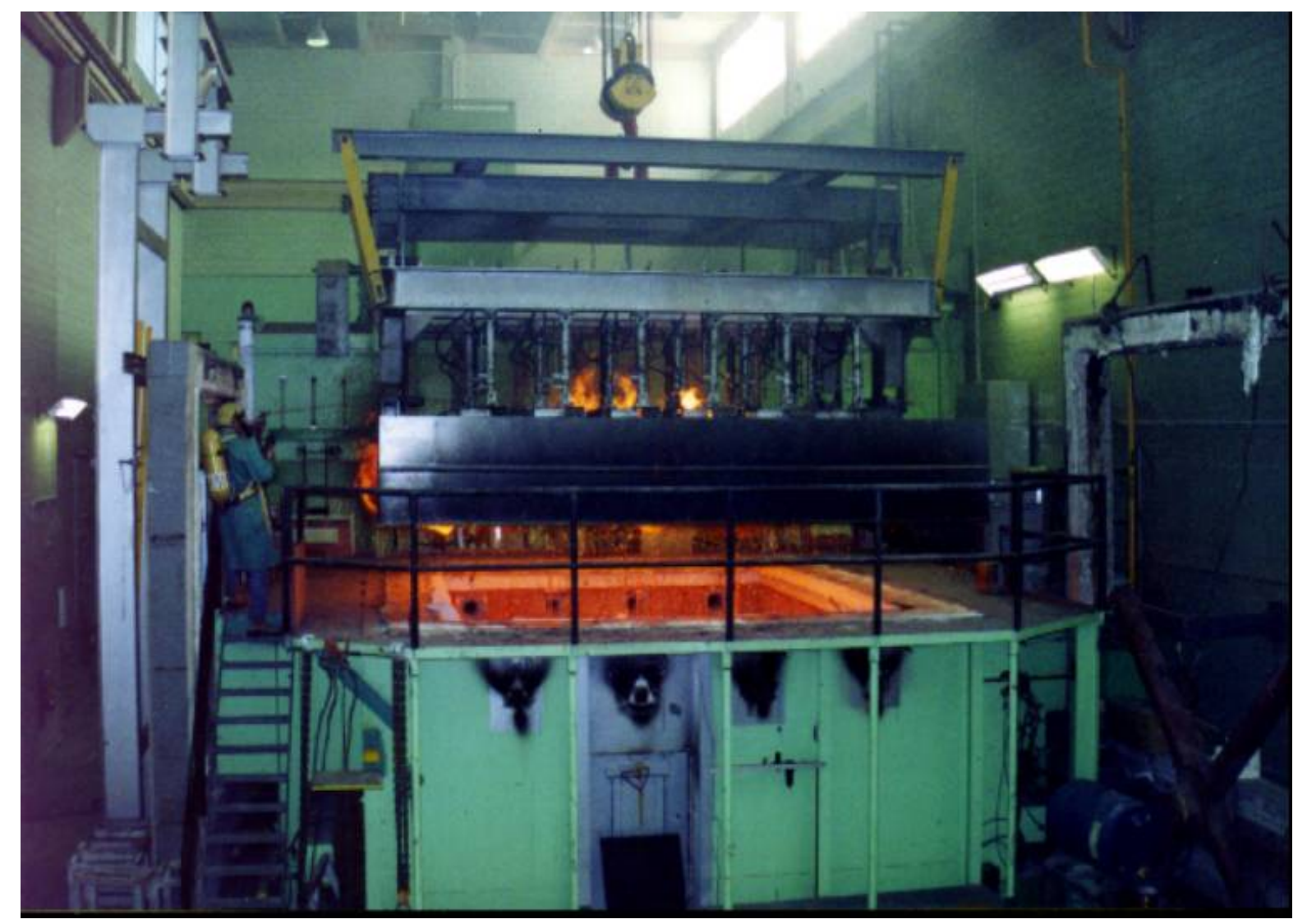

Figure 6. Photograph of modern floor testing furnace (Kodur)

Kodur summarized the factors that influence fire performance of concrete: compressive strength, reinforcement layout, moisture content, concrete density, heating rate, aggregate type, load intensity and type, and fiber reinforcement. The major factors that enhance spalling and decrease fire resistance are higher concrete strength and higher loads; factors that reduce spalling and increase fire resistance are closer tie spacing, $135^{\circ}$ ties, use of carbon aggregate, and use of reinforcing fibers. The experimental work conducted at CNRC was complimented by numerical studies of the factors influencing behavior, using thermal and mechanical properties measured at elevated temperatures, to develop design equations for fire resistant structures.

For the future, Kodur emphasized the need for realistic conditions when assessing fire resistance, the need for analytical tools and specified fire scenarios, with validated models, design fires and material properties. To be ready for performance-based codes, the industry must have suitable calculation methods, software packages and design guides. High performing materials must satisfy fire resistance criteria, and practical and cost-effective solutions to overcome current shortcomings are necessary.

\section{U. Wickstrom}

The need for improved fire testing in combination with calculations was the theme stressed by Wickstrom (Appendix III. I). When analyzing the performance of structures exposed to fires, 
one needs to consider the fire development (design fire), heat transfer to fire exposed structures, temperature development in the structures, and the resulting mechanical behavior of the structures. To improve fire resistance design, standard methods for measuring thermal and mechanical properties of structural and protective materials must be developed. Techniques for improving furnace testing and for monitoring deformation properties during the test are also required. Two specific techniques put forth by Wickstrom are the transient plane source, heat transmission, thermal diffusivity (TPS) apparatus and the plate thermometer. The former consists of a thin heater that is sandwiched between flat sections of the fire protection material under investigation. By following the temperature as a function of heat input, position, and time, key thermal properties can be generated. The plate thermometer can be used to monitor and control the temperature in the furnace (e.g., ISO 834 or ASTM E119). The benefit of the plate thermometer is that it allows one to calculate the true structural temperature in close agreement with the measured structural temperature (see Figure 7), in contrast to the standard shielded thermocouple. While no techniques were proposed for measuring deflection during the test, Wickstrom emphasized that such data are essential to relate calculated behavior to actual expected behavior.

\section{Plate Thermometer Measurements}

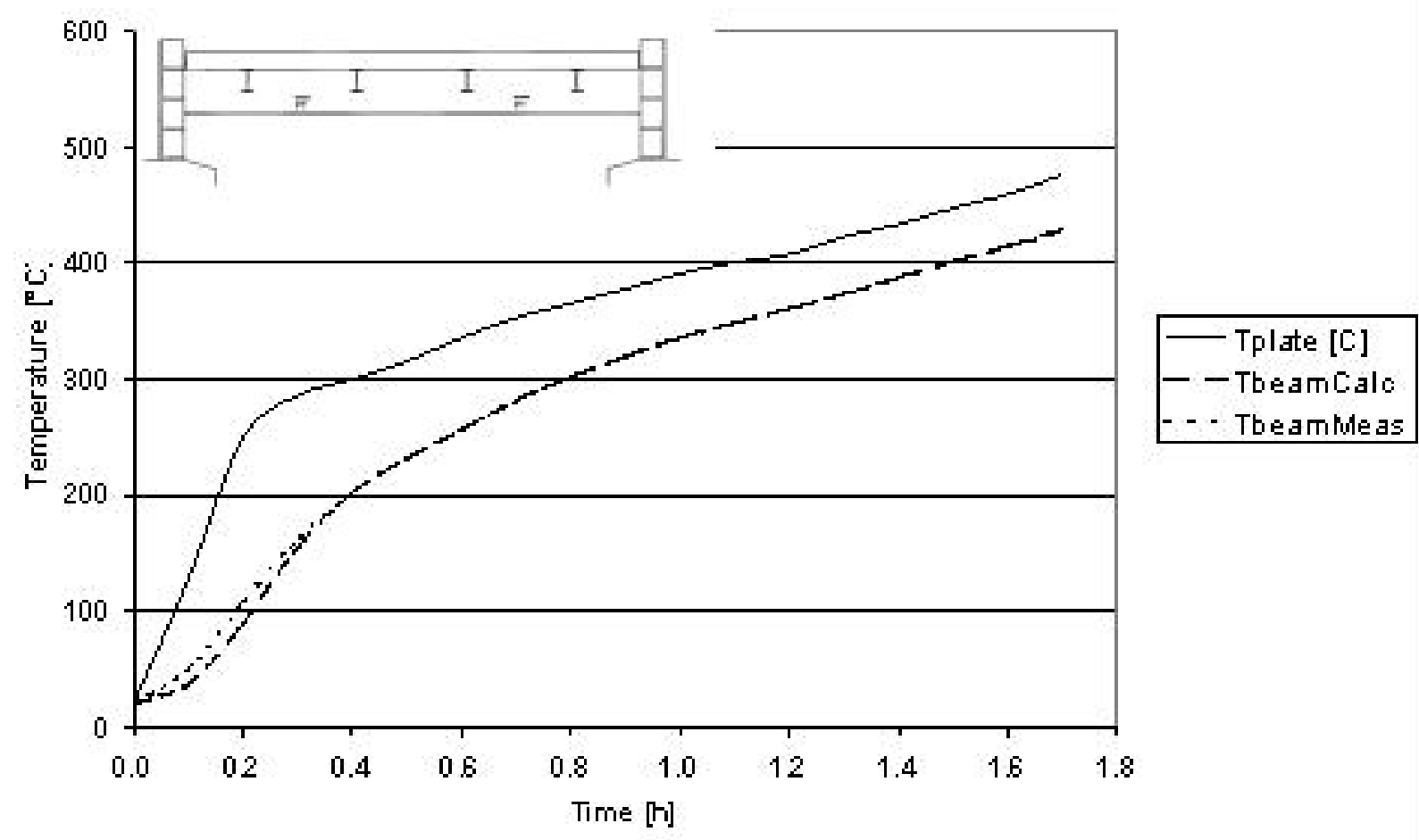

Figure 7. Temperature measurements in floor assembly furnace test, comparing the plate thermometer to the calculated temperature. 

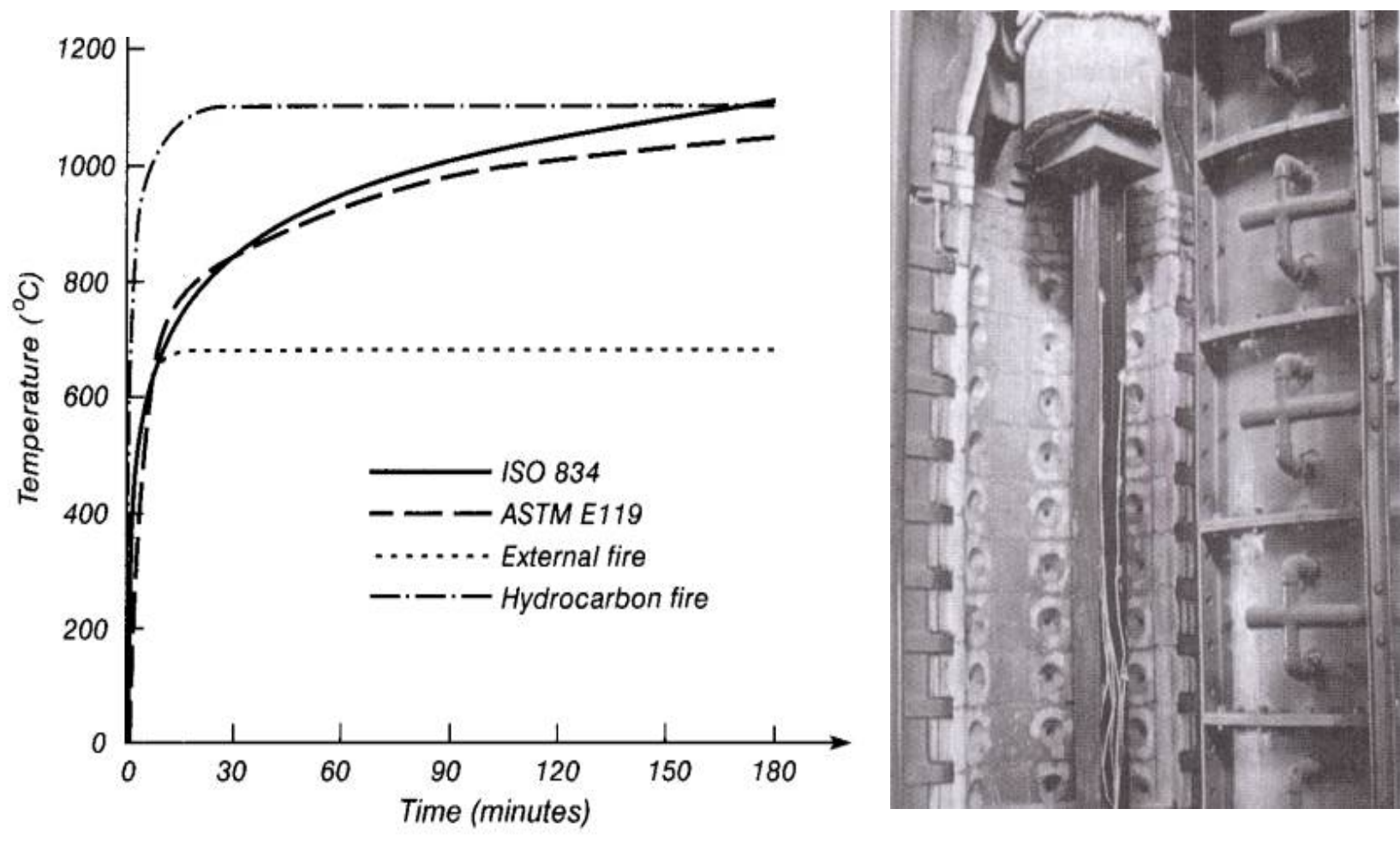

Figure 8. Alternative temperature-time curves for fire resistance tests (left), and a photograph of a steel column ready for testing in the furnace.

\section{FIRE RESISTANT MATERIALS}

\section{R.B. Williamson}

Williamson (Appendix III. K) briefed the participants on the history of fire protection of structural steel and the materials used for that purpose. Dating back to the 1898 Home Life Fire in New York City, a new approach to high rise safety began emerging that required buildings to be constructed of columns, floors, walls and other elements that were fire resistive, defined as the ability of an element to withstand the effects of fire for a specified period of time without loss of its fire separating or load bearing function. This ability was determined by exposure in a furnace to sustained high temperatures. Various temperature-time curves are used today, depending upon the country and application. Figure 8 compares the ISO 834 test, the hydrocarbon fire (ASTM E1529), and external fire exposures to the standard ASTM E119 curve (also shown in Figure 1). A column instrumented for a test is shown on the right.

The first materials used for fire proofing in the early 20th century were traditional construction materials such as masonry or concrete, which led to substantial labor costs and excessive weights. Gypsum-based systems such as wire lath and plaster systems came on the market thereafter, but these also suffered labor and weight penalties. Like concrete, these systems derived 


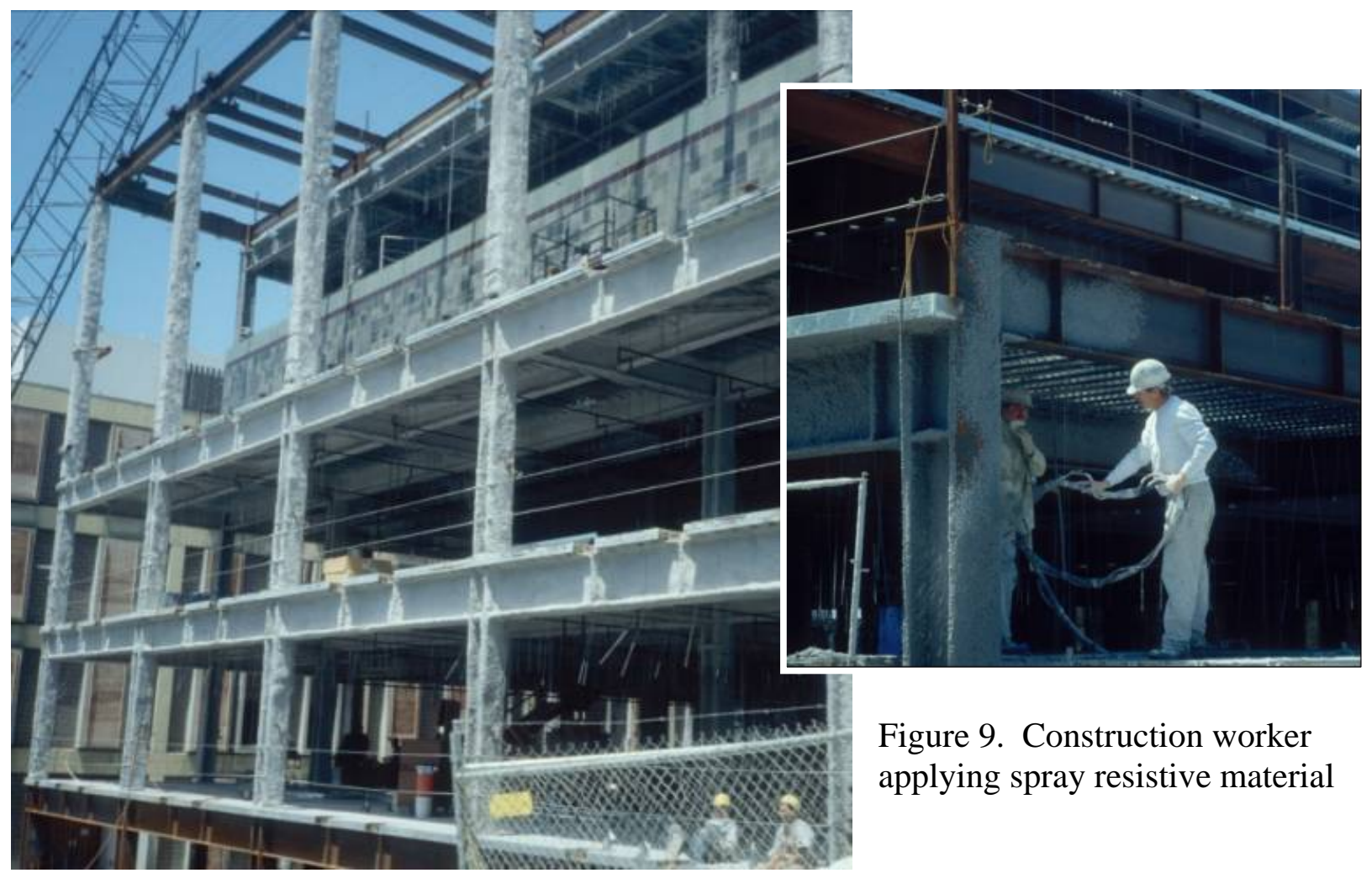

much of their effectiveness from water of crystallization, which is immune from normal evaporation. Sprayed fire resistive materials (SFRM) were introduced about 40 years ago as a lower labor cost, lighter weight alternative to concrete and lath/plaster. The SFRM also derived its fire resistive properties from water of hydration contained in the gypsum or portland cement used to bind various fibers and other fillers. A worker is shown applying SFRM at a recent construction site in Figure 9.

Williamson [13] specified four performance requirements of SFRM: performance under actual fire conditions; durability and integrity under normal life of structure; durability and integrity under the construction process; and integrity under extreme conditions (earthquakes, thermonuclear attack, severe fire). A number of ASTM tests currently are used (in addition to E119 for fire resistance) to address these requirements:

ASTM E605 [14], Thickness and Density

ASTM E736 [6], Test for Cohesive/Adhesive Properties of SFRM

ASTM E759 [15], Effect of Deflection

ASTM E760 [16], Effect of Impact on Bonding

ASTM E761 [17], Compressive Strength

ASTM E937 [18], Corrosion of Steel by SFRM

A fundamental weakness of all of these tests is that they are not well linked to materials science. According to Williamson (Appendix III. K), there are many different SFRM materials 
commercially available today, but the current test methods do not adequately address the most important properties or the range of conditions from ordinary fires to the extremes of a terrorist attack.

The current method for testing the cohesive/adhesive properties of SFRM (ASTM E736) consists of a disk with a hook for hanging a weight that is attached to the sprayed on fire resistive material with a quick setting adhesive. The material must withstand a minimum weight before becoming dislodged. The weakness of this method is that while failure from poor adhesion can be distinguished from failure due to poor cohesion, the method is incapable of providing failure loads for each, just whichever fails first. Williams [19] suggests an alternative approach to evaluate the adhesive properties separately, using what is called a blister test. Williamson (Appendix III. K) suggests adapting this technique to SFRM. A thin plastic bag with a bladder feed hose can be attached to the rigid steel substrate before applying the fire resistant material. The feed hose would extend beyond the fire resistive material layer. A measured pressure could be applied to the feed hose to cause the bag to inflate, and a blister would grow at the interface of the steel and SFRM to a size related to the interfacial properties.

Williamson concluded his remarks by recommending that the fire and non-fire performance of fire resistive materials be reevaluated in terms of current challenges to buildings and other structures. A new approach to testing and approvals is necessary, supported by sound research to characterize the available materials and to establish the micro-structure/property relationships that are central to materials science.

\section{$\underline{\text { F. Mowrer }}$}

Mowrer (Appendix III. J) listed a series of steps that typically might occur when a building is fireproofed.
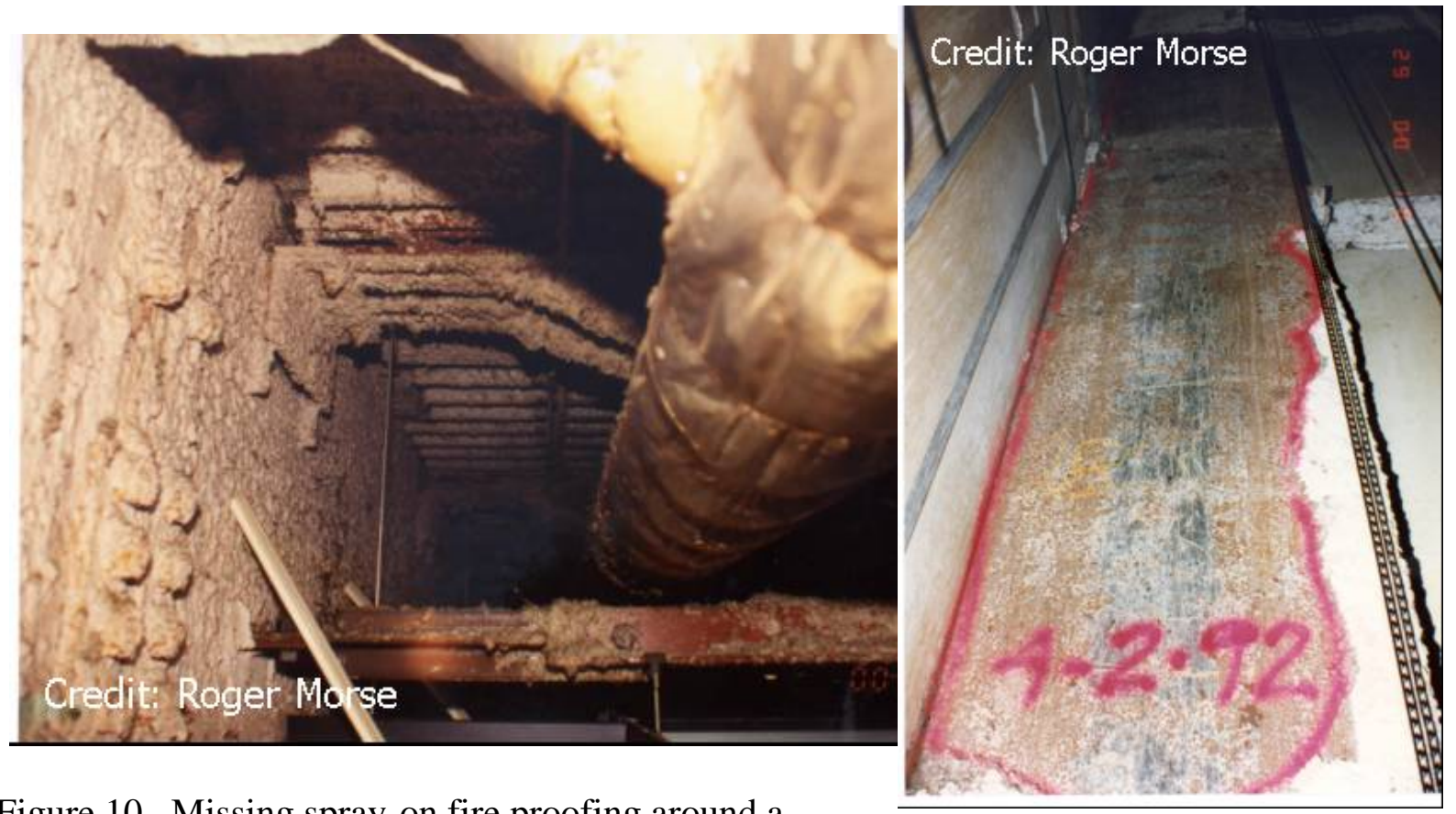

Figure 10. Missing spray-on fire proofing around a connection (left ) and missing fireproofing panels on a steel column (Mowrer). 
These include the following:

- $\quad$ structure erected

- fireproofing applied

- fireproofing inspected (maybe)

- fireproofing scraped off

- other building services installed

- everything covered with finishes

- fireproofing forgotten

Conditions that are troublesome include connections, attachments, members with extreme W/D ratios, long spans, and end restraints. Since connections are not evaluated in tests, what is the best way to protect them against fire? How much fireproofing do attachments require, and is it a function of the thickness and/or length of the element? Fireproofing thickness requirements are based upon standard geometries; how do those relate to round members and other non-planar arrangements? Four meters is about the maximum span tested; how are the fireproofing requirements extrapolated to spans that are considerably longer? Furnace test articles are often wedged into the frame; how does this arrangement relate to real-world constraint conditions? How can deficiencies in fire proofing be identified during inspections, and how can they be corrected? If fire proofing is damaged or missing, how does that impact the overall performance of the structure? (See Figure 10.) These are all issues that require research solutions.

\section{$\underline{\text { R. Iding }}$}

Iding (Appendix III. L) presented several case studies of performance-based structural analysis to determine fireproofing requirements [20]. There are three key elements in the approach:

- Fire Hazard Analysis - identify all possible fire scenarios and determine gas temperatures achieved adjacent to structural members.

- Thermal and Structural Analysis - calculate temperature history in structural elements and the elements' response (forces and stresses) to the fire with varying levels of fireproofing.

- Risk Mitigation Plan - revise fireproofing scheme, or devise alternative risk reduction schemes, to ensure performance is acceptable for type of building being designed.

A step-by-step methodology was described, with examples given for a transient trash fire in a power plant and fireproofing for an unusual structure for which no prescriptive code applied: the Eiffel Tower II in Las Vegas.

The following specific recommendations were provided by Iding:

- identify material properties at elevated temperatures, particularly those of spray-on fire proofing and intumescent paint

- develop analytical tools for structural connections

- develop peer review protocol for performance-based analysis during transition to new methodology

- incorporate basic capabilities for fire analysis into commercial computer codes that can handle non-linear structural effects 
- expose engineering students and practitioners to basics of structural fire analysis and computational tools, and sponsor workshops for non-specialists

- codify methods to calculate fire curves for most common scenarios to assist design engineers for routine applications

- examine fire safety of building as a whole and develop practical methods to avoid progressive collapse that could be incorporated into performance-based building codes

\begin{abstract}
A. Astaneh
Astaneh (Appendix III. M) discussed the protection of steel structures against impact, explosion and ensuing fire. An impact is a force applied on a building over a short time interval, and depending upon the geometry and velocity of the impacting object or pressure wave, dynamic forces are generated throughout the building which can cause serious damage at the local and global level to the structure and fire protection systems. The main route to life safety is by preventing collapse of the building directly following the initial impact and after any ensuing fire. The use of catenary action provided by a floor was presented as a possible technology to mitigate collapse. Cables imbedded in a floor specimen were shown to be able to significantly retard the onset of failure. The gross physical behavior was mimicked in a finite element analysis.

The challenge posed by Astaneh was for realistic modeling of the behavior of steel and composite structures exposed to sustained fires. Data are needed on the fire resistance of light weight and high strength concrete and on steel connections. More realistic models of local and overall buckling of steel and composite structures (including composite shear walls) at elevated temperatures are needed. Composite shear walls with a gap between the wall and frame could be used, for example, to protect egress routes. Research is also needed to better predict the performance of various structural systems, especially at elevated temperatures.
\end{abstract}

\title{
STRUCTURAL PERFORMANCE
}

\section{J-M. Franssen}

The frontiers of structural fire modeling were explored by Franssen (Appendix III. N). The temperature in the structure and mechanical behavior are simulated with SAFIR [21], a nonlinear, transient finite element model that determines the structure temperature as a function of three directions and the gas temperature, and determines the 3-dimensional displacements as a function of the structural temperature and loads. Limitations on computational resources constrain the capabilities of the mechanical model when 3-dimensional temperature field calculations such as those in Figure 11 are made. Beam finite element calculations provide a link between the thermal and mechanical analysis of the structural frame. Shell finite element calculations work well on thin elements and can successfully predict severe deformations, as shown in Figure 12.

The limits of structural fire modeling are associated with eight factors. (1) The first factor is the lack of thermal properties of structural materials (the thermal conductivity of concrete, for example, is presently under discussion in Europe, as well as the impact of radiative heat transfer to $\mathrm{H}$-steel sections, the so called shadow effect that reduces the radiation to the inner surface of a 


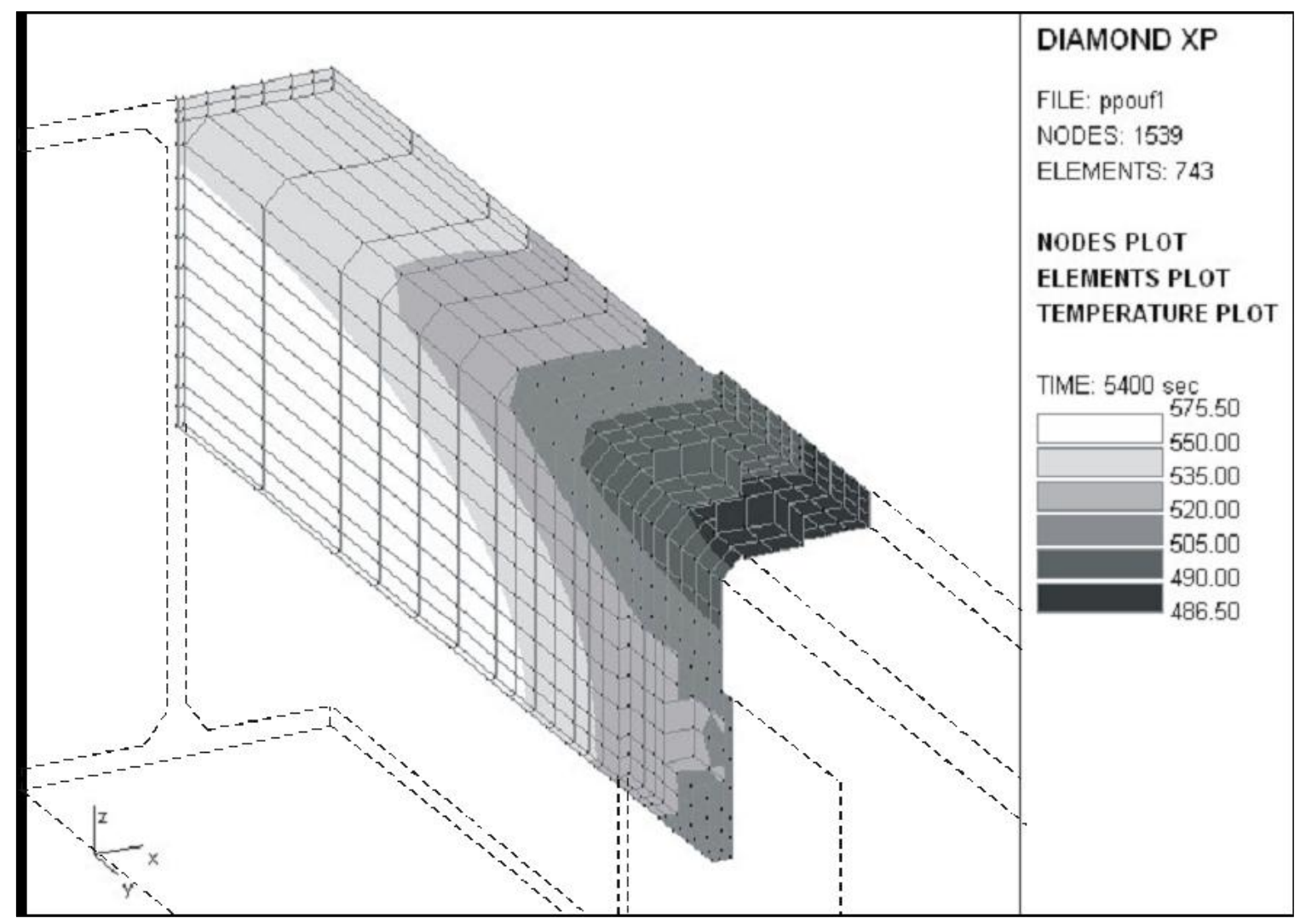

Figure 11. Temperature distribution in two steel beams connected by cover plates (Franssen)
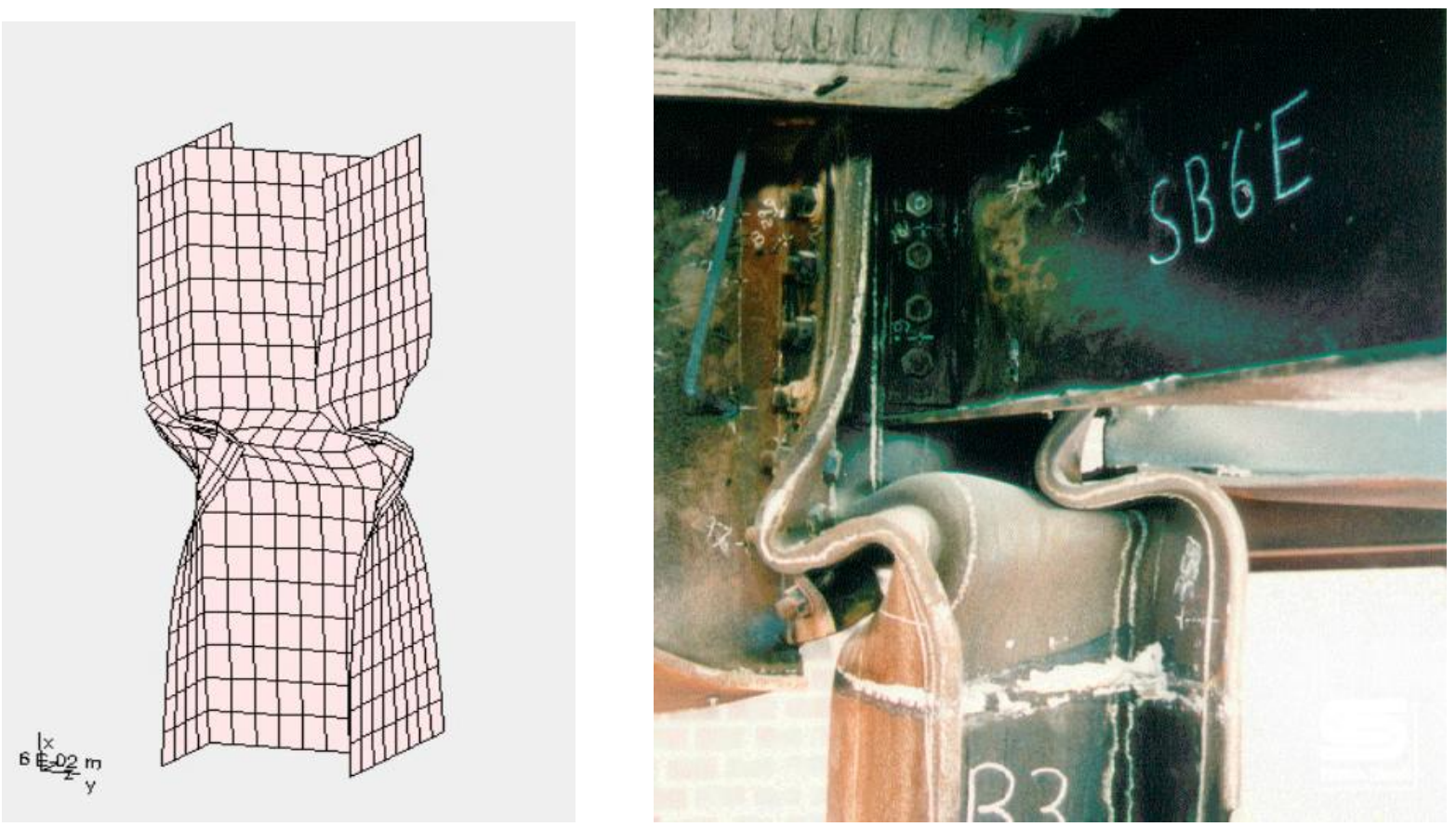

Figure 12. Shell finite element simulation showing severe deformation of a steel column (Franssen) 
wide flange section). (2) The second factor is the interaction between the gas and the structure in the case of localized fires, which is a problem for both CFD and zone models of the fire. (3) Spalling in concrete is a third factor that limits structural fire models. (4) The beam finite element models are based upon the Bernoulli hypothesis (that parallel planes remain parallel during deformation), which is a fourth factor limiting modeling in situations with significant rotation, local buckling, shear failure or debonding of reinforcing bars or prestressing tendons. (5) A non-physical local and/or temporary negative stiffness can arise in some situations, which causes the calculation to terminate. (6) Boundary conditions in the substructures are difficult to specify. Which may be more appropriate, fixed or free conditions? (7) A seventh limitation is the definition of failure. How much deformation qualifies as a failure of the element?

(Suggested criteria are given by Ryan and Robertson [22].) (8) Finally, structural fire models are limited to structures that do not exceed a certain size because computational resources are finite.

Franssen (Appendix III. N) concludes that

"for understanding and designing structures submitted to fire, numerical modelling offers capabilities that are unique. The frontiers at the moment are

- Spalling in concrete

- Thermal properties

- Local or temporary failures

- Very large structures

- Very large displacements

- Boundary conditions

- Interface with environment in localised fires

- $\quad$ Resources (money, time, people, ... )"

\section{J. Ricles}

The response of structures to earthquakes and extreme fires was reviewed by Ricles (Appendix III. O). Analysis and experimental testing are essential tools for predicting the fate of a building during an earthquake. Material modeling must deal with cyclic plasticity, cyclic degradation of material stiffness and strength, and fracture, all non-linear phenomena. Geometric nonlinearities accompany local buckling and global instabilities $(\mathrm{P}-\Delta)$.

Experimental testing is required to develop a database on real performance, to demonstrate proof of concept, and to calibrate analytical models. Shake table testing is precisely controlled and provides data in real time; however the specimen sized is quite limited. Reaction wall testing (pseudo-static or pseudo dynamic) allows one to test full-scale specimens, although the building system's response to the loads are not real time (compared to earthquake time scales). Full-scale component tests can also be conducted in multi-dimensional reaction wall facilities, although choosing the most appropriate boundary conditions, and controlling them requires careful attention. Time response remains an issue.

Finite element analysis can be applied to building details such as welded connections to examine the impact of cyclic load in the local region around the joints. Non-linear analysis of the 
structural system over time can also be performed, with the details of the connections such as panel zone deformations and connector flexibility (i.e., semi-rigid connections) considered.

Elevated temperatures effect the yield strength, the ultimate stress, the modulus of elasticity, and the coefficient of thermal expansion of all structural materials, leading to a dramatic decrease in structural performance of steel above $600{ }^{\circ} \mathrm{C}$. Member restraints change, large displacements can occur, and loads shifted to other parts of the structure. Beam twisting and local buckling, column local buckling, and connection failure are all observed.

Ricles (Appendix III. O) lists the following research issues and needs:

Testing

- determining the effects of structural redundancy, restraint, connections, and non-load bearing elements during structural component vs. structural system testing

- determining how to maintain the proper thermal environment

- developing heat resistant structural response sensors

- establishing proper testing protocol

- constructing and maintaining adequate facilities for fire testing $\underline{\text { Analysis }}$

- calibration of models with test data

- $\quad$ structural component vs. structural system modeling, with concern for the effects of structural redundancy, restraint, connections, and non-load bearing elements

- thermal input

- time scale

- non-linearities

- change in material properties due to thermal input and loading

- geometric non-linearities (large displacements, local buckling, load shifting)

- connection modeling (stiffness and strength deterioration, fracture)

Ricles concludes that success has been achieved in predicting the performance of structures to extreme earthquakes using sophisticated analytical models and experimental testing. Predicting the fire resistance and performance of structures is challenged by the physical complexities of structural fires, the level of sophistication needed for analytical models, and the compounding difficulty of experimental testing to calibrate these models.

\section{G. Deierlein}

Parallels were drawn by Deierlein (Appendix III. P) between performance-based engineering for fire and for earthquake hazards. Citing the ICC 2000 Performance Code [23], the objective of the design is "to limit the impact of a fire event in the building, its occupants, processes and use; and to limit the impact of an exposing fire on buildings, adjacent properties and processes." A level IV performance group (see Fig. 13) includes vital facilities that can sustain only moderate damage even under the rarest of disasters (earthquake or fire), while a low performing (level I), expendable structure can tolerate design criteria that lead to severe damage for a rare event, and moderate damage for frequent small events.

The qualitative description from the matrix can be made more explicit by relating the damage assessment to replacement cost and/or casualty rate, as shown in Figure 14 based upon the work 


\begin{tabular}{|c|c|c|c|c|}
\cline { 2 - 5 } \multicolumn{1}{c|}{} & \multicolumn{4}{c|}{ PERFORMANCE GROUPS } \\
\cline { 2 - 5 } \multicolumn{1}{c|}{} & I & II & III & IV \\
\hline $\begin{array}{c}\text { Very Large } \\
\text { (Very Rare) }\end{array}$ & SEVERE & SEVERE & HIGH & MODERATE \\
\hline $\begin{array}{c}\text { Large } \\
\text { (Rare) }\end{array}$ & SEVERE & HIGH & MODERATE & MILD \\
\hline $\begin{array}{c}\text { Medium } \\
\text { (Less Frequent) }\end{array}$ & HIGH & MODERATE & MILD & MILD \\
\hline $\begin{array}{c}\text { Small } \\
\text { (Frequent) }\end{array}$ & MODERATE & MILD & MILD & MILD \\
\hline
\end{tabular}

Figure 13. ICC 2000 performance matrix [23].

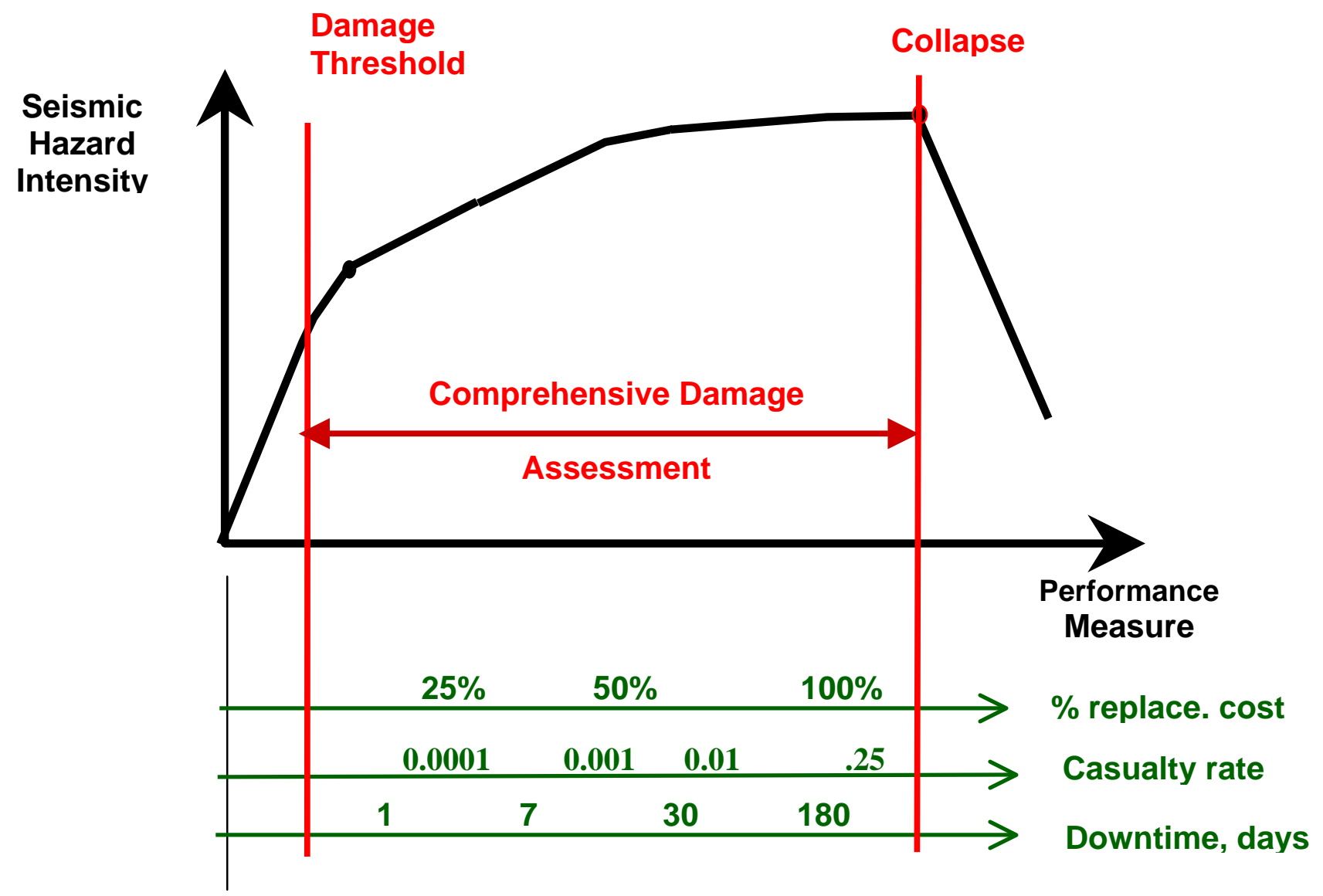

Figure 14. Explicit performance assessment in terms of earthquake intensity [24]. 
by Holmes [24]. As presented by Deierlein, the key attributes of performance based approaches are that they are more scientific and transparent, they address stakeholder decision needs at multiple levels, and they provide for a consistent treatment of risk and uncertainties. The methodology has four serial components: input damage intensity measures (e.g., earthquake duration and strength), engineering demand parameters (e.g., drift and acceleration felt by building), resulting damage measures (e.g., condition assessment and necessary repairs), and decision variables (e.g., fatalities and injuries, dollars lost, downtime). By examining each of the components in detail, a probabilistic description of a decision variable can be developed.

A parallel methodology was suggested to guide decisions involving fire safety design. Intensity measures could include fire load and compartment temperatures. Engineering demand parameters might be related to peak structural temperatures and deflections. The damage measures and decision variables would be similar to those used in the performance based earthquake engineering methodology, with the additional special considerations of the fire services. Questions that need to be answered in developing this methodology include the following:

- For whom is the methodology intended: the fire protection engineer, the structural engineer or the mechanical engineer?

- How does one describe the fire scenario, and how many scenarios need to be examined?

- How faithfully must the global analysis be able to predict local degradation of members, connections and composite action?

- Is there a different tolerance of risk for fires vis a vis earthquakes?

- What is the minimum level of protection required, and how does one quantify higher performance levels?

Deierlein summarized the issues and needs for improved fire resistance performance prediction o include a comprehensive methodology that is consistent with other hazards and evolving code provisions; a probabilistic fire hazard assessment; codification of acceptance criteria such as explicit numbers of causalities or dollars lost, component strength checks, and survival duration; structural simulation tools; and validation through laboratory tests and field reconnaissance.

\section{B. Lane}

Lane (Appendix III. Q) presented her list of items needed most for a numerical model of structural response to fire conditions, from the perspective of a consultant. She suggested that there were widespread concerns about the standard fire resistance test (temperature/time relationship is not the same as in real fires; structural response and fire protection materials response are important; how to deal with the huge body of existing data; how to relate standard fire test data to numerical structural fire models; the need for a new test). She felt that all could agree that mechanical response is not properly addressed in the current test (single elements tested and single elements analyzed; real frame behavior ignored, including effects of restrained thermal expansion, load transfer through connections to cooler elements, slab actions that sometimes may increase overall strength of composite frame). 
Current finite element models are just beginning to capture the complexities of structural fire response. The principles for advanced calculation models are laid out in the Eurocode 3, Part 1.2, Structural Fire Design [25], and in CIB W014 [26], Rational Fire Safety Engineering Approach to Fire Resistance in Buildings. There is also the ASCE/SFPE effort to guide fire model applications, and work sponsored by AISC. The information that needs to come from these studies should lead to a reference document for consultants and authorities having jurisdiction, stating design objectives and means for achieving acceptable results.

Clear guidance is required on the design-basis fires. Do we create a new standard fire resistance test, use temperature-time relationships from real fire data, or calculate the real fire environment from the known fuel load, ventilation, and boundary properties?

Once the design-basis fires are established, the heat transfer to the structural elements can be calculated, which leads to a time varying temperature field in each element. How well have existing heat transfer models been assessed, and are they sufficient for current construction materials and fire proofing? What level of detail is required regarding the temperature field?

The structure responds to the high temperature in a fire with a combination of effects: loss in strength and stiffness of the structural elements, compression forces in the elements produced by restraint to thermal expansion, greater deflections resulting from higher restraint, and curvature in the elements imposed by through-depth thermal gradients. The combination of these can produce a range of deflections and internal force patterns. Non-linear analysis is required to handle these complexities. A means to translate the results of the complex models into simple tables for mainstream design is needed, as is a way to use these models to incorporate new understanding into building codes. An intensive effort over the last decade in Europe is beginning to bear fruit. It is essential to build on this work rather than to start again, and to reformat the input and output to be useful in a design office.

Some specific models currently in use were mentioned by Lane. VULCAN [27], an implicit scheme developed by the University of Sheffield, applies to steel-framed buildings only, and was used to interpret the results of the Cardington full-scale tests. Geometric and material nonlinearities are included, and plate elements are used to simulate floor slabs. Beam-column elements are used to simulate beams and columns, and spring elements simulate the steel-to-steel connections. The heat transfer analysis is not a part of VULCAN. The University of Edinburgh used ABAQUS [10, 28], a non-linear model specifically for composite steel-framed buildings, to compare with the results of the Cardington fire tests. A stress resultant approach is used to describe the behavior of the shell elements simulating the floor slabs. Shear connectors are incorporated with rigid elements and pins joins approximate steel-t-steel connections. Reinforcements within the slab are included using a smeared model. ABAQUS includes heat transfer, assuming uniform temperature across elements but not necessarily along elements. Both an implicit and explicit version exist. Other models that should be examined are explicit such as LS-DYNA [29]. These models may be able to anticipate collapse because the can cope with highly non-linear situations. A thermal analysis may be conducted in parallel with the mechanical analysis. More computing time and power are obviously associated with these capabilities. 
Lane's wish list consists of the following:

- come to agreement on the concerns, issues and inaccuracies

- develop a reference document laying out acceptable principles required for AHJs and consultants

- establish the criteria for choosing a design fire, and the data, model, and input for codes

- establish heat transfer analysis capabilities

- compare and contrast existing 3D finite element models

- further develop these models to address complex behaviors associated with structural response to fire (beyond Cardington)

- develop usable commercial analysis tools

- develop the means to translate results into building codes and simple design methods

\section{SUMMARY}

Following the expert presentations described above, the participants broke into three parallel teams to discuss research issues and raise additional ones as they saw appropriate. Each team came up with their own list of priorities and shared them with the whole group on the second day. Their presentations are include in Appendices III. R. through III. T and summarized in the following paragraphs.

Lack of communication among disciplines was expressed by the first team as a hindrance to the introduction of new methods and technologies to structural fire safety. The proper education of young engineers and building designers would eventually overcome this hindrance, but it was felt to be critical to get the right information on structural fire performance to the structural engineering community and the authorities having jurisdiction in a more expeditious fashion. Establishing a full-time position at NIST dedicated to this problem, making use of steering committees to better define project goals and objectives, and development teams with fire modelers, structural engineers, computer scientists, and materials scientist were recommended as ways to increase communications across disciplines. The need to publish and to disseminate new research results across disciplines was also highlighted.

Construction materials were a second focus of recommendations. What is our current state of knowledge? Where gaps exist, we need to acquire basic thermal and physical properties using well thought out principles and accepted test methods, including under conditions likely to exist within a fire. The effects of material variability on installed performance need also be assessed. New information is required to characterize durability and reliability of fireproofing materials during normal operation and in the event of a fire, and the implication of these properties on inspection and maintenance protocols. Is there a role for new sensing methods?

There is a general lack of understanding of the science underlying existing test methods and the proper use of data derived therefrom. In fact, many current test methods are not well suited to collecting useful data; at the same time, the vast amount of test data that has been accumulated cannot be ignored. New fire test methods may be needed to address data gaps and to allow proper interpretation of the ratings generated from flawed or incomplete existing test methods. 
Although the tools used most often in design have an over reliance on empirical data and a general lack of scientific basis, a review and summary of the current generation of predictive methods would be useful. A recognized procedure for specifying the design fire is required. Integration of the gas phase fire models with structural response models is the key to progress, and we should borrow freely from computational methods generated outside the fire community as appropriate. Extending capabilities of current CFD models to better address flashover conditions is also required. All improved predictive capabilities will require full scale, fully instrumented validation tests with interaction between modellers and experimentalists. As a first step, a prototype simulation methodology could be developed joining a selected specific choice of existing software for fire simulation, thermal/mechanical properties, and structural response. Eventually, one would need a practical predictive tool for progressive collapse in fire, as well. The practical difficulty of blending structural numerical codes that are primarily commercial with fire numerical codes that are primarily public will need to be addressed as well

The second team listed validated engineering tools, a design framework for new construction, design for retrofitting existing construction, integration of structural and fire performance-based design, and education of engineers, designers and AHJs as the desired end products of a coordinated research effort. Tools for modeling fire growth include space independent models, a simplified approach that includes space/opening effects, and CFD models. The latter can not be used for direct routine design but can be used to develop design tools and for special design issues. A need-based approach must be established for fire growth models. The objective and amount of uncertainty that is acceptable helps define the need, which points out the utility of a standardized process for uncertainty quantification and analysis techniques.

Insulating and fire proofing materials dictate the amount of heat that will enter the structural elements. One needs to measure the thermal properties of insulating materials as a function of temperature, the adhesion/cohesion properties, and the tendency toward destructive decomposition due to abrasion and thermal degradation. Understanding the role of geometry (of the insulation and underlying structure) on durability is critical as well. The thermal/mechanical properties of structural materials as a function of temperature are a basic need. These include all properties of special steels (light gage steel, high strength/performance steels, welds, bolts, rebar, pre-stressing), high strength concrete, normal strength concrete , FRPs, aluminum, timber, and glazing.

Validation is needed of existing structural response tools for assemblies (including connections) and systems under fire conditions (including soot and other fire phenomena effects). Structural response engineering sub-models for specific fire phenomena and fire barrier models need to be developed. Structural response models need incorporation of high strength concrete behavior in analysis and design, and guidance on how to apply the "fire load" as a load combination to the entire structure. What are the design limit states (i.e., objectives of design)?

Performance criteria for insulating materials need to be developed for in-service use, including impact, maintenance and inspection over the life of the structure. The same is required for structural materials, products and systems. 
Improved fire measurement technologies (especially for heat flux) are required, along with standardized test methods for material property determination and for structural components such as connections. The possible use of existing ASTM E119 for standard fire model validation should be evaluated.

The third group listed fire exposure, thermal response, structural response, mitigation strategies (including the use of redundancy, prevention, and design with fire safety in mind) and improved communications among engineers, and regulators as critical needs. Instrumentation of real fires is needed to obtain better fuel load characterization, the impact of spatial distribution, temperature/oxygen histories, heat flux, products of combustion, and full cycle (heating and cooling) data. The behavior of fire proofing and non-structural elements (including glazing) needs to be modeled, including material properties and the thermal response of slabs, dehydration and cracking, improved high temperature performance data (modification of high strength concrete with polymer inclusion, composites), hysteresis, and the difference in response to "short-hot" and "long-cool" fires.

To predict structural response one needs to understand deflections and stresses, the behavior of connections, fire proofing materials, the impact of heating and cooling cycles, and to develop an efficient means to merge fire and structural models (zone with frame models). The models need also to be coupled with experiments for validation and to properly design the experiments and measurement methods. Detailed phenomenological models of chemistry, molecular dynamics, crack development, and pyrolysis behavior will aid the development of new materials and a better understanding of the thermal environment created by the fire.

Validation experiments and measurements are needed for basic material properties (especially the effect of temperature), constitutive properties of slabs (concrete), single step experiments, (ignition, fire spread), multiple step experiments (corner fires, flashover), and integrated tests (enclosures, building fires). Proper instrumentation is required to capture spatial and temporal aspect of fires, behavior of non-structural components (glazing), local stresses and deflection, and heat transfer through connections. The "real world" provides opportunities for validation through analysis of accidental fires.

Performance objectives should include the ability to relate test conditions to the real world. A danger with testing to traditional temperature-time curves arises from the dimensionality of the real world, which has the important implication that it determines the response; e.g., a plume impacting on the ceiling combines convection and radiation loads on the structure; flash-over has not been modeled, and yet the transition can significantly modify the heat transfer; and illdefined air availability changes the dynamics of the fire. There is a need to translate test results into real world situations. The integrity of fire walls is a major factor. Fire test data need to be used to validate models, but there are little data on more complex structures.

\section{RECOMMENDATIONS}

The stated objectives of the workshop were to review current practices for achieving fire resistance; to explore the promise of fire dynamics simulations and structural behavior predictions; to identify new fire resistance options coming from materials science; to identify 
opportunities and needs in advanced computational methods; and to identify applications and needs for emerging measurement, instrumentation and test methods. The first objective was clearly met as documented in this report and referenced material. A better appreciation was achieved across the multiple disciplines represented of what can and cannot be done with the current generation of fire dynamics and structural behavior models. No new fire resistance options nor materials technologies were revealed, although the paucity of technical data on current fireproofing materials and the inadequacy of test methods to evaluate their performance were themes that emerged continuously. The need to measure additional variables during structural fire testing and to quantify the uncertainty of parameters regularly measured were identified as problems worthy of study. An issue not originally raised but which emerged naturally during the discussions was the need to increase communications and education horizontally across technical disciplines and vertically from the research community to the regulator.

The following recommendations are the editor's synthesis of the discussions and opinions expressed by participants of the workshop:

\section{Communication/Education/Training}

- Cross-train practicing structural engineers, architects and fire protection engineers involved in new building construction and retrofit projects to ensure that rational fire safety is inculcated into the profession.

- Modify engineering and architecture curricula to increase student exposure to crossdisciplinary team work to enhance awareness of the other disciplines' capabilities in, and constraints to, assuring practical fire safe designs.

- Develop innovative techniques to better educate building code officials, AHJs, and the fire service of the capabilities and limitations of standard test methods and computational tools.

\section{$\underline{\text { Thermal and Mechanical Properties of Materials }}$}

- Identify existing and/or develop new experimental techniques for measuring the thermal and mechanical properties of structural materials (normal and high strength concrete, steel, steel/concrete composite, aluminum, fiber-reinforced composite, timber) at temperatures up to their point of failure.

- Standardize measurement methods and use them to accumulate a consistent, reliable high temperature data base on the thermal and mechanical properties that dominate the response of a structure to a severe fire up to the point of failure.

- Develop experimental protocols for measuring, at elevated temperature, the thermal and mechanical properties of non-structural building materials (glazing, fire stops, intumescent coatings, structural fireproofing) that impact structural integrity during a fire, and accumulate a consistent, reliable high temperature data base.

\section{Measured Behavior of Connections and Assemblies}

- Develop experimental methods and protocols for measuring the thermal and mechanical behavior of fireproofing as installed and when degraded by time, temperature, and stress. 
- Develop experimental methods and protocols for measuring the response of structural connections (including welds, bolts, rivets and adhesives) when exposed to severe fire conditions and loads.

- Develop fully instrumented experimental facilities for exposing floor and wall composite assemblies to controlled fires under measured loads up to the point of failure.

- Develop large-scale test facilities to the extent necessary to extrapolate the behavior of connections and assemblies to the behavior of whole building frames.

\section{Computational Models}

- Develop a guide for AHJs and designers detailing the range of fire and structural models that currently exist, including limitations and constraints.

- Establish a framework (or more likely a patchwork) of models to couple the fire exposure, the heat transfer, and structural behavior.

- Develop more efficient structural and CFD algorithms to expand the number of significant physical phenomena and the range of length scales that can be practically accommodated.

- Develop subgrid models to better resolve the heat transfer from the fire environment to the structural elements, and expand fire models to include post-flashover conditions.

- Develop efficient submodels for failure of structural connections and interfaces at elevated temperatures.

- Use numerical models to design experiments and standard test methods, and use results of experiments and tests to improve computational models.

\section{Standard Test Methods and Codes}

- Establish as a goal the need to predict the performance of coupled building systems to the point of impending failure in a fire.

- Determine the extent to which ratings from current standard fire resistance tests indicate the reserve capacity of structural assemblies under moderate and severe fire conditions.

- Modify standard test methods or develop new ones to demonstrate our ability to predict reserve capacity from computational models and measured behavior of connections and assemblies.

- Identify which existing engineering tools and fire-proofing materials that have been developed and evaluated in the past 50 years provide an opportunity to significantly upgrade our ability to design fire resistance into buildings, and work to fast-track their acceptance into current building codes.

- Develop a strategy to effectively incorporate technological advances in structural fire resistance into engineering tools that support performance-based design alternatives.

By acting on these recommendations, we will move towards the vision put forth at the workshop of buildings whose designs balance competing demands for function, aesthetics, fire safety and economy, using scientifically-based performance predictions that are so sound that the predictions can be endorsed by all major stakeholders. 


\section{REFERENCES}

[1] "ASTM E 119-98: Standard Test Methods for Fire Tests of Building Construction Materials," ASTM International, West Conshohocken, PA, 1999.

[2] Ingberg, S.H., "Tests of the Severity of Building Fires," Quarterly of NFPA 22, 43-61 (1928).

[3] Photo by Hugh Miller in "Fire Test of Brick Joisted Buildings, " Quarterly of NFPA 22, 65 (1928).

[4] "NFPA 251: Standard Methods of Test of Fire Endurance of Building Construction Material," NFPA International, Quincy, MA, 1999.

[5] "ISO 834: Fire resistance tests -- Elements of Building Construction," International Organization for Standardization, Geneva.

[6] "ASTM E 736-92, Test Method for Cohesion/Adhesion of Sprayed Fire-Resistive Material Applied to Structural Members," ASTM International, West Conshohocken, PA, 1999.

[7] Chiapetta, R.L., and Salmon, M.A., "A Computer Program for the Analysis of Fire

Endurance of Structural Building Components," IITIRI Report, Illinois Institute of Technology, Chicago, May 1975.

[8] Babrauskas, V., "COMPF2: A Program for Calculating Post-Flashover Fire Temperatures. Final Report," NBS TN 991, National Bureau of Standards, Gaithersburg, MD, June 1979.

[9] "ASTM E 1529-00: Standard Test Methods for Determining Effects of Large Hydrocarbon Pool Fires on Structural Members and Assemblies," ASTM International, West Conshohocken, PA, 2002.

[10] Bengtsson, L-G., Gustavsson, S., Tuovinen, H., and Werling, P., "Experiments at the Cardington Large Building Test Facility," Brandforsk project no. 746-961, SP AR 1997:15, Brandteknik, Boras, 1997.

[11] ABAQUS Theory Manual and Users Manual, ver. 5.4, Hibbit, Karlsson and Sorensen, Inc., Pawtucket, RI, 1994.

[12] Lamont S. "The behavior of multi-storey composite steel framed structures in response to compartment fires," PhD thesis The University of Edinburgh, 2002.

[13] Williamson, R.B., Report to Sprayon International, 1972.

[14] "ASTM E 605-93: Test Method for Thickness and Density of Sprayed Fire-Resistive Material (SFRM) Applied to Structural Members," ASTM International, West Conshohocken, PA, 1999.

[15] "ASTM E 759-92: Test Method for Effect of Deflection on Sprayed Fire-Resistive Material Applied to Structural Members," ASTM International, West Conshohocken, PA, 1999.

[16] "ASTM E 760-92: Test Method for Effect of Impact on Bonding of Sprayed Fire-Resistive Material Applied to Structural Members," ASTM International, West Conshohocken, PA, 1999. [17] "ASTM E 761-92: Test Method for Compressive Strength of Sprayed Fire-Resistive Material Applied to Structural Members," ASTM International, West Conshohocken, PA, 1999. [18] "ASTM E 937-93: Test Method for Corrosion of Steel by of Sprayed Fire-Resistive Material (SFRM) Applied to Structural Members," ASTM International, West Conshohocken, PA, 1999.

[19] Williams, M.L., Appl. Poly. Sci 14, 735-745 (1970).

[20] Iding, Robert H., "Performance-based Structural Analysis to Determine Fireproofing Requirements: Methodology, Case Studies, and Research Needs," Proceedings of the Workshop to Identify Innovative Research Needs to Foster Improved Fire Safety in the United States, 
National Academy of Sciences/National Research Council, Washington, D.C., April 15-16, 2002.

[21] Nwosu, D.I., Kodur, V.K.R., Franssen, J.-M., and Hum, J.K., User Manual for SAFIR: A Computer Program for Analysis of Structures at Elevated Temperature Conditions, National Research Council Canada, int. Report 782, 1999, p 69.

[22] Ryan, J.V., and Robertson, A.F., "Proposed Criteria for Defining Load Failure of Beams, Floors, and Roof Construction During Fire Tests," Journal of Research of the National Bureau of Standards - C. Engineering and Instrumentation, 63C, 121-124 (1959).

[23] International Building Code, International Code Council, Inc., Falls Church, VA, 2000.

[24] Holmes, W., and Barry, T.F., "FPEQRA: Fire Protection Engineering Quantitative Risk Assessment," in Proceedings, Fire Risk and Hazard Assessment Symposium, National Fire Protection Research Foundation, San Francisco, June 1996.

[25] Eurocode 3: Design of steel structures - Part 1.2: General rules - Structural fire design (together with United Kingdom National Application Document) DD ENV 1993-1-2:2001 Corrected and reprinted September 2001.

[26] "Rational Fire Safety Engineering Approach to Fire Resistance in Buildings," CIB Report, Publication 269, W014 Fire.

[27] Allam, A.A., Burgess, I.W. and Plank, R.J., "The Large-Deflection Behaviour of Steel and Composite Frames in Fire", Proc. SFPE International Conference on Engineered Fire Protection Design, San Francisco, June 2001.

[28] Usmani A.S., Rotter J.M., Lamont S., Sanad A.M. and M.Gillie, "Fundamental principles of structural behavior under thermal effects," Fire Safety Journal Vol. 36 No. 8, 2001.

[29] LS-DYNA Users Manual Version 950, Livermore Software Technology Corporation, 1999. [30] Phan, L.T., "High-Strength Concrete at High Temperature - An Overview," Proceedings of $6^{\text {th }}$ International Symposium on Utilization of High Strength/High Performance Concrete, June, Leipzig, Germany 2002, pp. 501-518.

[31] Phan, L.T., and Carino, N.J., "Effects of the Test Conditions and Mixture Proportions on Behavior of High-Strength Concrete Exposed to High Temperatures,” ACI Materials Journal, Vol. 99, No. 1, January-February 2002.

[32] Phan, L.T.; Carino, N.J., "Mechanical Properties of High-Strength Concrete at Elevated Temperature,” NISTIR 6726, National Institute of Standards and Technology, Gaithersburg, MD 20899, March 2001. 


\title{
APPENDIX I. Workshop Agenda
}

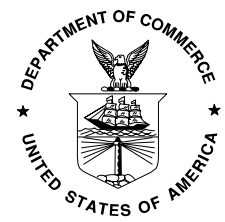

\section{RESEARCH NEEDS FOR FIRE RESISTANCE DETERMINATION \& PERFORMANCE PREDICTION}

\author{
National Institute of Standards and Technology \\ Gaithersburg, Maryland, USA \\ Building 101, Lecture Room B \\ February 19 and 20, 2002
}

\section{WORKSHOP AGENDA}

\section{Tuesday}

8:45 Introductory Session (Chair: William Grosshandler, Chief, Fire Research Division, NIST)

Welcome to NIST, Jack Snell, Director, Building and Fire Research Laboratory

NIST Response to Sept. 11, Shyam Sunder, Chief, Structures Division, NIST

Goals of Workshop, William Grosshandler

9:20 Session I (Chair: William Grosshandler)

Overview of Designing Buildings for Fire Resistance, Craig Beyler and Philip DiNenno, Hughes Associates, Baltimore, USA

ASCE/SFPE Standard on Performance-based Structural Fire Protection Analyses, James Milke, Department of Fire Protection Engineering, University of Maryland, USA

10:00 Break

10:20 Session II (Chair: William Pitts, Fire Research Division, NIST)

Simulation of Accidental Fires and Explosion, Adel Sarofim and Philip Smith, Department of Chemical Engineering, University of Utah, USA

Research Needs for Building Fire Models, Howard Baum, Fire Research Division, NIST, USA

Simulation of the Cardington Fire Tests, Asif Usmani, University of Edinburgh, UK

Fire Resistance Evaluation of Large-scale Structural Systems, Venkatesh Kodur, Institute for Research in Construction, NRC-CANADA

Improved Fire Testing in Combination with Calculation, Ulf Wickstrom, SP Fire Technology, Borås, SWEDEN

Discussion and short presentations from participants on fire modeling

12:20 Lunch, NIST cafeteria 
1:15 Session III (Chair: Edward Garboczi, Building Materials Division, NIST)

Degradation in Performance of Installed Fire Resistance Materials, Frederick Mowrer, Department of Fire Protection Engineering, University of Maryland, USA

Performance-Based Analytical Prediction of Fireproofing Requirements in Complex Buildings, Robert H. Iding, Wiss, Janney, Elstner Associates, San Francisco, USA

Materials for the Fire Protection of Structural Steel, Brady Williamson, Department of Civil and Environmental Engineering, University of California, Berkeley, USA

Protection of Steel Structures Against Blast, Impact and Ensuing Fires, Abolhassan Astaneh, Department of Civil and Environmental Engineering, University of California, Berkeley, USA

Discussion and short presentations from participants on fire resistant materials

3:20 Session IV (Chair: John Gross, Structures Division, NIST)

Structural Fire Modeling: Where is the Frontier Nowadays? Jean-Marc Franssen, Institute de Mécanique et Génie Civil, University of Liege, BELGIUM

Fire Resistance and Performance Prediction: Structural Analysis Issues and Research Needs, James Ricles, Department of Civil and Environmental Engineering, Lehigh University, USA

Parallels Between Performance-Based Engineering for Fire and Earthquake Hazards, Greg Deierlein, Department of Civil and Environmental Engineering, Stanford University, USA

A Consultant's Wish List for a Numerical Model of Structural Response to Fire Conditions, Barbara Lane, Arup Fire, London, UK

Discussion and short presentations from participants on structural modeling

5:00 Break-out sessions to identify research needs (W. Pitts [LR-B], J. Gross [B111], and E. Garboczi [B113], facilitators)

6:30 Dinner and informal discussion at local restaurant

Wednesday

8:30 Reconvene breakout sessions (W. Pitts [LR-D], J. Gross [B111], and E. Garboczi [B113])

10:45 Summary of breakout session discussions (spokespersons from parallel sessions), LR-D

12:15 Lunch, NIST cafeteria

1:15 Open discussion, LR-D (Chair: W. Grosshandler)

Workshop Recommendations and Assignments

4:00 Adjourn

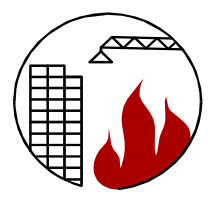


APPENDIX II. Workshop Attendance List

\begin{tabular}{|c|c|c|}
\hline Name & Organization & CONTACT Information \\
\hline Ronald Alpert & $\begin{array}{l}\text { FM Global Research } \\
\text { P.O. Box } 9102 \\
\text { Norwood, MA } 02062\end{array}$ & $\begin{array}{l}\text { ronald.alpert@fmglobal.com } \\
\text { tel. 781-255-4920 } \\
\text { FAX 781-255-4024 }\end{array}$ \\
\hline Farshad Alamdari & $\begin{array}{l}\text { Fire Research \& Risk Sciences (FRS) } \\
\text { BRE, Garston, Watford, WD25 9XX, UK }\end{array}$ & $\begin{array}{l}\text { alamdarif@bre.co.uk } \\
\mathrm{T} \quad+44(0) 1923664947 \\
\mathrm{~F}+44(0) 1923664910 \\
\mathrm{M}+44(0) 7775701792\end{array}$ \\
\hline J. Guadalupe Arguello & $\begin{array}{l}\text { Sandia Nat'l Laboratories } \\
\text { P. O. Box 5800 - MS } 0847 \text { Albuquerque, } \\
\text { NM 87185-0847 }\end{array}$ & $\begin{array}{l}\text { jgargue@sandia.gov } \\
\text { tel. (505) 844-1482 } \\
\text { FAX (505) 844-9297 }\end{array}$ \\
\hline$\underline{\text { Abolhassan Astaneh-Asl }}$ & $\begin{array}{l}\text { University of California } \\
781 \text { Davis Hall } \\
\text { Berkeley, CA } 94720\end{array}$ & $\begin{array}{l}\text { astaneh@ce.berkeley.edu } \\
\text { (510) 642-4528 }\end{array}$ \\
\hline Jonathan Barnett & $\begin{array}{l}\text { Worcester Polytechnic Institute } \\
100 \text { Institute Rd. } \\
\text { Worcester, MA } 01609\end{array}$ & $\begin{array}{l}\text { jbarnett@wpi.edu } \\
508 \text { 831-5113 } \\
508831-5680\end{array}$ \\
\hline Howard Baum & $\begin{array}{l}\text { Building and Fire Research Laboratory } \\
\text { NIST, MS-8663 } \\
\text { Gaithersburg, MD } 20899\end{array}$ & $\begin{array}{l}\text { howard.baum@nist.gov } \\
\text { (301) 975-6668 }\end{array}$ \\
\hline Robert M. Berhinig & $\begin{array}{l}\text { Underwriters Laboratories } \\
333 \text { Pfingsten Rd. } \\
\text { Northbrook, IL } 60062 \\
\end{array}$ & $\begin{array}{l}\text { robert.m.berhinig@us.ul.com } \\
\text { (847) 664-2292 }\end{array}$ \\
\hline Jesse Beitel & $\begin{array}{l}\text { Hughes Assoc. } \\
3610 \text { Commerce Dr., Ste. } 817 \\
\text { Baltimore, MD } 21227\end{array}$ & $\begin{array}{l}\text { jbeitel@haifire.com } \\
410-737-8677 \\
410-737-8688 \text { fax }\end{array}$ \\
\hline Craig Beyler & $\begin{array}{l}\text { Hughes Assoc. } \\
3610 \text { Commerce Dr., Ste. } 817 \\
\text { Baltimore, MD } 21227\end{array}$ & $\begin{array}{l}\text { cbeyler@haifire.com } \\
410-737-8677 \\
410-737-8688 \text { fax }\end{array}$ \\
\hline Nelson Bryner & $\begin{array}{l}\text { Building and Fire Research Laboratory } \\
\text { NIST, MS-8661 } \\
\text { Gaithersburg, MD } 20899\end{array}$ & $\begin{array}{l}\text { nelson.bryner@nist.gov } \\
\text { (301) 975-6868 }\end{array}$ \\
\hline Richard Bukowski & $\begin{array}{l}\text { Building and Fire Research Laboratory } \\
\text { NIST, MS-8664 } \\
\text { Gaithersburg, MD } 20899\end{array}$ & $\begin{array}{l}\text { richard.bukowski@nist.gov } \\
\text { (301) 975-6853 }\end{array}$ \\
\hline Peter Chang & National Science Foundation & pchang@nsf gov \\
\hline Ken Chong & National Science Foundation & ken.chong@nist.gov \\
\hline Len Cooper & Hughes Associates & $\begin{array}{l}\text { lycooper@erols.com } \\
\text { (301) 229-4474 }\end{array}$ \\
\hline
\end{tabular}




\begin{tabular}{|c|c|c|}
\hline Name & Organization & CONTACT Information \\
\hline John Danko & $\begin{array}{l}\text { Isolatek International } \\
41 \text { Furnace Street } \\
\text { Stanhope, NJ } 07874\end{array}$ & $\begin{array}{l}\text { jdanko@isolatek.com } \\
\text { 973-347-1200, x } 202 \\
\text { 973-347-9443 fax }\end{array}$ \\
\hline Greg Deierlein & $\begin{array}{l}\text { Stanford University } \\
\text { Dept. of Civil \& Env. Engr } \\
\text { Stanford, CA, 94305-4020 }\end{array}$ & $\begin{array}{l}\text { ggd@stanford.edu } \\
\text { tel. 650-723-0453 } \\
\text { FAX 650-723-7514 }\end{array}$ \\
\hline Jason Dreisbach & National Academy of Sciences & jdreisba@nas.edu \\
\hline Philip DiNenno & $\begin{array}{l}\text { Hughes Assoc. } \\
3610 \text { Commerce Dr., Ste. } 817 \\
\text { Baltimore, MD } 21227\end{array}$ & $\begin{array}{l}\text { phil@haifire.com } \\
410-737-8677 \\
410-737-8688 \text { fax }\end{array}$ \\
\hline Clarissa Ferraris & $\begin{array}{l}\text { Building and Fire Research Laboratory } \\
\text { NIST, MS-8621 } \\
\text { Gaithersburg, MD } 20899\end{array}$ & $\begin{array}{l}\text { clarissa.ferraris@nist.gov } \\
\text { (301) 975-6711 }\end{array}$ \\
\hline Jean-Marc Franssen & $\begin{array}{l}\text { Université de Liège } \\
\text { Inst. de Mécanique et Génie Civil } \\
\text { Chemin des chevreuils, } 1 \\
4000 \text { Liège } 1 \text {, Belgium }\end{array}$ & $\begin{array}{l}\text { jm.franssen@ulg.ac.be } \\
\text { tel.+32-4-366.92.65 (dir.) } \\
+32-4-366.92 .51 \text { (secr.) } \\
\text { fax.+32-4-366.95.34 }\end{array}$ \\
\hline Thomas Fritz & $\begin{array}{l}\text { Armstrong World Ind. } \\
2500 \text { Columbia Avenue, Room 5203A } \\
\text { Lancaster, PA } 17604\end{array}$ & $\begin{array}{l}\text { Thomas_W_Fritz@armstrong.com } \\
\text { tel.717-396-5679 } \\
\text { FAX 717-396-5486 }\end{array}$ \\
\hline Ed Garboczi & $\begin{array}{l}\text { Building and Fire Research Laboratory } \\
\text { NIST, MS-8621 } \\
\text { Gaithersburg, MD } 20899\end{array}$ & $\begin{array}{l}\text { edward.garboczi@nist.gov } \\
\text { (301)975-6708 }\end{array}$ \\
\hline Richard Gewain & $\begin{array}{l}\text { Hughes Assoc. } \\
3610 \text { Commerce Dr., Ste. } 867 \\
\text { Baltimore, MD } 21227\end{array}$ & $\begin{array}{l}\text { dgewain@haifire.com } \\
\text { 410-737-8677 }\end{array}$ \\
\hline Jeff Gilman & $\begin{array}{l}\text { Building and Fire Research Laboratory } \\
\text { NIST, MS-8665 } \\
\text { Gaithersburg, MD } 20899\end{array}$ & $\begin{array}{l}\text { jeffrey.gilmani@nist.gov } \\
\text { (301) 975-6573 }\end{array}$ \\
\hline James Griffith, Jr. & $\begin{array}{l}\text { Southwest Research Institute, Bldg } 143 \\
\text { PO Drawer } 28510 \\
\text { San Antonio, TX 78228-0510 }\end{array}$ & $\begin{array}{l}\text { jgriffith@swri.edu } \\
\text { (210) 522-2311 }\end{array}$ \\
\hline Louis Gritzo & $\begin{array}{l}\text { Sandia Nat. Laboratories } \\
\text { P.O. Box } 5800 \\
\text { Albuquerque, NM } \\
87185-0821\end{array}$ & $\begin{array}{l}\text { lagritz@sandia.gov } \\
\text { tel. (505) 844-8353 } \\
\text { FAX: (505) 845-3151 }\end{array}$ \\
\hline John Gross & $\begin{array}{l}\text { Building and Fire Research Laboratory } \\
\text { NIST, MS-8611 } \\
\text { Gaithersburg, MD } 20899\end{array}$ & $\begin{array}{l}\text { john.gross@nist.gov } \\
\text { (301)975-6068 }\end{array}$ \\
\hline
\end{tabular}




\begin{tabular}{|c|c|c|}
\hline Name & Organization & CONTACT Information \\
\hline William Grosshandler & $\begin{array}{l}\text { Building and Fire Research Laboratory } \\
\text { NIST, MS-8660 } \\
\text { Gaithersburg, MD } 20899\end{array}$ & $\begin{array}{l}\text { william.grosshandler@nist.gov } \\
\text { (301) 975-2310 }\end{array}$ \\
\hline Anthony Hamins & $\begin{array}{l}\text { Building and Fire Research Laboratory } \\
\text { NIST, MS-8663 } \\
\text { Gaithersburg, MD } 20899\end{array}$ & $\begin{array}{l}\text { anthony.hamins@nist.gov } \\
\text { (301) 975-6598 }\end{array}$ \\
\hline Robert H. Iding & $\begin{array}{l}\text { Wiss, Janney, Elstner Assoc. } \\
2200 \text { Powell St. } \\
\text { Emeryville, CA } 94608\end{array}$ & $\begin{array}{l}\text { riding@wje.com } \\
\text { tel. 510-428-2907 } \\
\text { fax 510-429-0456 }\end{array}$ \\
\hline Rudy Jagnandan & $\begin{array}{l}\text { Isolatek International } \\
41 \text { Furnace Street } \\
\text { Stanhope, NJ } 07874\end{array}$ & $\begin{array}{l}\text { rjagnandan@isolatek.com } \\
\text { 973-347-1200, x } 204 \\
\text { 973-347-9170 fax }\end{array}$ \\
\hline Richard Kaczkowski & $\begin{array}{l}\text { USG Research \& Technology Center } \\
700 \text { N. Highway } 45 \\
\text { Libertyville, IL } 60048\end{array}$ & $\begin{array}{l}\text { RKaczkowski @usg.com } \\
\text { Tel: 1-847-970-5255 } \\
\text { Fax: 1-847-970-5299 }\end{array}$ \\
\hline Venkatesh Kodur & $\begin{array}{l}\text { Institute for Research in Construction; } \\
\text { National Research Council of Canada } \\
\text { Bldg. M59, } 1500 \text { Montreal Road Ottawa, } \\
\text { ON, K1A 0R6 Canada }\end{array}$ & $\begin{array}{l}\text { venkatesh.kodur@nrc.ca } \\
\text { tel. (613) 993-9729 } \\
\text { FAX. (613) 954-0483 }\end{array}$ \\
\hline Mamoru Kohno & $\begin{array}{l}\text { Building Research Institute } \\
\text { Tachihara 1, Tsukuba 305-0802, Japan }\end{array}$ & $\begin{array}{l}\text { kohno@kenken.go.jp } \\
+81-298-79-0692\end{array}$ \\
\hline Barbara Lane & $\begin{array}{l}\text { Arup Fire, Ove Arup and Partners Ltd } \\
13 \text { Fitzroy St, London, W1T 4BQ }\end{array}$ & $\begin{array}{l}\text { barbara.lane@arup.com } \\
\text { tel. +44 } 2077553303 \\
\text { FAX +44 } 2077552001\end{array}$ \\
\hline Dan Madrzykowski & $\begin{array}{l}\text { Building and Fire Research Laboratory } \\
\text { NIST, MS-8661 } \\
\text { Gaithersburg, MD } 20899\end{array}$ & $\begin{array}{l}\text { daniel.madrzykowski@nist.gov } \\
\text { (301) 975-6677 }\end{array}$ \\
\hline Kevin McGrattan & $\begin{array}{l}\text { Building and Fire Research Laboratory } \\
\text { NIST, MS-8663 } \\
\text { Gaithersburg, MD } 20899\end{array}$ & $\begin{array}{l}\text { kevin.mcgrattan@nist.gov } \\
\text { (301) 975-2712 }\end{array}$ \\
\hline James Milke & $\begin{array}{l}\text { Dept. of Fire Protection Engineering } \\
\text { University of Maryland } \\
\text { College Park, MD }\end{array}$ & milke@eng.umd.edu \\
\hline David Moore & $\begin{array}{l}\text { Construction Division } \\
\text { BRE, Garston } \\
\text { Watford, WD25 9XX, UK }\end{array}$ & mooredb@bre.co.uk \\
\hline Fred Mowrer & $\begin{array}{l}\text { Dept. of Fire Protection Engineering } \\
\text { University of Maryland } \\
\text { College Park, MD }\end{array}$ & $\begin{array}{l}\text { fmowrer@eng.umd.edu } \\
\text { 301-405-3994 }\end{array}$ \\
\hline
\end{tabular}




\begin{tabular}{|c|c|c|}
\hline Name & Organization & CONTACT Information \\
\hline George Mulholland & $\begin{array}{l}\text { Building and Fire Research Laboratory } \\
\text { NIST, MS-8662 } \\
\text { Gaithersburg, MD } 20899\end{array}$ & $\begin{array}{l}\text { george.mulholland@nist.gov } \\
\text { (301) 975-6695 }\end{array}$ \\
\hline Harold Nelson & $\begin{array}{l}\text { Hughes Assoc. } \\
4217 \text { Kings Mill Lane } \\
\text { Annandale, VA }\end{array}$ & $\begin{array}{l}\text { hnelson444@aol.com } \\
\text { (703) 256-2004 } \\
\text { (703) 256-0411 FAX }\end{array}$ \\
\hline Andrew Osborn & $\begin{array}{l}\text { Wiss, Janney, Elstner Associates, Inc. } \\
14 \text { Washington Rd., Ste. } 501 \\
\text { Princeton Junction, NJ } 08550\end{array}$ & aosborn@wje.com \\
\hline Long Phan & $\begin{array}{l}\text { Building and Fire Research Laboratory } \\
\text { NIST, MS-8611 } \\
\text { Gaithersburg, MD } 20899\end{array}$ & $\begin{array}{l}\text { long.phan@nist.gov } \\
\text { (301) 975-6077 }\end{array}$ \\
\hline William Pitts & $\begin{array}{l}\text { Building and Fire Research Laboratory } \\
\text { NIST, MS-8662 } \\
\text { Gaithersburg, MD } 20899\end{array}$ & $\begin{array}{l}\text { william.pitts@nist.gov } \\
\text { (301) 975-6486 }\end{array}$ \\
\hline Kuldeep Prasad & $\begin{array}{l}\text { Building and Fire Research Laboratory } \\
\text { NIST, MS-8663 } \\
\text { Gaithersburg, MD } 20899\end{array}$ & $\begin{array}{l}\text { kuldeep.prasad@nist.gov } \\
\text { (301) 975-3968 }\end{array}$ \\
\hline Ron Rehm & $\begin{array}{l}\text { Building and Fire Research Laboratory } \\
\text { NIST, MS-8663 } \\
\text { Gaithersburg, MD } 20899\end{array}$ & $\begin{array}{l}\text { ronald.rehm@nist.gov } \\
\text { (301) 975-2704 }\end{array}$ \\
\hline James M. Ricles & $\begin{array}{l}\text { Department of Civil and Environmental } \\
\text { Engineering } \\
117 \text { ATLSS Drive } \\
\text { Bethlehem, PA 18015-4729 }\end{array}$ & $\begin{array}{l}\text { (610) 758-6252 } \\
\text { jmr5@lehigh.edu }\end{array}$ \\
\hline Richard Roby & $\begin{array}{l}\text { Combustion Science Engineering } \\
8940 \text { Old Annapolis Rd., Ste. } 2 \\
\text { Columbia, MD } 21045\end{array}$ & $\begin{array}{l}\text { roby@csefire.com } \\
\text { (410) 884-3266 }\end{array}$ \\
\hline James Rossberg & $\begin{array}{l}\text { Structural Engineering Inst, ASCE } \\
1801 \text { Alexander Bell Dr. } \\
\text { Reston, VA 20191-4400 }\end{array}$ & jrossberg@asce.org \\
\hline Arnold Rosenberg & $\begin{array}{l}\text { Building and Fire Research Laboratory } \\
\text { NIST, MS-8621 } \\
\text { Gaithersburg, MD } 20899\end{array}$ & $\begin{array}{l}\text { arnold.rosenberg@nist.gov } \\
\text { (301) 975-2421 }\end{array}$ \\
\hline Adel Sarofim & $\begin{array}{l}\text { U. Utah/Reaction Engineering } \\
\text { Salt Lake City, UT }\end{array}$ & $\begin{array}{l}\text { sarofim@reaction-eng.com } \\
\text { (801)585-9258 } \\
\text { (801) 364-6977 FAX }\end{array}$ \\
\hline Paul E. Senseny & $\begin{array}{l}\text { FM Global } \\
\text { P.O. Box } 9102 \\
\text { Norwood, MA 02062-9102 }\end{array}$ & paul.senseny@fmglobal.com \\
\hline
\end{tabular}




\begin{tabular}{|c|c|c|}
\hline Name & Organization & CONTACT Information \\
\hline Mark Shmorhun & $\begin{array}{l}\text { Grace Performance Chemicals } \\
62 \text { Whittemore Avenue } \\
\text { Cambridge, MA } 02140\end{array}$ & $\begin{array}{l}\text { Mark.Shmorhun@grace.com } \\
\text { (617) 498-4316 } \\
\text { (617) 498-4360 FAX }\end{array}$ \\
\hline Phil Smith & $\begin{array}{l}\text { Dept. of Chemical and Fuels Engineering } \\
\text { University of Utah } \\
\text { Salt Lake City, UT } 84112\end{array}$ & $\begin{array}{l}\text { smith@crsim.utah.edu } \\
\text { 801-585-3129 }\end{array}$ \\
\hline Richard Smith & $\begin{array}{l}\text { National Science Foundation } \\
\text { CTS Division } \\
\text { 4201 Wilson Blvd. } \\
\text { Arlington, VA } 22203\end{array}$ & $\begin{array}{l}\text { rnsmith@nsf.gov } \\
\text { (703) 292-8371 }\end{array}$ \\
\hline Kenneth Steckler & Treasury/ATF & KDsteckler@atfhq.atf.treas.gov \\
\hline Shyam Sunder & $\begin{array}{l}\text { Building and Fire Research Laboratory } \\
\text { NIST, MS-8610 } \\
\text { Gaithersburg, MD } 20899\end{array}$ & $\begin{array}{l}\text { sunder@nist.gov } \\
\text { (301) 975-6713 }\end{array}$ \\
\hline Amal Tamim & $\begin{array}{l}\text { WR Grace } \\
62 \text { Whitemore Ave } \\
\text { Cambridge, MA } 02140\end{array}$ & $\begin{array}{l}\text { amal.tamim@grace.com } \\
\text { tel. 617-498-4441 } \\
\text { FAX:617-498-4419 }\end{array}$ \\
\hline Russ Thomas & $\begin{array}{l}\text { National Research Council Canada, Bldg. } \\
\text { M-59 } \\
\text { Montreal Road } \\
\text { Ottawa, Ontario K1A OR6, CANADA }\end{array}$ & $\begin{array}{l}\text { russ.thomas@nrc.ca } \\
(613) \text { 993-0817 } \\
\text { (617) 954-0483 fax }\end{array}$ \\
\hline Jose Torero & $\begin{array}{l}\text { Dept. of Civil and Environmental Engr. } \\
\text { The University of Edinburgh } \\
\text { Edinburgh, EH9 3JN, UK }\end{array}$ & jltorero@eng.umd.edu \\
\hline Asif Usmani & University of Edinburgh & asif.usmani@ed.ac.uk \\
\hline Alex Wenzel & $\begin{array}{l}\text { Southwest Research Institute, Bldg } 143 \\
\text { PO Drawer } 28510 \\
\text { San Antonio, TX 78228-0510 }\end{array}$ & $\begin{array}{l}\text { awenzel@swri.edu } \\
\text { (210) 522-2311 }\end{array}$ \\
\hline Ulf Wickstrom & $\begin{array}{l}\text { SP Fire Technology } \\
\text { Box 857, SE-501 } 15 \text { Borås } \\
\text { SWEDEN }\end{array}$ & $\begin{array}{l}\text { ulf.wickstrom@sp.se } \\
\text { Tel: +46 } 33165194 \\
\text { Fax: +46 } 33417759\end{array}$ \\
\hline R. Brady Williamson & $\begin{array}{l}\text { UC Berkeley } \\
1052 \text { Merced Street } \\
\text { Berkeley, CA } 94707 \\
\end{array}$ & $\begin{array}{l}\text { bradywilliamson@sbcglobal.net } \\
\text { tel: (510) 527-2248 (home) } \\
\text { fax: (510) 525-3009 }\end{array}$ \\
\hline Phillip Wearne & The Learning Channel & $\begin{array}{l}\text { pkwearne@hotmail.com } \\
\text { (202) 232-2875 }\end{array}$ \\
\hline Robert Wills & $\begin{array}{l}\text { Regional Director, Construction Codes \& } \\
\text { Stds., American Iron \& Steel Inst. } \\
907 \text { Spyglass Circle } \\
\text { Birmingham, AL } 35244\end{array}$ & $\begin{array}{l}\text { rwills@steel.org } \\
\text { 205) 980-0016 } \\
\text { (205) 980-0391 Fax }\end{array}$ \\
\hline
\end{tabular}




\title{
APPENDIX III. Presentations
}

\author{
A. NIST Response to Sept. 11
}

Shyam Sunder, Chief, Structures Division

Building and Fire Research Laboratory, NIST

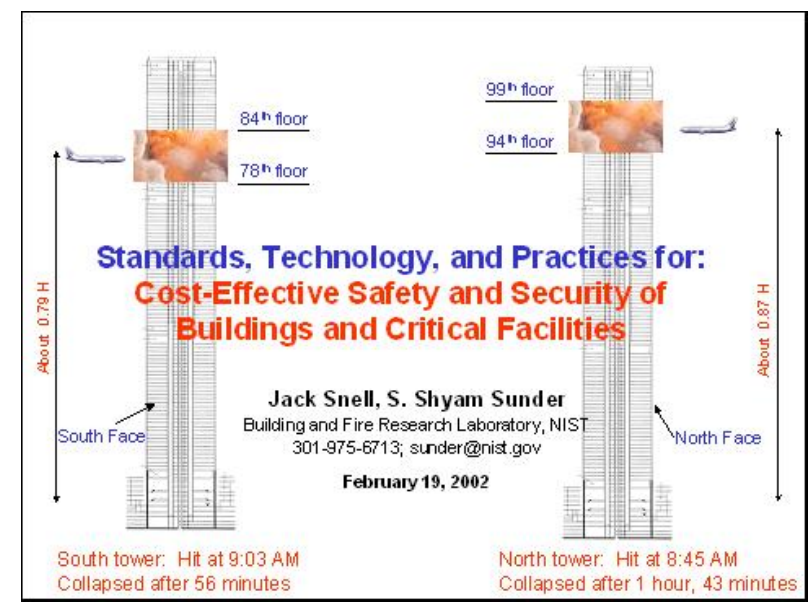

I. National Building and Fire Safety Investigation of the World Trade Center Disaster (\$15.4 M)

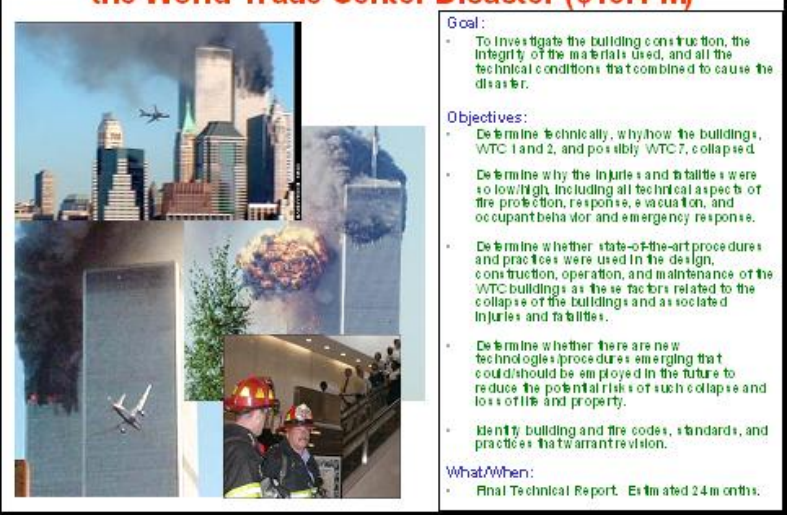

\section{Response Plan - Overview}

I. National Building and Fire Safety Investigation of the World Trade Center Disaster

II. Structural Fire Protection

III. Human Behavior, Emergency response \& Mobility

IV. Building Vulnerability Reduction

V. National Construction and Infrastructure Roadmap and Support

National Construction Safety Board
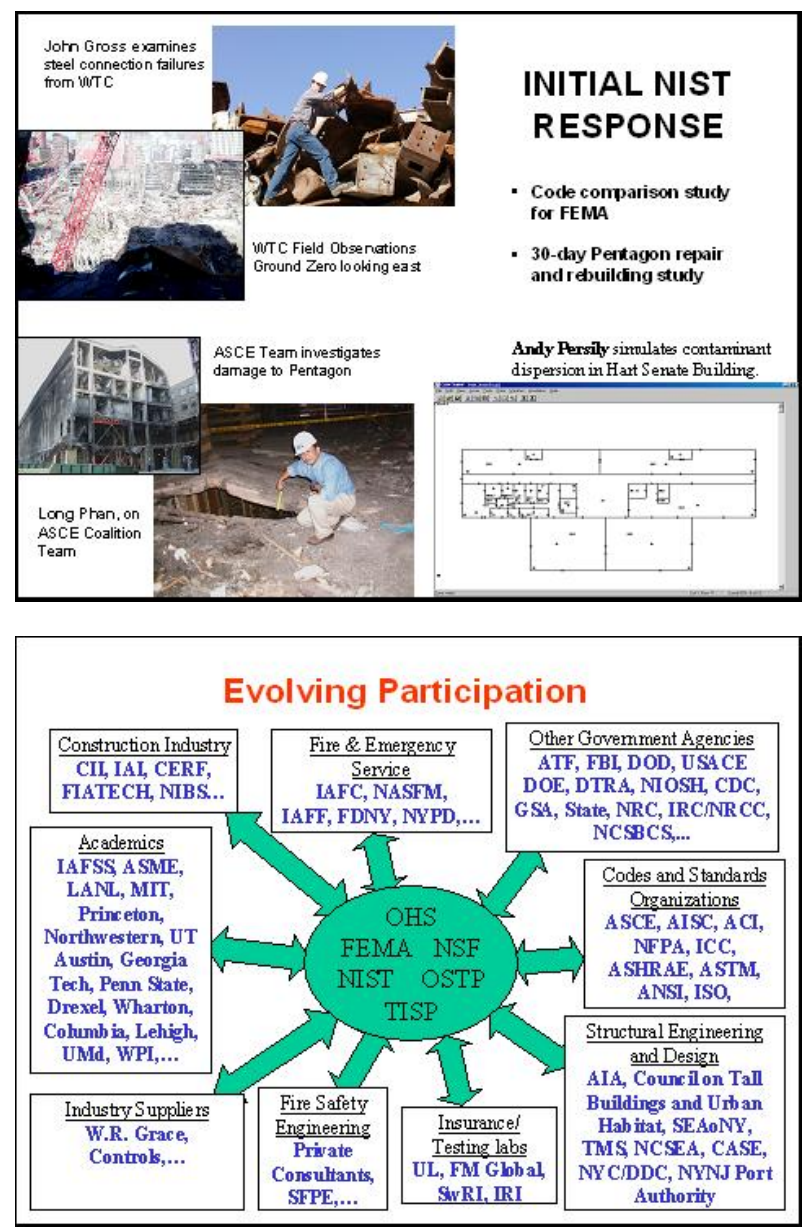

Overall Strategy and Plan

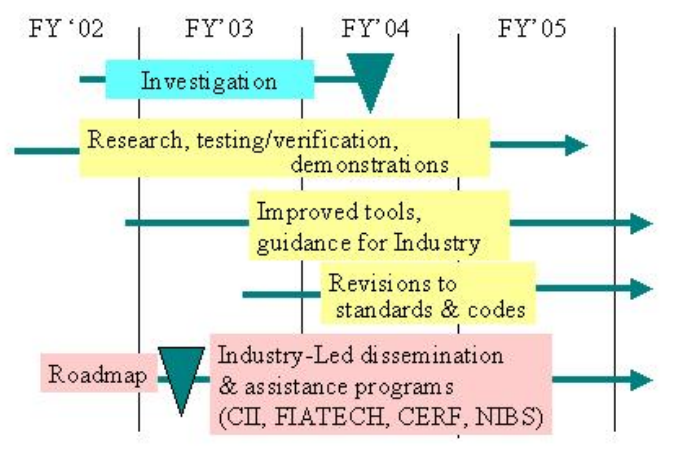



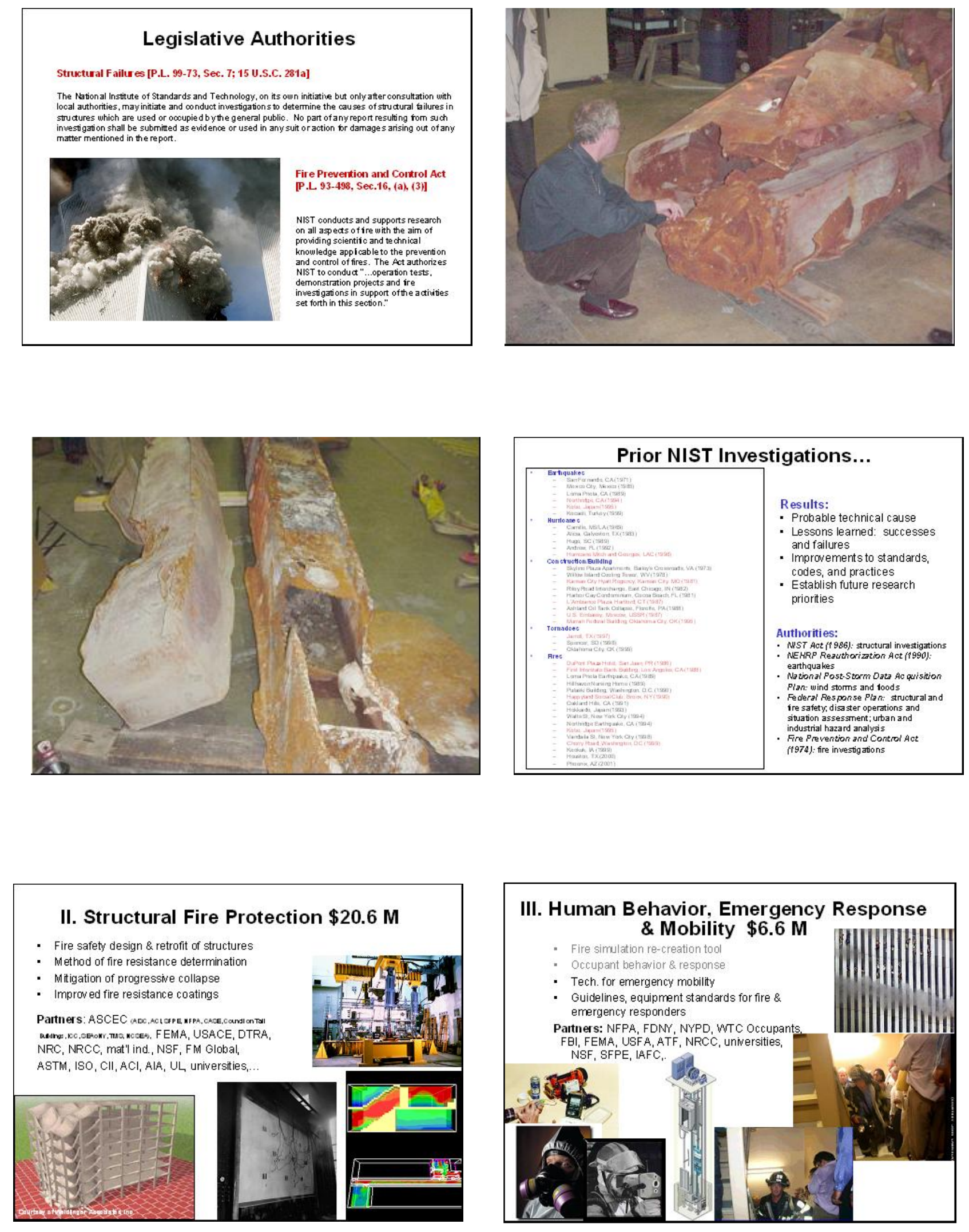


\section{Building Vulnerability Reduction $\$ 7.8 \mathrm{M}$}

- Standard information models

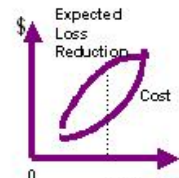

- Guidelines, advanced technology for Chem. Bio.

Rad. attacks

- Cost-effective risk management tools

Partners: IAI, FIATECH, ASHRAE, GSA, DOD State Department, GSA, Wharton, NSF, Cll, NCSBCS,..

Level of Prevention
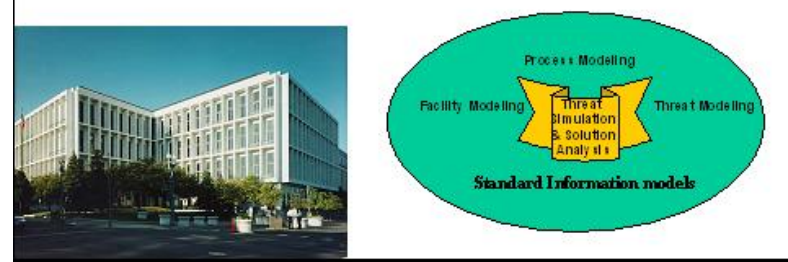

\section{National Construction and Infrastructure Roadmap and Support $\$ 6.0 \mathrm{M}$}

Principal national forum through which facility owners and
contractors deliver and disserninate results of research into ongoing contradors deliver and disserninate

Draw on top management, chief scientiststechnology officers to

dired and motivate needed change.

Complement and support parallel eftorts of engineering societies to improve technology, codes, and standards.

Functions:

Provide advice on best practioes, guidance on vinerability assessment, guidanoe on standards and codes needs. Conduct satety related $R \& D$.

- Dissen inate and implement R\&D outputs.

Adt as dearinghouse (Q\&AS, industry inputs, needsipriorities, etc,,.. .

- Benchmark results

Partners:

Construction Industry Institute (CII)

- CMI Engineering Research Foundaton (CERF) - National Institute of Building Scienoes (NIBS)

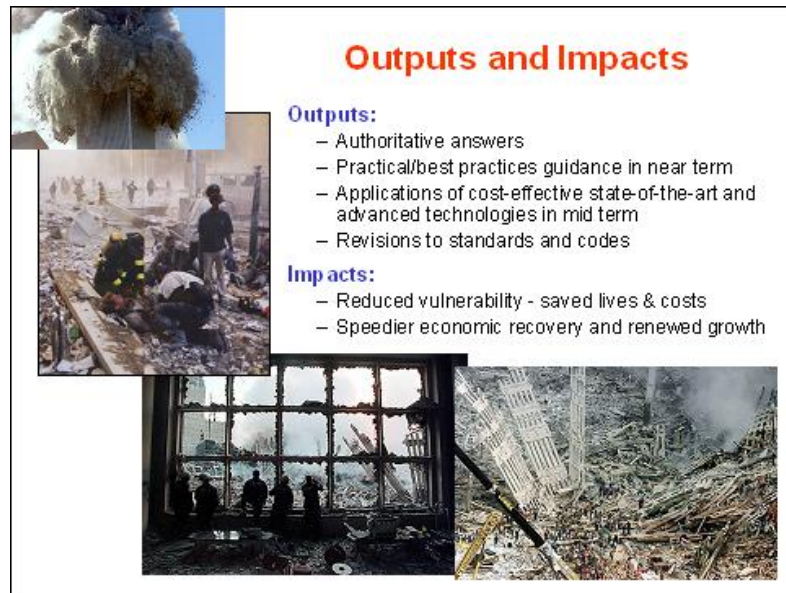


B. Goals of Workshop

William Grosshandler, Chief, Fire Research Division

Building and Fire Research Laboratory, NIST

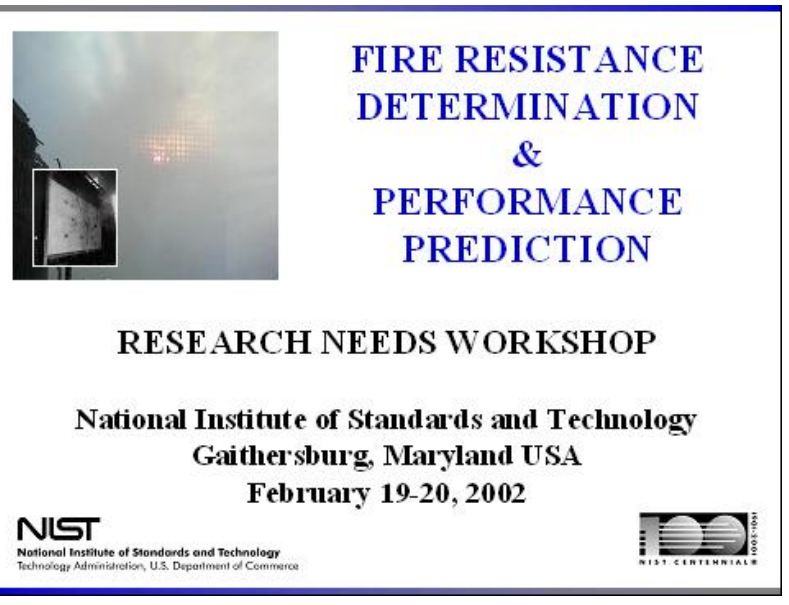

\section{FIRE RESISTANCE DETERMINATION \& PERFORMANCE PREDICTION}

Developments needed to achieve vision:

- Validated tools (instrumentation, computational methods, measurement techniques) necessary to predict performance of building materials, products, structural elements, and systems up to the point of imminent fire-caused collapse of tall buildings

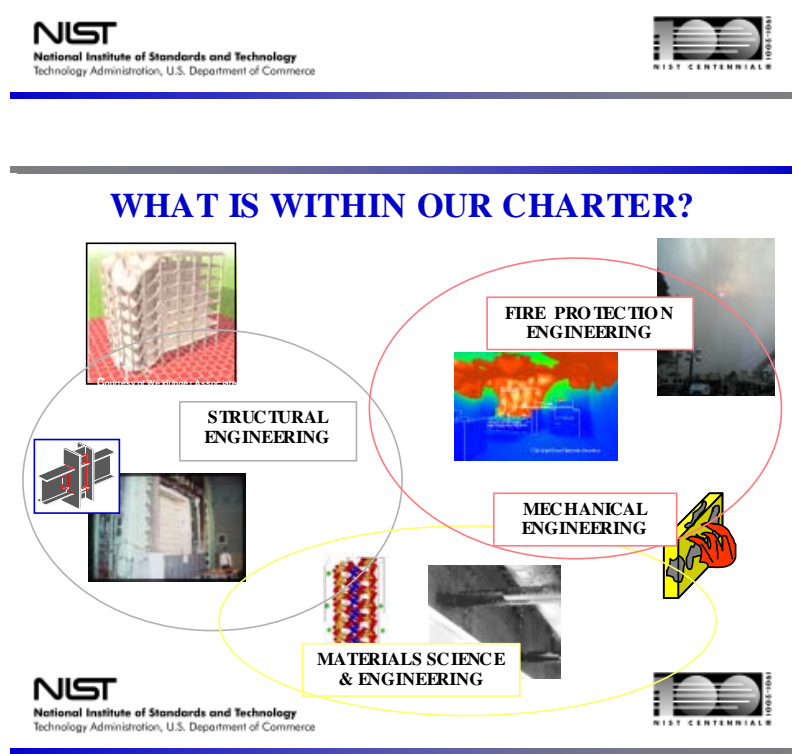

\section{FIRE RESISTANCE DETERMINATION \& PERFORMANCE PREDICTION}

Vision: A rational balance of competing demands for function, aesthetics, fire safety and economy in tall buildings

- enabled by scientifically-based performance predictions, and

- endorsed by all major stakeholders.

Time Horizon: Ten years

\section{NIT}

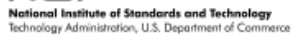

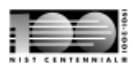

\section{FIRE RESISTANCE DETERMINATION \& PERFORMANCE PREDICTION}

Objectives of Workshop:

- Review current practices for achieving fire resistance.

- Explore promise of fire dynamics simulations and structural behavior predictions.

- Identify opportunities in materials science.

- Identify opportunities/needs in advanced computational methods; and for new measurement, instrumentation, and test methods.

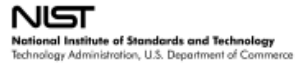

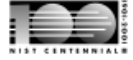

\section{WHAT IS OUTSIDE OUR CHARTER?}

- Buildings less than ten stories tall

- Industrial facilities

- Impact damage

- Blast protection

- Progressive collapse not initiated by fire

- Incremental improvements to current codes and standards

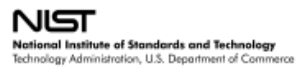




\section{WORKSHOP PRODUCTS}

- Report summarizing objectives and general consensus on priority, approach, funding options and associated timelines, and required follow-on actions

- Roadmap to streamline implementation of research results into international product standards, fire codes, and construction practices

\section{NIST}

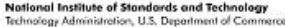

WORKSHOP MECHANICS (1/2)

Invited presentations, with comments and discussion throughout (Tuesday morning and afternoon)

- overview of fire protection designs

- fire modeling

- fire resistant materials

- structural modeling

Lunch/breaks: NIST cafeteria

Concur on vision and begin parallel break-out sessions (Tuesday, late afternoon) (Bill Pitts, LR-B; John Gross, B111; Ed Gar'b eczi, B113)

\section{NLT}

\section{WORKSHOP MECHANICS (2/2)}

Dinner, informal discussion ( 7 pm):

Mrs. O'Leary's, 555 Quince Orchard Rd.

Parallel break-out sessions (Wednesday morning)

(Bill Pitts, LR-D; John Gross, B111; Ed Garboczi, B113)

Report out (spokepersons)

Discussion among all particip ants, leading to recommendations and assigmments

Adjourn (4 pm Wednesday)

NIT 
C. Overview of Designing Buildings for Fire Resistance

Craig Beyler and Philip DiNenno

Hughes Associates, Baltimore, MD

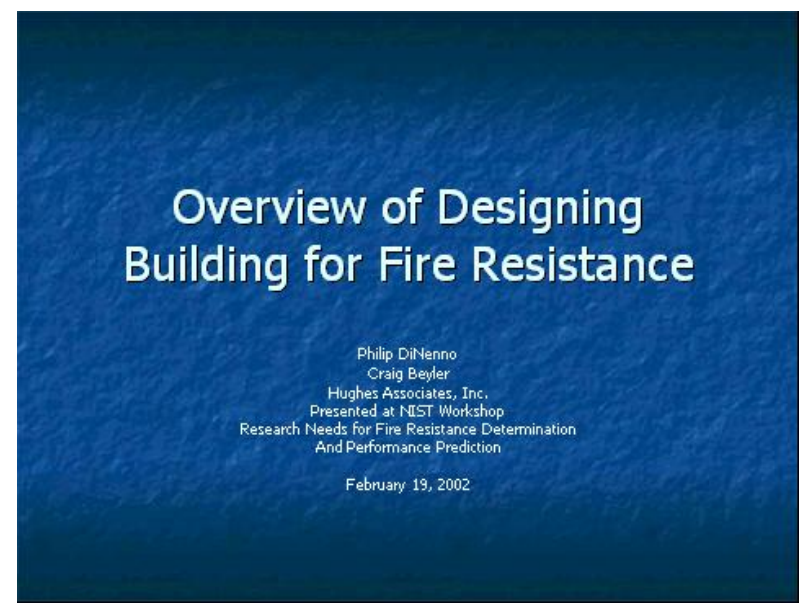

\section{Overview}

- Brief History

- Current Status

- Current Role in Fire Safety

- Current Status

- Status Circa 1965-1970

- Needs for Science Based Structural F.P.

\section{History}

1890 - Denver - 1st fire endurance tests (floors)

1896 - NYC Bldg. Dept Floor system - $2000^{\circ} \mathrm{F}\left(1093{ }^{\circ} \mathrm{C}\right), 5$ hours

- $150 \mathrm{lb} / \mathrm{ft} 2 \rightarrow 600 \mathrm{lb} / \mathrm{ft} 2(24 \mathrm{lrs})$

- Led to requirements In NYC BC

1902 - Columbia U Fumace

\section{History}

1906 - ASTM - Committee after Balt. fire - $1700^{\circ} \mathrm{F}, 150 \mathrm{lb} / \mathrm{ft}^{2}-600 \mathrm{lb} / \mathrm{ft}^{2}$

1908-1909 - 1st ASTM Standards

1910 - FM, NBFU, NIST > fumaces At UL

1917 - Column Test

\section{History}

1918

- ASTM C-5

- Floor and Wall

- Time related end points (temp and mech)

- Test for $25 \%$ Safety Factor wrt time

- Standard TTC

1922

- NBS/INGBERG - Fuel Load \& Fire Resistance Time equivalency

- Fuel Load-Fire resistance time "Equivalence" 


\section{Current Status}

\section{Current}

- Fire Resistance Requirement

Established by building code - function of

- Occupancy

- Sprinkler protection

- Testing per UL, NFPA, ASTM

- Listing by UL/FM et al

- Find requirement in hours

- Look it up in a listing book

- Spec it

- Maybe Inspect it
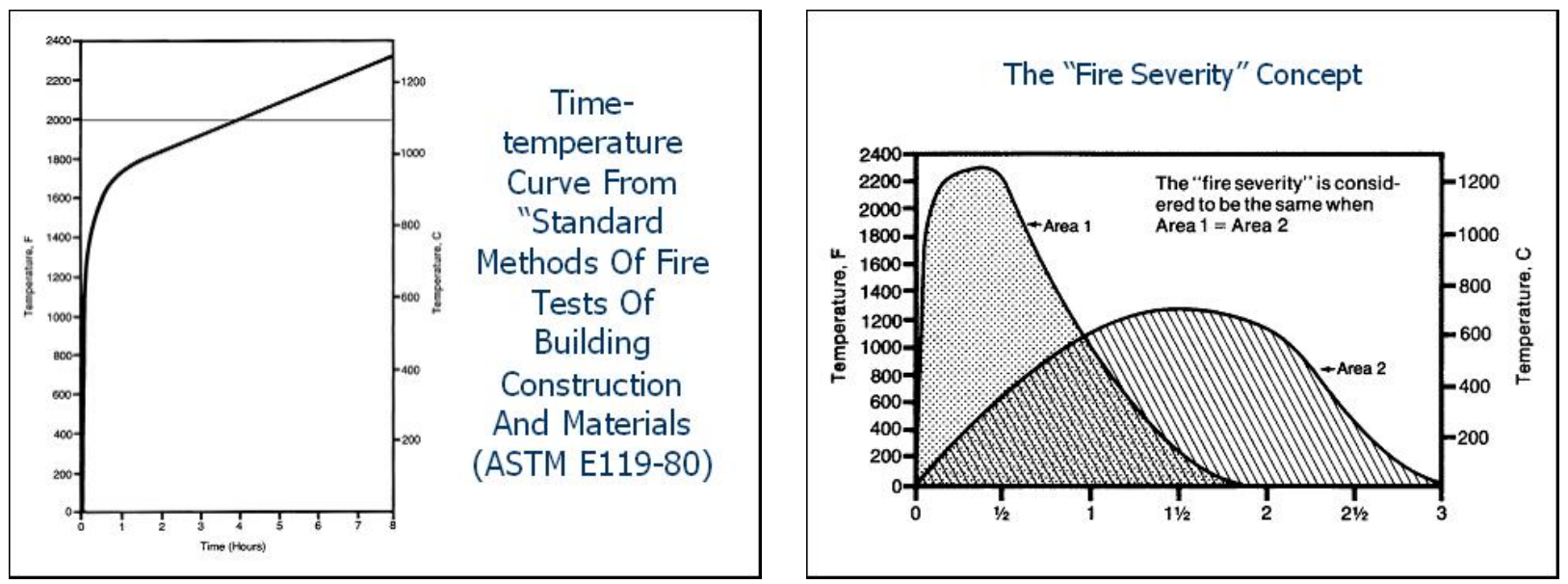

Relationship Between Fire Load and Fire Endurance

\begin{tabular}{|c|c|c|}
\hline Average Fire Load ps* & $\mathrm{kg} / \mathrm{m}^{2}$ & $\begin{array}{c}\text { Equivalent Fire } \\
\text { Endurance (hours) }\end{array}$ \\
\hline 5 & 24.4 & $1 / 2$ \\
\hline $71 / 2$ & 36.6 & $3 / 4$ \\
\hline 10 & 48.8 & 1 \\
\hline 15 & 73.2 & $11 / 2$ \\
\hline 20 & 97.6 & 2 \\
\hline 30 & 146.5 & 3 \\
\hline 40 & 195.3 & $41 / 2$ \\
\hline 50 & 244.1 & 6 \\
\hline 60 & 292.9 & $71 / 2$ \\
\hline
\end{tabular}

* Determined on the basis of a potential heat of aporoximately 8000 Btu's per pound
Fire Exposure:

(circa 1920) in furnace

Thermal Response
- Temperature Measurement from Sample

Mechanical

- Ifloaded, can't open or collapse

- No connections

Physical Properties

- No vitriconim

Reliability

Implicitly treated though listing/app roval

- Done in small $\%$ of cases 


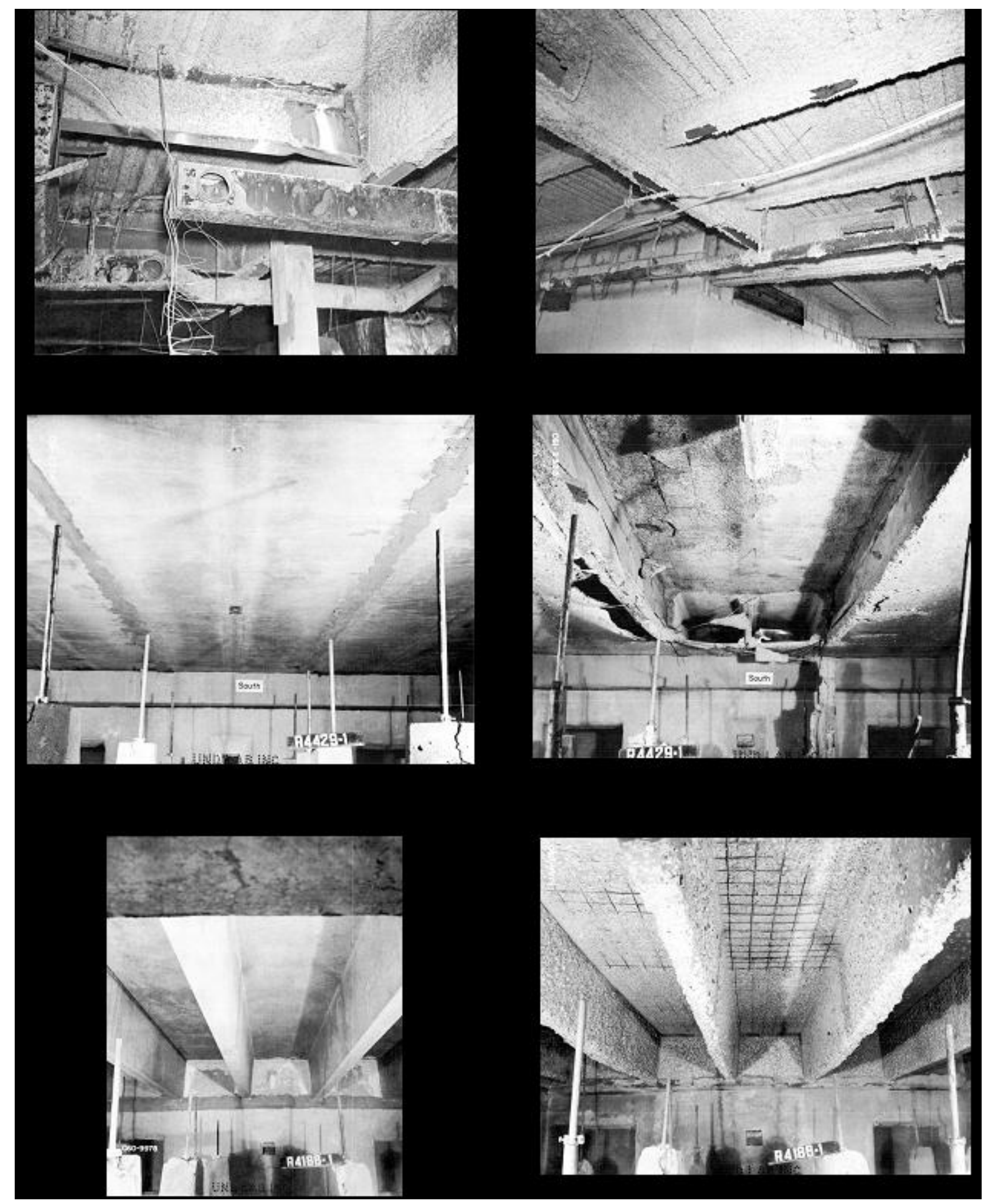




\section{Materials/Systems Currently Used}

- Spraved Fiber

- Cementitious

- Mastic

- Intumescent Paint

- Membrane

- Suspended ceilings

- Drywall assemblies

- Concrete encasement

- Tile

- Plaster/lath
Effect of Window Area on Fire Temperatures

During Bumout Tests with Natural Ventilation

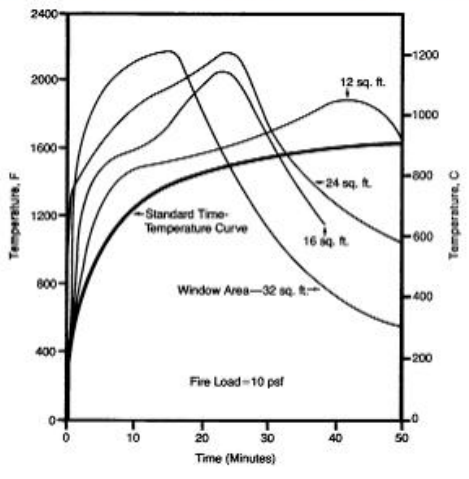

\section{State of Art (circa 1965-1975)}

- Fire Exposure

- Design exposure curves

- Post-flashover

- Ventilation controlled

- Insulation properties of wall linings

- Thermal Response

- Critical temperature

- Columns, beams

- 1-D analytical

- 2-D finite differences schemes
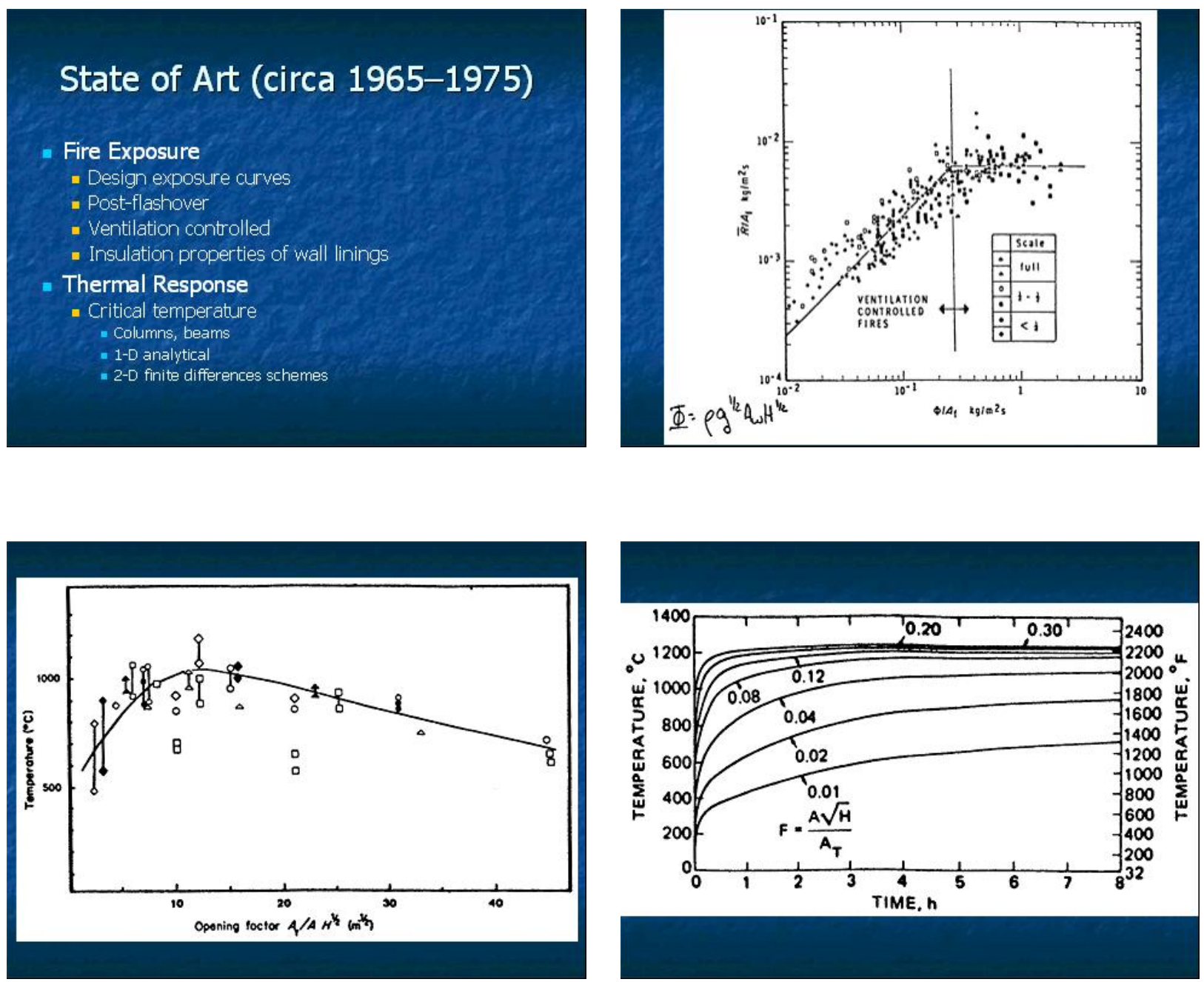

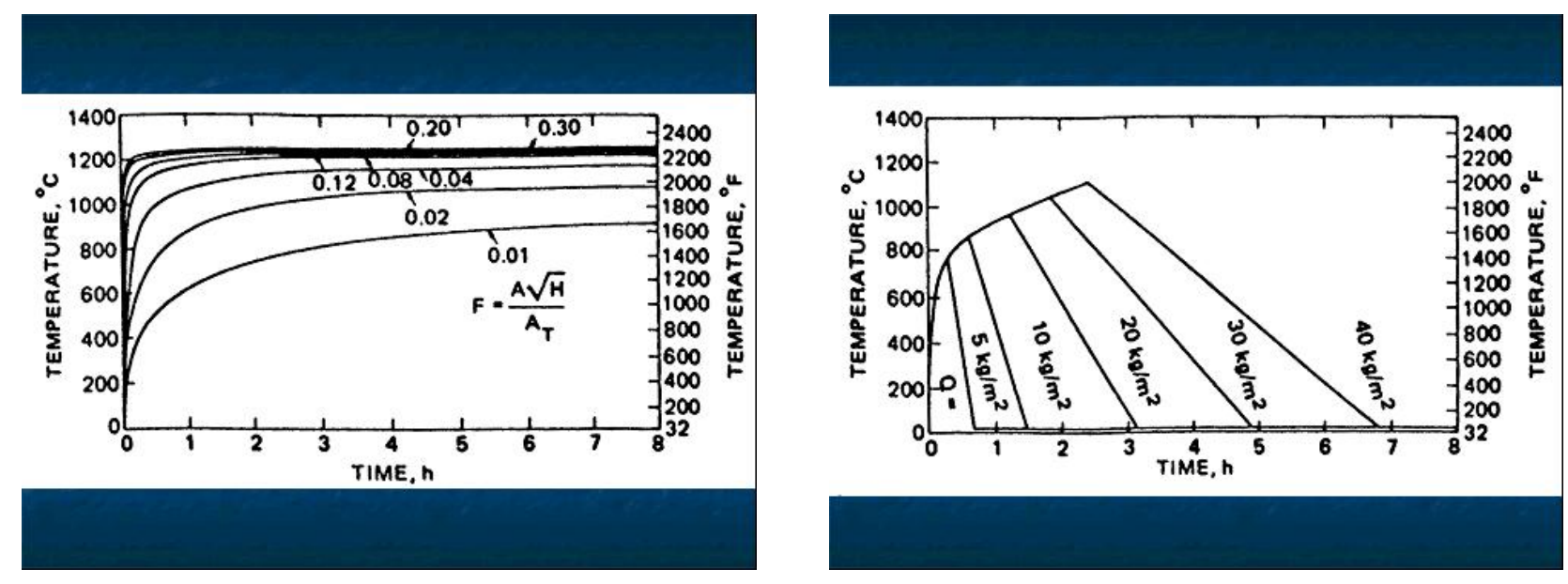

State of Art (circa 1965-1975)

\section{$1975-1980$}

- Mechanical Response

- Column buckling

- Beam deflection

- Truss deflection

- Physical properties

- Transport \& Mechanical properties as a F (T)

Question: Capability for $30-35$ years... integrated into design guides and never utilized in US regulations

\section{Needs for Science-Based}

Structural Fire Protection Design

Design fire exposure

- Thermal/Mechanical Response of Insulation Systems

- Structural Performance in Fire

- Test methods

- Performance Criteria

- Technology Transfer

\section{Science-Based Structural Fire Protection Design}

- 3-D Finite Element Heat Transfer Model

- Structural Response Model (FASBUS)

- Model of Post Flashover Fires ( COMPF)

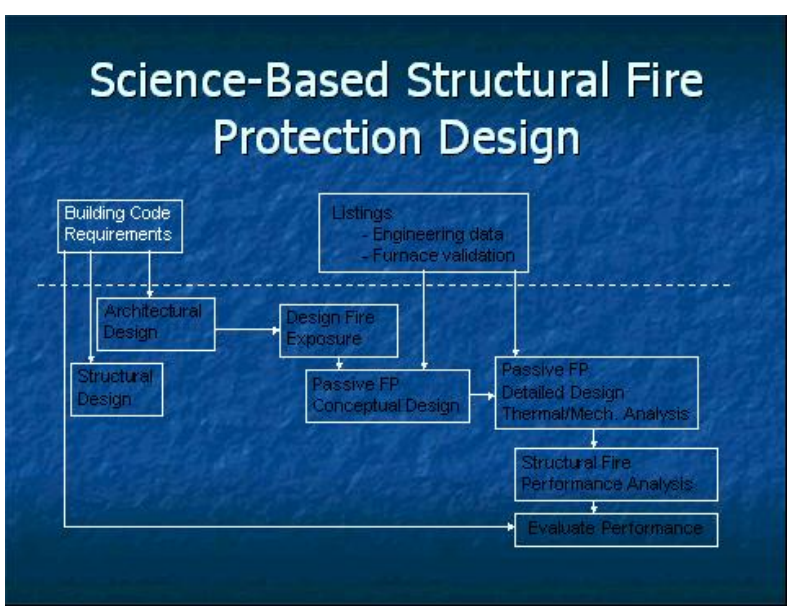




\section{Design Fire Exposure}

- Modern fire load survey data

- Combined local/global fire exposure characterization, i.e. beyond well stirred

\section{Thermal/Mechanical Response} of Insulation Systems

- Institutionalized thermal properties test methods

- Test methods and performance criteria for mechanical response; non-fire, impact loading, fire exposure

- Fire barrier performance- must address along with structural frame performance

\section{Structural Performance in Fire}

Assess needs for full structural frame analysis vs more detailed local deformation analysis

- Assessment of connection performance

\section{Test Methods}

- Need full compliment of test methods for engineering properties

- Revisit furnace testing methods: -exposure should be severe (1709) -test should be a validation of

engineering methods -revisit the relationship between the test and real structural frames

\section{Performance Criteria}

- What are we trying to achieve?

- Acceptable local performance

- Acceptable global performance

- Risk, reliability, and relationship to the total fire protection design

- Inspection, Testing, and Maintenance (ITM)

\section{Technology Transfer "The Real Problem"}

- Develop a broad consensus for the need to change how we do SFP

- Codify SFP design practice

- Formulate building code requirements

- Educate engineers, architects, AHJ's 


\section{Needs for Science-Based} Structural Fire Protection Design

- Design fire exposure

- Thermal/Mechanical Response of Insulation Systems

- Structural Performance in Fire

- Test methods

- Performance Criteria

- Technology Transfer

\section{Summary}

- Science-based structural fire protection is clearly technically achievable

- It will require a total reexamination of the SFP process from listing, to design, to ITM

- The payoff? - known, cost effective performance and safety 
D. ASCE/SFPE Standard on Performance-based Structural Fire Protection Analyses James Milke, Department of Fire Protection Engineering University of Maryland, College Park, MD
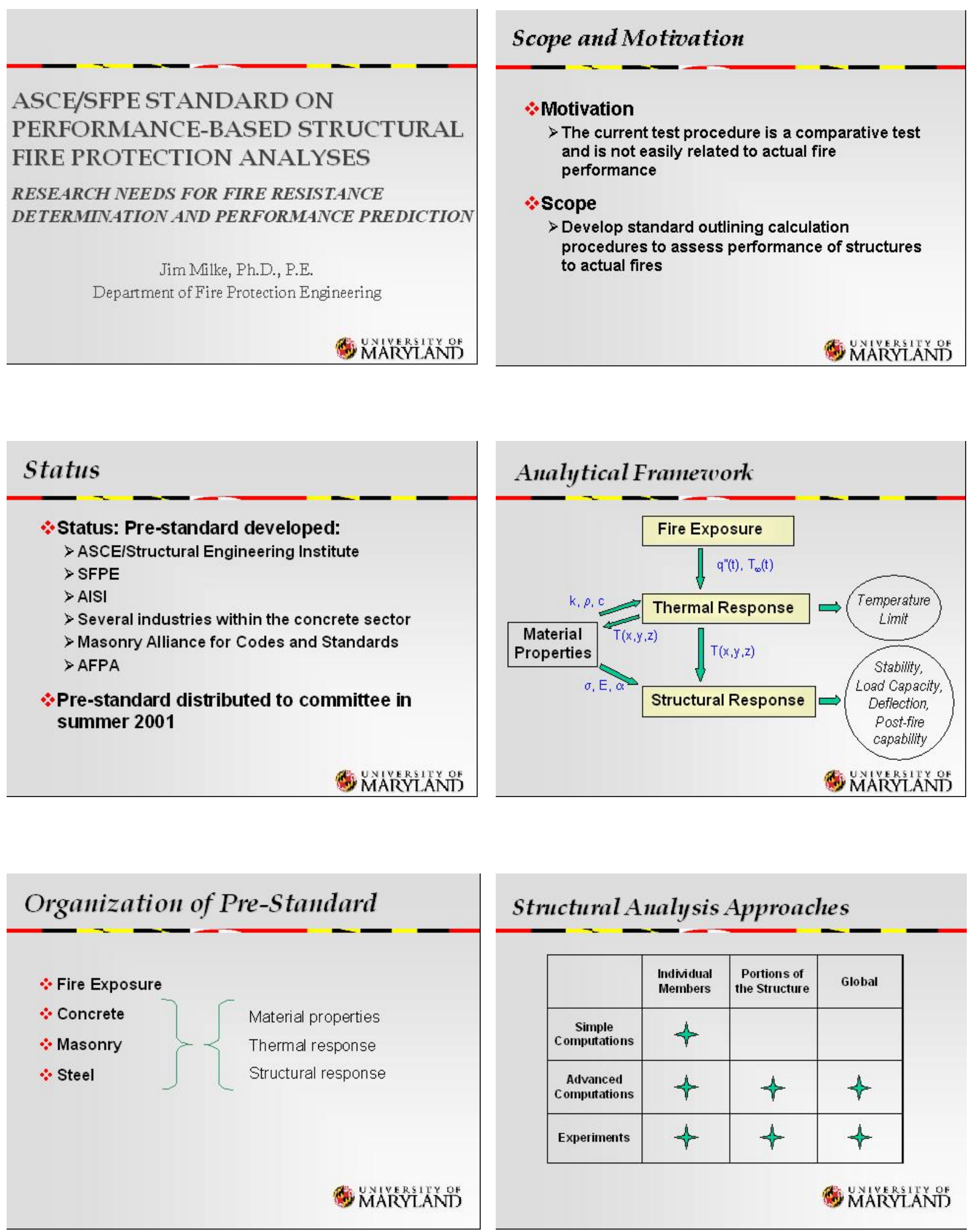

Structural Analysis Approaches

\begin{tabular}{|c|c|c|c|c|}
\hline & $\begin{array}{l}\text { Individual } \\
\text { Members }\end{array}$ & $\begin{array}{c}\text { Portions of } \\
\text { the Structure }\end{array}$ & Global & \\
\hline $\begin{array}{c}\text { Simple } \\
\text { Computations }\end{array}$ & $d$ & & & \\
\hline $\begin{array}{c}\text { Advanced } \\
\text { Computations }\end{array}$ & 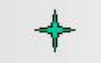 & $t$ & $d$ & \\
\hline Experiments & $\Rightarrow$ & $d$ & $t$ & \\
\hline & & & $y^{u}$ & LAN 암 \\
\hline
\end{tabular}



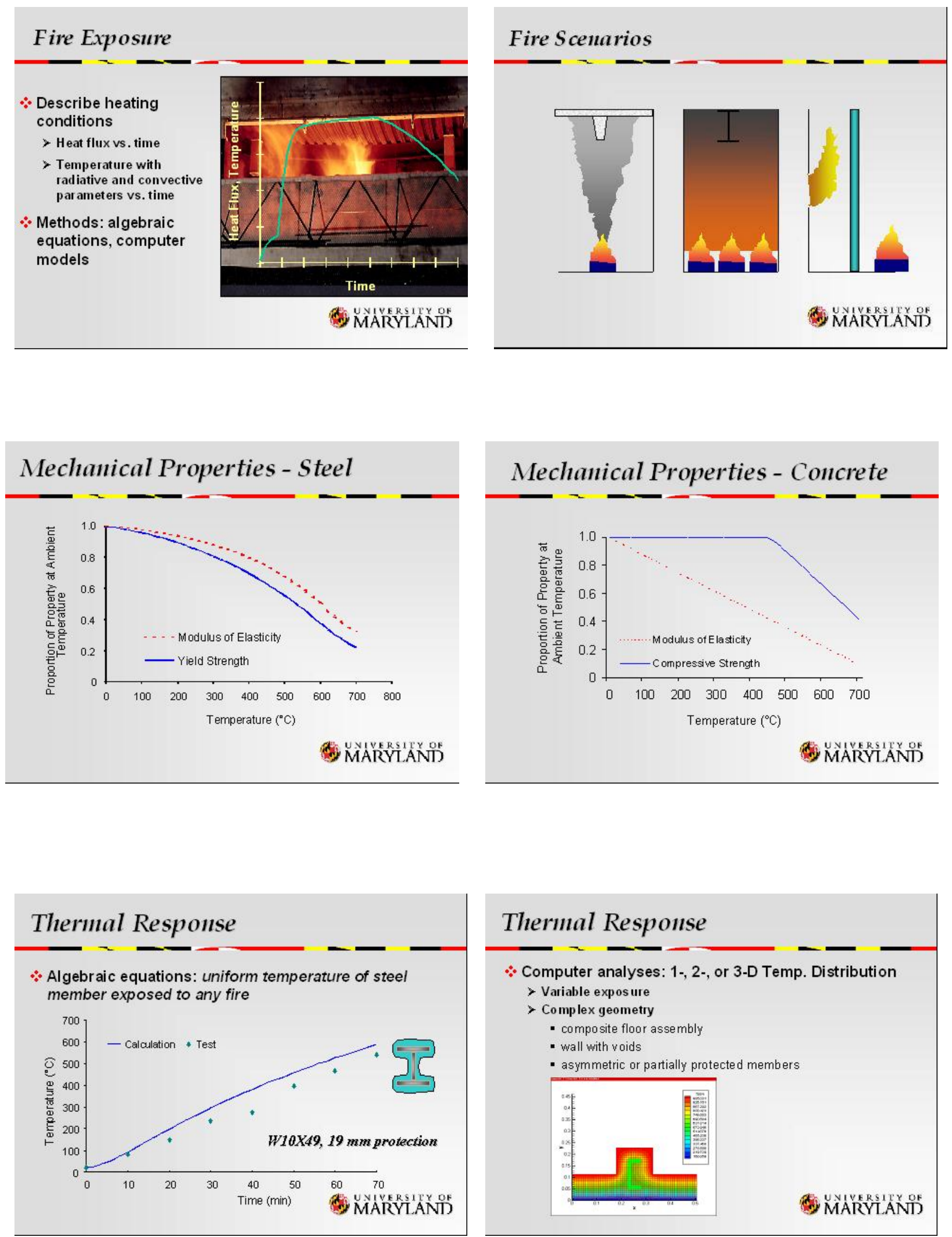

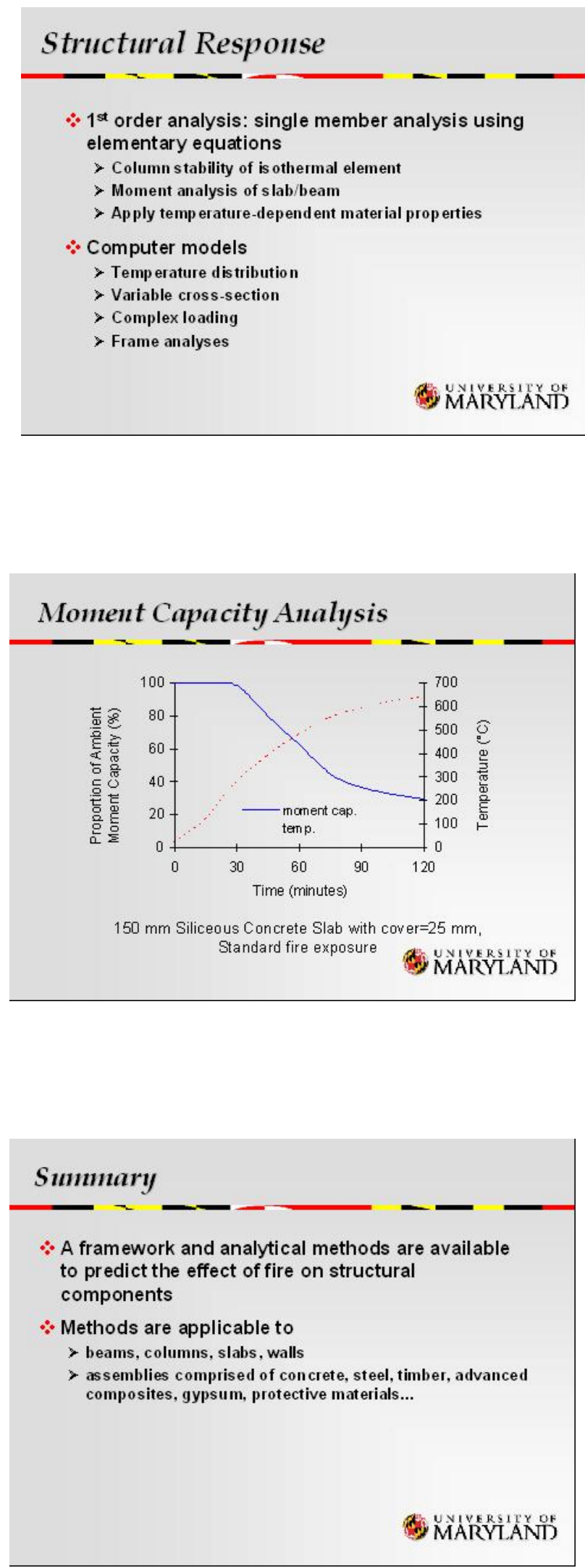

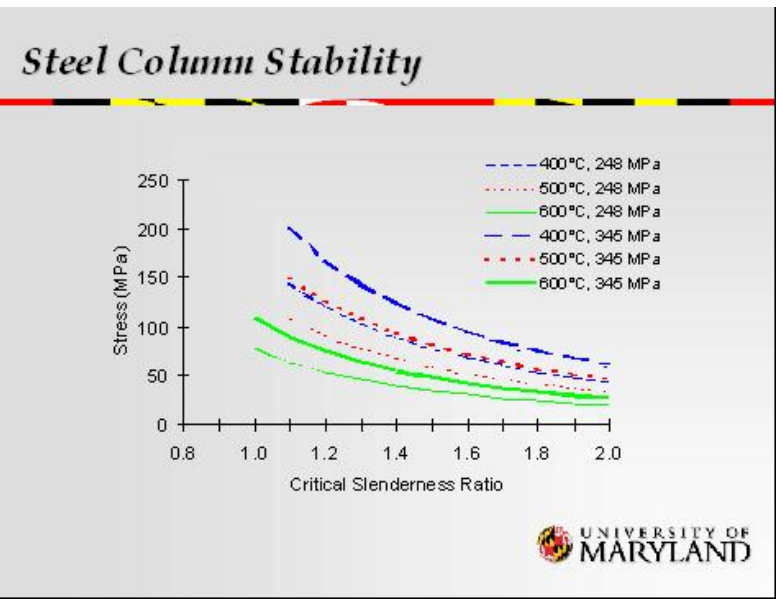

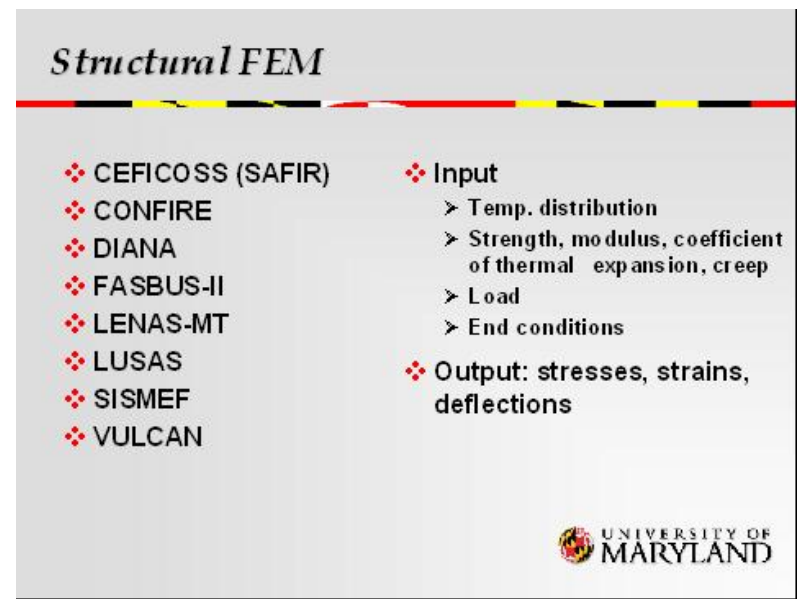


E. Simulation of Accidental Fires and Explosions Adel Sarofim and Philip Smith, Department of Chemical Engineering

University of Utah, Salt Lake City, UT

\section{Center for the Simulation of Accidental Fires and Explosions}

Adel F. Sarofim and Philip J. Smith

Department of Chemical and Fuels Engineering

University of Utah

Workshop on

RESEARCH NEEDS FOR FIRE RESIST ANCE

DE TERMINATION AND PERFORMANCE

PREDICTION

NIST Gaithersburg

February 19, 2002

\section{OUTLINE}

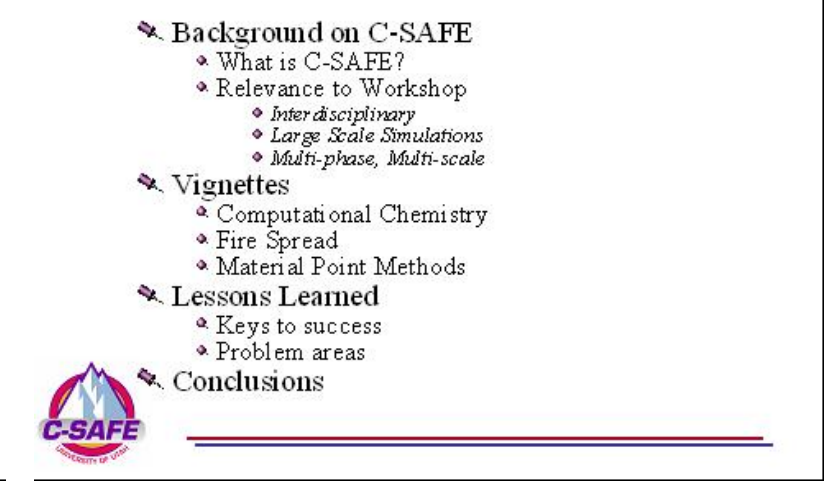

\section{ASCI \& C-SAFE}

The Accelerated Strate gic Computing Initiative (ASCI) Alliances have been set up to develop unclassified simulation science in support of the DOE Defense Program Laboratonies mission to safeguard the U.S. nuclear stockpile. Five universities have been funded as part of the ASCI alliance:

Stanford University: development of technology suitable for the design of gas turbine engines

California Institute of Technology: shock waves induced by high explosives on various materials in different phases

University of Chicago: long-standing problem of astrophysical thermonuclear flashes

University of Utah: science-based tools for numerical simulation of accidental fires and explcoions, within the conte xt of handling and storing highly flammable material (C-SAFE's project)

yer sity of Ilimois: whole-system simulation of solid propellant rockets under C.SAFE FE both nomal and abnormal operating conditions.

CSAFEE

\section{C-SAFE Team Structure}

\begin{tabular}{|c|c|c|c|c|}
\hline $\begin{array}{l}\text { All- } \\
\text { SDRM } \\
\text { Step } \\
\text { Teams }\end{array}$ & \multicolumn{4}{|c|}{$\begin{array}{c}\text { Comp uter Science } \\
\text { Leaders: Tom Henderson; Steve Parker - SA } \\
\text { Software Engineer: Davison de St. Germain } \\
\text { Key Partic ipants Chris Johnson, Chuck Hansen, } \\
\text { Gary Lindstrom, Kris Silkorski }\end{array}$} \\
\hline Ignition & \begin{tabular}{|l} 
Fire \\
Spread
\end{tabular} & \begin{tabular}{|l|} 
Container \\
Dynamics
\end{tabular} & \begin{tabular}{l|} 
High Energy \\
Transformations
\end{tabular} & $\begin{array}{l}\text { Accidental } \\
\text { Detonation }\end{array}$ \\
\hline I & Phil Smith & Pat Mc Murtry & Chuck Wight & \\
\hline $\begin{array}{l}\text { Software } \\
\text { Engineer: }\end{array}$ & Rajesh Rawat & John Schmidt & M. Ovchinnilgy & SDRM- \\
\hline Key & $\begin{array}{l}\text { Thanh Truong } \\
\text { Adel Sarofim } \\
\text { Homer Waller }\end{array}$ & $\begin{array}{l}\text { Dan Adams } \\
\text { John Nairn } \\
\text { Jeff Weiss } \\
\text { Grant Smith }\end{array}$ & $\begin{array}{l}\text { Greg Voth } \\
\text { Thanh Truong } \\
\text { Jack Simons } \\
\text { Grant Smith } \\
\text { Merrill Beckstead }\end{array}$ & $\begin{array}{l}\text { specific } \\
\text { Step } \\
\text { Teams }\end{array}$ \\
\hline & KeyP & $\begin{array}{l}\text { Validati } \\
\text { ders: Adel Sar } \\
\text { ants: Ron Pug }\end{array}$ & $\begin{array}{l}\text { Eric Eddings } \\
\text { Thiokrol }\end{array}$ & \\
\hline
\end{tabular}

Specific Focus

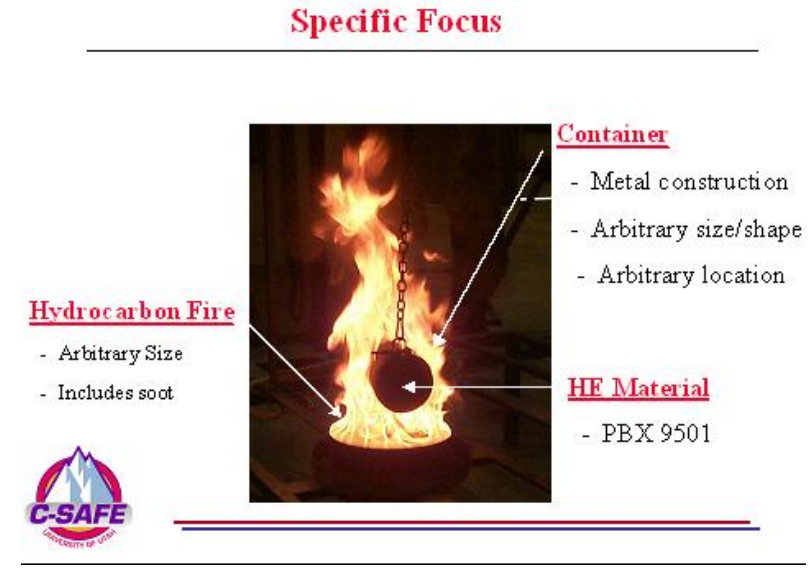

Firespread

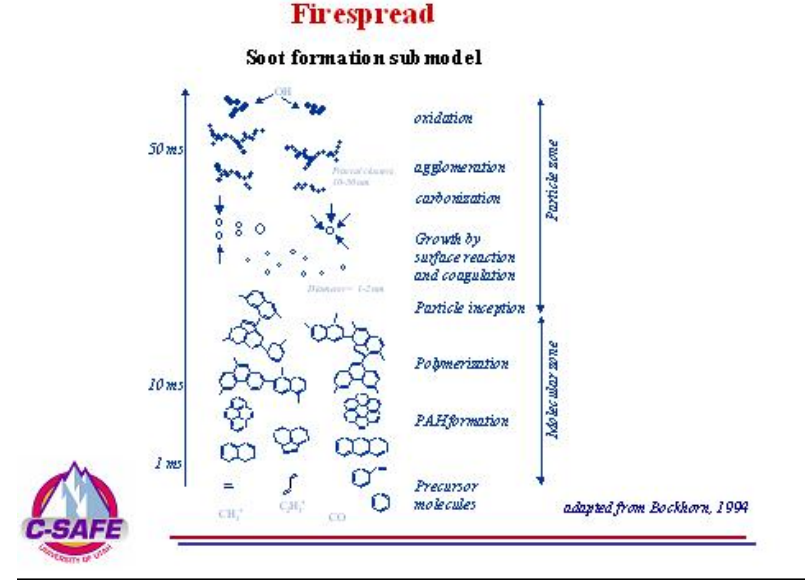



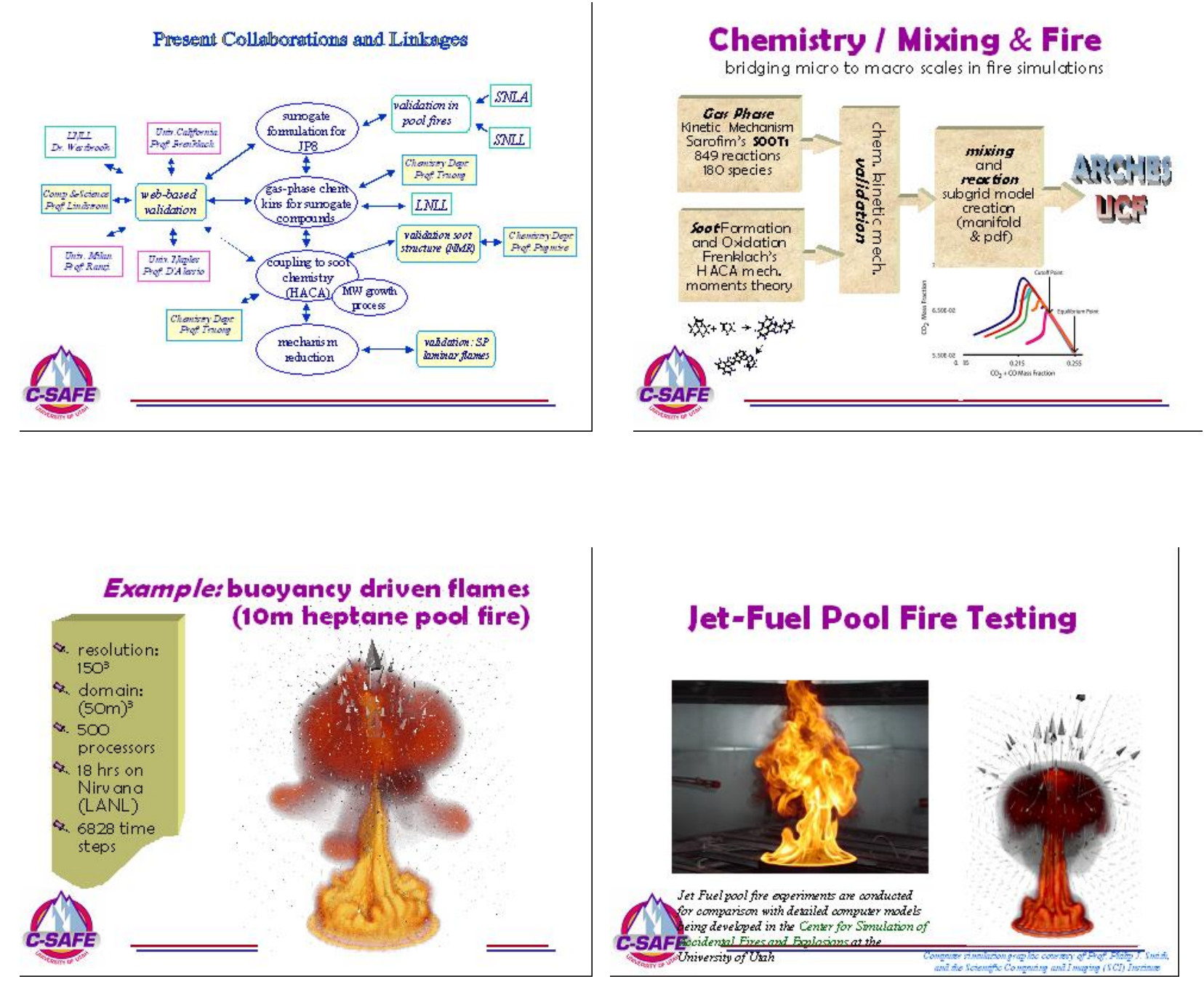

\section{Jet-Fuel Pool Fire Testing}
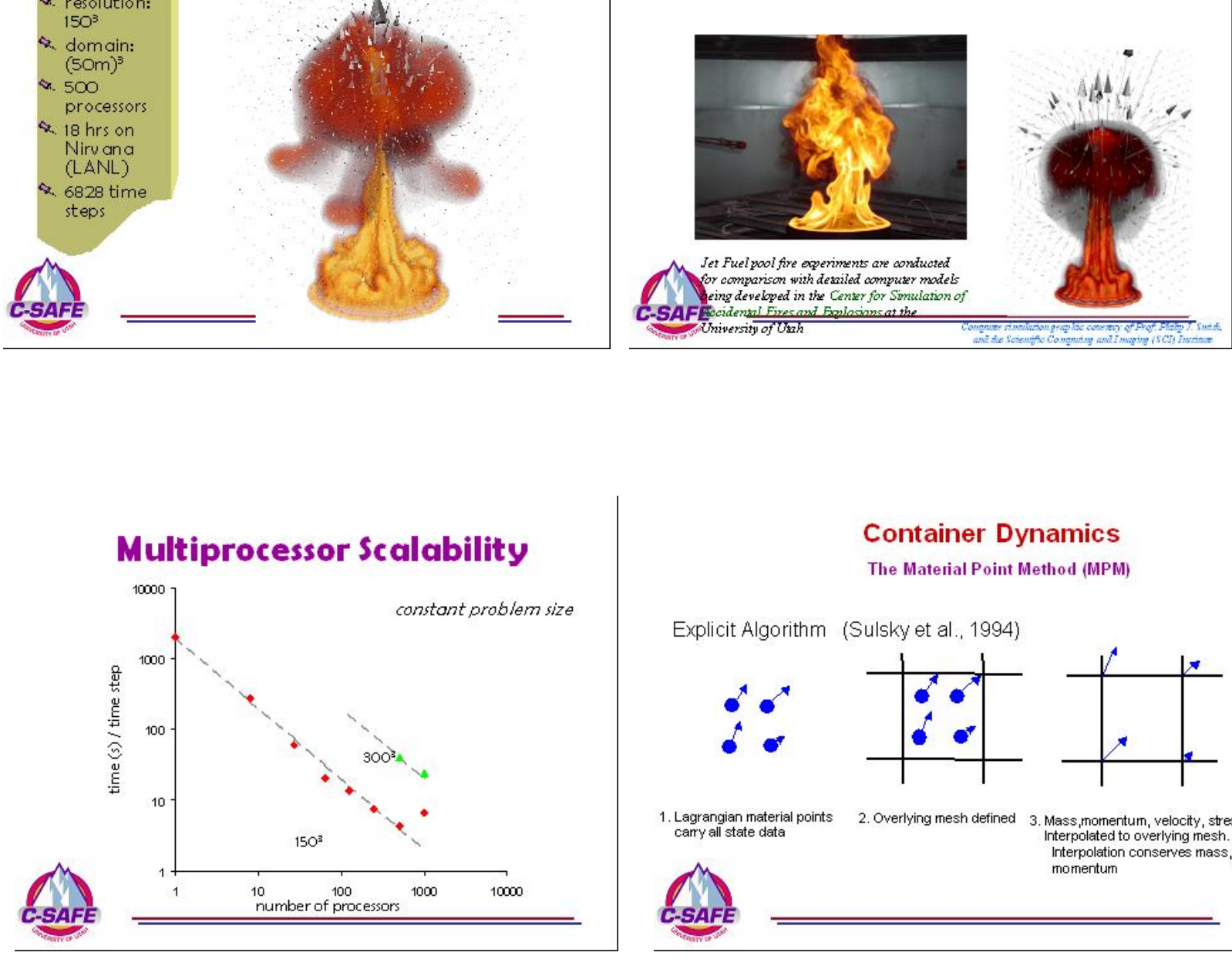

\section{Container Dynamics}

The Material Point Method (MPM)

Explicit Algorithm (Sulsky et al., 1994)
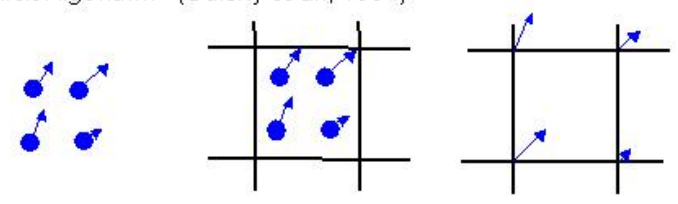

1. Lagrangian material points

2. Overlying mesh defined 3. Mass, momentum, velocity, stress Interpolation conserves mass, momentum 


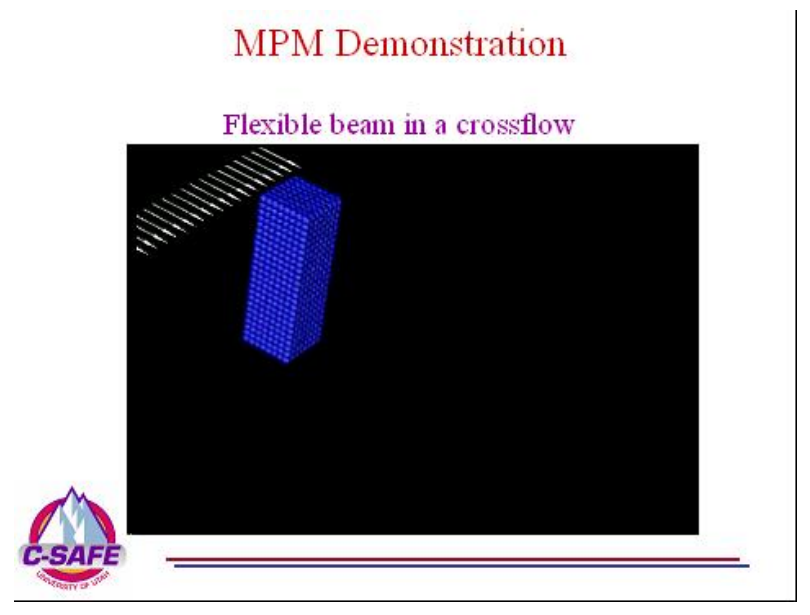

HIGH ENERGY MATERIALS

Container/PBX Heating Response Simulation

Container: Steel

bulk modulus: $200 e 9 \mathrm{~Pa}$

shear modulus: $77.8 \mathrm{e} 9 \mathrm{~Pa}$

yield stress: $250 e 6 \mathrm{~Pa}$

hardening modulus: $77 \mathrm{e} 7 \mathrm{~Pa}$

OD: $0.03136 \mathrm{~m}$

ID: $0.02496 \mathrm{~m}$

Thickness: $0.0016 \mathrm{~m}$

Contents: PBX - ViscoScram

Center hole: $0.0032 \mathrm{~m}$

Burn Model: HE Team, rate $=\mathrm{Akp}{ }^{n}$

Initial Temperature: PBX, 300K

Specified heat flux at container surface
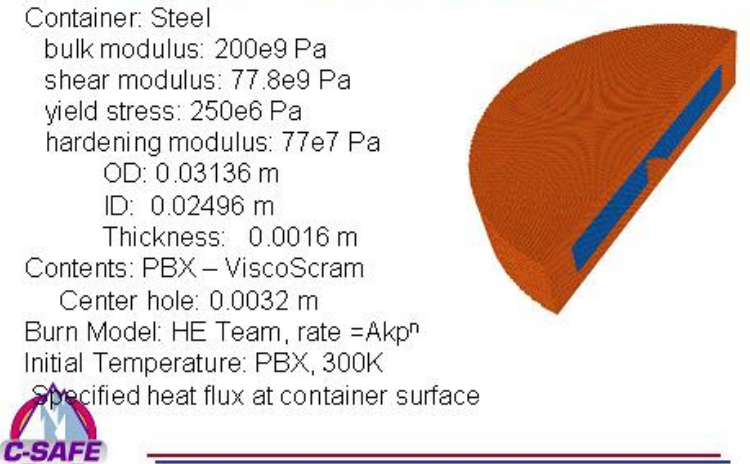

Container/PBX Heating Response Simulation

Mass evolution
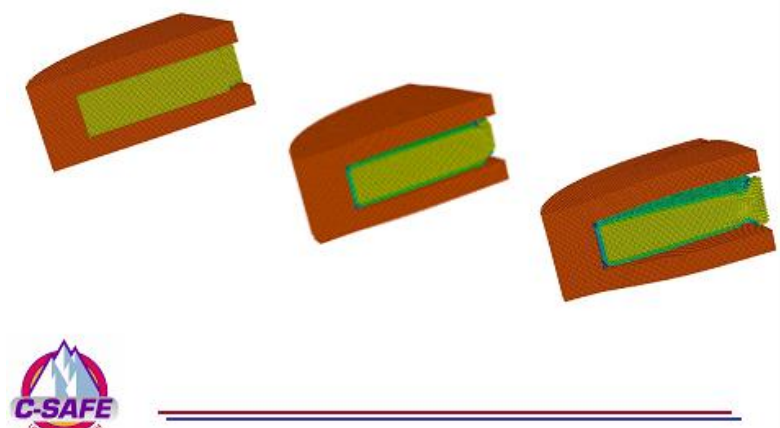

Time to Explosion Correlates with Heat Flux (Inferred from T-t using Duhsmmel Superposition)
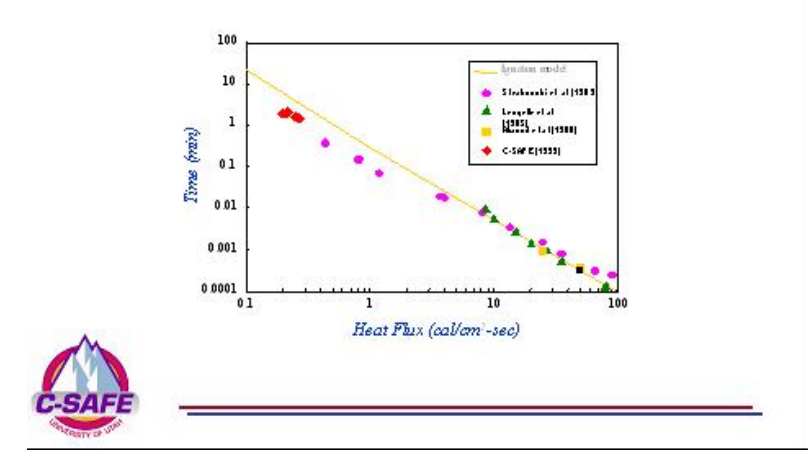

Heat $F$ hax (cal $/ o n-5 e c)$

\section{Images from Propane-Fired} Fast-Cook Off Test

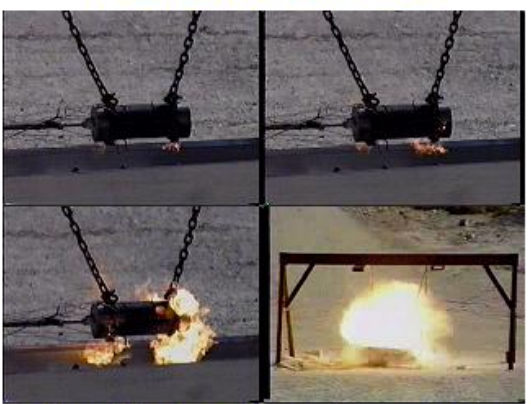

(a), (b) and (c) Release of pyrolysis gases; (d)Explosion

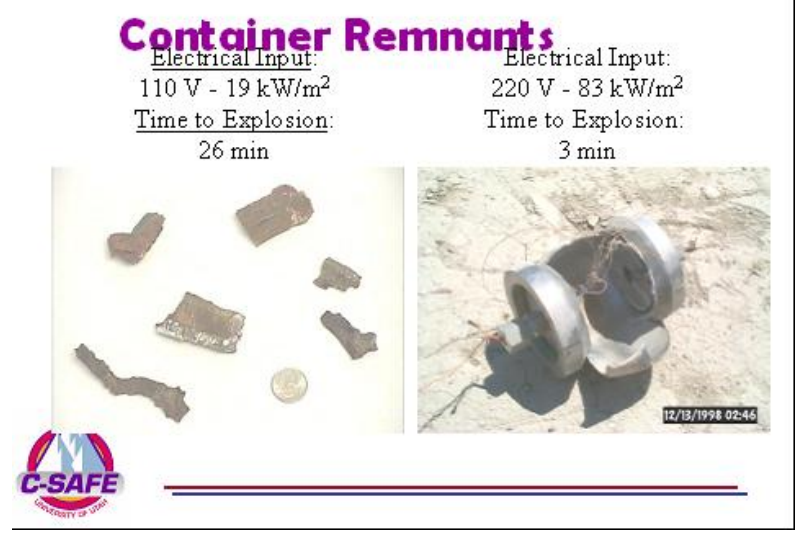




\section{Uintah Computational Framework}

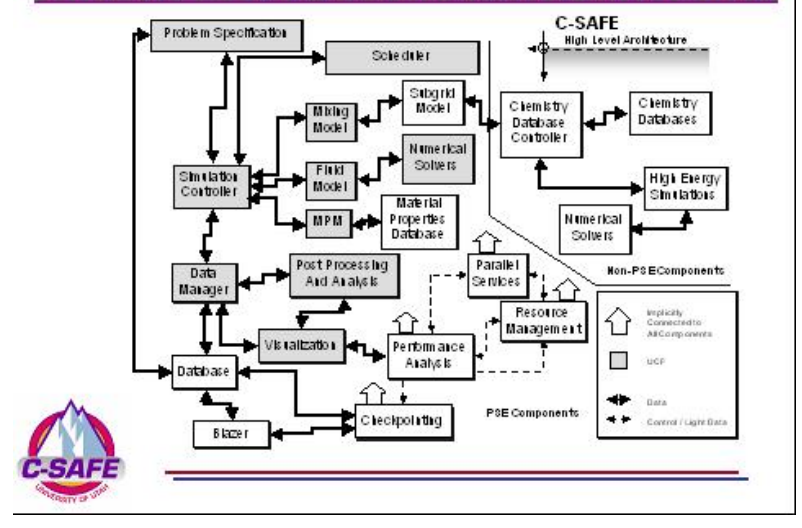

Problem Areas

\& Interfaces

a Between phases

a Communication

a Between disciplines

a With ultimate user

\& Data

a Communication

astorage

a Mining

\section{Keys to Success}

\& Well-defined goals

Manage ment Committee chaired by Dave Pershing to provide priorities,

a resource allocation,

Designation of software engineer for each step to work with the computer scientists on

* Algorithm development

- Common computer architectur

- Problem solving environmen

- Parellelination, Virualization

* Networking with the DOE laboratories and with national and other discipline experts

Tie in with experimental programs for validation

\section{Conclusions}

* Crosscutting Issues need Inter disciplinary Approaches a C-SAFE experience underlines importance of close collaboration between software engineers and computer scientists

a 'Amphibians' needed to bridge gaps between disciplines

- Importance of communication cannot be overstated (GBS: "The greatest myth about taken place.")

\& Major Advances in Simulation Science

a Computational chemistry for properties,

mechanisms, kinetics

- More detailed kinetic and fluid mechanics models can be included in massively parallel computations

a Material point metho ds show promise for handling

large deformations and break up of structures

Experimental validation and guidance is crucial 
F. Research Needs

Howard Baum, Fire Research Division

Building and Fire Research Laboratory, NIST

- Defining the building

- Generating electronic databases

- HVAC systems, stairways, and elevators

- Burning the office environment

- Furniture and other non-planar items

- Libraries and paper files

- Fire induced geometry changes

- Window breaking

- Warping of partitions 


\section{G. Simulation of Cardington Fire Tests \\ Asif Usmani, \\ University of Edinburgh, UK}

School of Civil \& Environmental Engine ering STRUCTURES AND FIRE RESEARCH INSTITUTE

Min Redte, DD Drysdale, BY Sinha, J Terero, AS Usmani, Farkaj, M Colite

Computational Modelling of the Cardington fire tests

\section{AS Usmani}

coworkers: S Lamont, M Gillie, AM Sanad, M O'Connor, JM Rotter, DD Drysdale, B Lane

University of Edinburgh, Scotl and, UK

Corus Plc, Ove-Arup \& Partners

\section{Background}

- Events showed structural design for fire as overly conservative

- Cardington tests carried out to address primarily this, and to - improve understanding of structural behaviour

- produce data for validating computer models

- eventually help develop more rational design methods

- reduce cost of steel fire protection and sell more steel!

- Move on from the entrenched poor practice! standard fire test
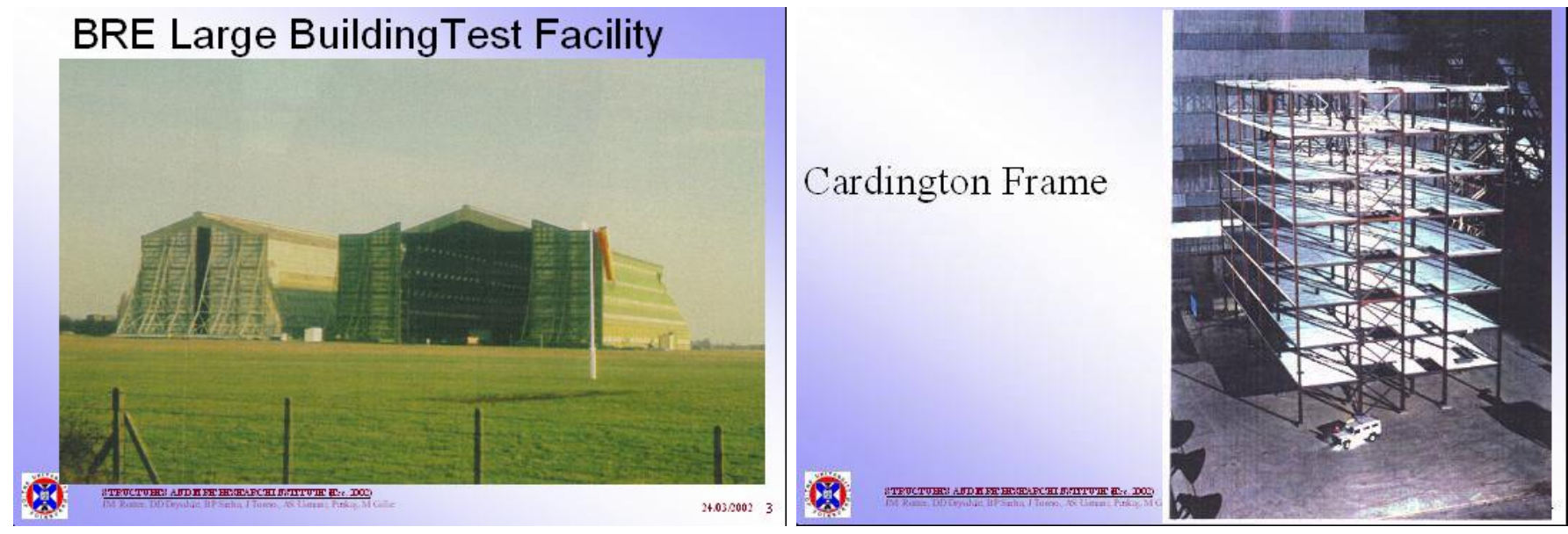

British Steel Test 4 (Demonstration Test)

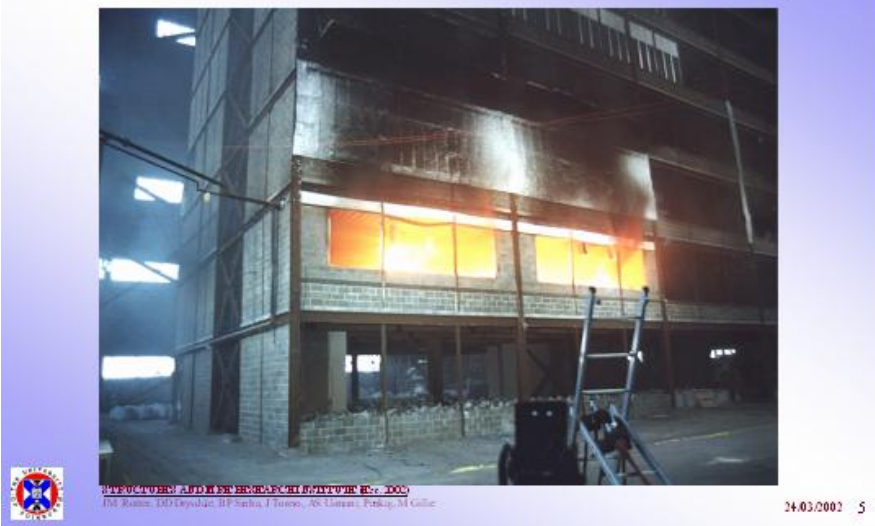

Modelling project plan after Cardington \begin{tabular}{|l|}
\hline $\begin{array}{l}\text { DETR Sponsored Structural Engineering } \\
\text { projects based on Cardington fire tests }\end{array}$ \\
\hline
\end{tabular}

Annlysts Project Dedgan Project

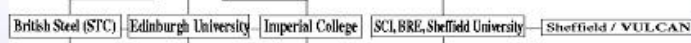
ABAOUS ADAPTIC

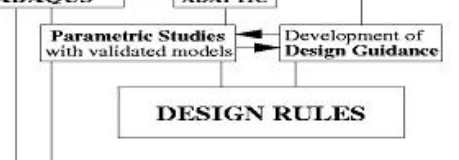

UNDERSTANDING STRUCTURAL
BEHAVIOUR

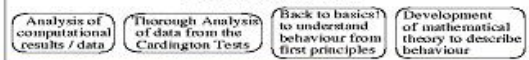

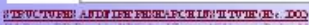




\section{Key equation}

$$
\begin{aligned}
\varepsilon_{\text {total }}=\varepsilon_{\text {thermal }}+\varepsilon_{\text {mechanical }} & \\
\varepsilon_{\text {total }} & \Rightarrow \text { Displacements } \\
\varepsilon_{\text {mechanical }} & \Rightarrow \text { Stresses }
\end{aligned}
$$

Thermal expansion

$$
\varepsilon_{\text {thermal }}=>\varepsilon_{T}=\alpha \Delta T
$$

\section{Unrestrained thermal expansion}

Uniform temperature cise $\Delta T$
$\varepsilon_{\text {total }}=\varepsilon_{t}=\varepsilon_{T}=\alpha \Delta T$
$\varepsilon_{\text {mechanical }}=\varepsilon_{m}=0$

Thermal expansion

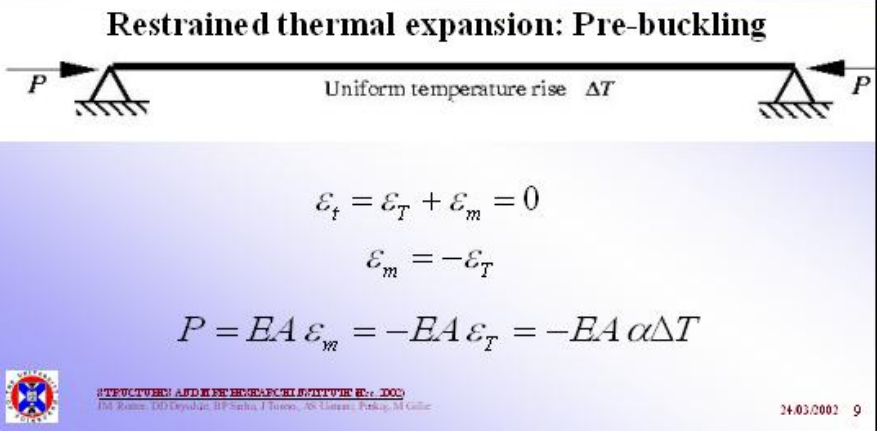

Thermal expansion

Buckling due to restrained thermal expansion

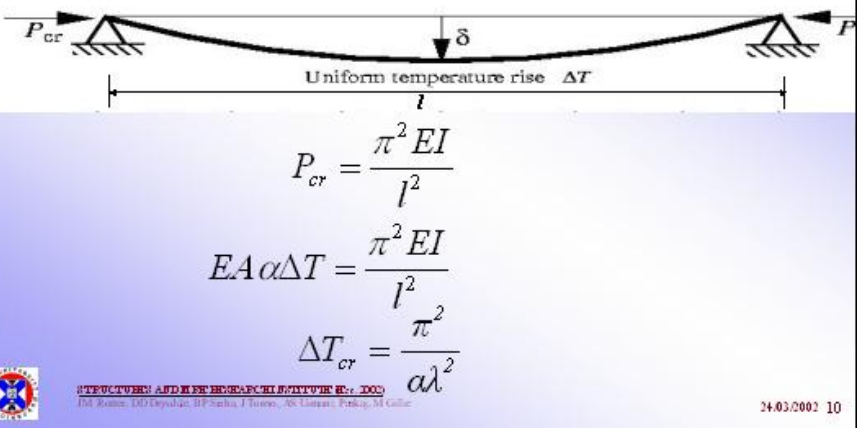

Thermal bowing

Curvature $=>\quad \phi=\alpha T_{, y}$

Thermal Bowing with ends restrained against rotation

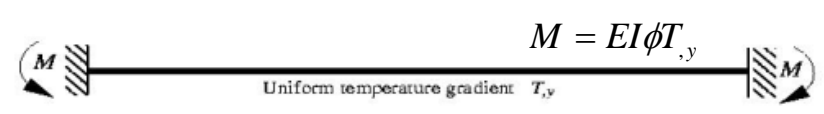

Thermal Bowing with ends restrained against translation<smiles>C[TeH]</smiles>

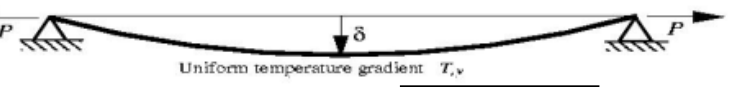

Various temperature-deflection responses

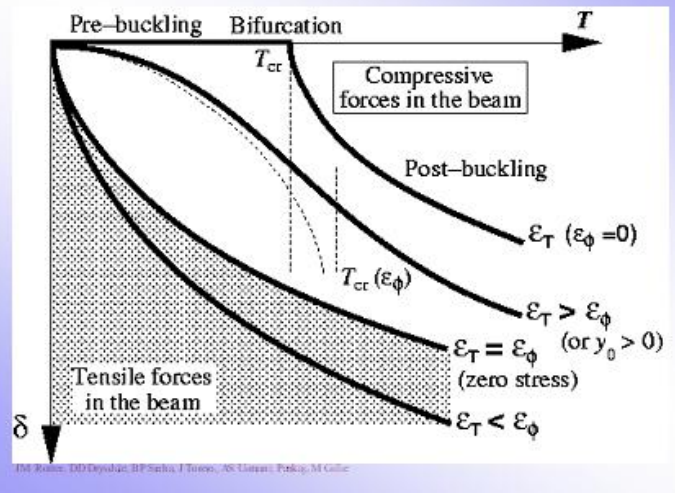

24.03200212 


\section{Main principles to interpret model output}

- Fire effect on beams and slabs can adequately be described in terms of mean temperature increment $\Delta T \&$ through depth thermal gradient $T$

- Restraint to lateral translation produces compression (small restraint enough)

- Thermal gradients impose curvature in unrestrained pin ended members

- Gradients induce moment in members with rotationally restrained ends

- Gradients induce tension in pin-ended translationally restrained members

- Combinations of thermal expansion and bowing with various restraint conditions produce a large range of deflection and internal force patterns

In slabs and other $2 \mathrm{D}$ members compatibility of displacements in the two directions may govern internal forces and displacements
British Steel Test 1 (Restrained beam test)

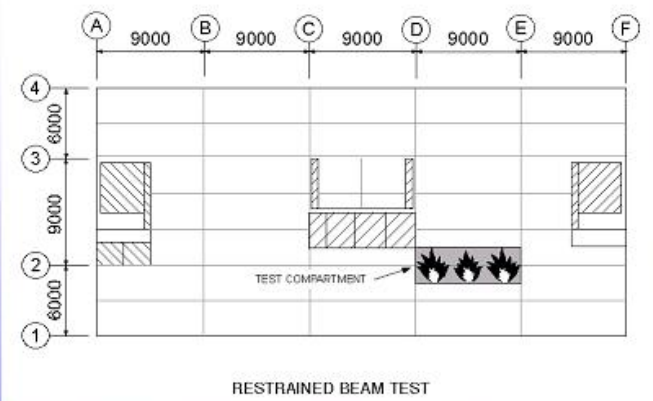

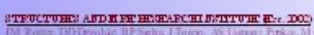

British Steel Test 1 (Restrained beam test)

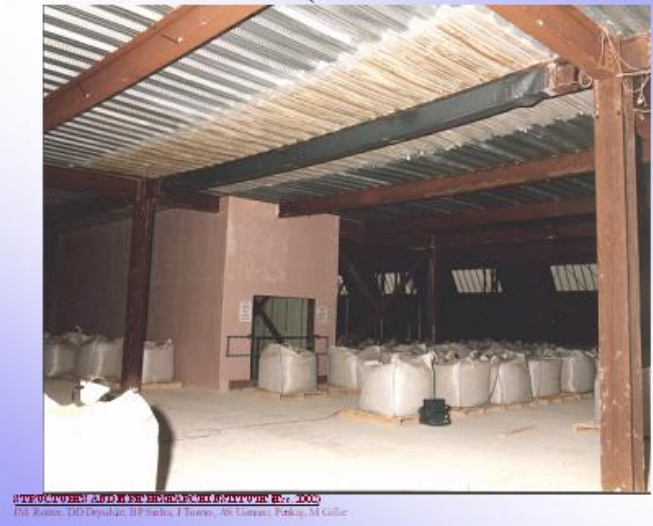

Grillage model for Restrained beam test

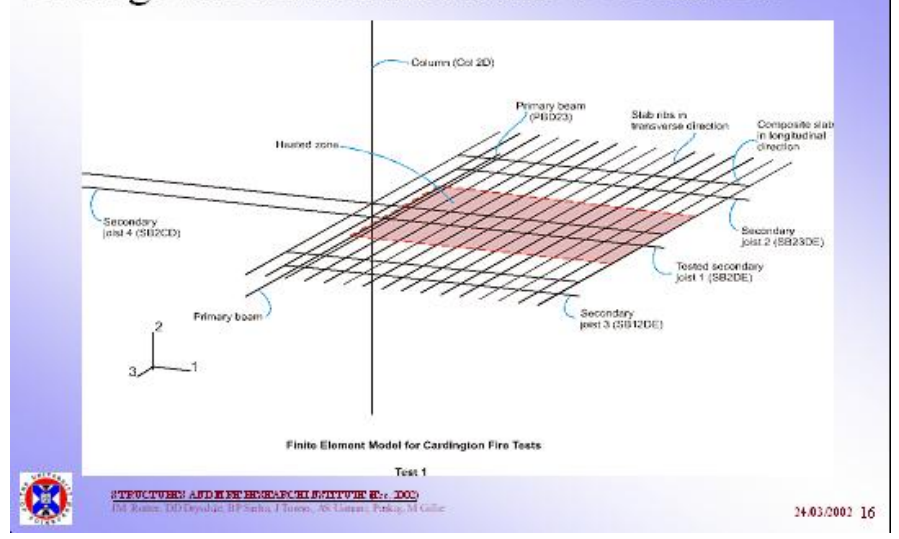

\section{Deflected model}

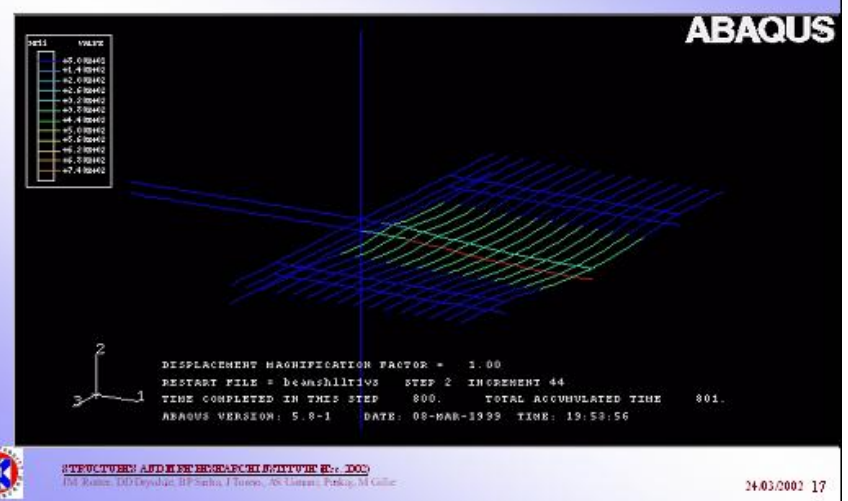

\section{Deflections}

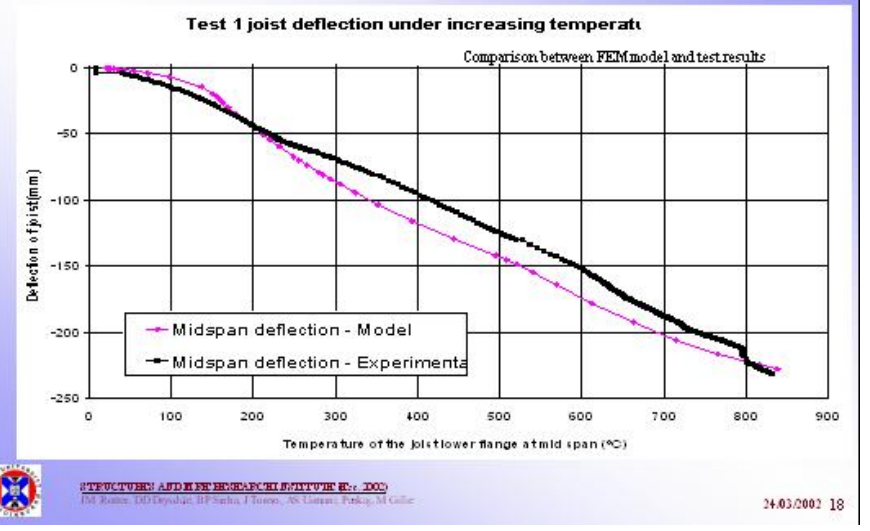


Column lateral displacement at floor level

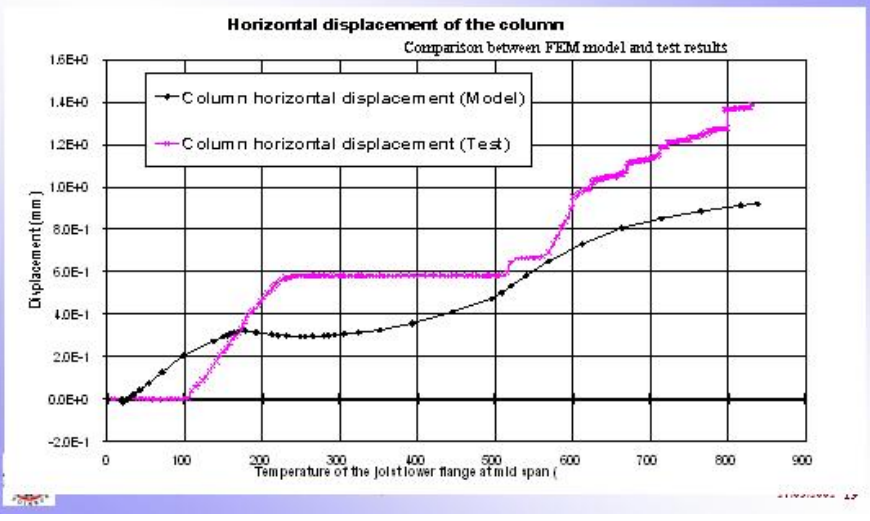

Composite beam moments during fire

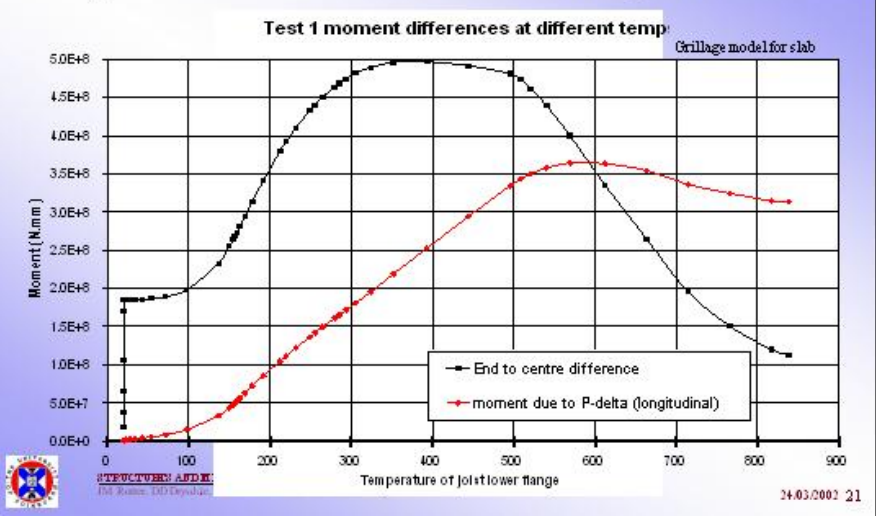

Strain in the top flange of adjacent beam

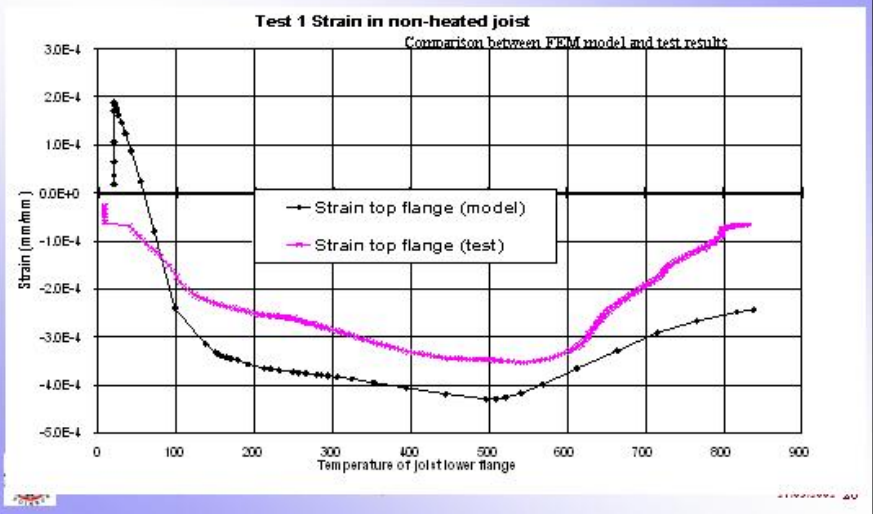

Slab rib shears during fire

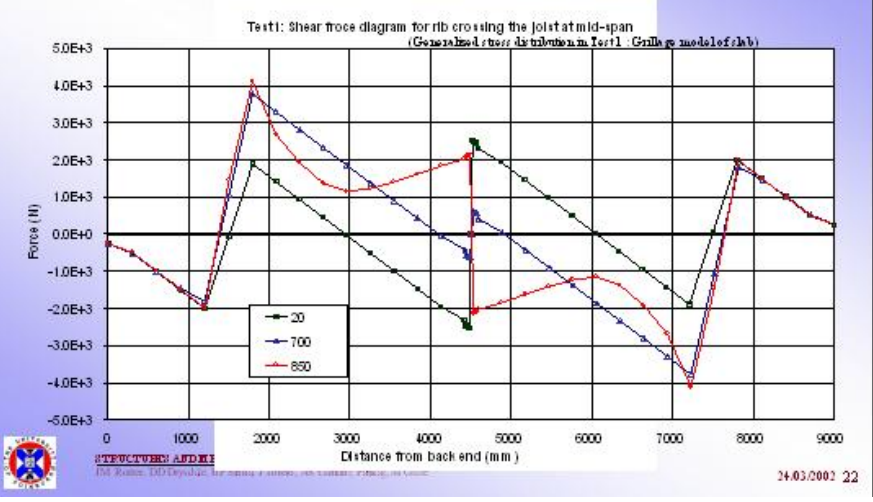

\section{Effect of steel section size}

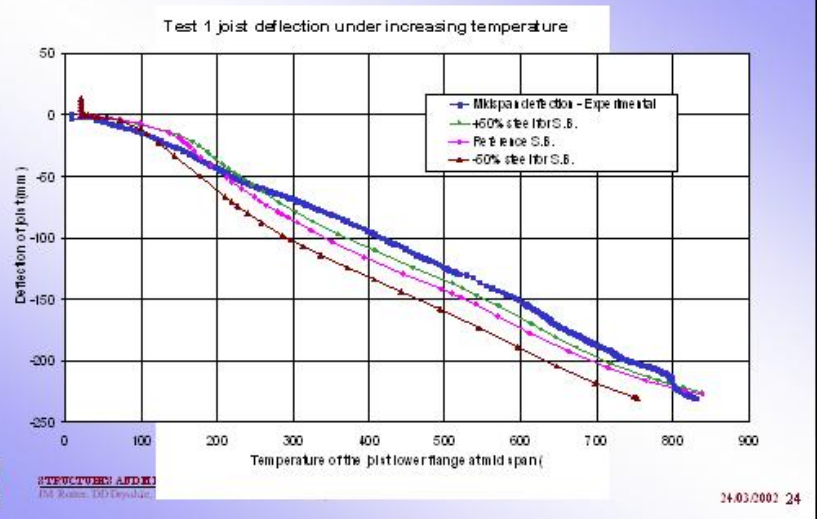



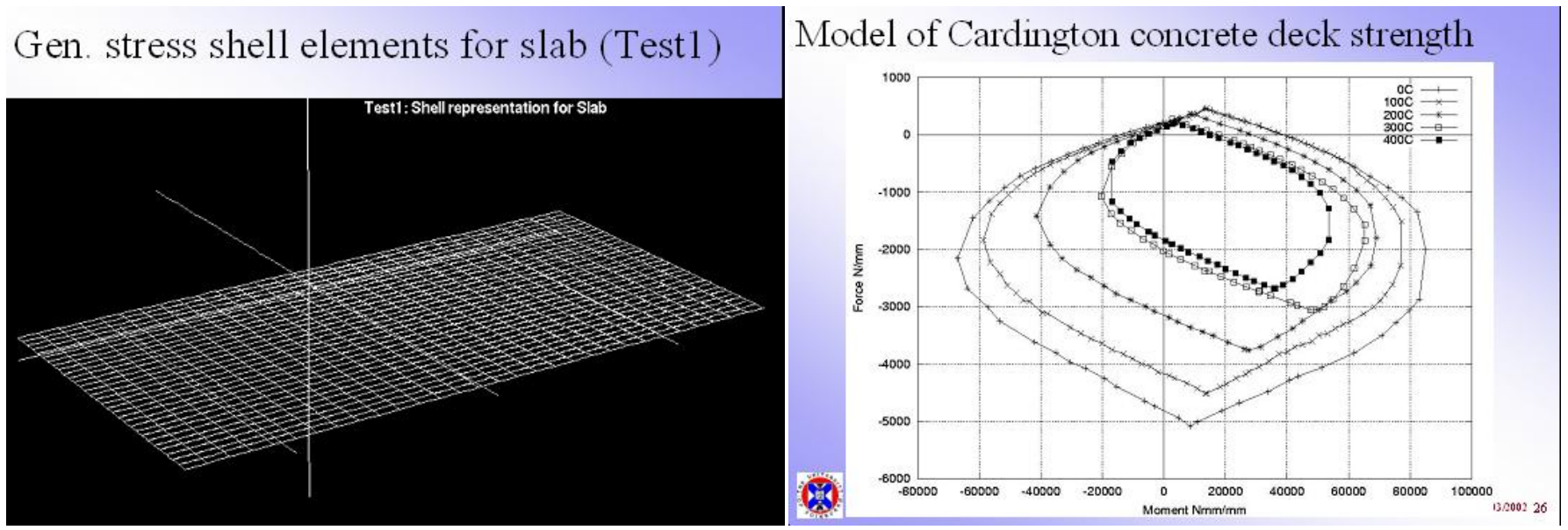

Deflections from generalised stress shell

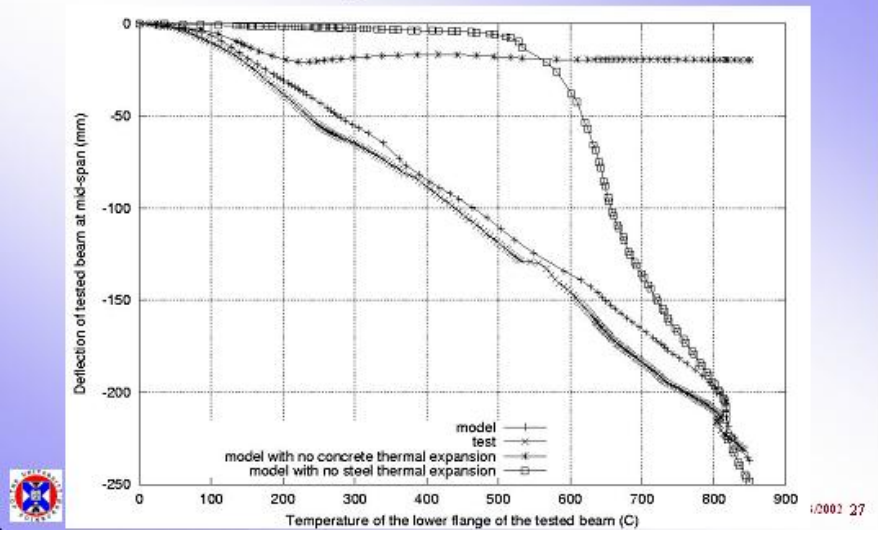

Longitudinal strains at reinf. level

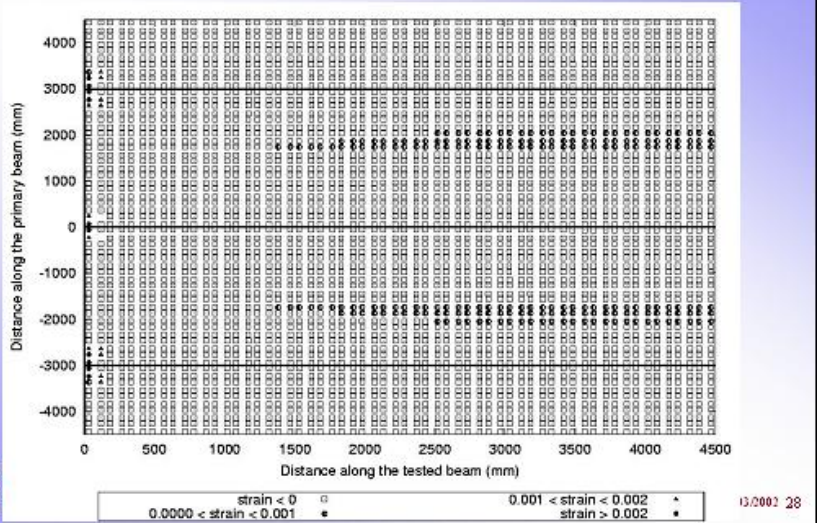

Transverse strains at reinf. level

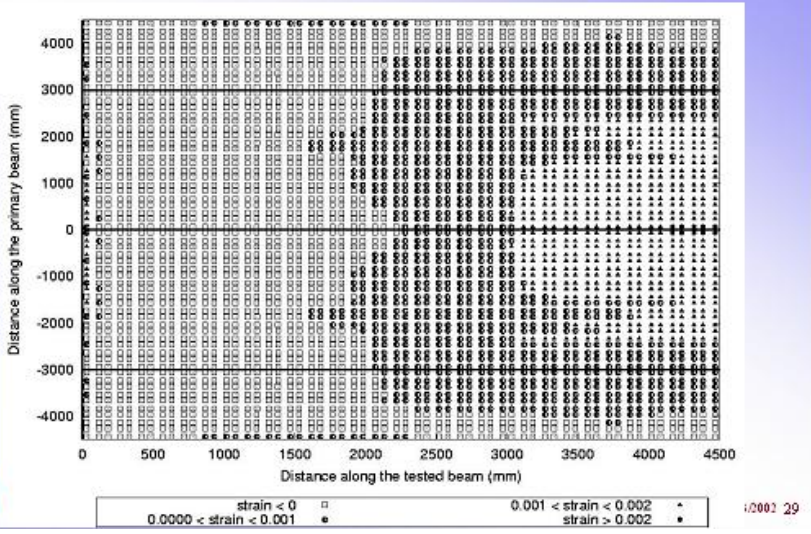

British Steel (now Corus) Corner Test

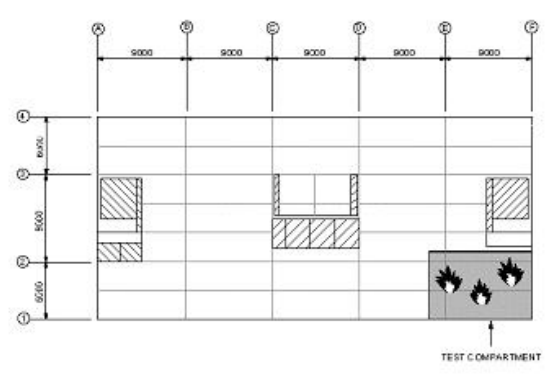

TEST 3 : CORNER COMPARTMENT TEST 
British Steel Corner Test (structure)

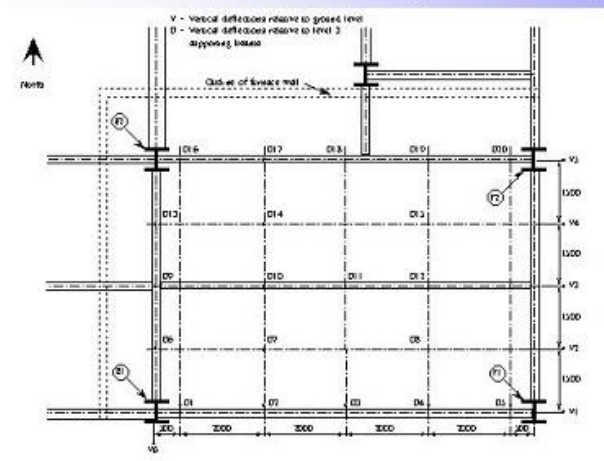

(2)
British Steel Corner Test - Finite element mesh

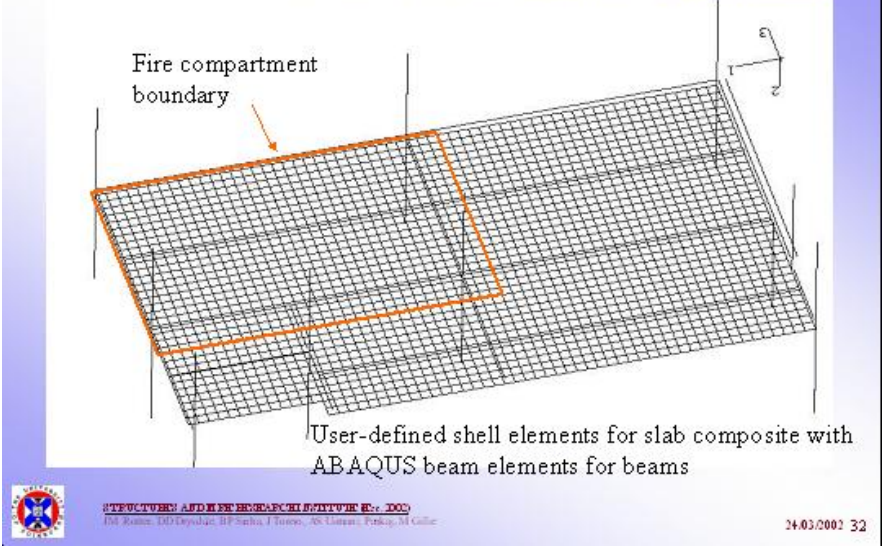

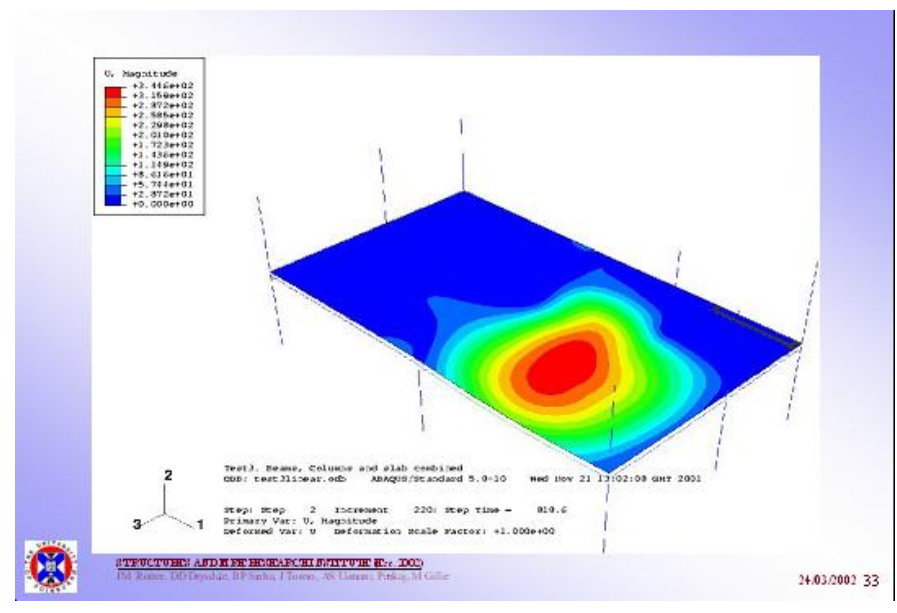

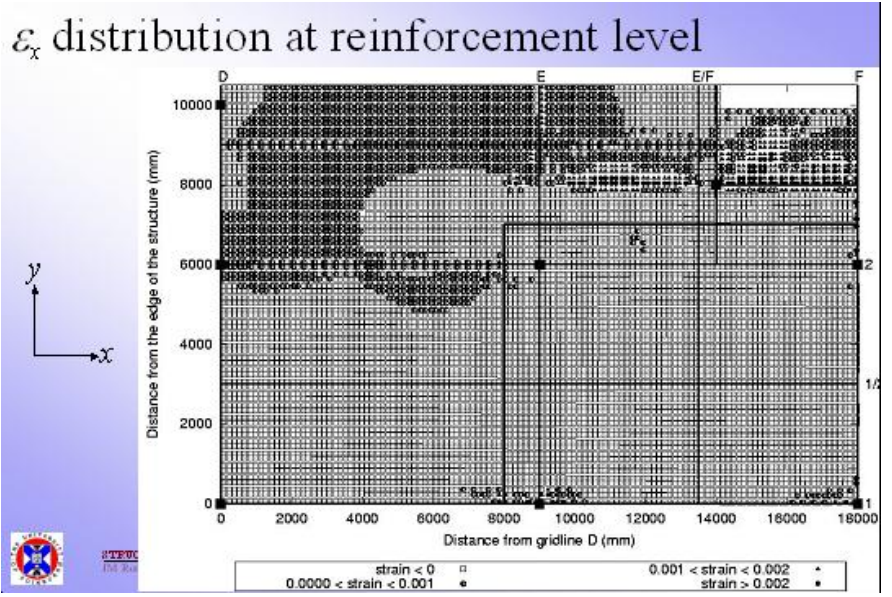

$\varepsilon_{y}$ distribution at reinforcement level

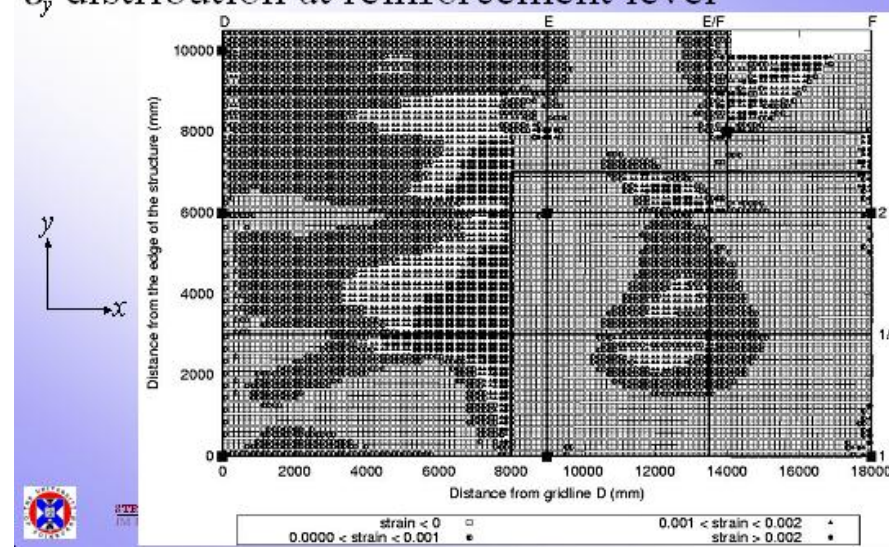

Estimated strains in concrete (corner test)

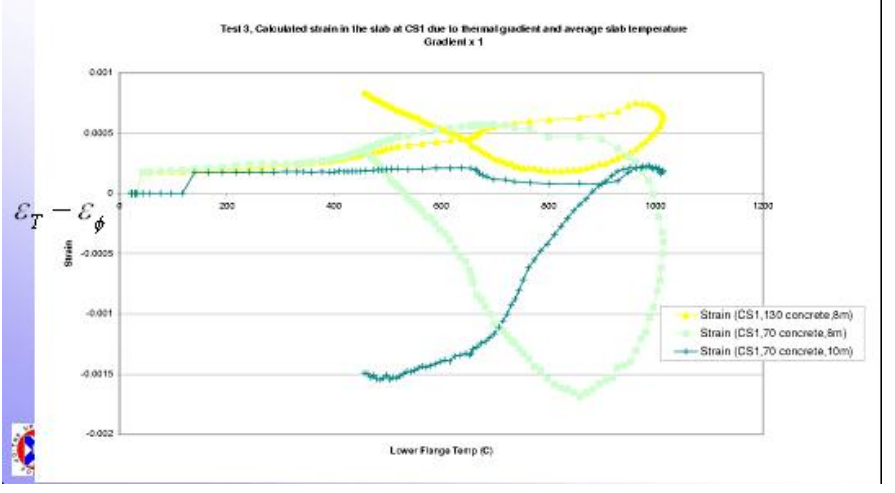


Elastic shell model

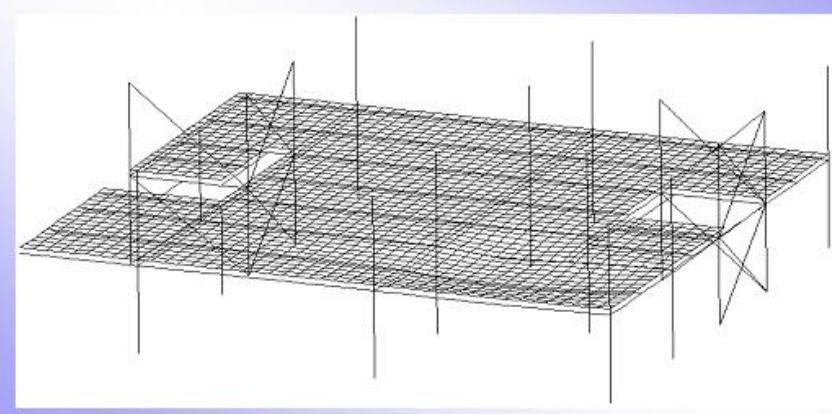

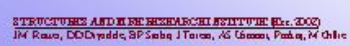

Elastic shell model with detailed beam modelling

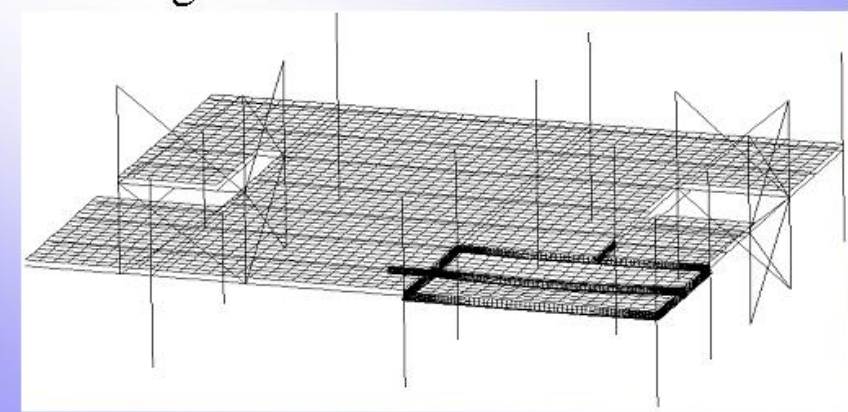

19.

2503200238
British Steel "Office" Test

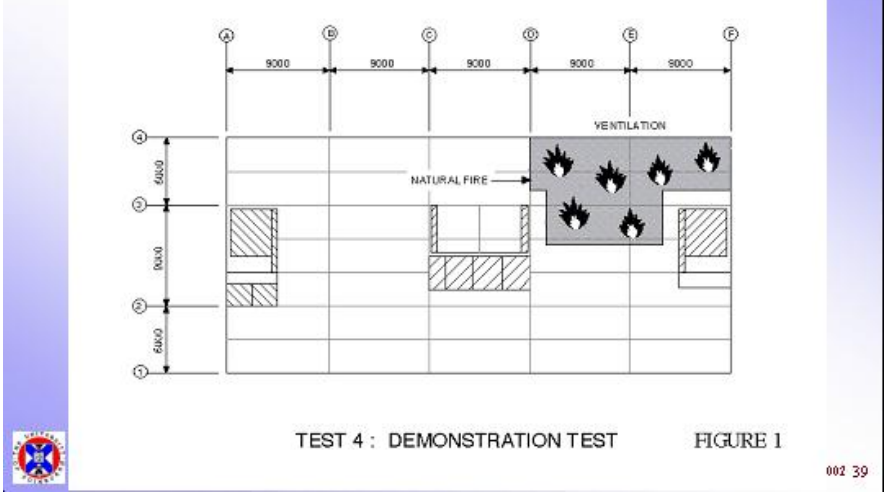

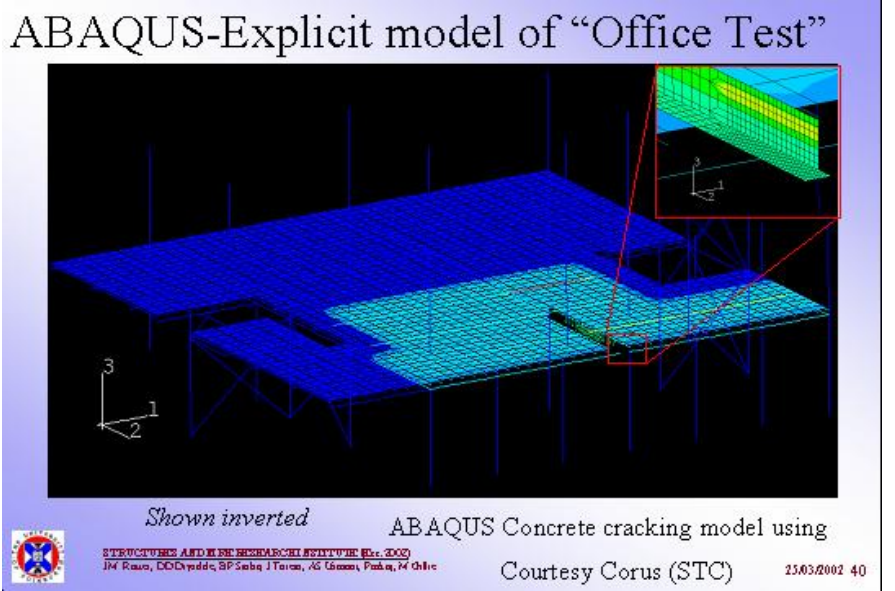

Shell principal stress pattern at 1100

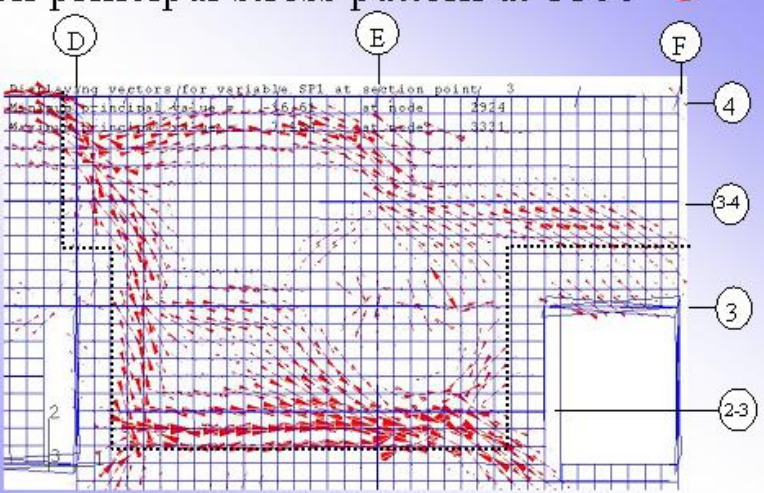

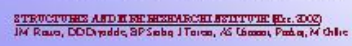

Courtesy Corus (STC)

2503200241

\section{LESSONS}

Restraint to thermal strains dominates response

Conventional loading much less important when restraint is high

Response sensitivity to steel strength is low

The above will change near failure or collapse, failure not observed in tests of modelling, how far is it?

Tensile membrane action (TMA) in the spans and compressive membrane action (CMA) near perimeter observed

This load carrying mechanism more reliable in fire, thermal strains help produce the "right shape"

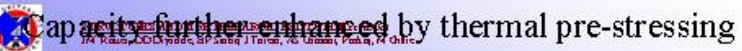


FURTHER MODELLING

The two key thermal effects governing structural behaviour

$\checkmark$ mean temperature increase $=>$ compression $\Rightarrow$ long cool fires

- through depth thermal gradients $\Rightarrow$ tension $\Rightarrow$ short hot fires

Cardington was a medium size braced frame (high redundancy)

- What about small frames (low redundancy) and whole floor fires

- What about very large frames (with large compartments)

Tensile membrane force need anchoring at compartment perimeter

- Interior continuity can be provided by lapping reinforcement

Edge and corner compartments have discontinuous edges
The $2 \times 2$ generic frame mesh

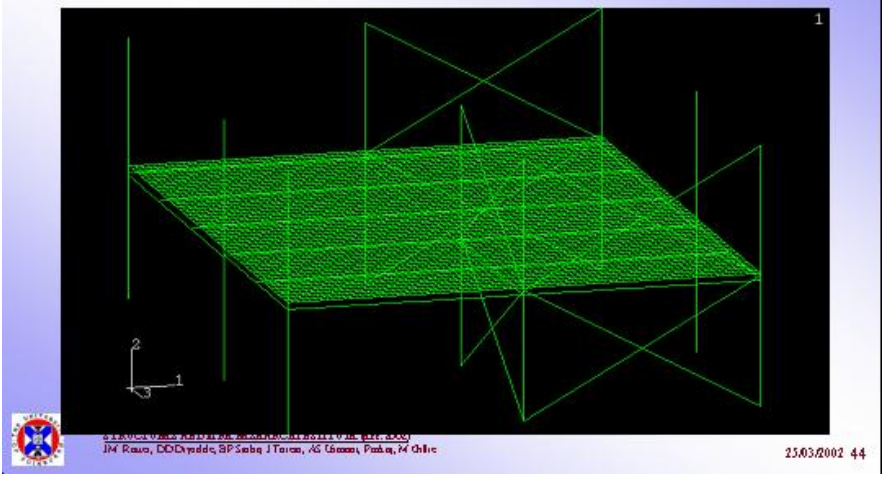

\section{Pettersson design fires}

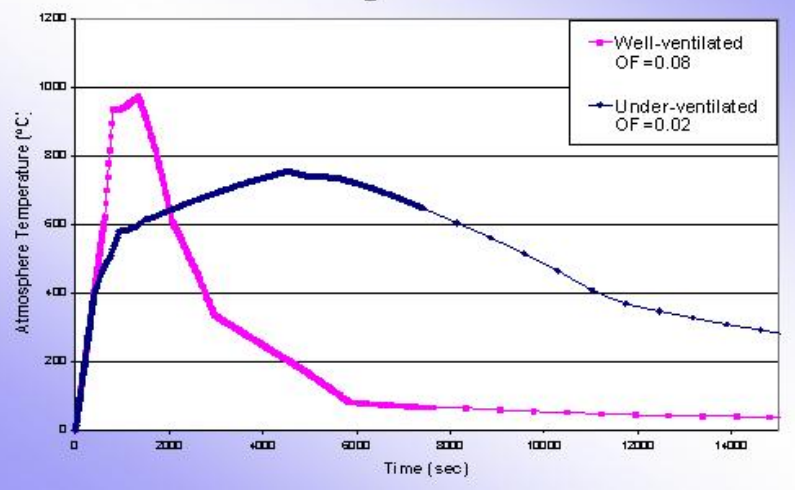

The $2 \times 2$ generic frame mesh

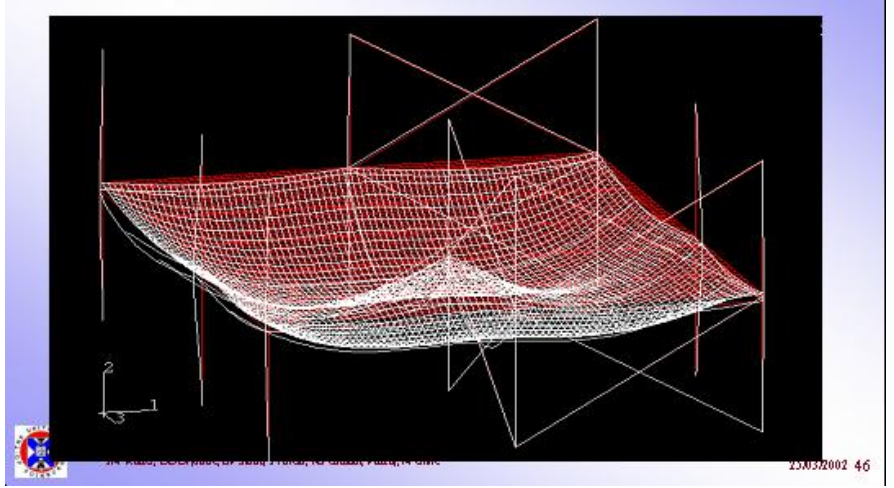

Studies with different fire scenarios

Long-Cool fires

Short-Hot fires

Deflection Contours - $2 \times 2$ generic frame (protected edge beams) max. defl $=310 \mathrm{~mm} @ 78 \mathrm{mins}$ max. steel tempr $=750^{\circ} \mathrm{C}$

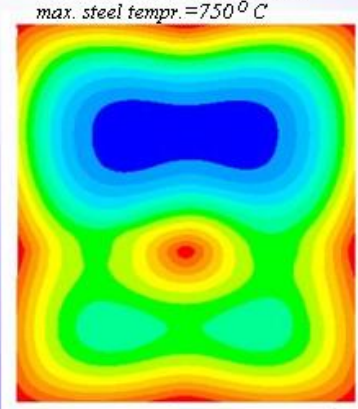

max. defl. $=365 \mathrm{~mm} @ 23$ mins max. steel tempr. $=950^{\circ} \mathrm{C}$

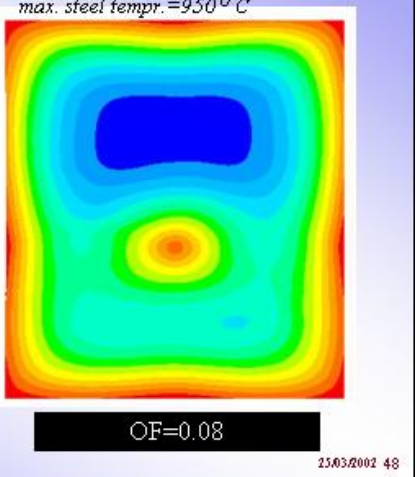




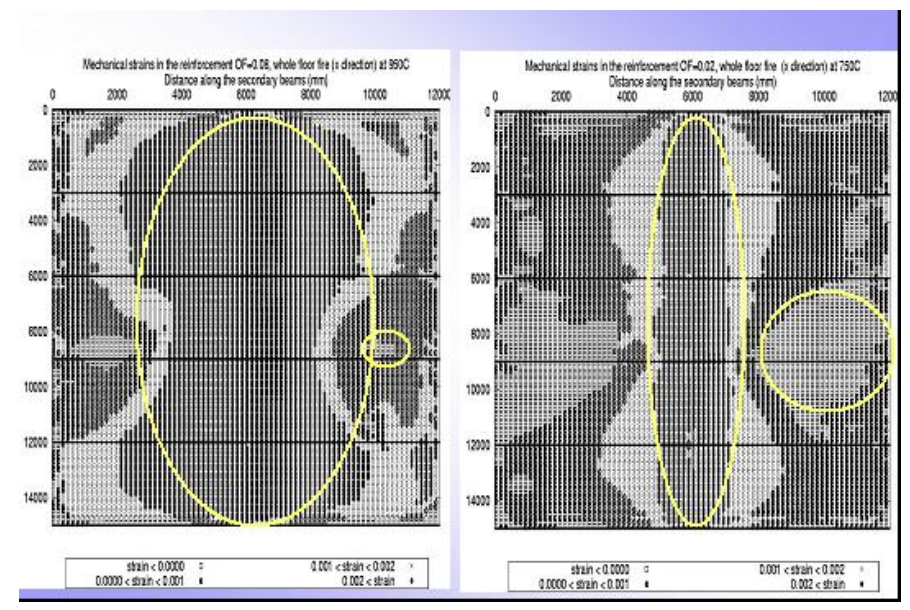

Studies with different edge beam protection

Edge beams protected

Edge beams unprotected

Deflection Contours - $2 \times 2$ generic frame $(\mathrm{OF}=0.08)$
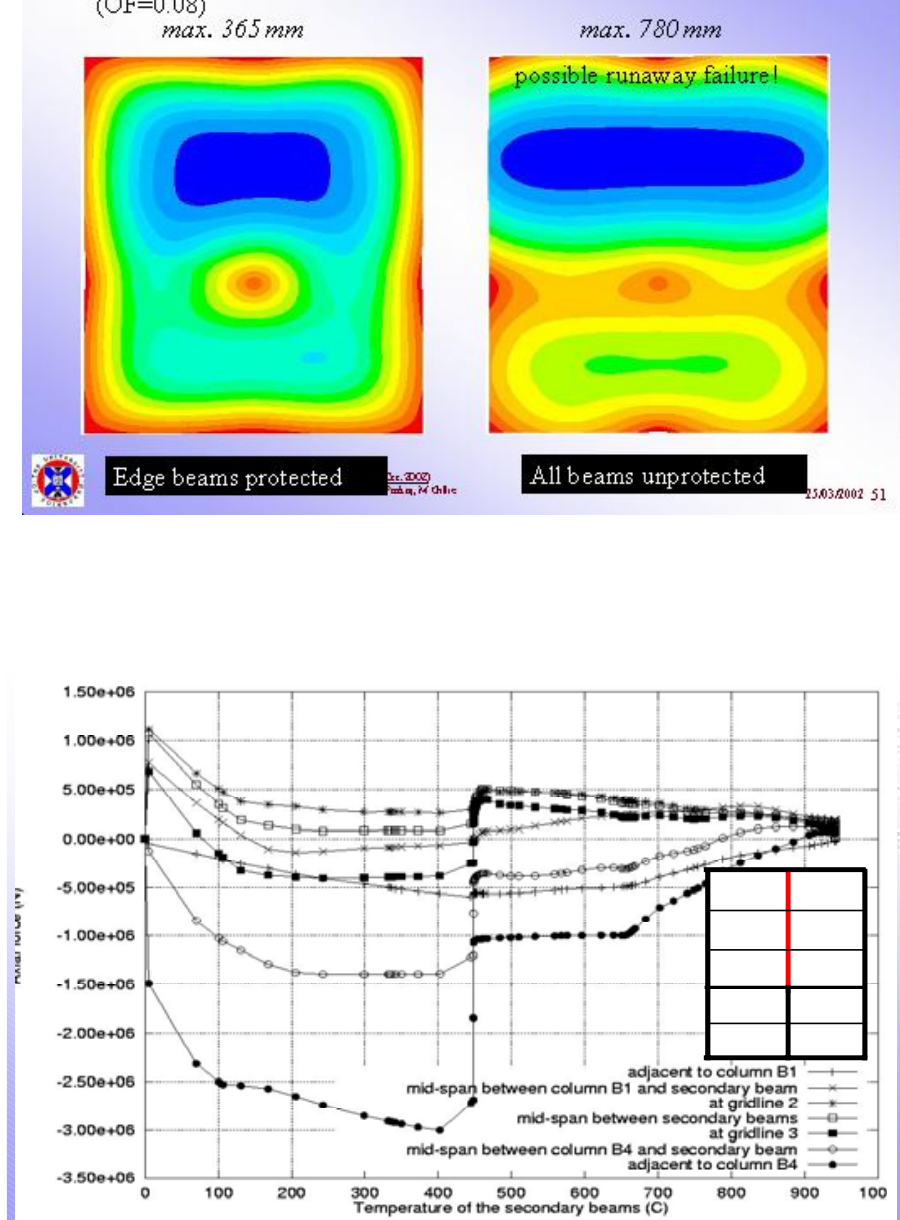

Axial force in primary beam B14: All beams unprotected

\section{Moment resisting ends}

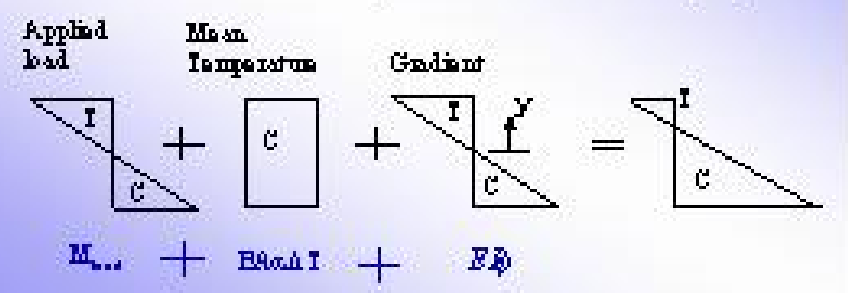


Primary beam instability

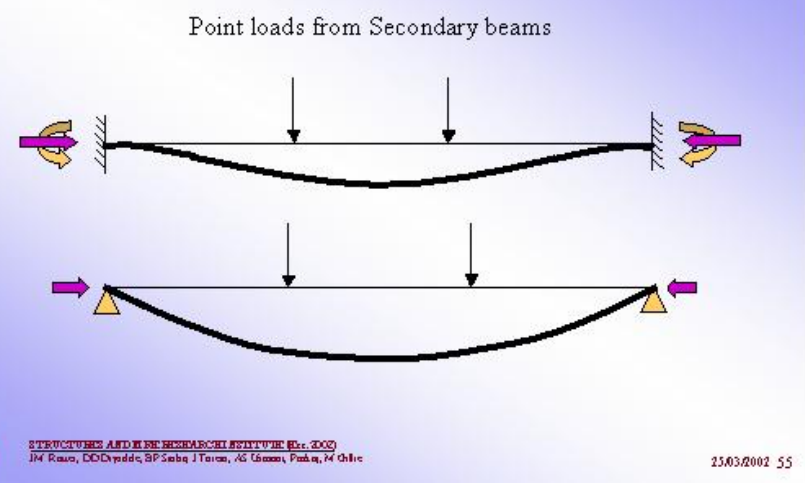

Simple ABAQUS beam model

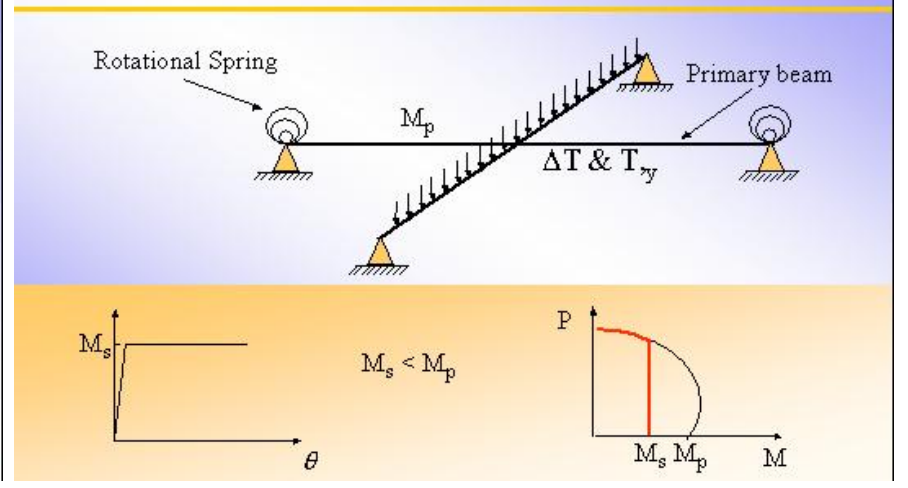

Instability occurring in the simple model

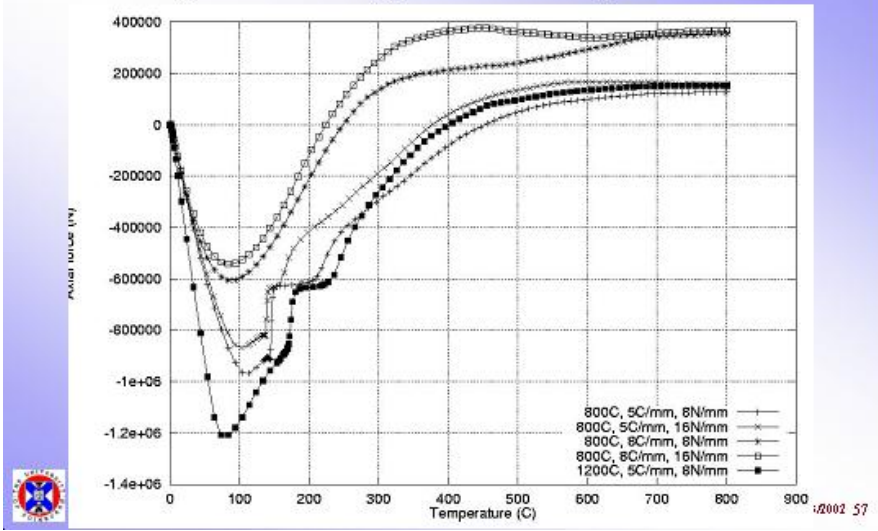

Fire scenarios (air temperature vs time)

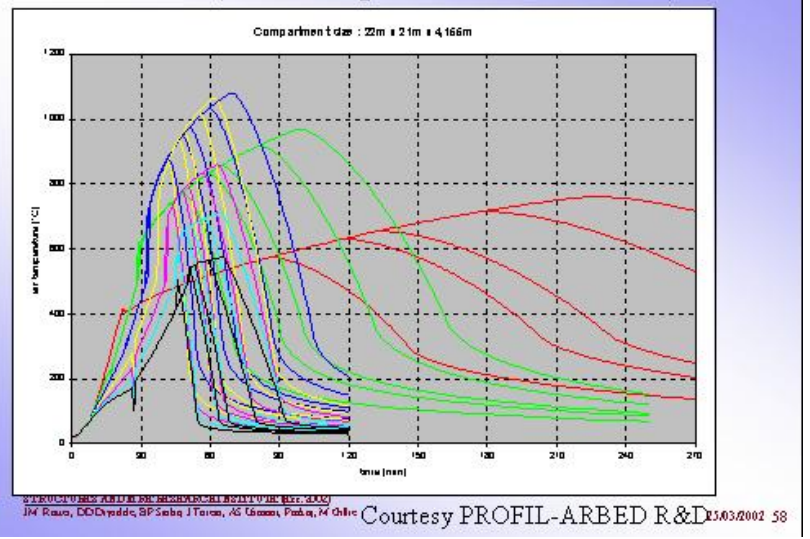

\section{DIANA analysis ("short hot" fire)}

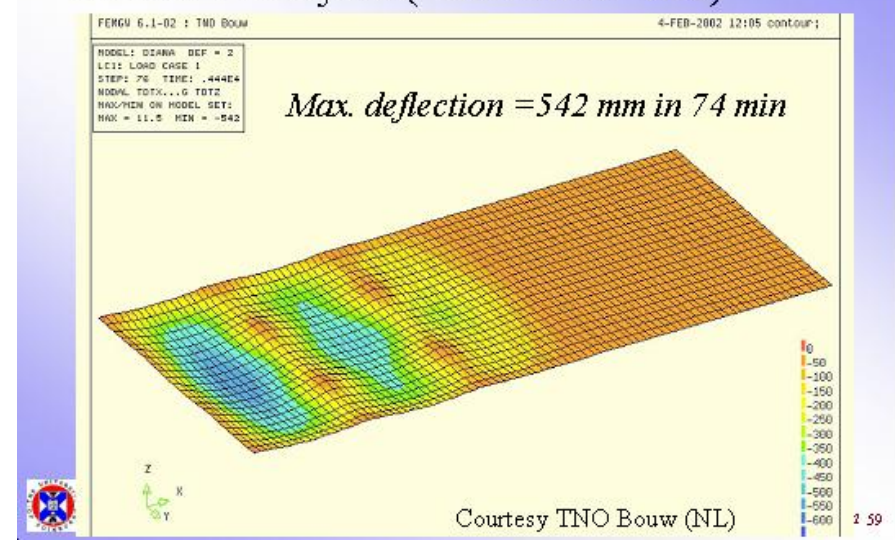

IANA analysis ("long cool" fire)

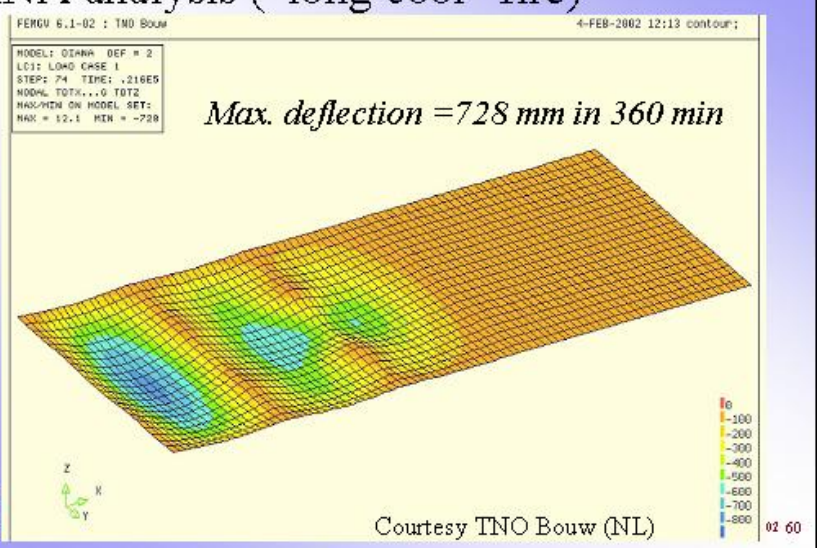



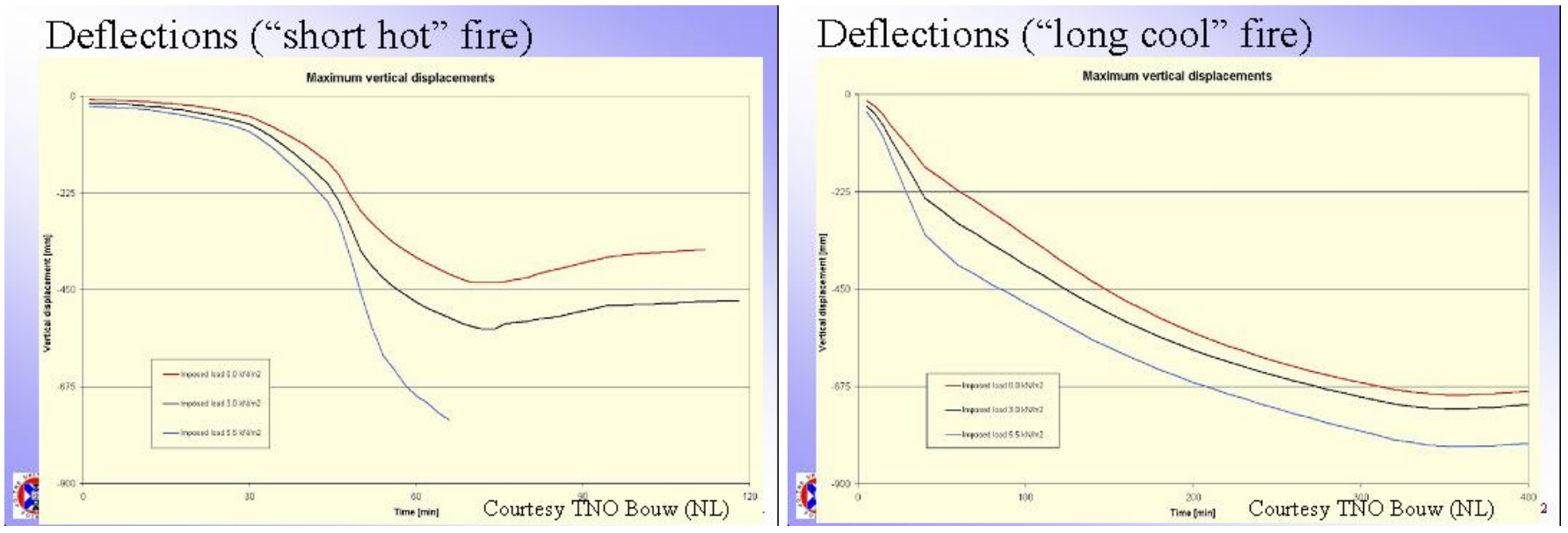

\section{Conclusions}

- Firodes ign is based on timo-structurel rosponso depends on temporvtu ro and rote of heating

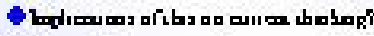

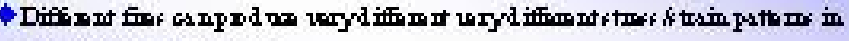
os mporit flooriyt trix

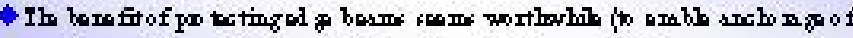

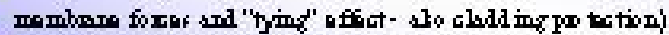

- $A$ nowr (ond poss b I drnam ic) phen omenon ident ified which nesds con firmation and as sess ment of it potentio l fo $r$ do mage

\section{Further research: Strategic}

- Werst rase fire scenario can only be based on its potential for structural damange (ouly for structural integrity cossiderations)

- Limit state deriga scenicion must be tae basa of all stractural desaga

- Iinir states resulning from extreme fire evonts should be ineluded

- Localised collapse stoubd sot caust over all progressive collapst

- Iall buldings (where suppressian'evacuatioat time is large), will require special consideration (no cellapse) .html 
H. Fire Resistance Evaluation of Large-scale Structural Systems Venkatesh Kodur, Institute for Research in Construction NRC-CANADA
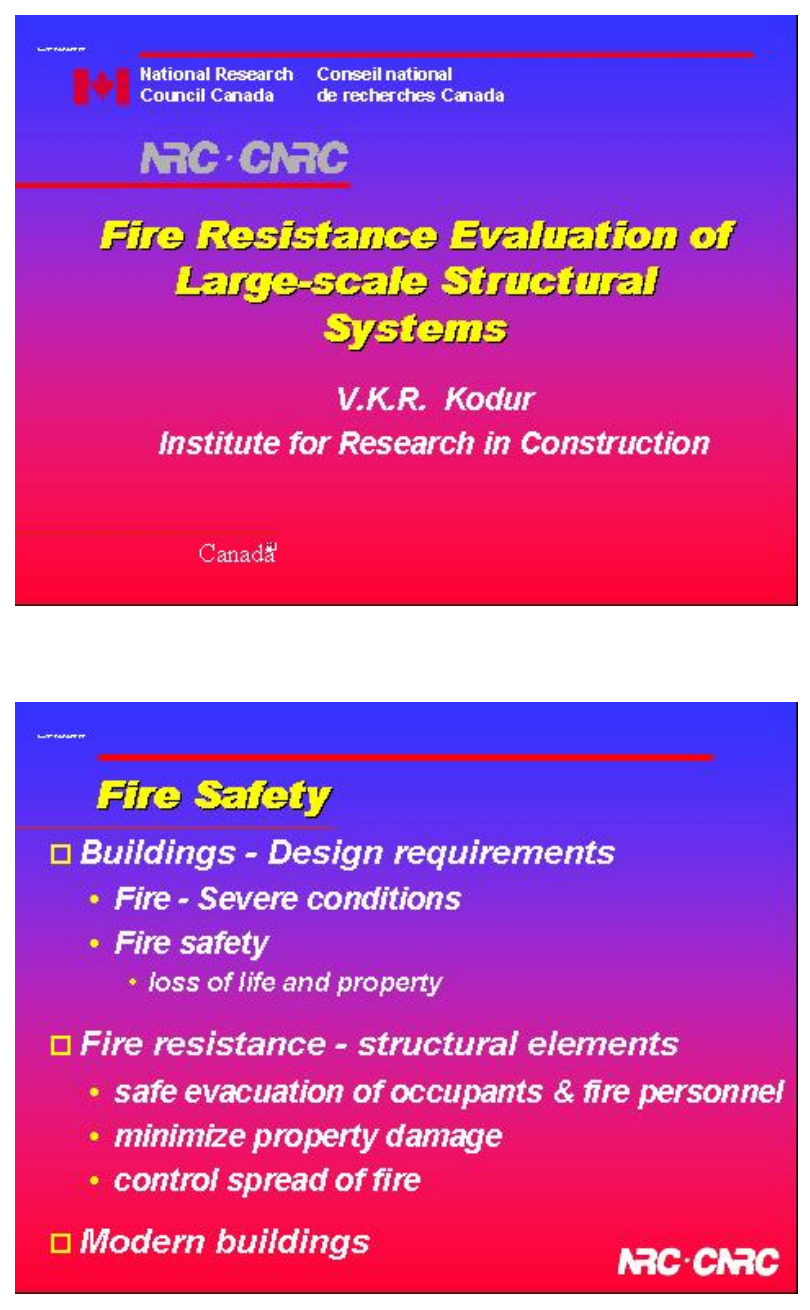

Steel stu Wall Assembly in Wall Fumace

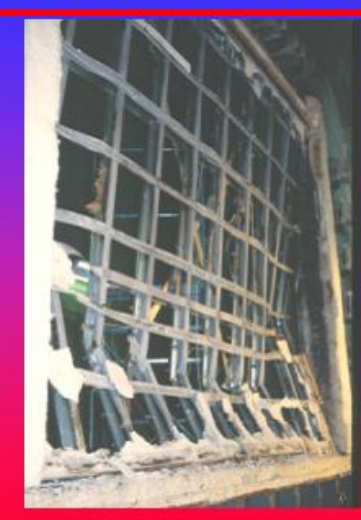

Anc. Che
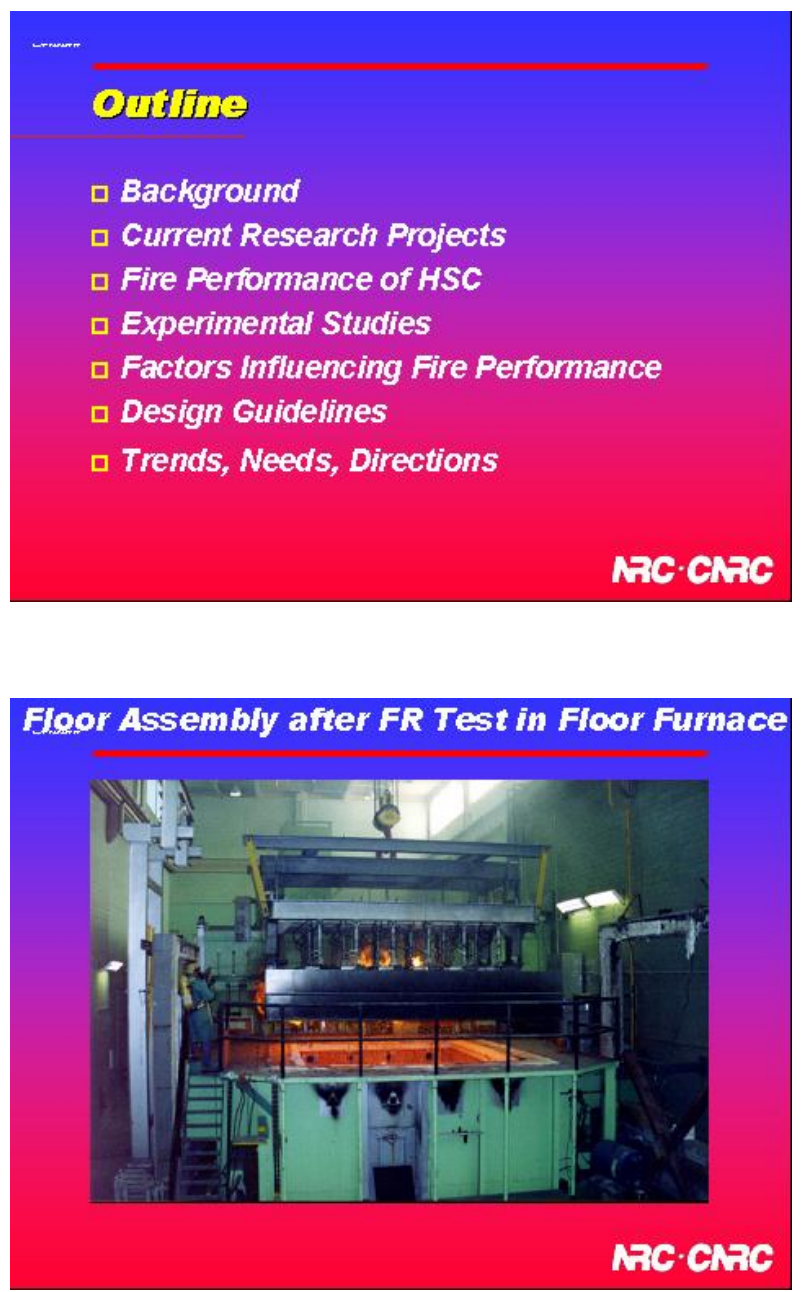

Steel Sud Wall Assembly in Wall Fumace

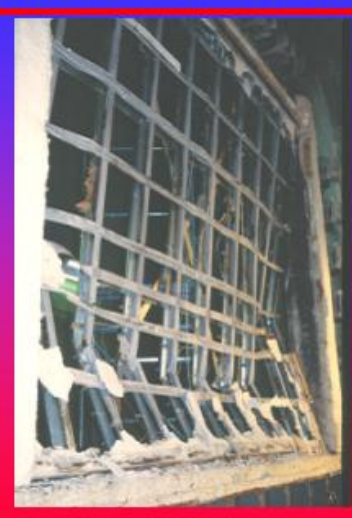

Receres 
Intermedate Scale Fumace - Walls \& Floors

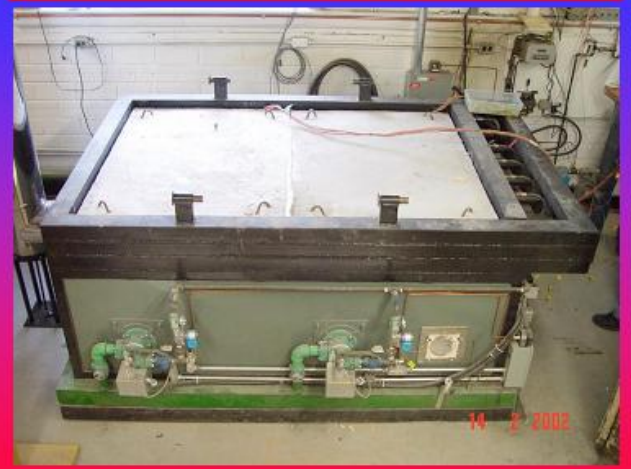

Re. CNAC

\section{High Strength concrate}

$\square$ Superior Performance

- High strength

- Durability

$\square$ Applications

- Bridges, Infrastructure Projects

- Buildings - Columns

AC. Chac

\section{HSO Exposed to Fire}

$\square$ NSC - good fire resistance

$\square$ HSC - behaviour of different from NSC

口Spalling

- Jow porosity, high density

- pore pressure

$\square$ No guidelines on HSC exposed to fire

- NBCC, ACI 318/216, CSA-A23.3

$\square$ Eliminate fire protection
Exporimental Studtes

$\square R C$ columns - HSC, NSC

$\square$ Test variables

- 28-day compressive strength

- siliceous, carbonate aggregate

- reinforcement configuration - ties

- size

- load Intensity

- fibre reinforcement

- fire intensity

Meche

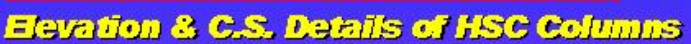

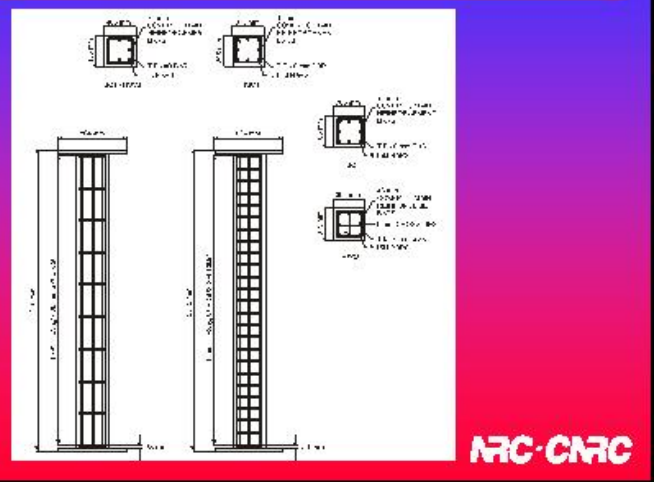

\section{Fine Resistance Experiments}

- full-scale specimens

- designed to code specifications

- loads, ends conditions

- std. time-temperature (ASTM-E119/E1529)

- temperatures, deffections, fire resistance

- spalling

AC. Che 

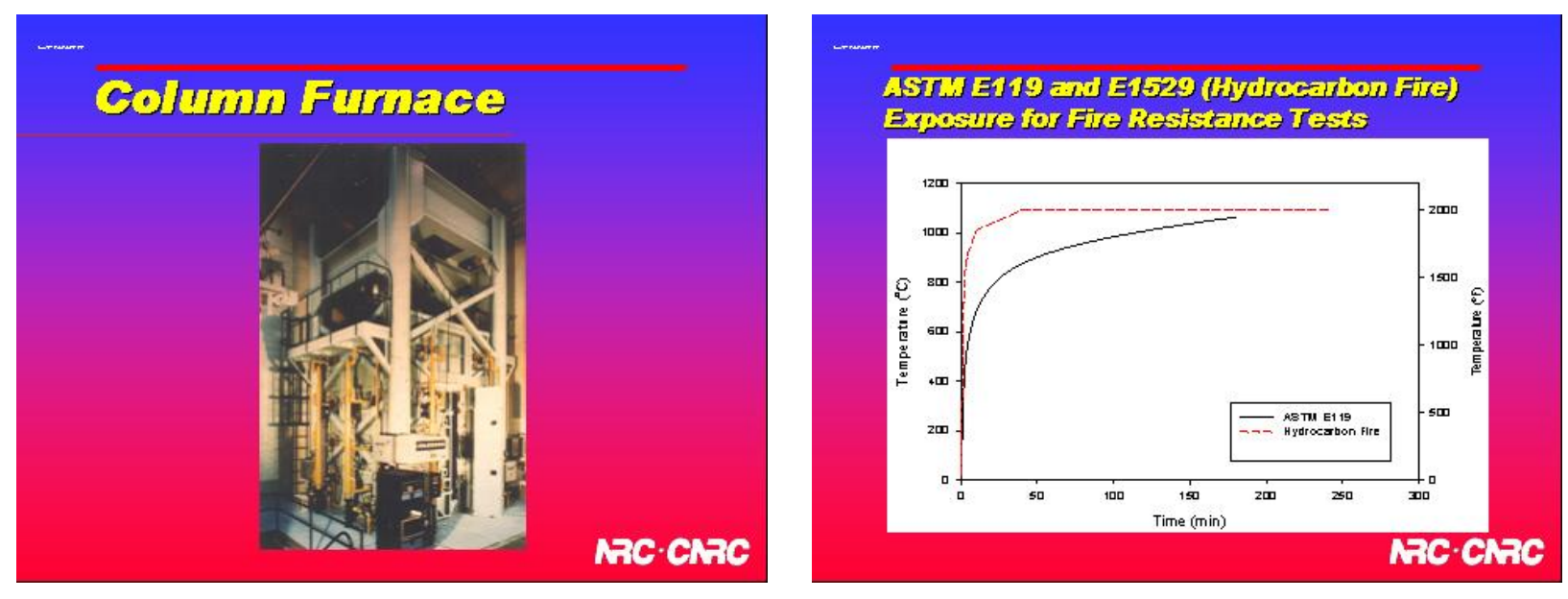

\section{HSe Column after Fire} Resistance Test

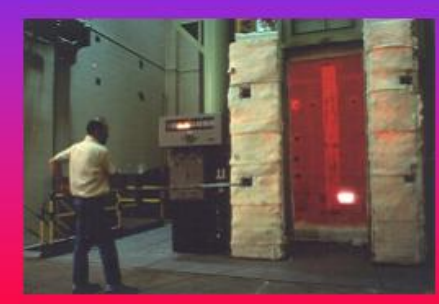

AC. CRTC

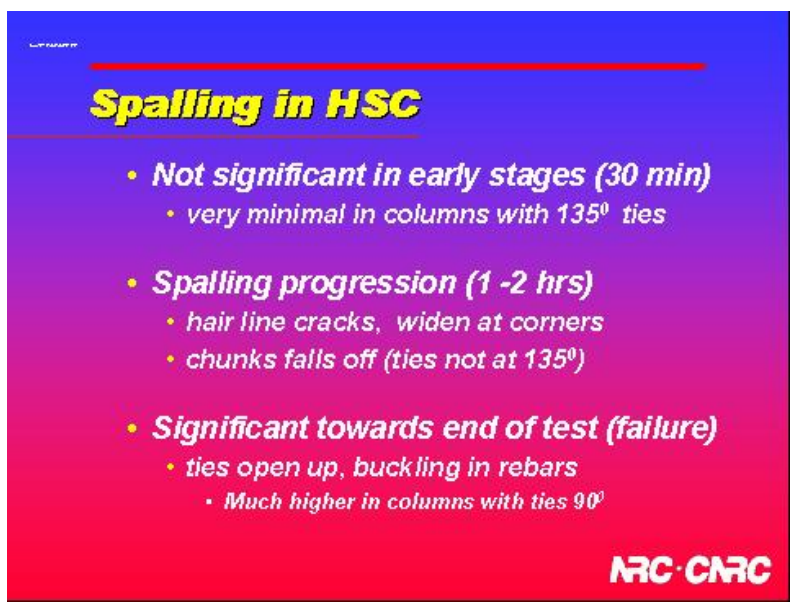

\section{Post-fallure Observations}

口NSC Column

- ties did not open up

- less buckling of rebars

- less spalling

- failure confined to locally

$\square$ HSC Column

- ties opened up

- buckling of rebars

- significant spalling - cross-section loss

- failure over length of column

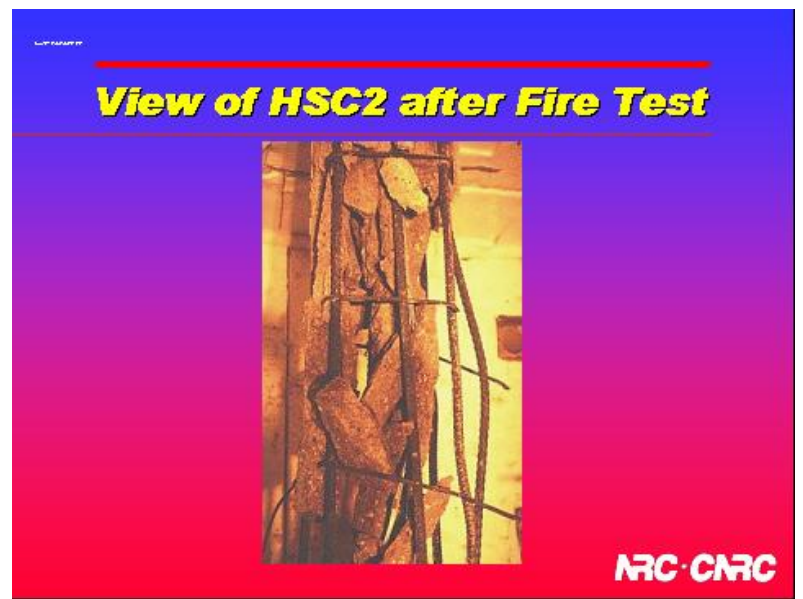




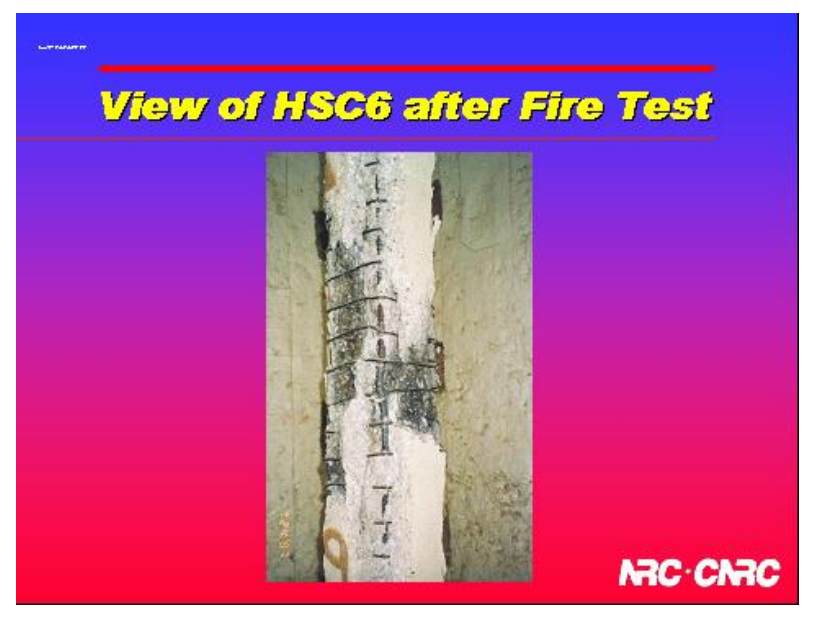

Vantaton of Temperature with fine in

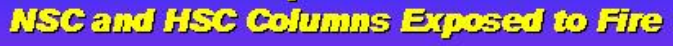

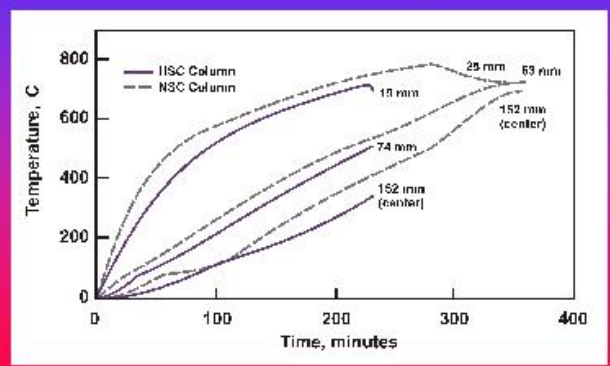

Re. CRAC

Vautaton of Deiteston whi Inte in MSc

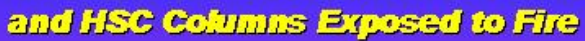

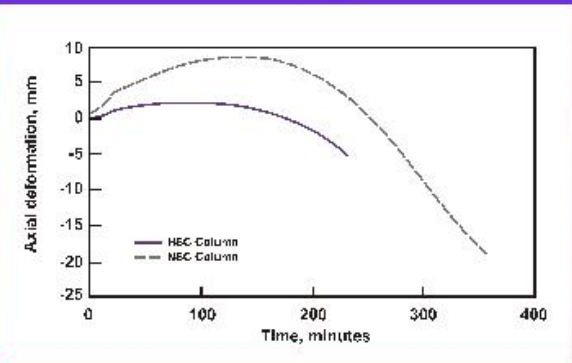

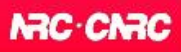

Factors InIJonofig Fite

Performance

- Compressive strength

- Reinforcement layout

- Moisture content (RH)

- Concrete density

- Heating rate (fire intensity)

- Aggregate type

- Load intensity, Type

- Fibre reinforcement

\section{Eitect of Strongth}

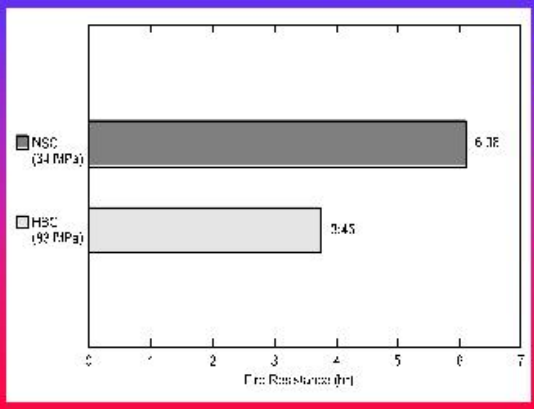

Higher

Concrete

Strength

- Decreases

Fire

Resistance

- Enhances

Spalling

MC. CKac

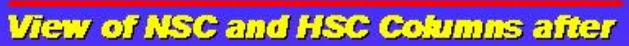
Fire Resistance Tests
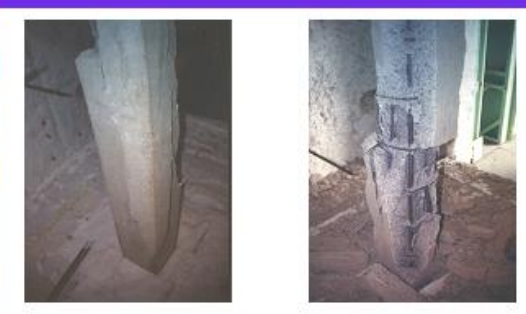

(a) Normal strength concrete columm 

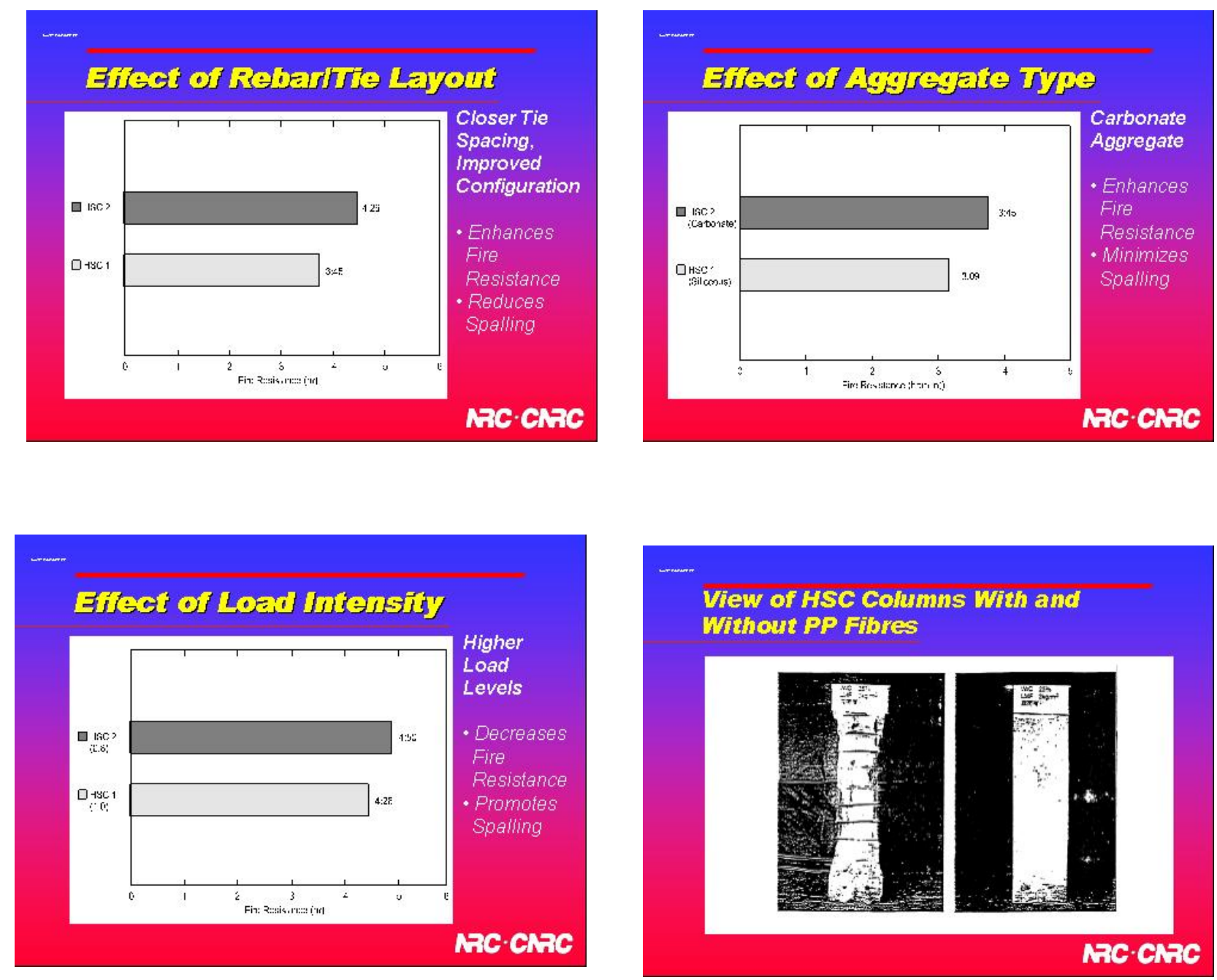

View of HSC Blocks, with and with out nibres, after two hour Hydrocarbon Fire Tests

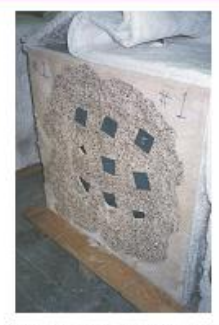

(a) HSC Block with out fibres

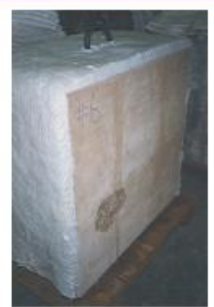

(b) HSC Block with polypropylene fibres ARC. ChC

View of HSC Columns with and Without PP Fibres

Rec.erts
Dosign Solutions

\section{$\square$ HSC columns}

$\square$ Reinf. detailing

- tie configuration

- bending ties @ $135^{\circ}$

- tie spacing - closer

- cross ties

- minimizes spalling

- enhances FR

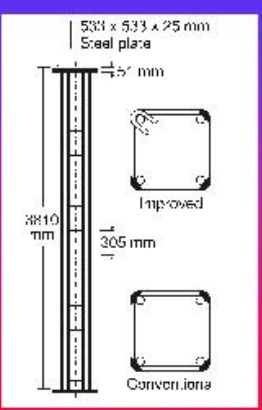

Mechec 


\section{Cures (Solutions) - Spallfug}

口 Carbonate aggregate (imestone)

口 Nomal density aggregate

$\square$ Sufficient concrete cover

口 Lower load intensity; eccenticity

\section{Numerical Studies}

$\square$ Material properties at elevated temp.

- Themal and mechanical properties

$\square$ Computer program

- Predicting the behaviour of HSC columns

$\square$ Parametric studies

- Factors infuencing the behaviour

- Design equations for fire resistance

- Integration with structural design

Re. Chac
Temperadues from model 8 test
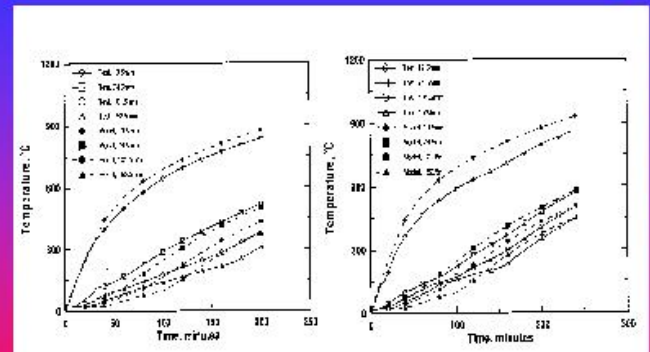

io. Colum TICA

itisist. nn TIIIII

\section{Axial deformation from model \& test}

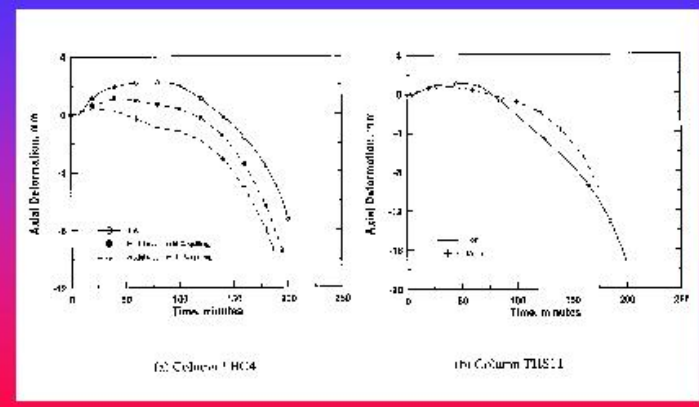

ARC.CRC

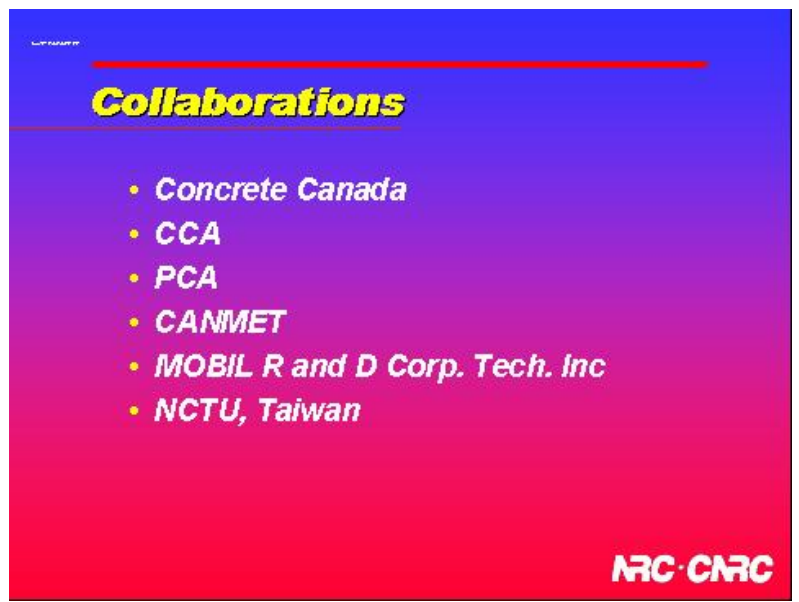

Future fromds, Industry Nosis, Rosearch Directions

口 Fire Resistance - Realistic Considerations

- tools for analysis, fire scenarios

- validated models, design fires, properties

口 Performance-based Codes

- calculation methods

- design guides, software packages

口 High Performing Materials

- satisfy fire resistance - governing factor

- Practical \& cost-effective solutions

MC. CNAC 
I. Improved Fire Testing in Combination with Calculation Ulf Wickstrom, SP Fire Technology

Borås, SWEDEN

"Improved fire testing in combination with calculations".

- Ulf Wickström

- SP

- Borås, Sweden

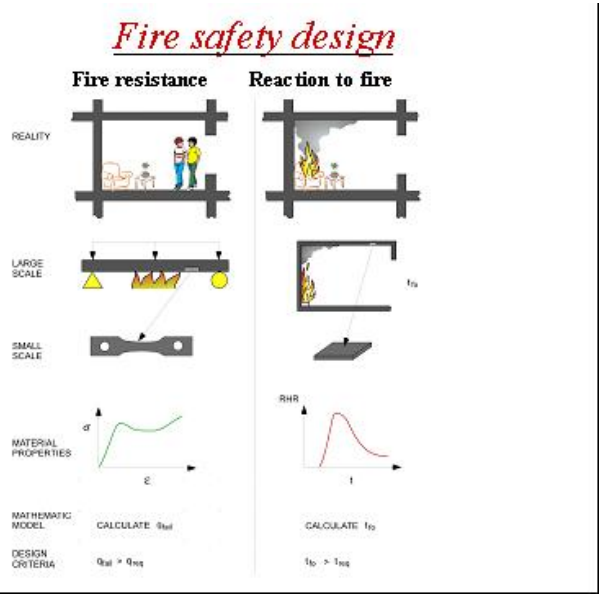

Proposals for improvements in fire resistance design

\section{Analysis of fire exposed structures}

- Fire development - design fires

- Heat transfer to fire exposed structures

- Temperature development in structures

- Mechanical behaviour of structures

\section{TPS apparatus for measuring thermal properties}

TPS = transient plane so ure, heat transmission, thermal diffusirity

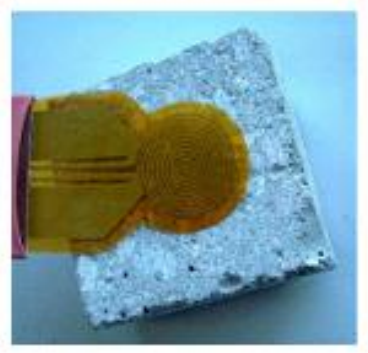

TPS apparatus for measuring thermal properties

TPS = transient plane source, heat transmission, thermal diffusivity

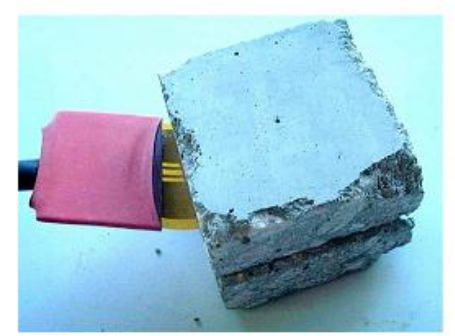


TPS apparatus for measuring thermal properties

TPS = transient plane source, heat transmission, thermal diffusivity

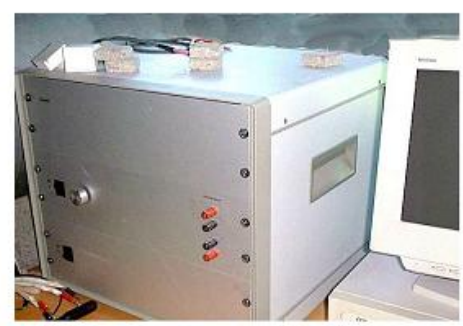

Temperature control of furnaces

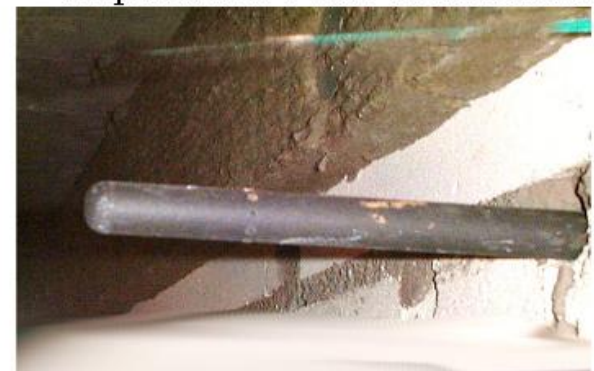

ASTM
Plate thermometer measurments

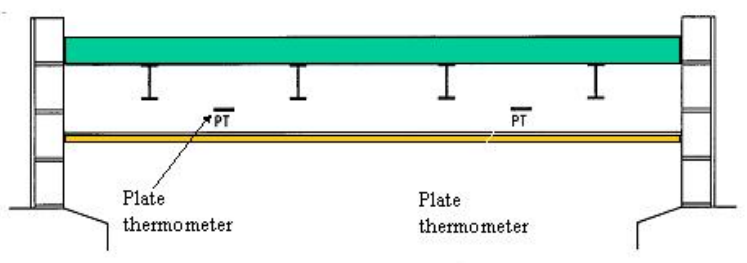

Furnace
Proposals for improvements in fire furnace testing

- Use Plate Thermometers to monitor and control temperature in furnaces

- Measure the deformation properties of structural elements during fire test exposure
The Plate Thermometer yields better temperature control of

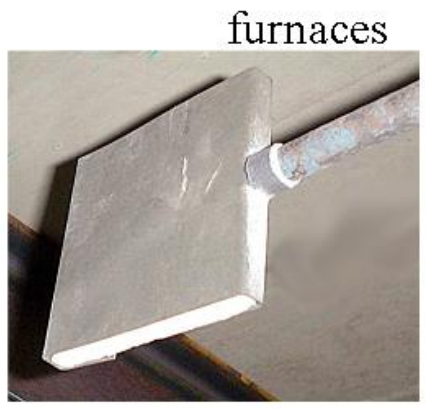

CEN and ISO
Plate thermometer measurments

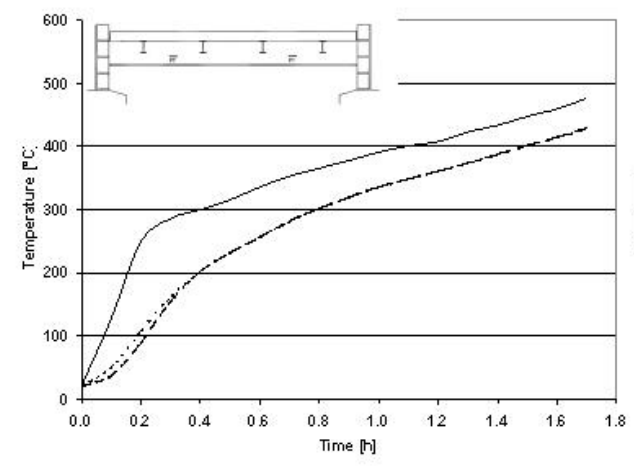


Test model in standard test

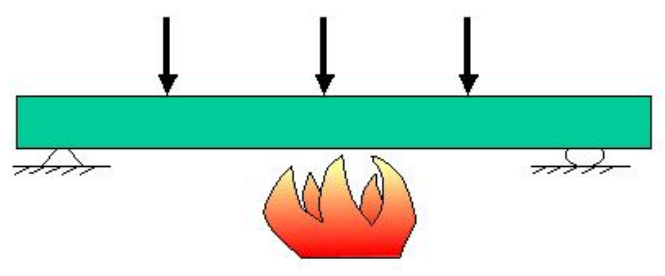

Standard testing of a loadbearing beam yields only the fire endurance time

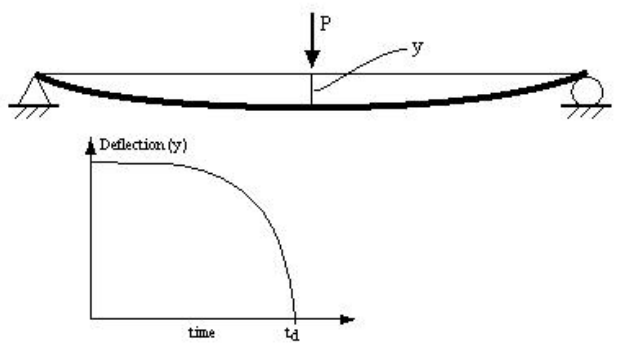

A global analysis requires member deformation properties

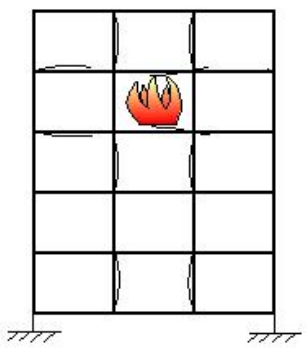

Finite element modelling

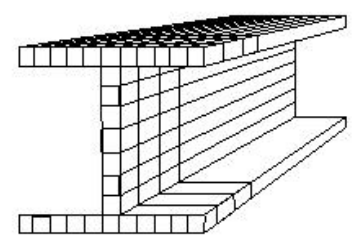

Composite structure

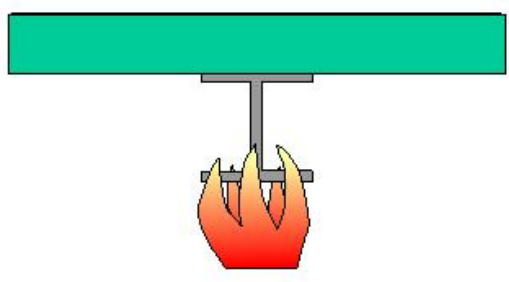

Get the deformation properties during fire testing
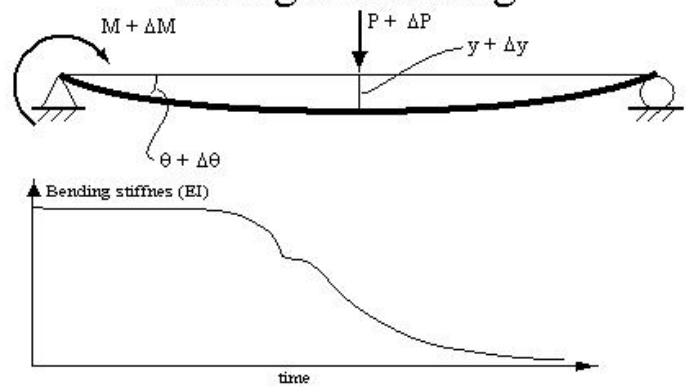
J. Degradation in Performance of Installed Fire Resistance Materials

Frederick Mowrer, Department of Fire Protection Engineering

University of Maryland, College Park, MD

\section{Performance of Installed Fire Resistance Materials}

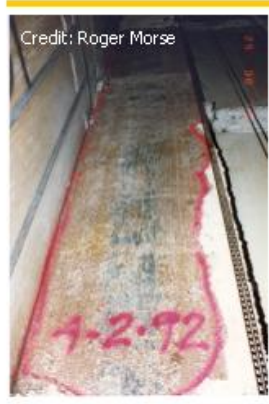

Frederick $W$. Mowrer

Dept. of Fire Prot. Eng.

University of Maryland

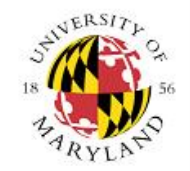

\section{Some issues}

Connections

Attachments

- Long spans

End restraint

Condition of fireproofing

W/D ratios

\section{Attachments}

How much fireproofing do attachments require? Thickness? Length?

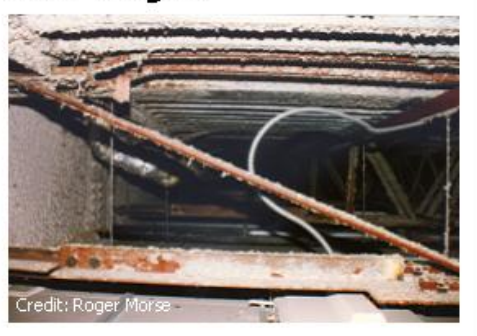

\section{Process}

Erect structure

Apply fireproofing

Inspect fireproofing (maybe)

-Scrape off fireproofing

- Install other building services

- Cover everything up with finishes

Forget about it

\section{Connections}

Connections not evaluated in tests

-How should they be protected?

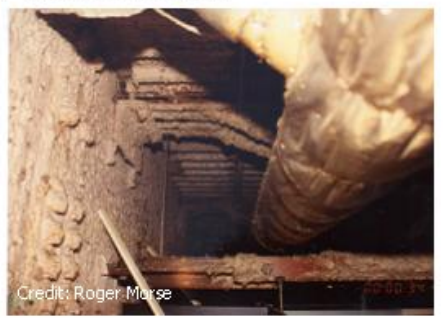

\section{Long spans}

Spans of approximately 12-15 feet tested

Actual spans can be much longer

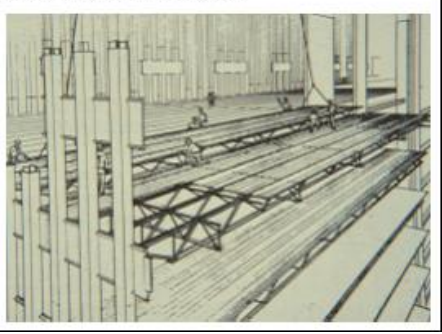




\section{End restraint}

- Test specimens wedged into frame

- How does this relate to real-world restraint?

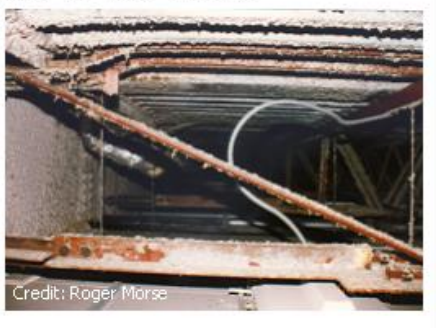

\section{Missing fireproofing}

-What is the effect on overall performance?

-What tools are needed / available to analyze?
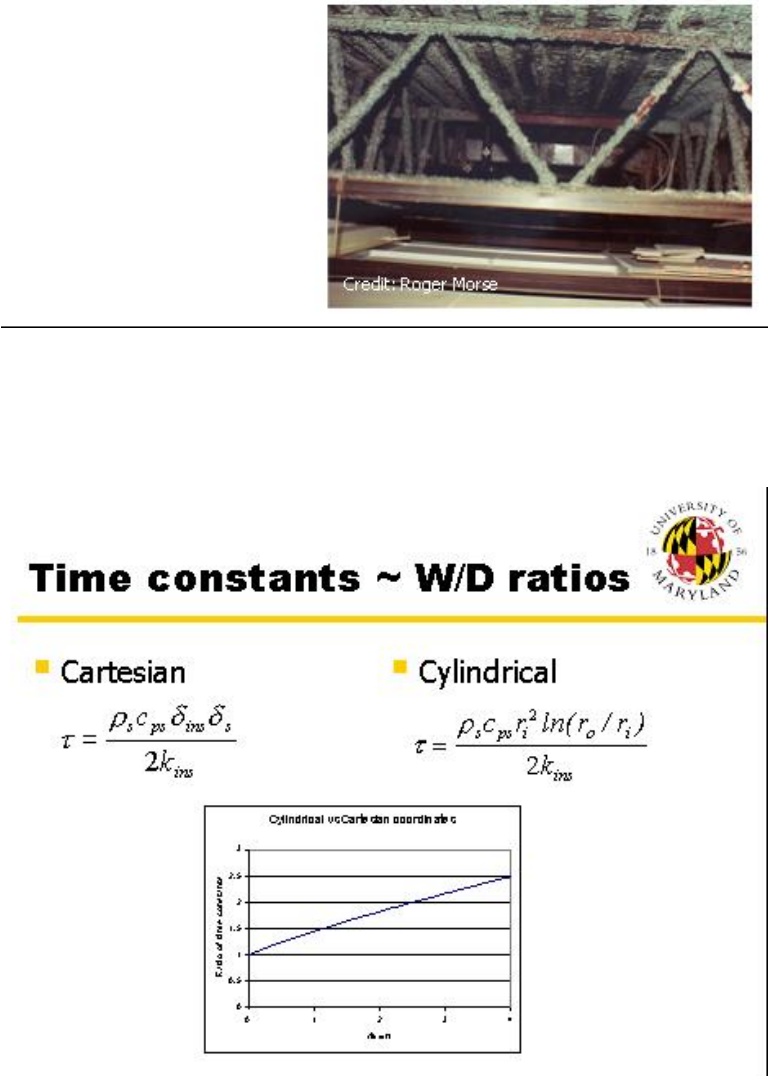

\section{Condition of fireproofing}

- How can deficiencies in fireproofing be recognized? How can they be analyzed?

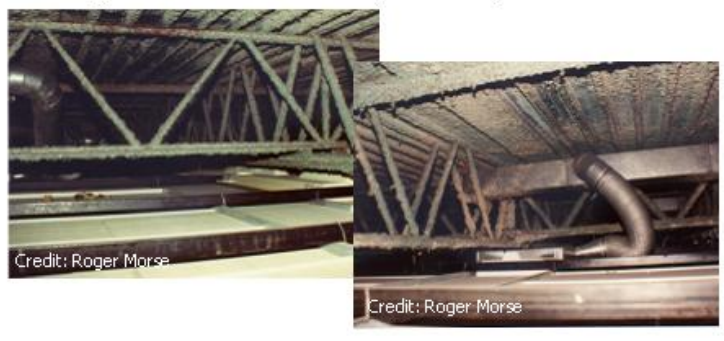

\section{W/D ratios}

W/D ratios used for different geometries

- Theory based on Cartesian 1-D analysis

- Not applicable to cylindrical coordinates
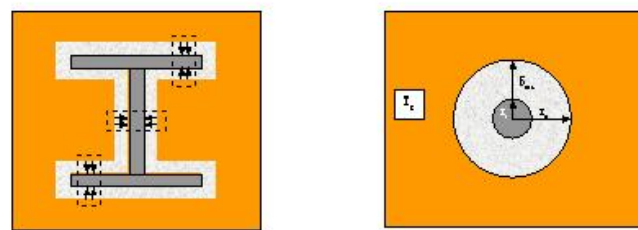

\section{Example}

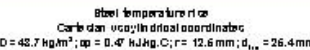

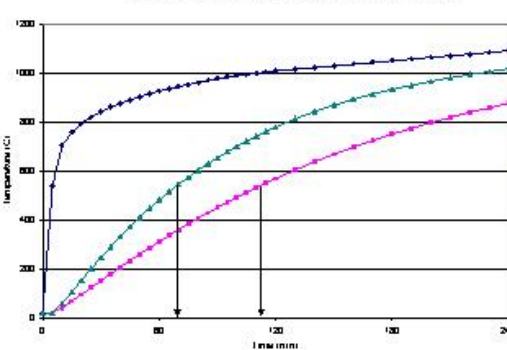




\section{Summary}

- There are a number of significant issues related to predicting field performance of structural fire protection

- Some issues are widely recognized - Missing fireproofing / attachments / restraint

- Some issues not as widely recognized - Connections / spans / W/D ratios

-All issues require research to improve predictive capabilities 
K. Materials for the Fire Protection of Structural Steel

R. Brady Williamson, Department of Civil and Environmental Engineering

University of California, Berkeley CA

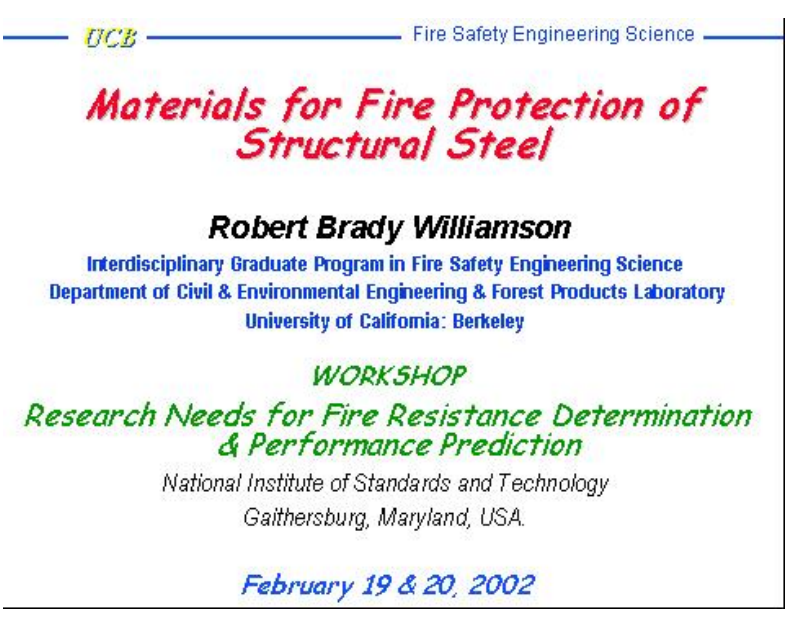
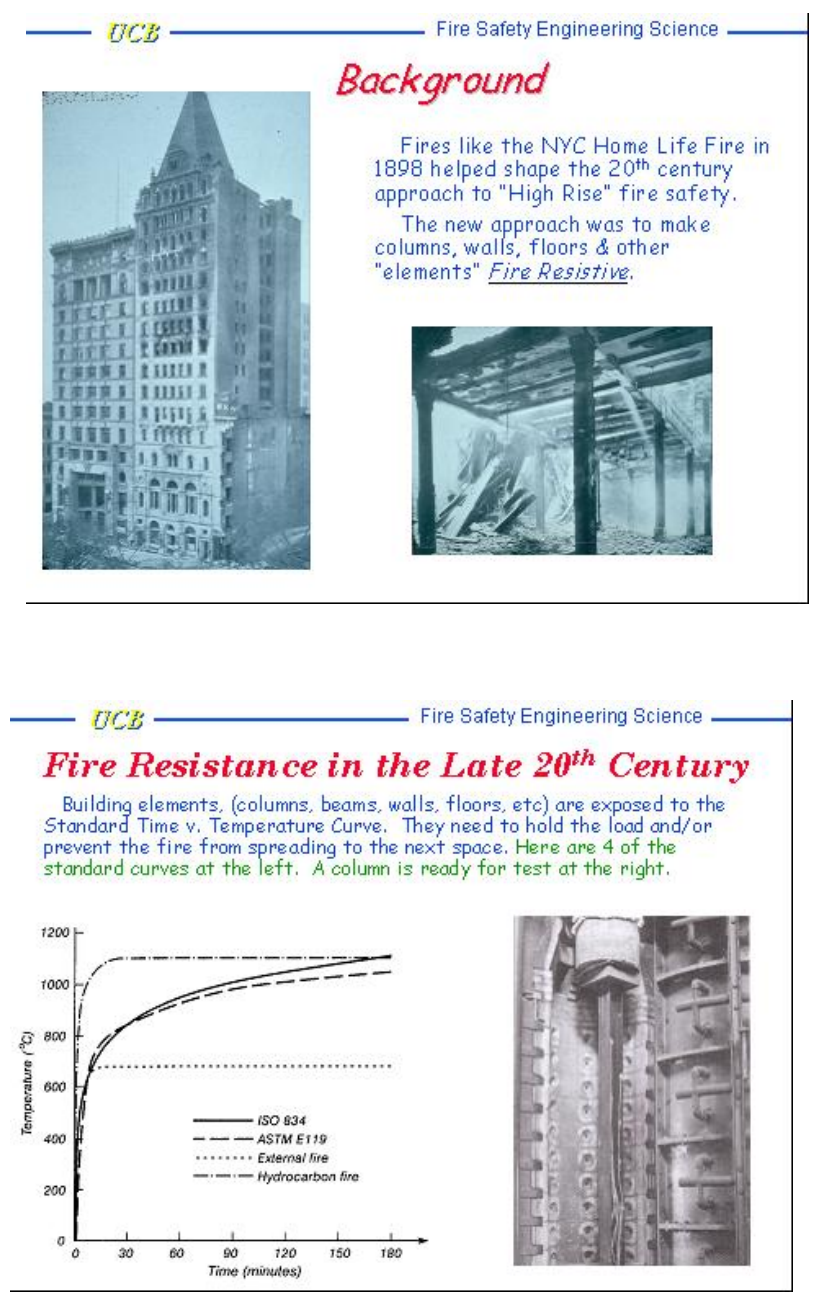
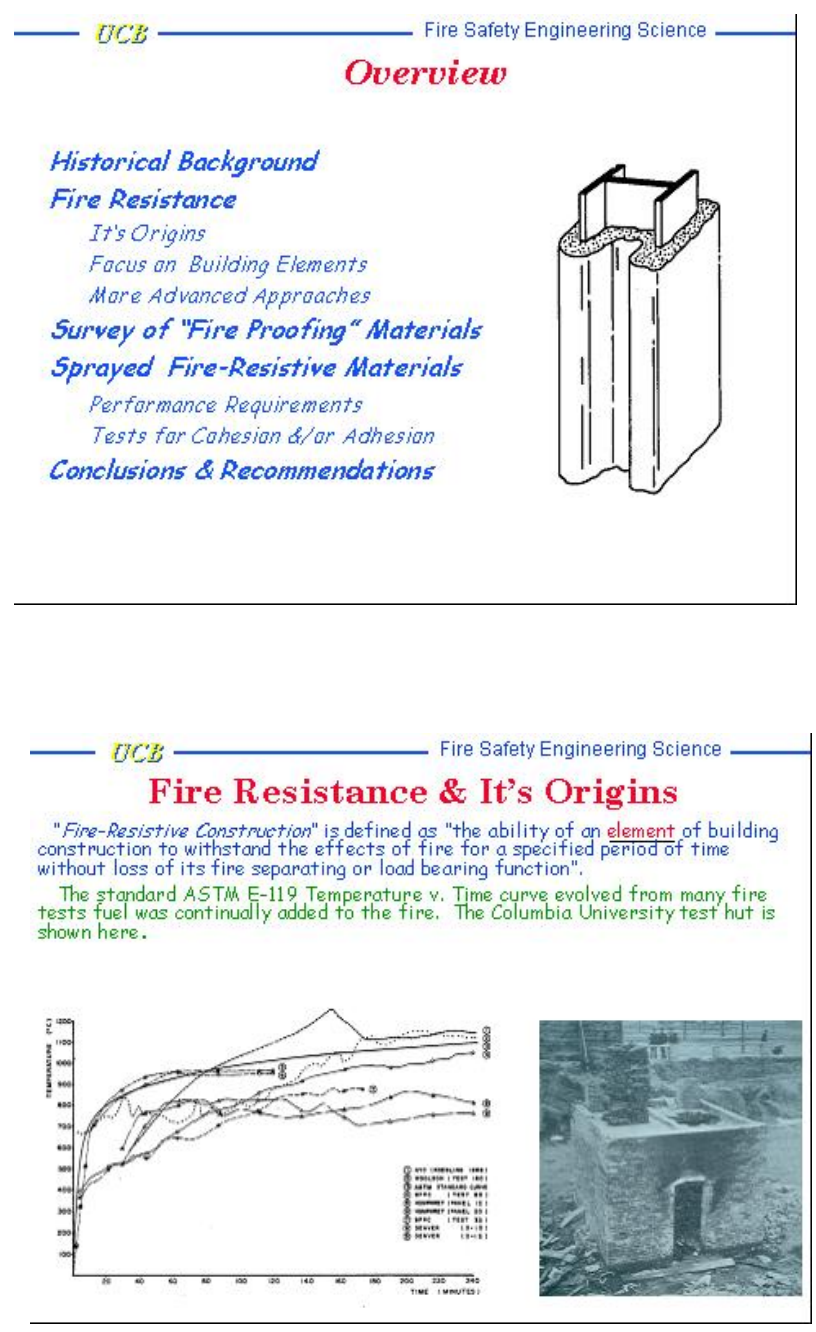

\section{$O C E$ \\ The First Materials Used for "Fire Proofing"}

The $1^{\text {st }}$ materials used in the early $20^{\text {th }}$ century were

traditional

construction materials such as masonry or concrete.

These required substantial labor costs $\&$ high densities.

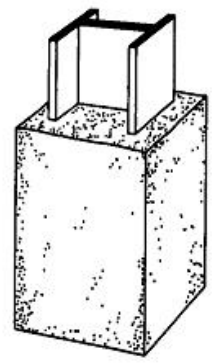




\section{$O C E$ \\ In the Middle Decades of the $20^{\text {th }}$ Century Gypsum Plaster Came into Use}

The first gypsum-based systems, such as the wire lath \& plaster system at the right, also required substantial labor, \& they were not very light.

They shared the basic protection mechanism with concrete of hydrated water.

This water of crystallization was immune from "drying out" \& was very effective in achieving good fire performance.

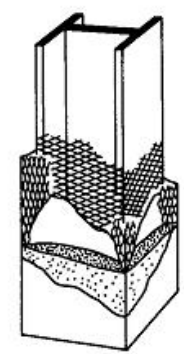

$-0$

In the Last Half of the $20^{\text {th }}$ Century "Sprayed FireResistive Materials" Became Important

There was a general change from the traditional fire proofing systems to "Sprayed Fire-Resistive Materials" (SFRM) which used hydrated gypsum or portland cement as a binder with various fibers \& other fillers.

These required lower labor costs \& imposed weight penalties than the materials that had been previously used.

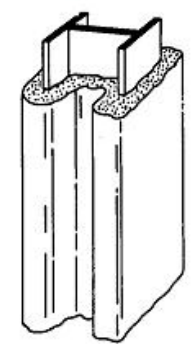

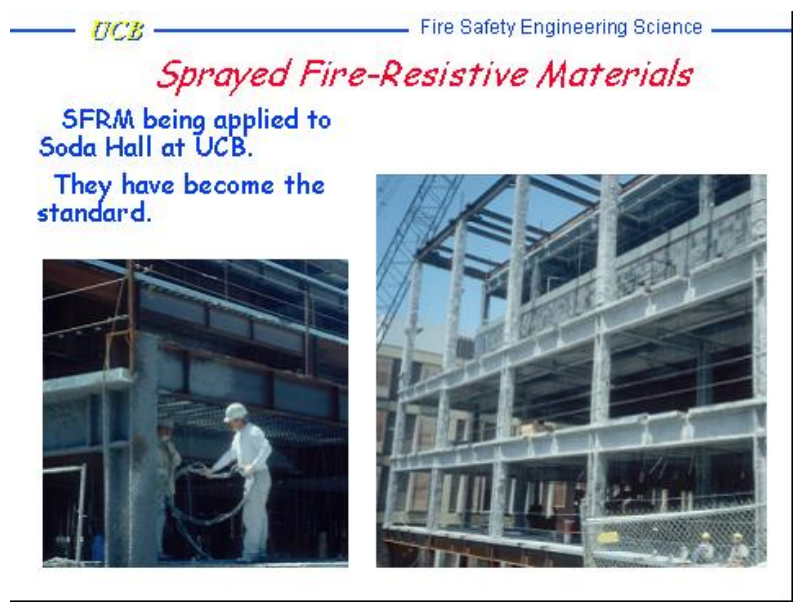

$O C B$

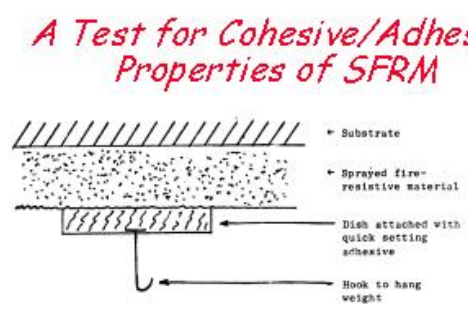

The test method schematically shown above is described in ASTM 736 which was originally published in 1980.

The fundamental problem with this test is that failure can occur in two ways as captured in the title: it is either a cohesive or an adhesive failure.
$U C B$

\section{Performance Requirements for SFRM}

In 1972 Williamson gave 4 requirements for SFRM

A. Performance under actual fire conditions.

B. Durability \& integrity under normal life of the structure.

C. Durability \& integrity under the construction process, \&

D. Integrity \&/or general condition under special condifions such as earthquakes, thermo-nuclear attack, or the relative ease of repair following a fire exposure.

* Williamson, R.B., Report to Sprayon International, 1972. 

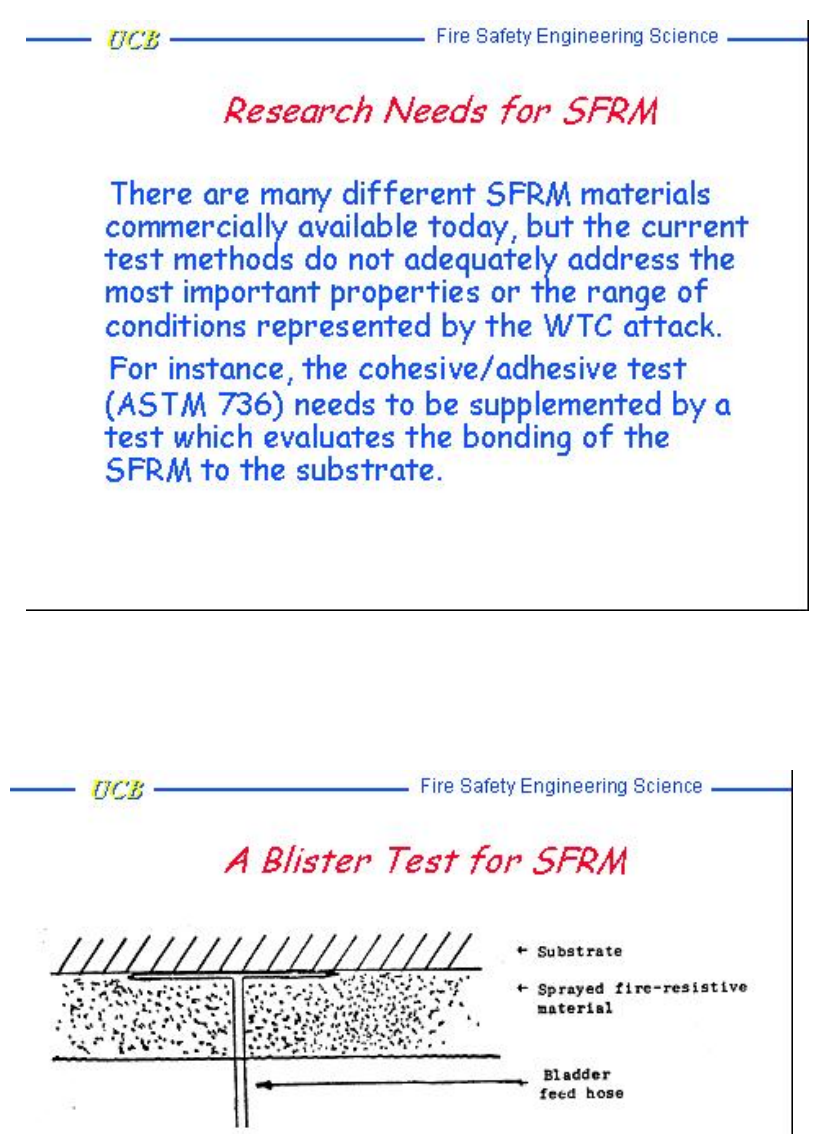

A thin plastic "bag" can be attached to the substrate before the SFRM is applied.

Then a measured pressure can be applied to the feed hose to cause the bag to inflate.
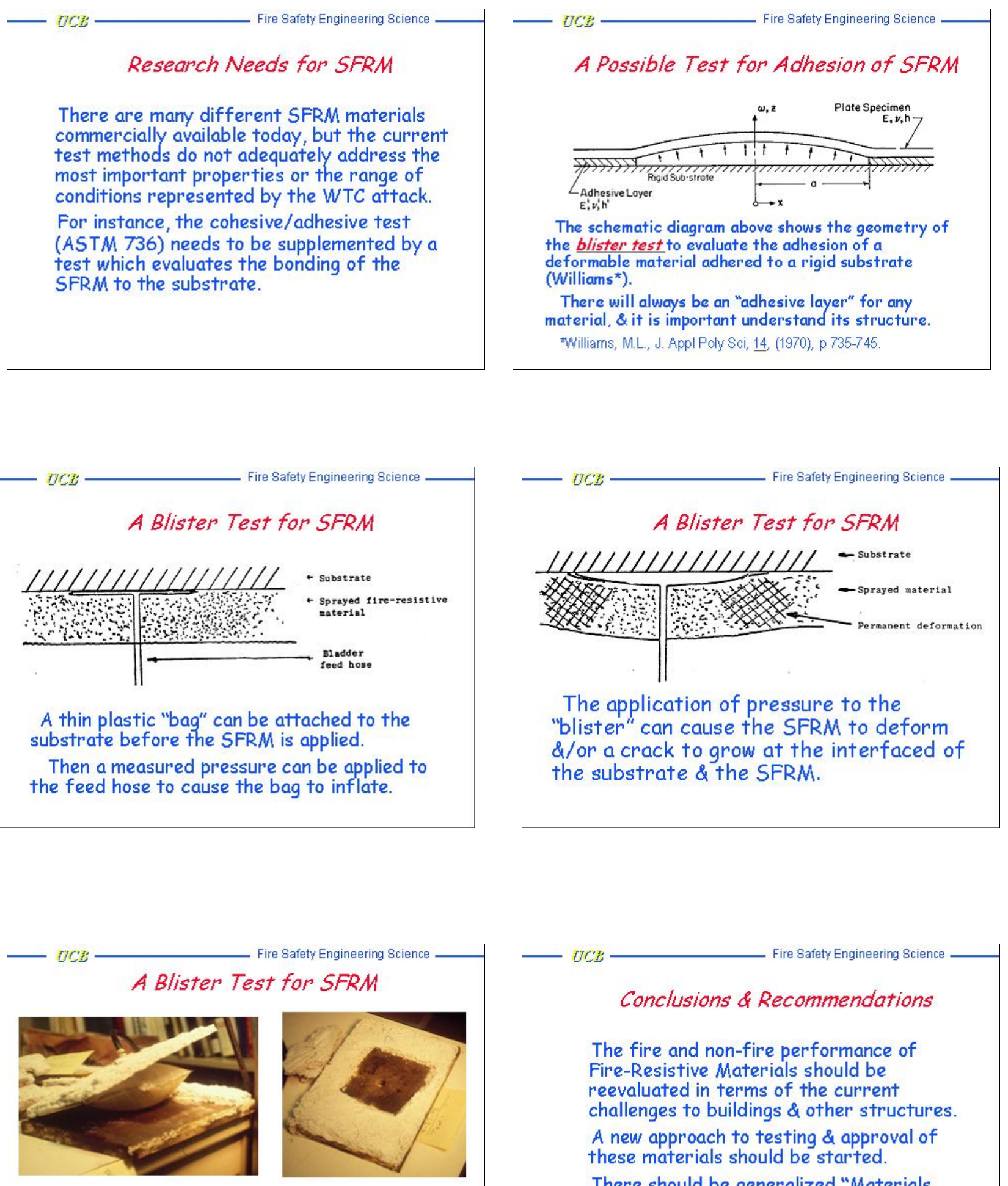

The substrate on the left was oily \& the SFRM had poor adherence

The SFRM was well bonded to the steel. 
L. Performance-Based Analytical Prediction of Fireproofing Requirements in Complex Buildings, Robert H. Iding, Wiss, Janney, Elstner Associates, San Francisco (See file App III L.pdf) 
M. Protection of Steel Structures Against Blast, Impact and Ensuing Fires Abolhassan Astaneh, Department of Civil and Environmental Engineering Unversity of California, Berkeley CA

Protection of Steel Structures Against Impact, Explosion and Ensuing Fire

\section{By}

Abolhassan Astaneh-Asl

University of California, Berkeley

A Presentation at the

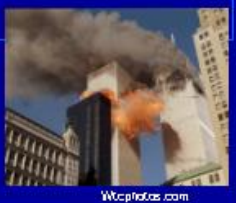

RESEARCH NEEIS F OR FIRE RESISTANCE DETRULNATION AND FER FORMANCE

Nations hositinte of Standaris and Teduology

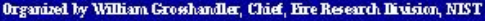

Felinuary 19-20, 2002, Wastimgton D.C.
Types of Impact, Explosives and Ensuing Fires on Tall Buildings

Impact of airbome or ground attacks such as jetliners, smaller planes, rockets and cars

Explosions inside or outside the building as a result of above attacks

Ensuing Fires due to fuel delivered by attackers or fuel present inside the building.
Effects of Impact on the Buildings

1. Applies concentrated dynamic force to the building.

2. Depending on dynamic interaction of the building with impacting object, dynamic forces will be generated throughout the building and its structure.

3. Such dynamic forces can cause serious damage at local and global level to structural, non-structural and fire protection system.
In case of "extreme event" attacks and fires, the main goal of protection is life safety by preserving egress routes and preventing Collapse.

A building can collapse due to:

a. Initial damage to its structure,

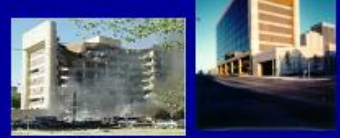

Deterioration caused by ensuing îre.

\section{Effects of Impact and Ensuing} Fire on the Structure

1. Local and Global Damage to Structure

2. Initial Damage to Fire Protection Systems

3. Progressive Collapse Due to Deterioration in Strength or Stability of Gravity Load Carrying System Caused by Ensuing Fire.
Tests of Floors Catenary Action to Prevent Progressive Collapse

Abolhassan Astaneh-Asl, Ph.D., P.E. Erik Madsen and Roger Jung

Department of Civil and Environmental Engineering University of California, Berkeley 2000-2001 

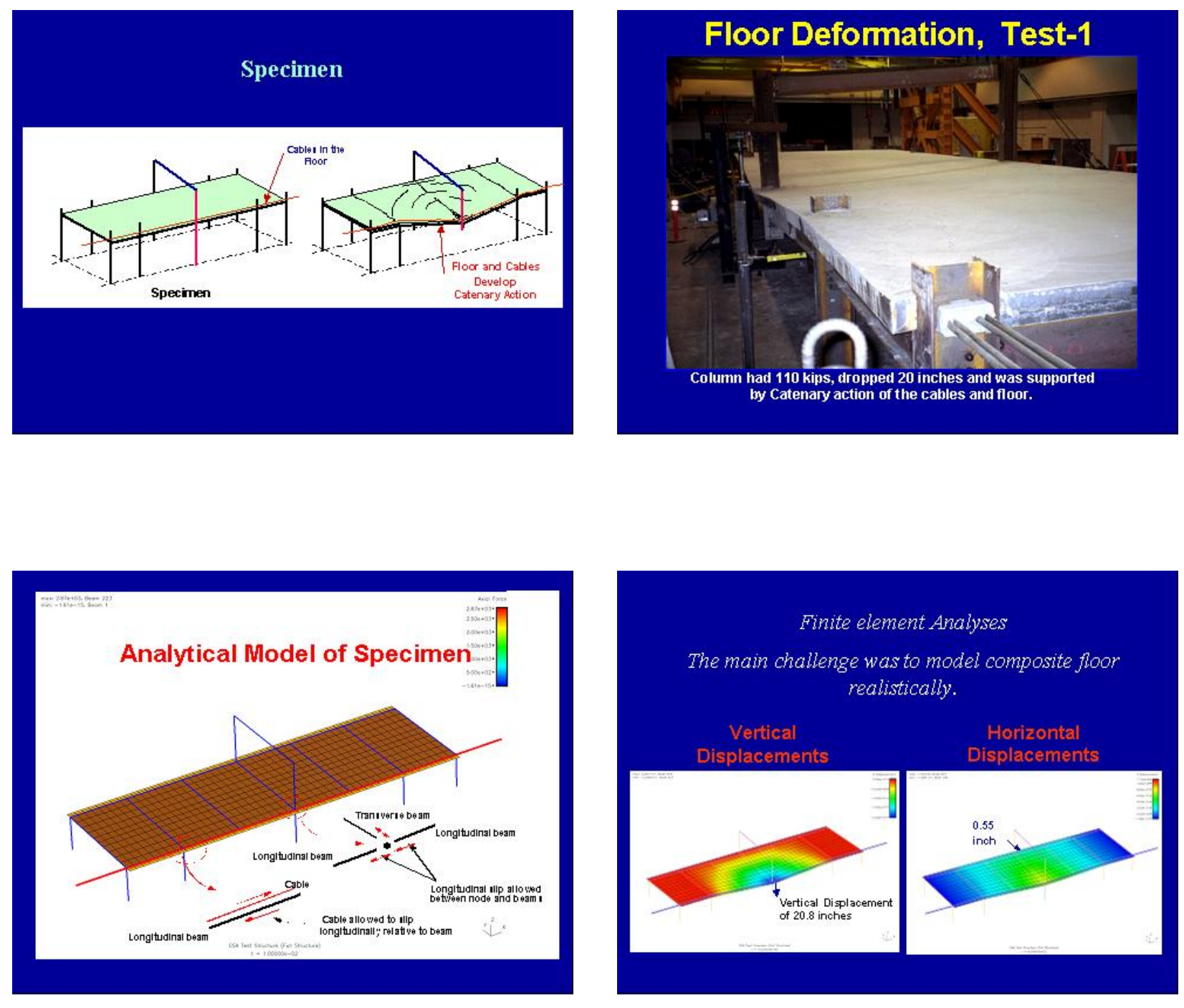

Challenges and Research Needs in Realistic Modeling of Behavior of Steel and Composite Structures Under Intense and Sustained Fires

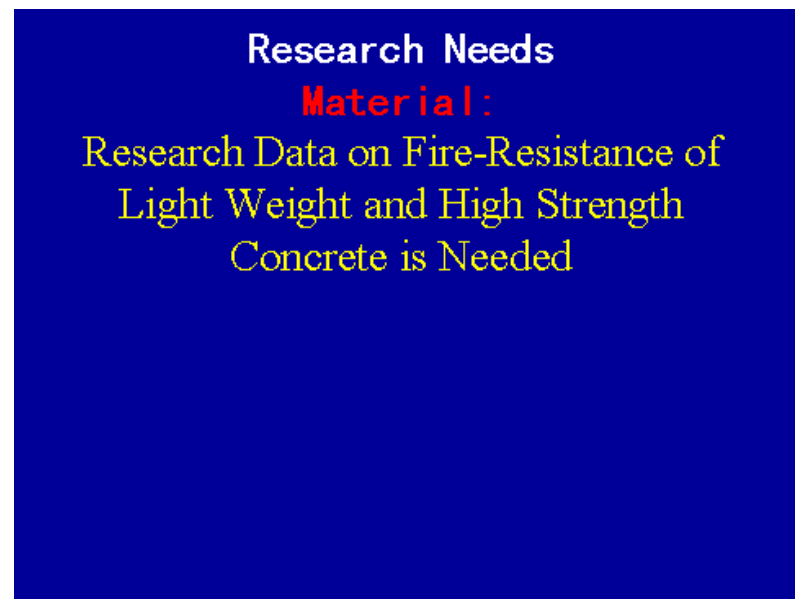




\section{Stee I Structures:}

\section{Connect ions}

Research Funded by NSF
Stee I Structures

Research data and more realistic models of :

1. Local Buckling

2. Overall Buckling and

3. Connections

can be very useful.
Local Buckling in Steel and Composite Structures at Elevated Temperatures:

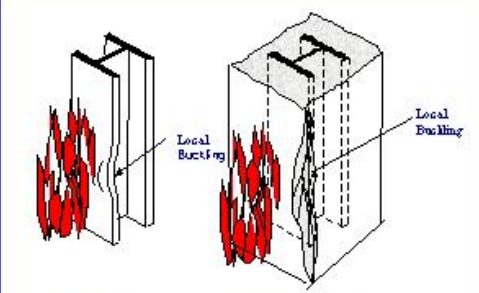

Steel Composite

More reliable data and better prediction models are needed
Loca | Buckling in Steel and Composite Structures at Elevated Temperatures:
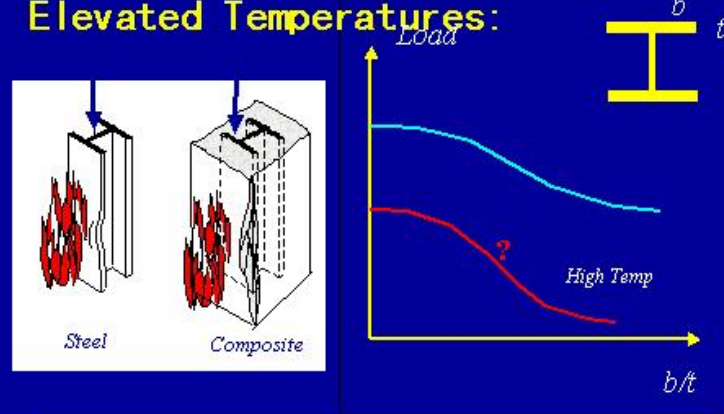

More reliable data and better prediction models are needed
Overal| Buckling in Steel and Composite Structures at Elevated Temperatures:

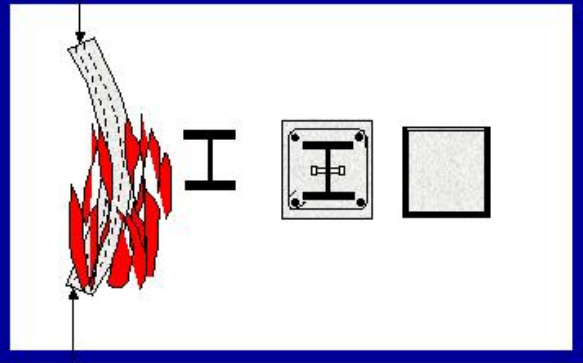

More reliable data and better prediction models are needed

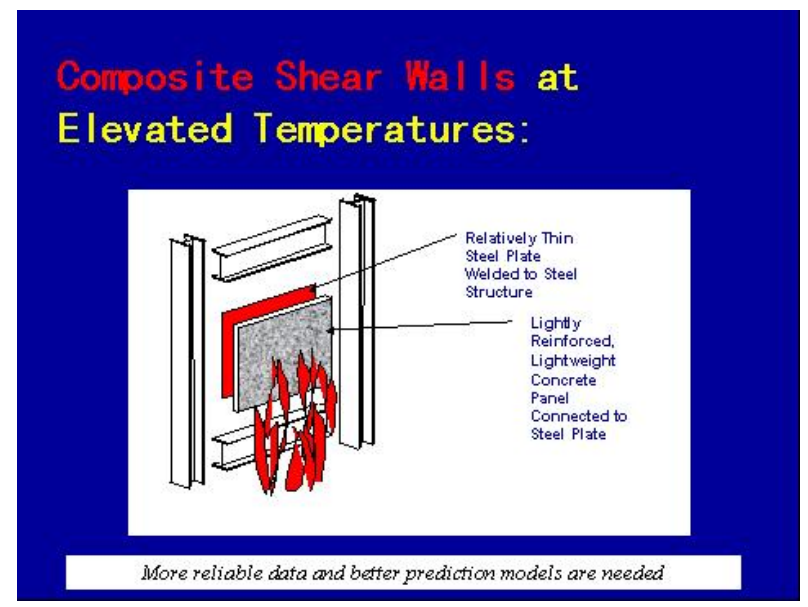


Seismic Studies of an Innovative and Traditional

Composite Shear Walls

by $Q$. Zhao and A. Astaneh-AsI

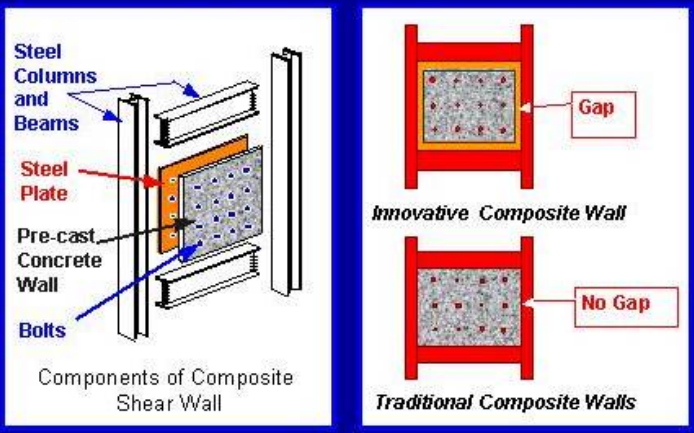

Sponsor: National Science Foundation
Ongoing Cyclic Tests of Composite Shear Walls

$\square$ Two 1/2-scale specimens tested.

$\square$ Cyclic shear displacements applied to the top of specimens.

$\square$ Drifts of up to $4.5 \%$ reached

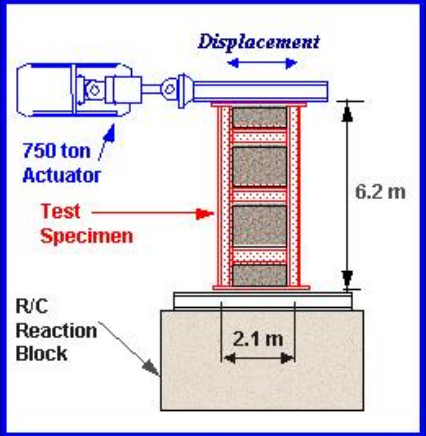

Seismic Studes of an movative and Tradtional Composite Sher Wals, by Q. Zhao and $\mathrm{M}$. Mstaneh-Msl
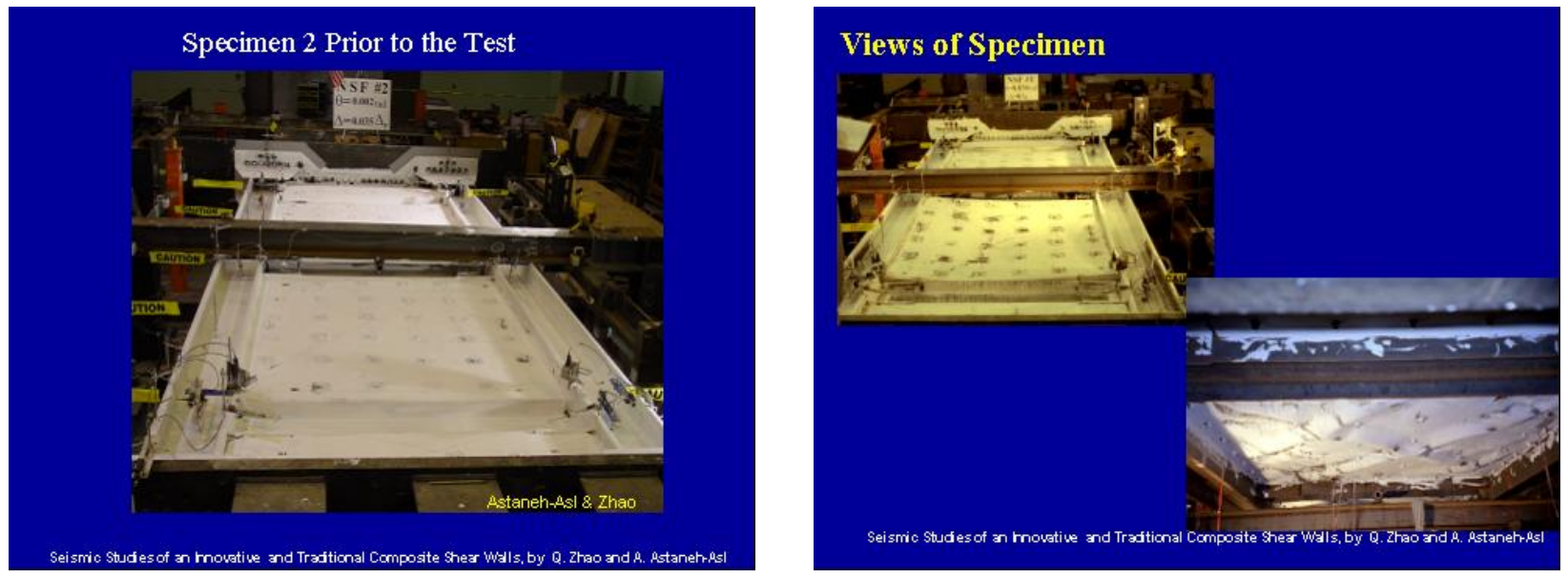

Composite Shear Walls Can Be Used Around Stairwells to Protect Egress Routes
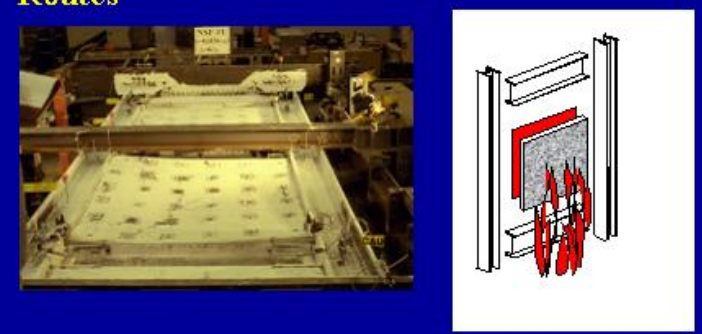

Research Data on Fire Resistance Can be Useful Seismic Studes of an movative and Tradticnal Composite Shea Wals, by $Q$. Zhao and $A$. Astaneh-Asl
Global Performance of Various Structural Systems at Elevated Temperatures:

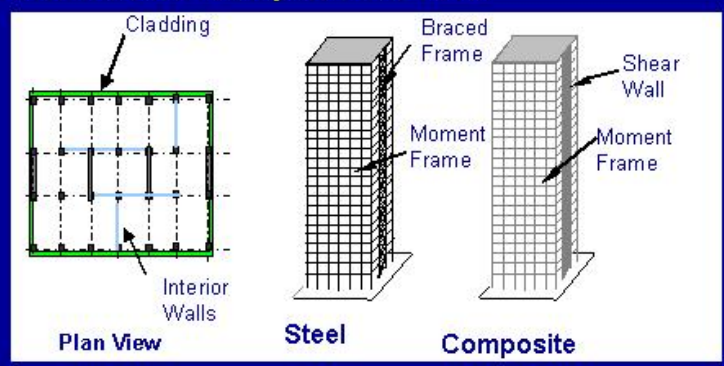

More reliable data on Progressive Collapse are needed 
Some Ressearch Needs on Steet and

Composite Structures Subjected to High

\section{Temperature}

Light Weight Concrete

Local Buckling

* Overall Buckling

* Peformance of Various Systems 
N. Structural Fire Modeling: Where is the Frontier Nowadays? Jean-Marc Franssen, Institute de Mecanique et Genie Civil

University of Liege, BELGIUM
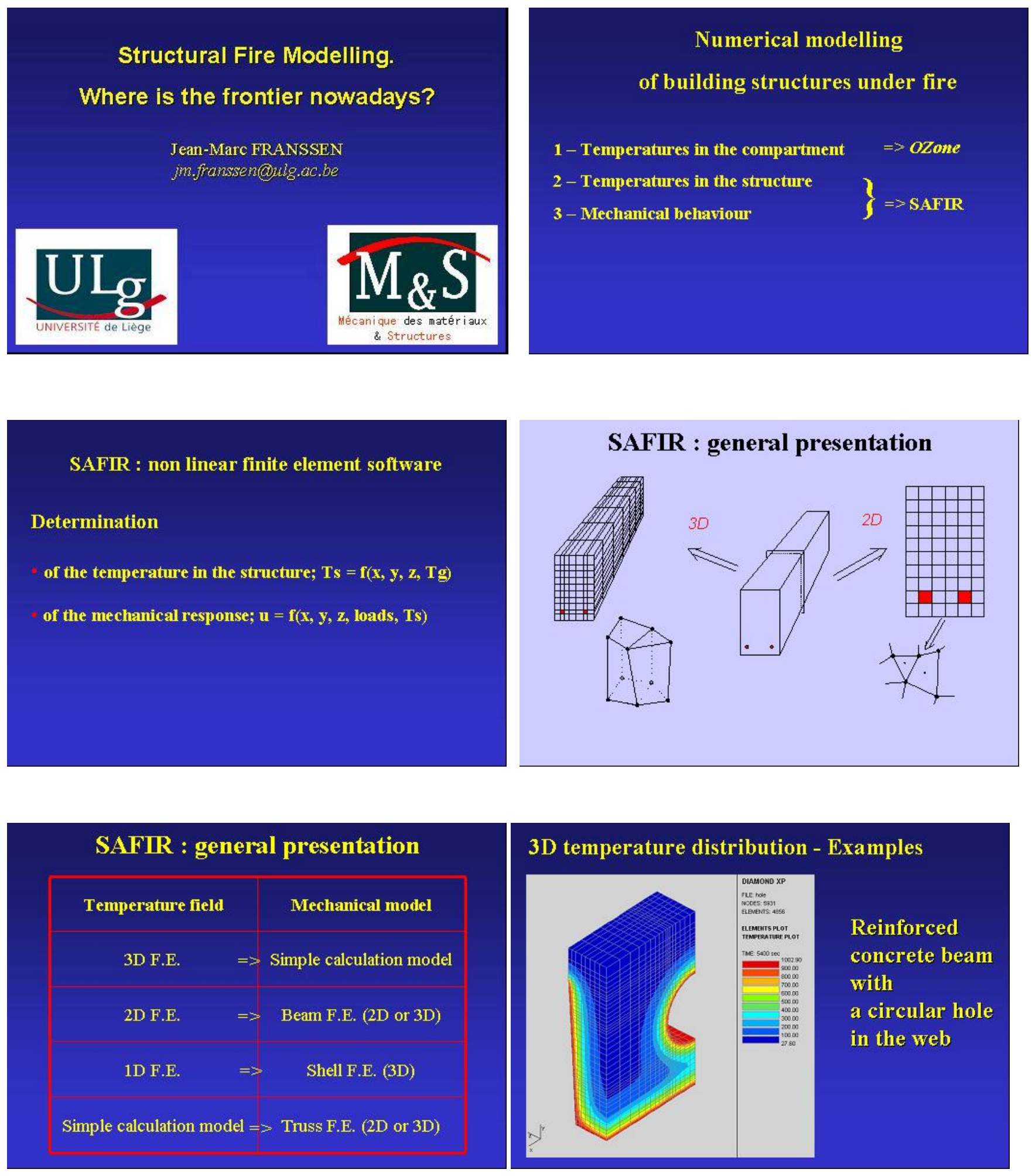


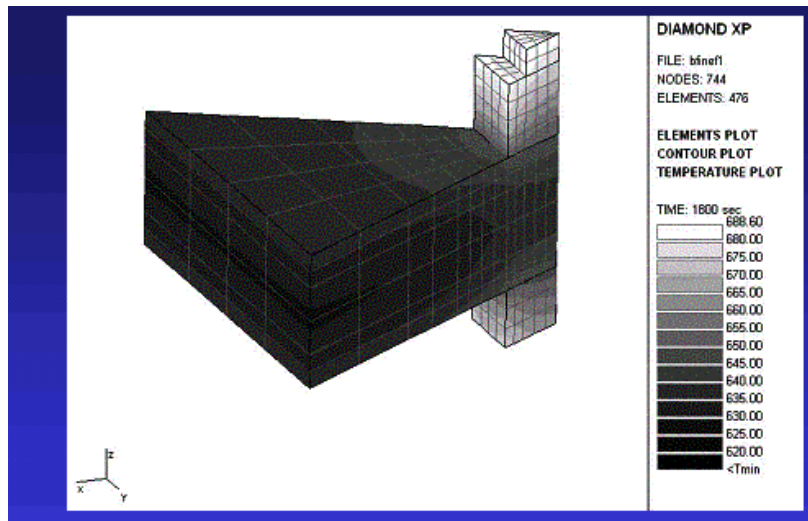

A bolt thr ough 2 steel plates (1/8 represented)

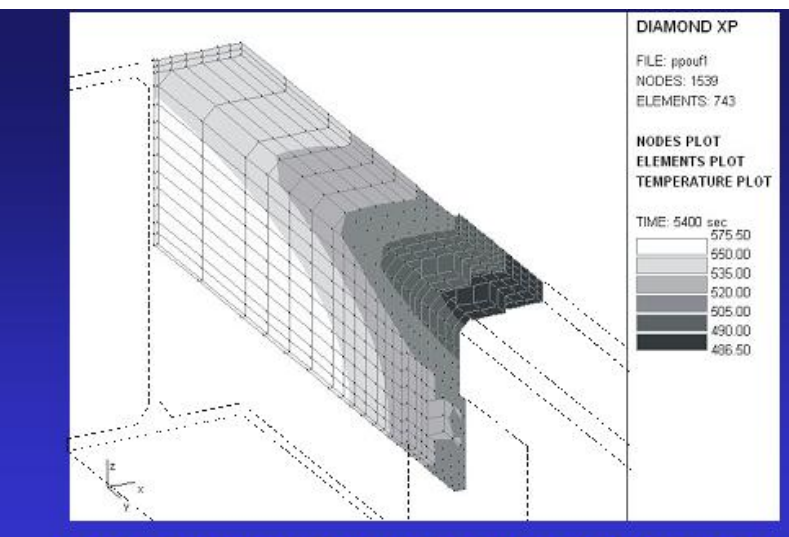

2 steel beams comnected by cover plates (1/8 represented)
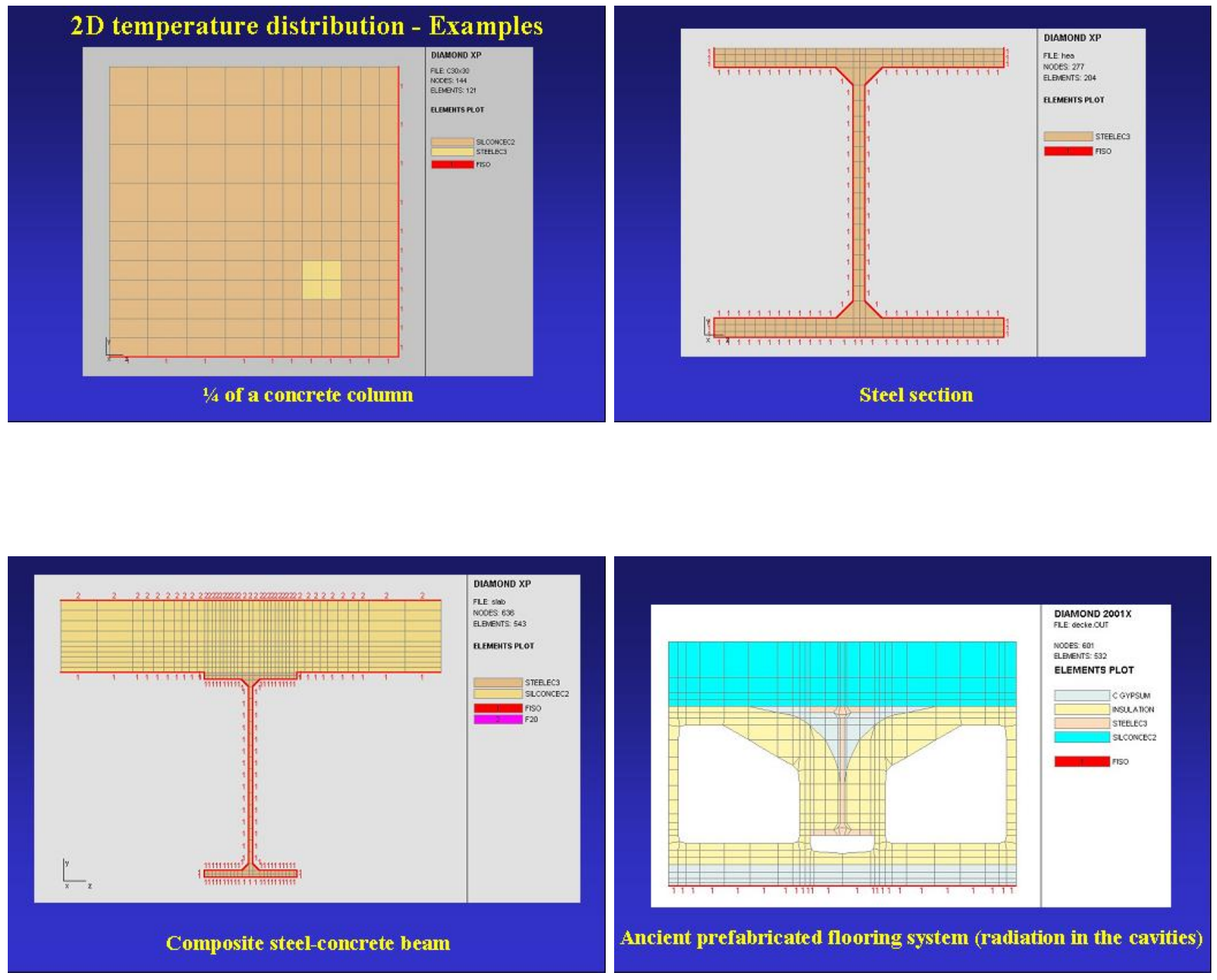

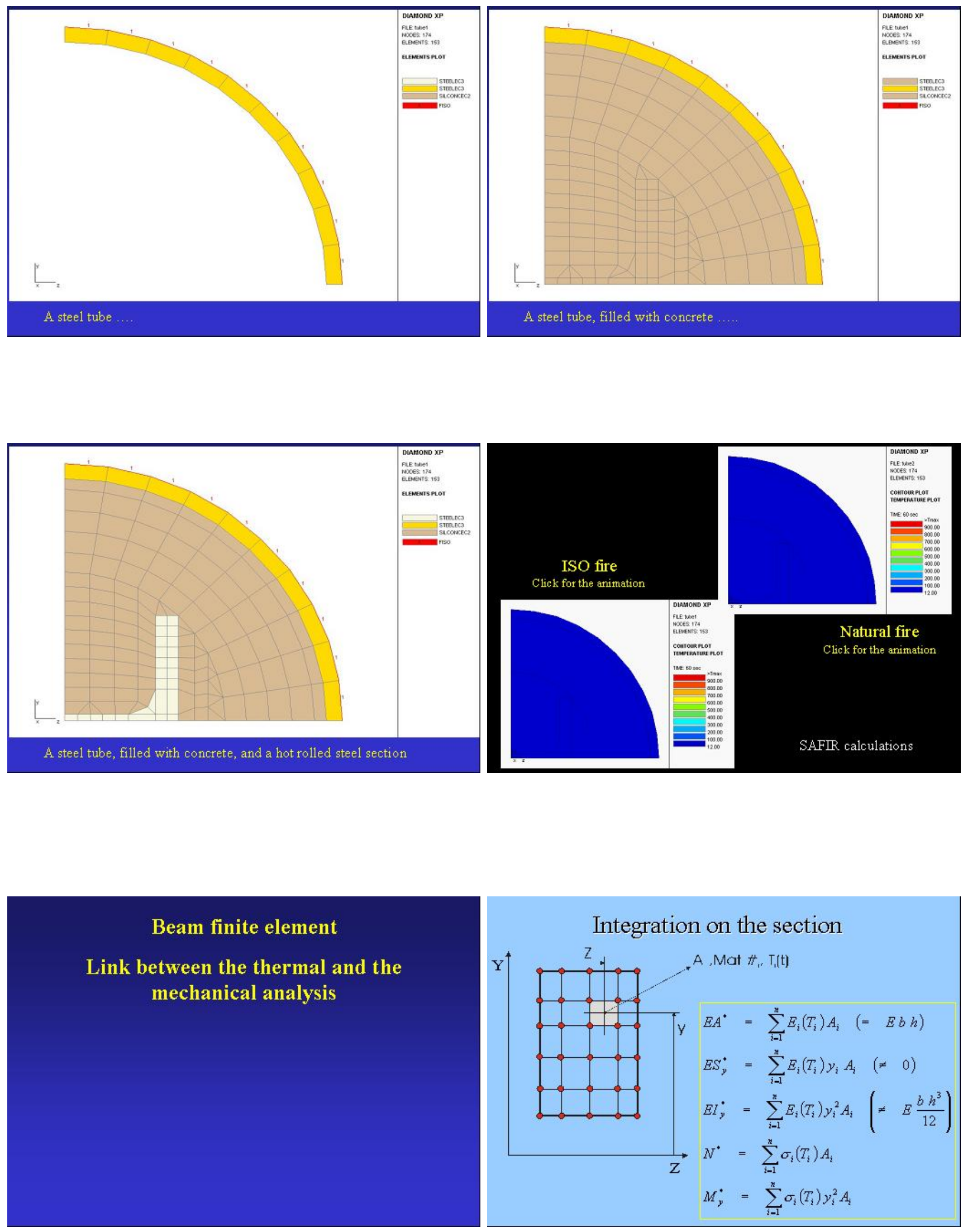


\section{Beam finite element}

Example

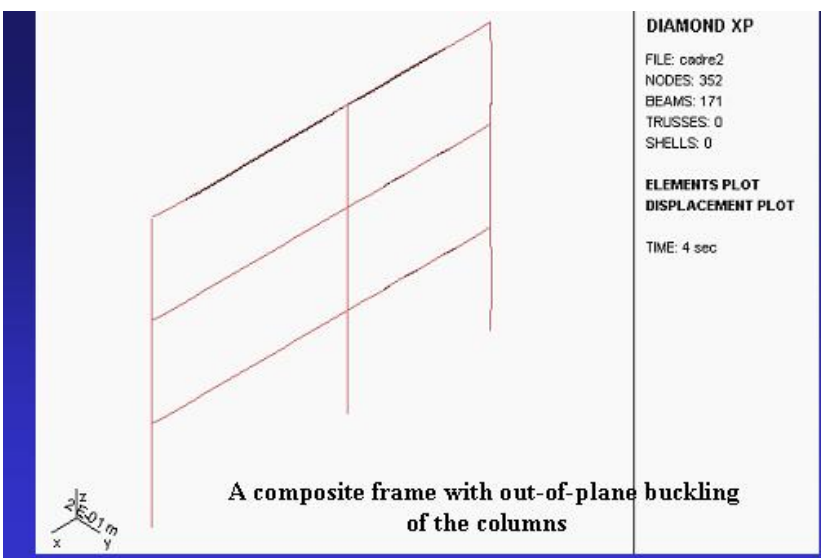

Click for the animation
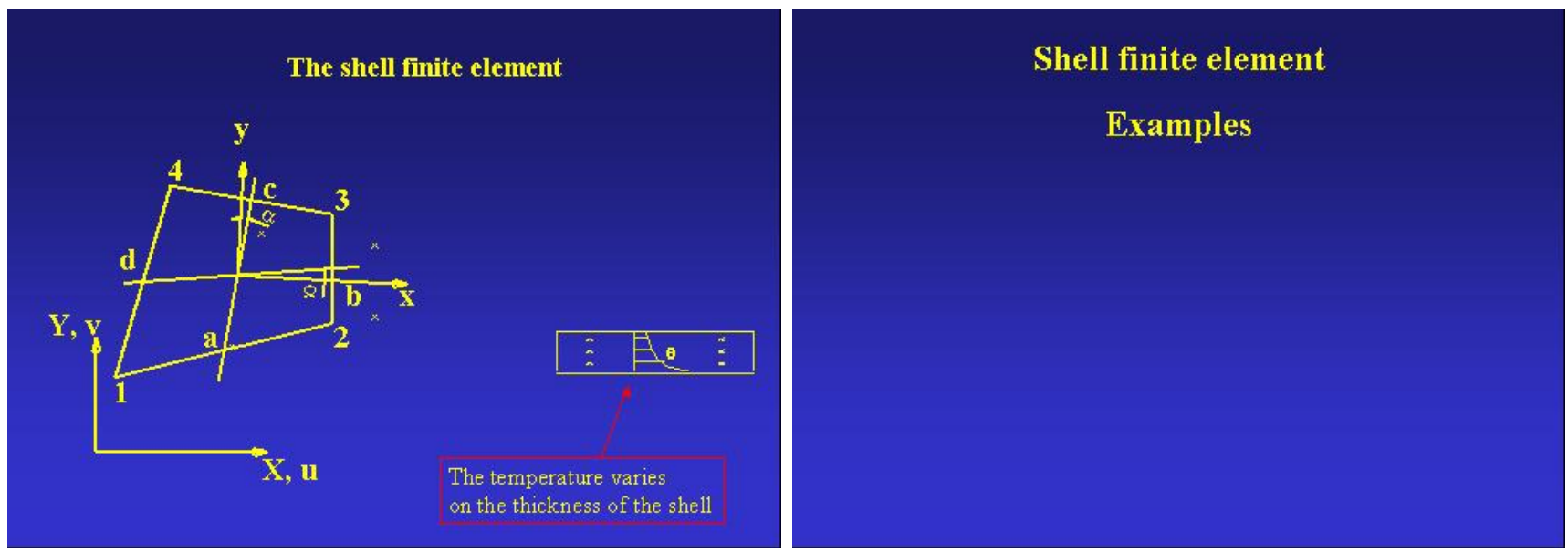

Benchmark test : hemispheric dome (1/4 modelled)

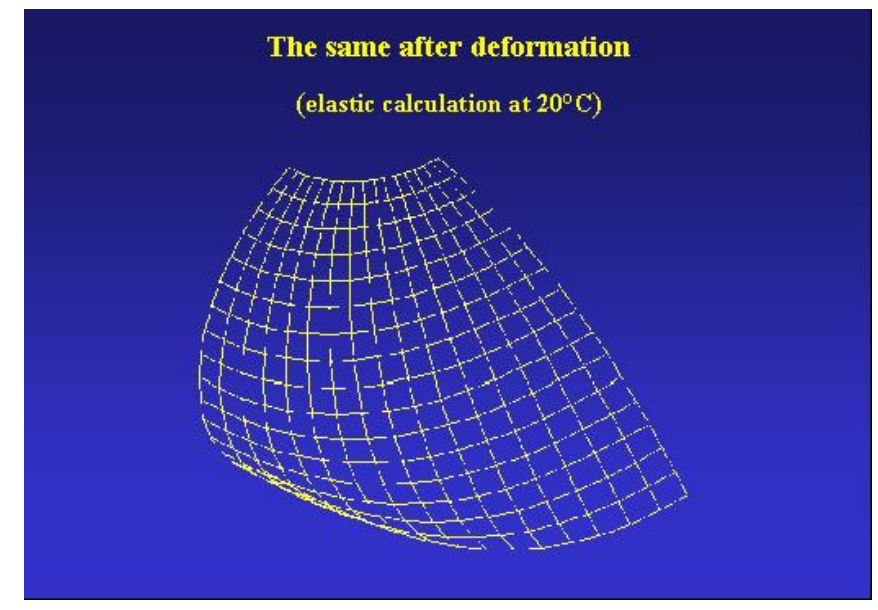



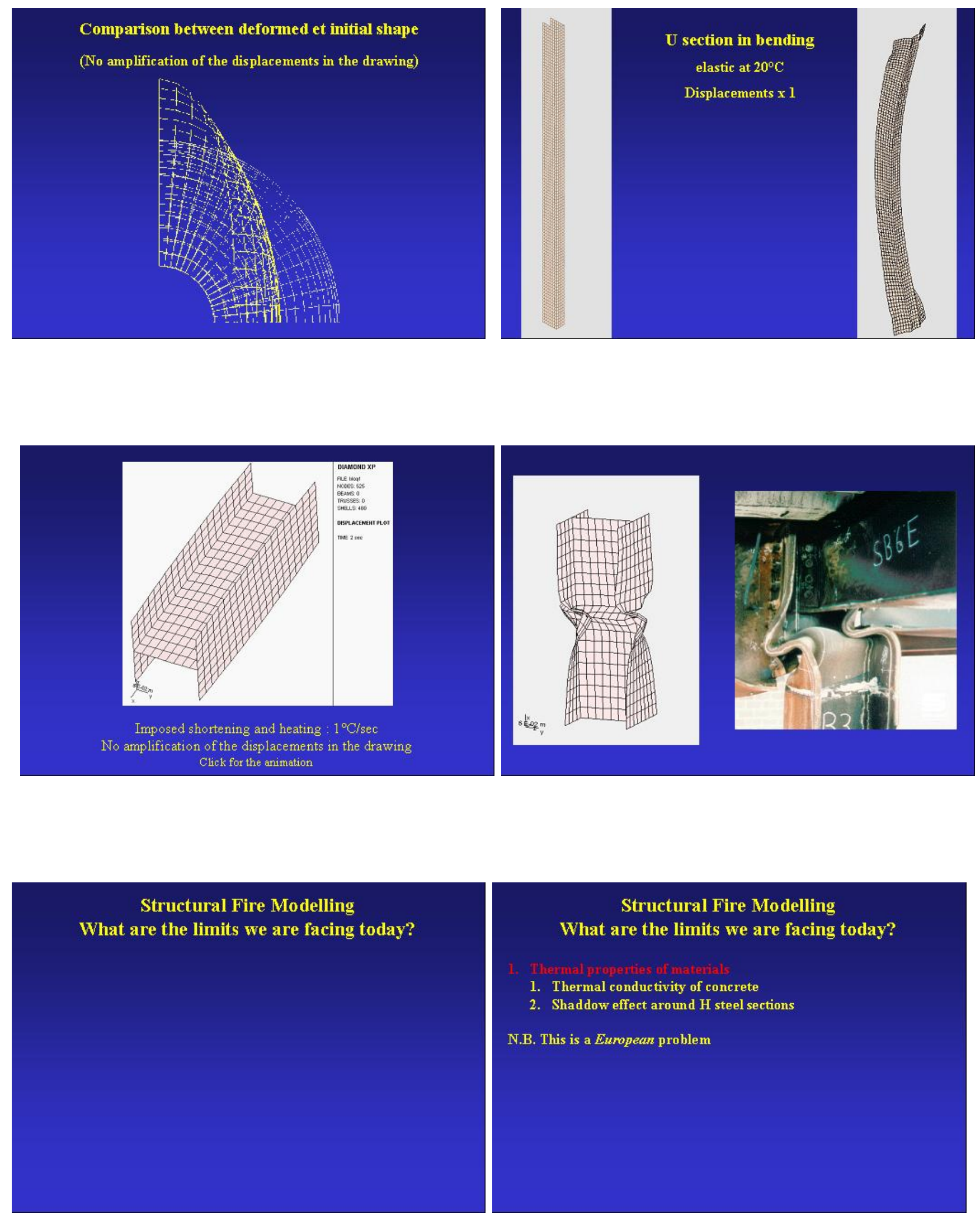


\section{Structural Fire Modelling}

What are the limits we are facing today?

1. Thermal properties of materials

1. In case of C.F.D. modelling

2. Also for zone models

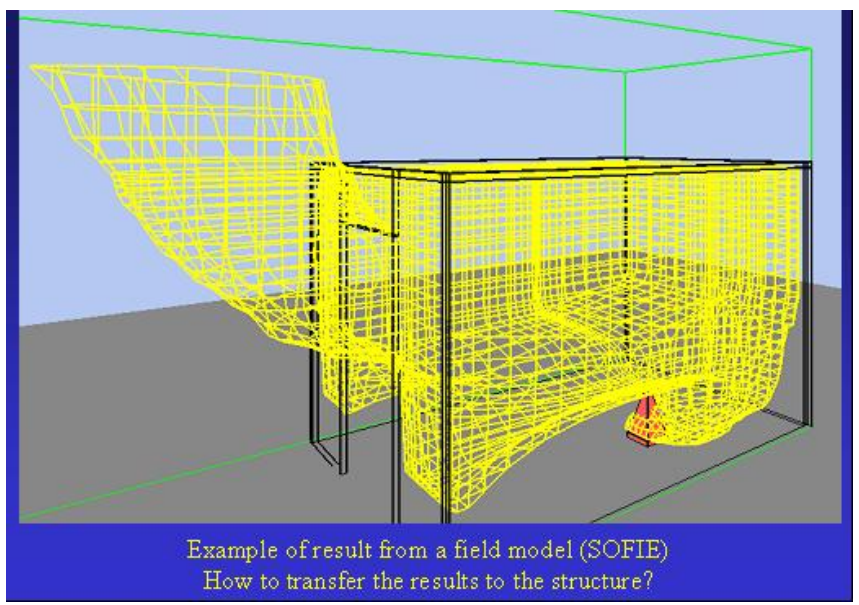

Structural Fire Modelling

What are the limits we are facing today?

1. Thermal properties of materials

2. Interaction between the gas and the structure in case of localised fires

More a producers's problem than a modeller's problem. Research can help in explaining the phenomena and identifying the parameters, but not give a deterministic answer (even if it could, at what price in terms of required data?).

\section{Structural Fire Modelling}

What are the limits we are facing today?

1. Thermal properties of materials

2. Interaction between the gas and the structure in case of localised fires

3. Spalling in concrete
1. Rotation capacity
2. Local buckling
3. Shear failure
4. Debonding

All sections are seen by a Bernoulli beam F.E. as Class 1 sections

- Class $1 \Rightarrow$ no problem

- Class 2 => normally, no hyperstatic structure

- Class 3 m use modified properties

- Class 4 =>???? 

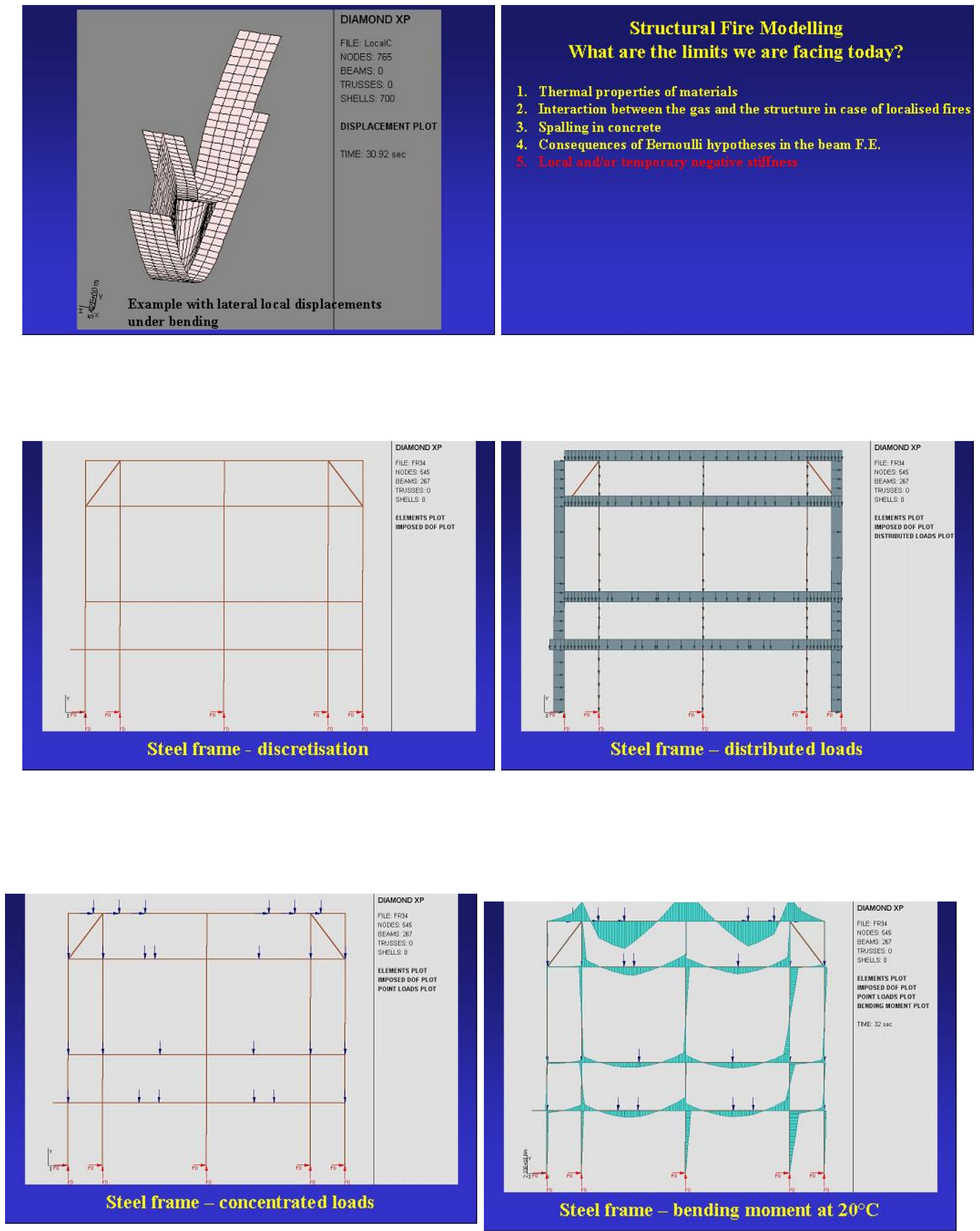

Steel frame - bending moment at $20^{\circ} \mathrm{C}$ 


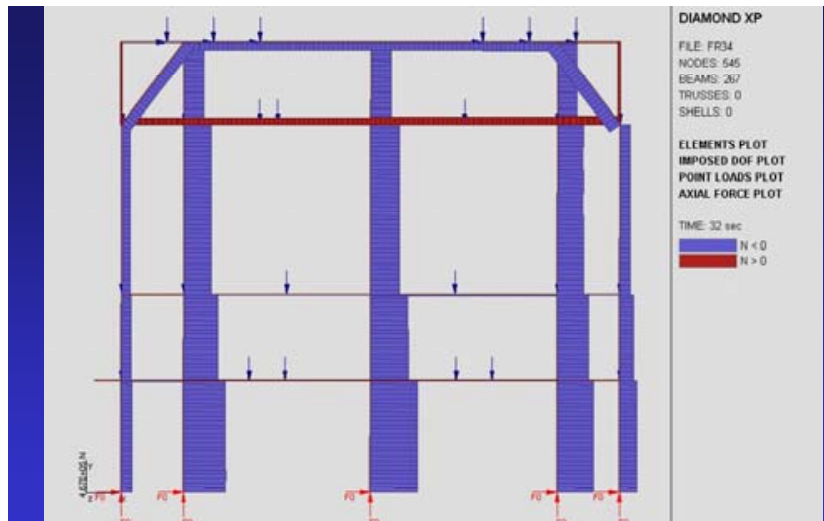

Steel frame - axial forces at $20^{\circ} \mathrm{C}$

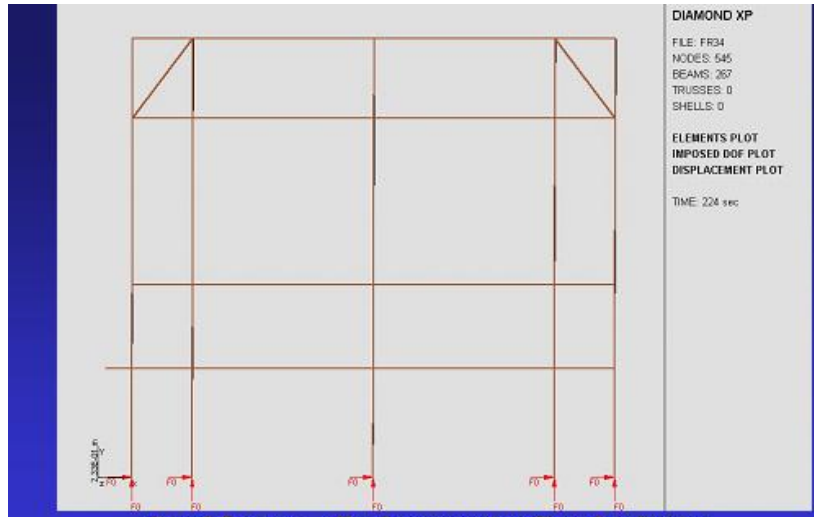

Steel frame - displacements after 4 minutes The simulation cannot go beyond 4 minutes
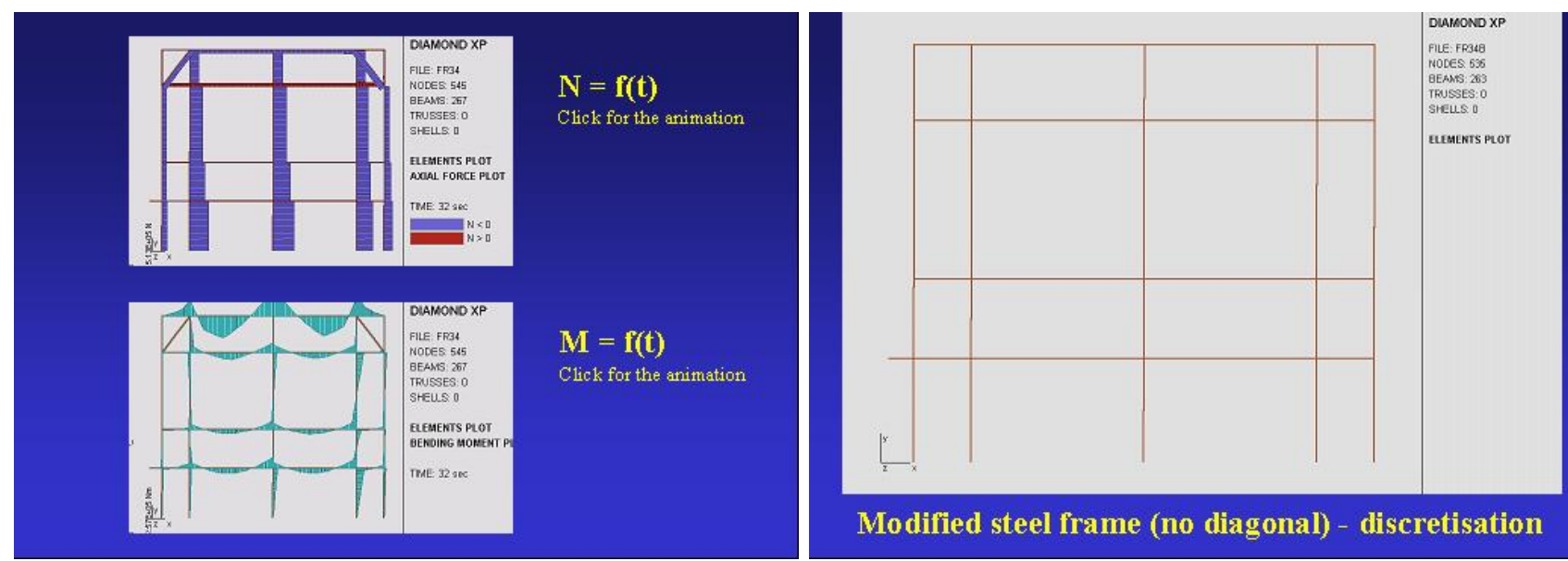

Modified steel frame (no diagonal) - discretisation

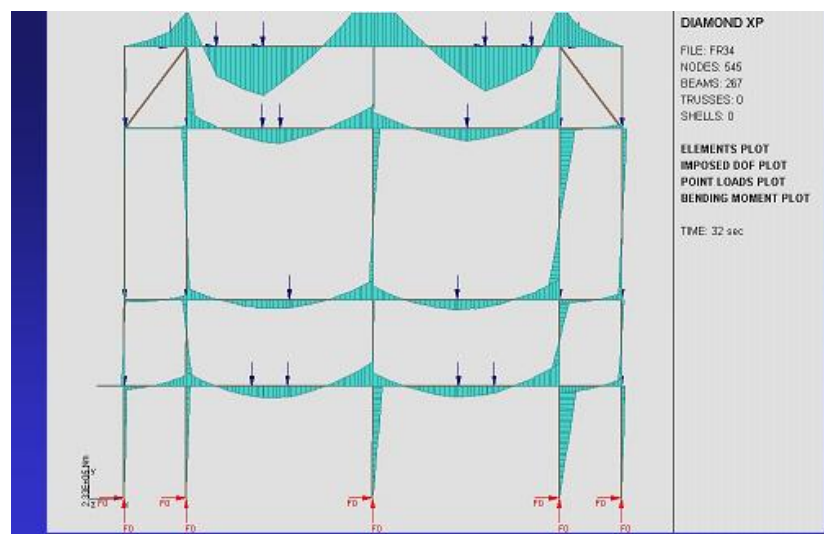

Steel frame - bending moment at $20^{\circ} \mathrm{C}$

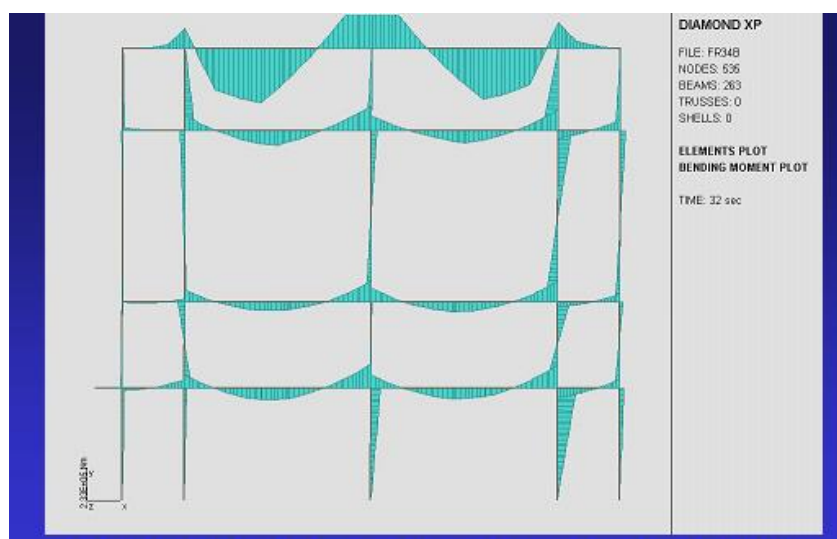

Modified steel frame - bending moment at $20^{\circ} \mathrm{C}$ 


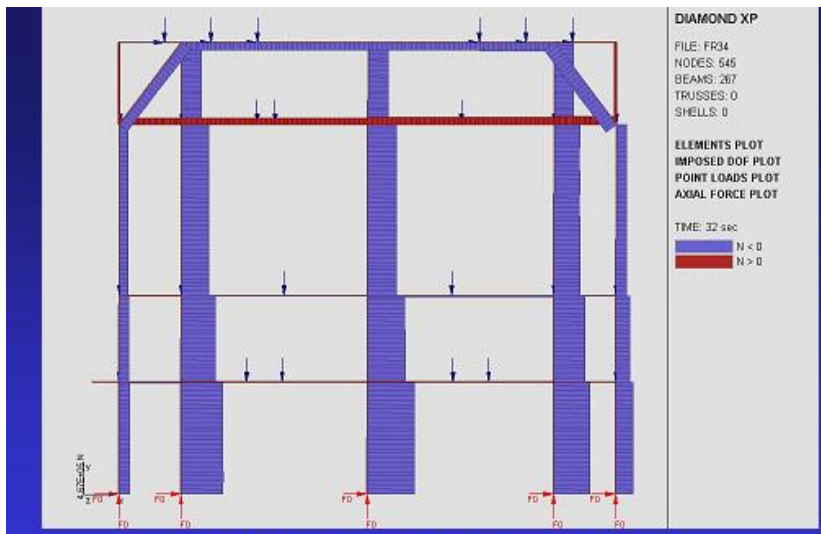

Steel frame - axial forces at $20^{\circ} \mathrm{C}$

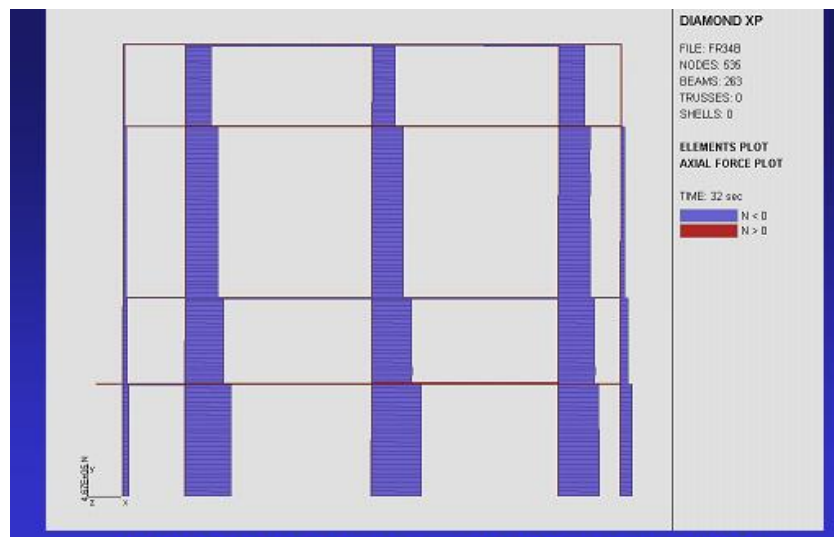

Modified steel frame - axial forces at $20^{\circ} \mathrm{C}$

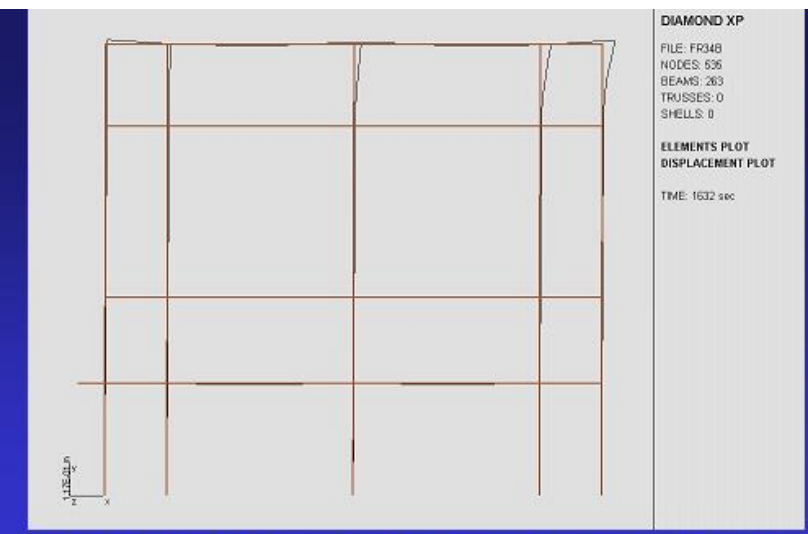

Modified steel frame - displacements after $27 \mathrm{~min}$.
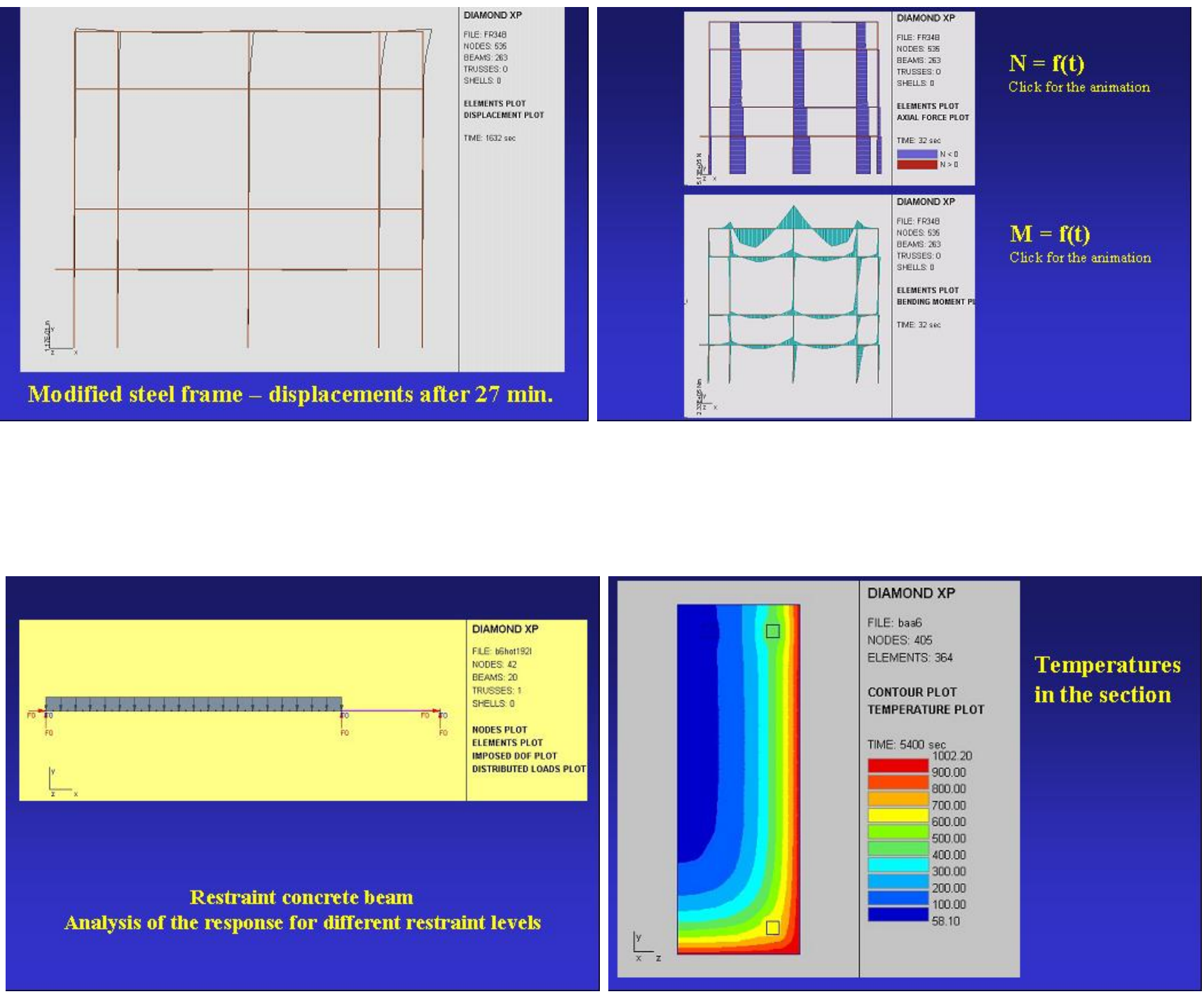

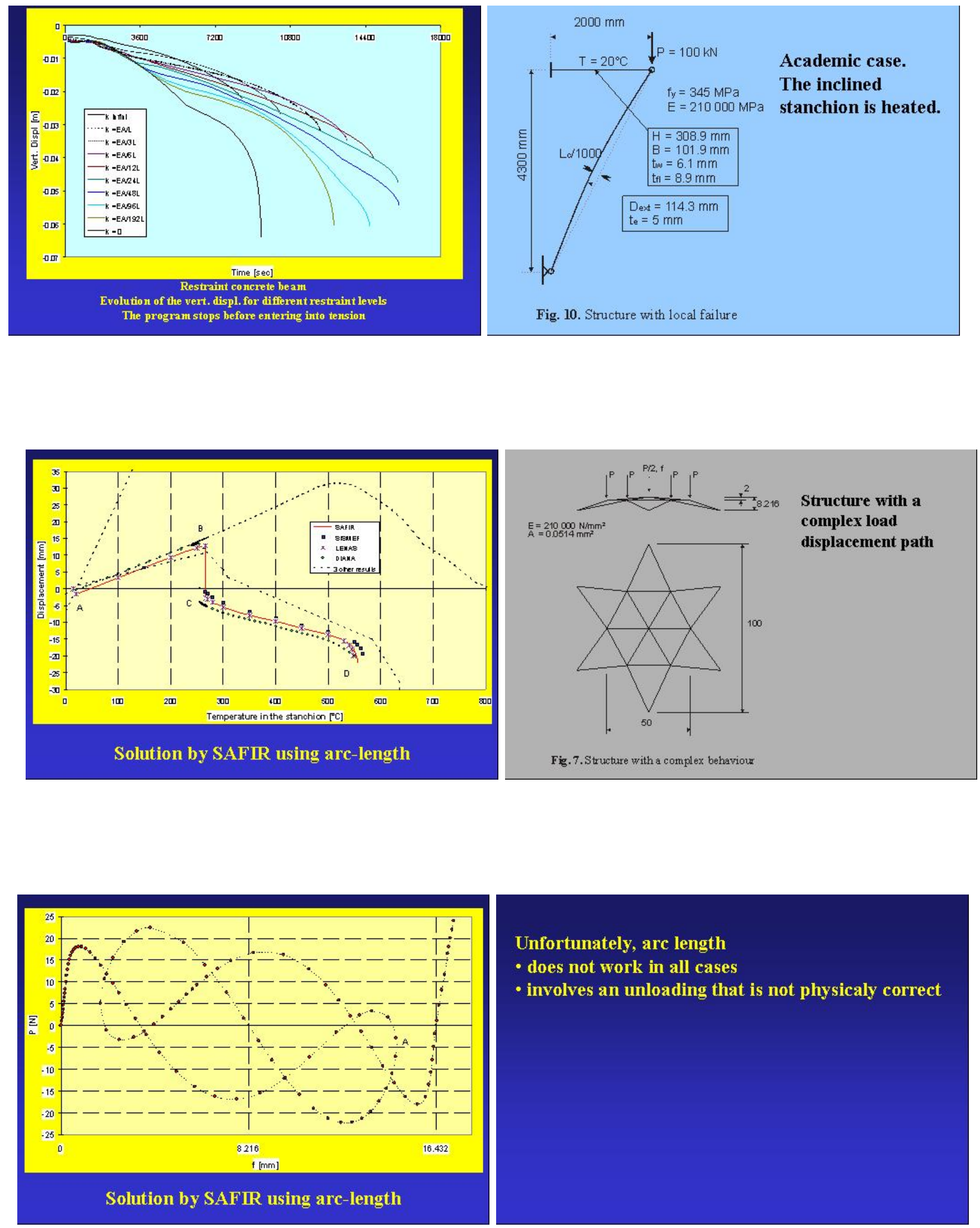

Solution by SAFIR using arc-length 


\section{Structural Fire Modelling \\ What are the limits we are facing today?}

1. Thermal properties of materials

2. Interaction between the gas and the structure in case of localised fires

3. Spalling in concrete

4. Consequences of Bernoulli hyp otheses in the beam F.E.

5. Loc al and/or temporary negative stiffness

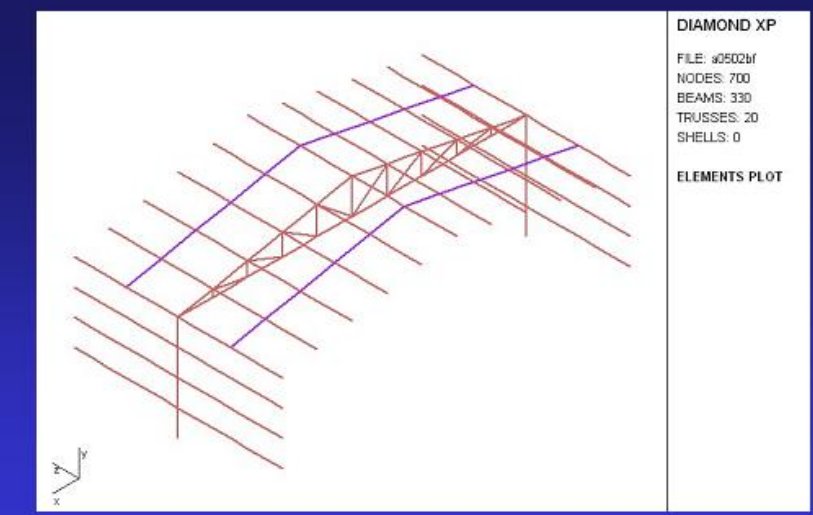

Industrial building: one frame + purlins represented
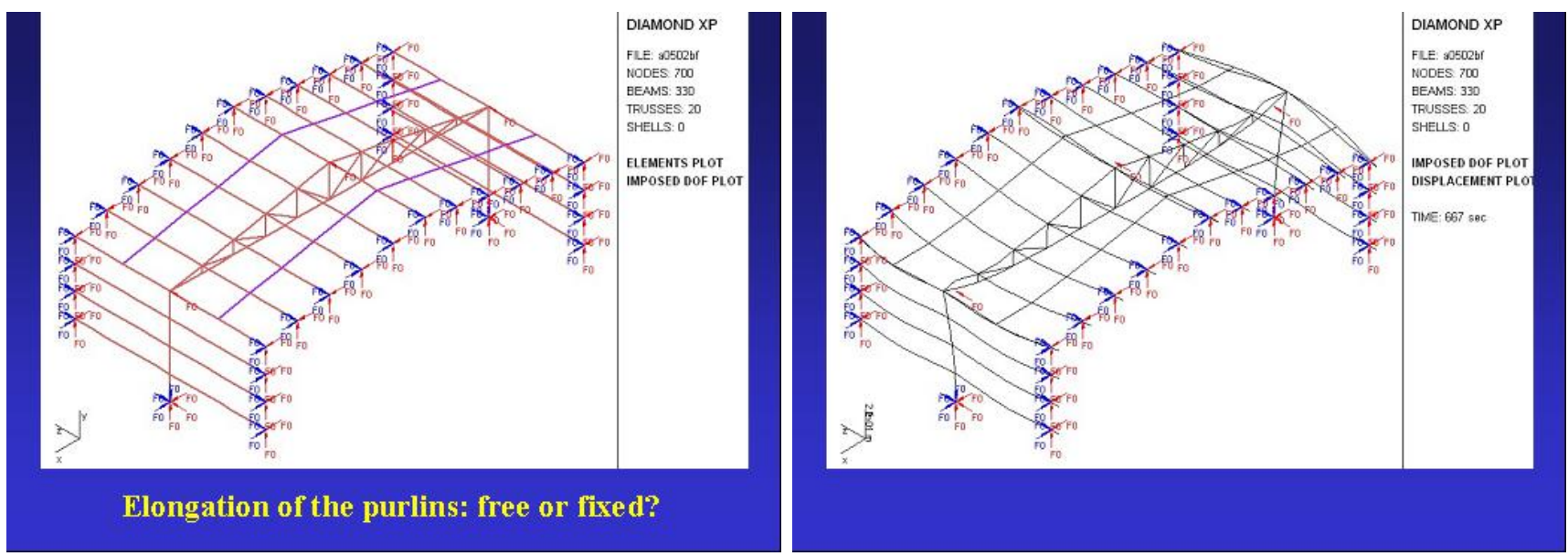

\section{Structural Fire Modelling}

What are the limits we are facing today?

1. Thermal properties of materials

2. Interaction between the gas and the structure in case of localised fires

3. Spalling in concrete

4. Consequences of Bernoulli hypotheses in the beam F.E.

5. Local and/or temporary negative stiffness

6. Boundary conditions in substructures

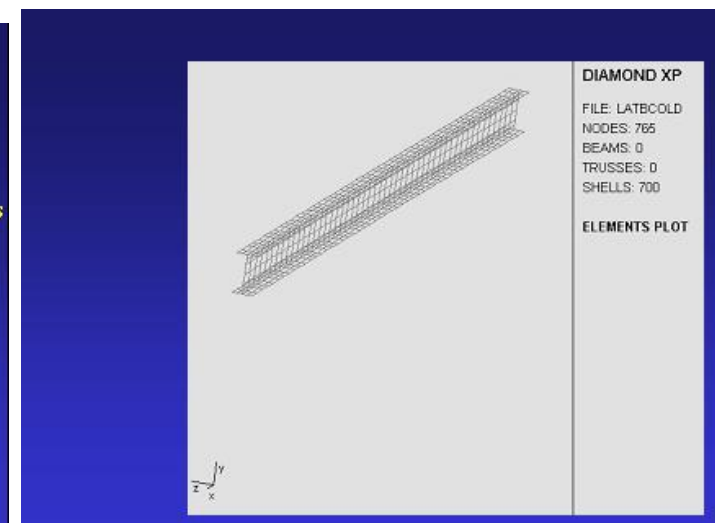

Simply supported beam (displacements $\mathrm{x} 1$ ) 

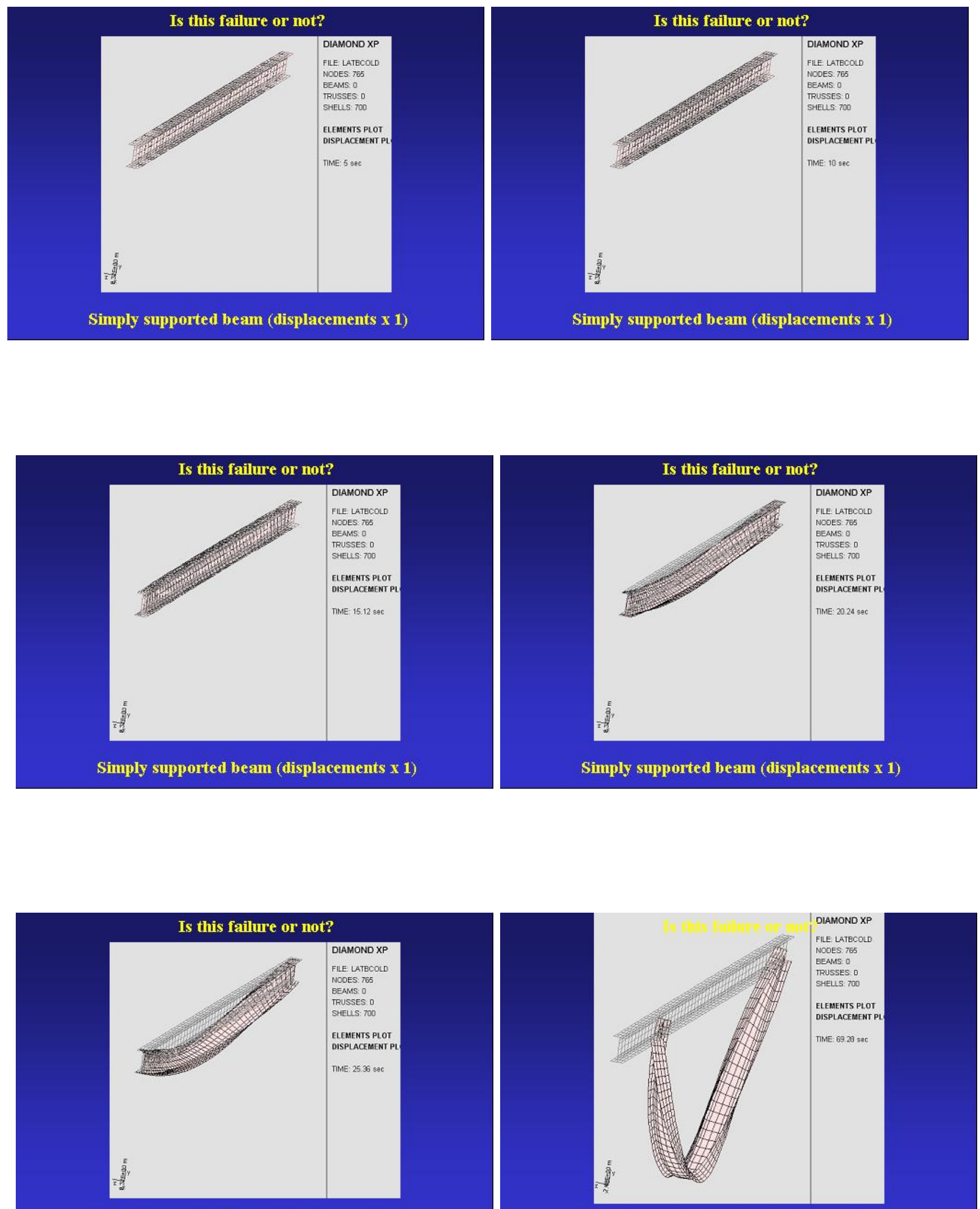

Simply supported beam (displacements $\mathbf{x} 1$ )

Simply supported beam (displacements $\mathbf{x} 1$ ) 


\section{Structural Fire Modelling}

What are the limits we are facing today?

1. Thermal properties of materials

2. Interaction between the gas and the structure in case of localised fires

3. Spalling in concrete

4. Consequences of Bernoulli hypotheses in the beam F.E.

5. Local and/or temporary negative stiffness

6. Boundary conditions in substructures

7. Definition of failure in case of very large displacements
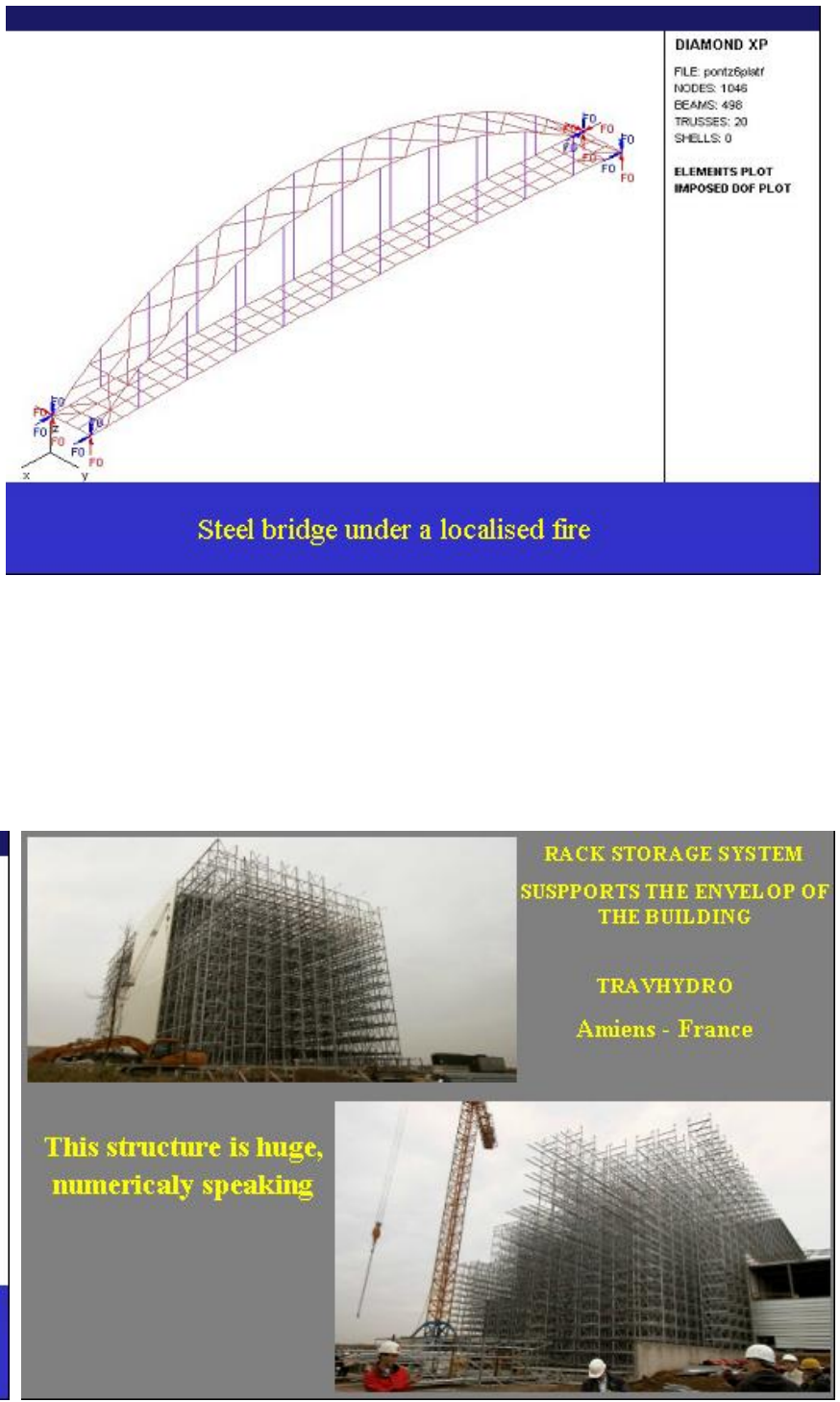

This structure is large geometricaly, but not numericaly speaking

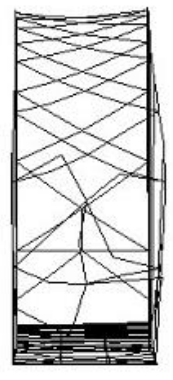

$\rightarrow \times 0 \times 1 \times 10$

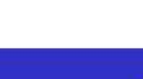

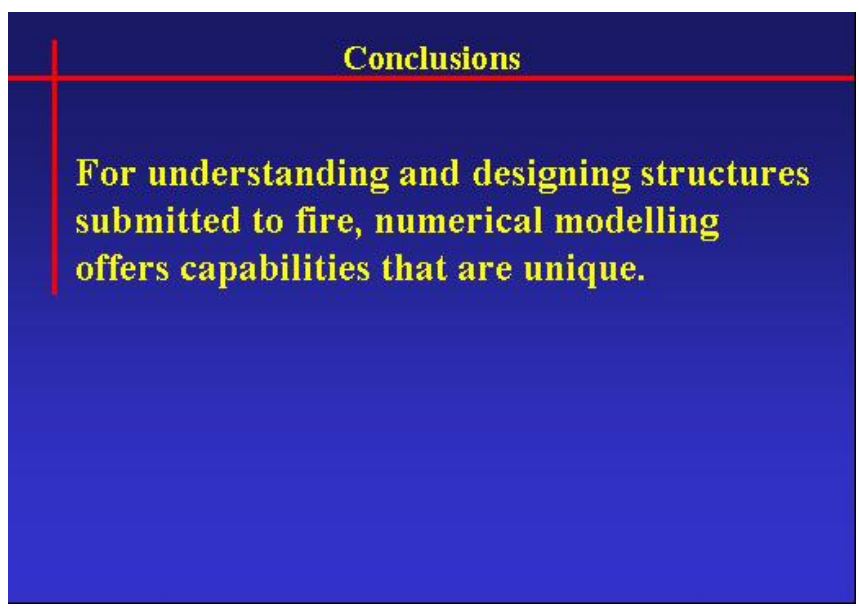


O. Fire Resistance and Performance Prediction: Structural Analysis Issues and Research Needs

James Ricles, Department of Civil and Environmental Engineering

Lehigh University, Bethlehem PA

(see file App III O.pdf) 
P. Parallels Between Performance-based Engineering for Fire and Earthquake Hazards Greg Deierlein, Department of Civil and Environmental Engineering

\section{Stanford University, Stanford CA}

Parallels Between PerformanceBased Engineering for Fire and Earthquake Hazards

Greg Deierlein Stanford University \& PEER

NIST - Research Needs for Fire Resistance Detemination and Performance Prediction Feb. 19-20, 2002

Traditional Earthquake Engrg. Approach

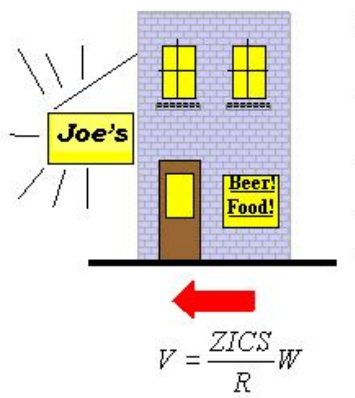

Linear analysis model

Simplified design base shear

- Prescriptive details

- Uncertain outcomes

Owners informed of code conformance, but not building performance $V=\frac{Z I C S}{R} W$

More Explicit Performance Assessment

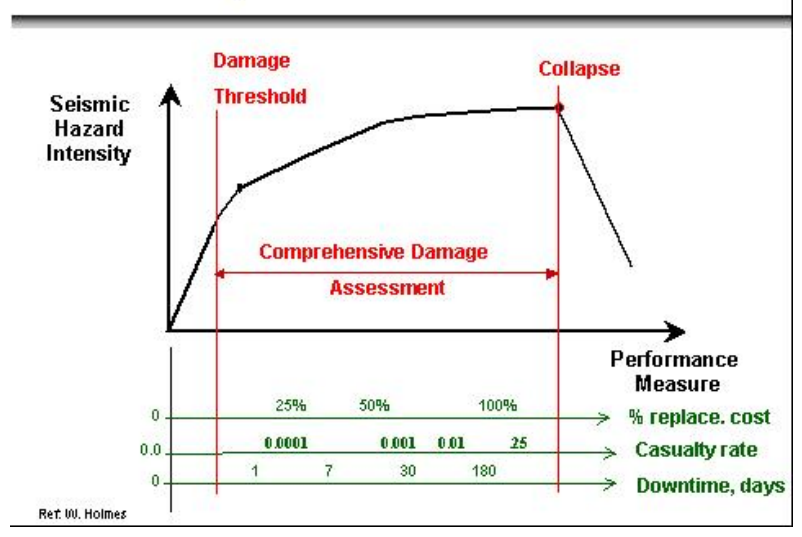

Final Draft ICC Performance Code (ICC 2000).

Objective: To limit the impact of a fire event on the building, its occupants, processes and use; and to limit the impact of an exposing fire on buildings, adjacent properties and processes.

\begin{tabular}{|c|c|c|c|c|}
\hline & \multicolumn{4}{|c|}{ PERFORMLANCE GROUPS } \\
\hline & I & II & III & IV \\
\hline $\begin{array}{l}\text { Very Large } \\
\text { (Nery Rare) }\end{array}$ & SEVERE & SEVERE & HIGH & MOD ERATE \\
\hline $\begin{array}{l}\text { Large } \\
\text { (Rare) }\end{array}$ & SEVERE & HIEH & MOD ERATE & MILD \\
\hline $\begin{array}{c}\text { Mredim } \\
\text { (Less Prequent) }\end{array}$ & HIGH & MODERATE & MILD & MILD \\
\hline $\begin{array}{c}\text { Small } \\
\text { (Frequert) }\end{array}$ & MOD ERATE & MILD & MILO & MILD \\
\hline
\end{tabular}

FEMA 273/356 Performance Assessment

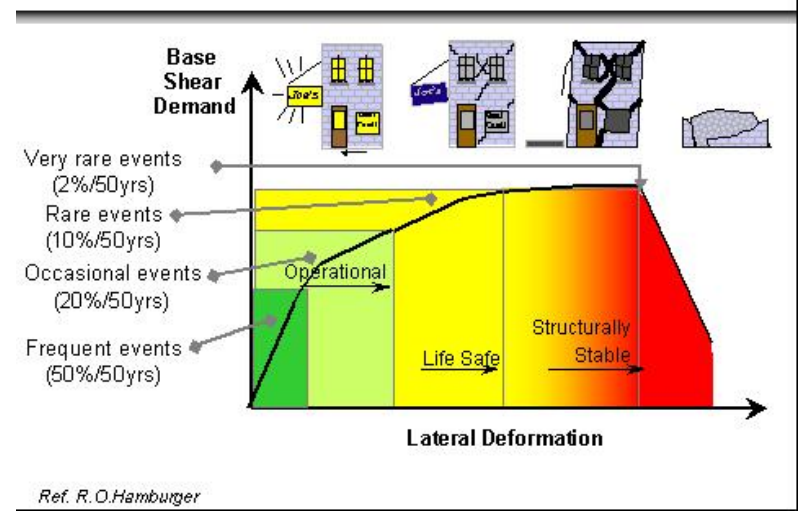

Key Attributes of Performance Based Approaches

- More Scientific \& Transparent

- Address Stakeholder Decision Needs

- multi-level decision-oriented performance objectives

- Consistent treatment of risk and uncertainties 
PBEE Methodology Components

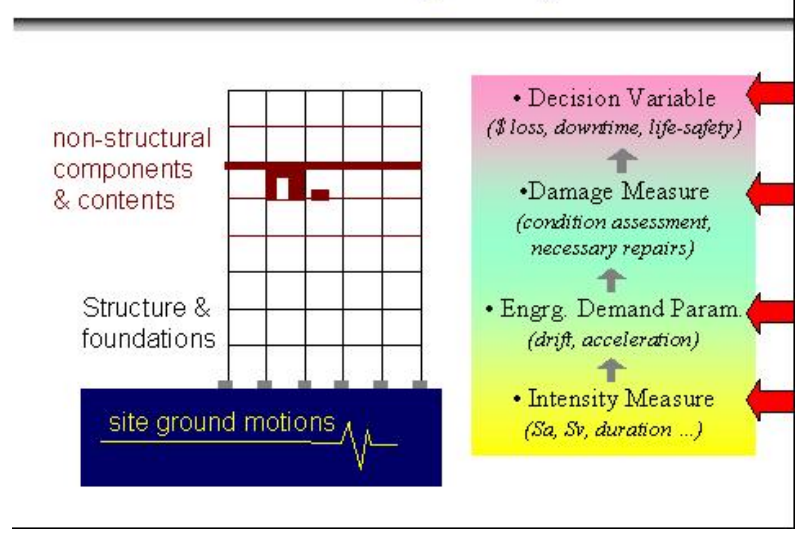

Hazard Intensity Measure (IM)

Current Practice: Spectral Acceleration $\mathrm{S}_{\mathrm{a}}\left(\mathrm{T}_{1}\right)$

USGS Hazard Curves

IMpped Foult Locations

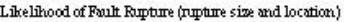

Probabilistic Mngnitude Prediction (M)

Distance (R) to Site

Atteruation Relationstips: $\mathrm{Sa}(\mathrm{T})=\mathrm{fon}(\mathrm{M}, \mathrm{R}, \mathrm{T}$, soil $\ldots)$

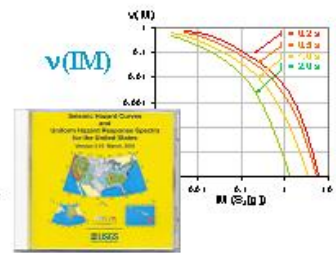

Static Analysis: $V \propto S_{\alpha}\left(T_{1}\right)$

Dynamic Analysis: scale records to $S_{a}\left(T_{1}\right)$ ?

\section{PBEE - Probability Framework Equation}

$v(D V)=\iiint G(D V|D M\rangle|d G\langle D M \mid E D P\rangle| d G\langle E D P \mid Z M\rangle \mid d \lambda(Z M)$

Impact Performance (Loss) Models and Simulation Hazard

MM-Intensity Measure

EDP Implementation Through

DV-LRFD-like Format:

$\left.\underset{\text { (e.g, Mean A }}{\nu(\mathrm{DV})-\text { Prob }} \gamma_{\mathrm{D} \mid \mathrm{S}_{\mathrm{a}}} \cdot \hat{\mathrm{D}}_{\mathrm{S}_{\mathrm{a}}} \leq \phi_{\mathrm{C}} \cdot \hat{\mathrm{C}}\right]$ riable

Mean Annual
IM to EDP via "Incremented Dynamic Analysis"

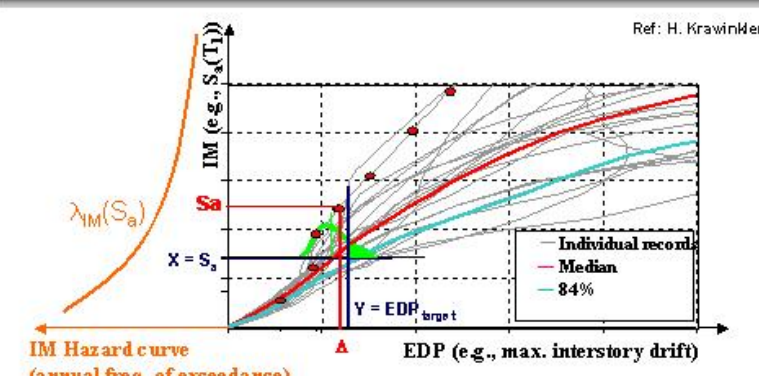

(anuual freq. of exceedance)

$$
\lambda_{\mathrm{EDP}}(\mathrm{y})=\int \mathrm{P}[\mathrm{EDP} \geq \mathrm{y} \mid \mathrm{IM}=\mathrm{x}]\left|\mathrm{d} \lambda_{\mathrm{IM}}(\mathrm{x})\right|
$$

\section{EDP Hazard Curve (Interstory Drift)}

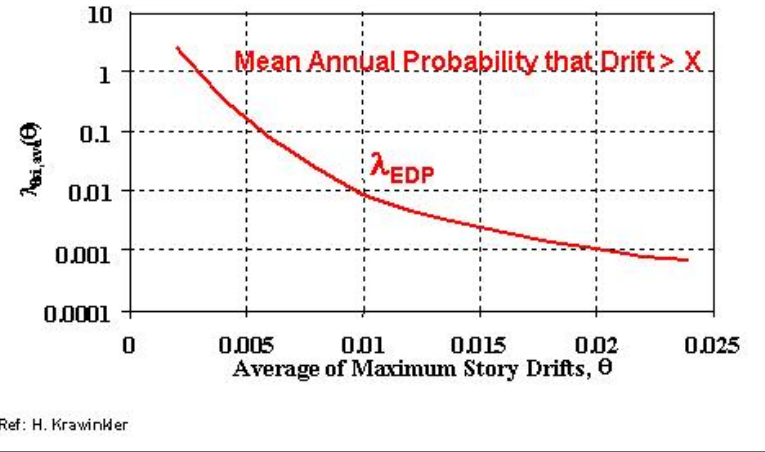

\section{Damage Measures}

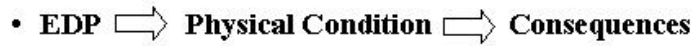

- Physical Condition

- cracking spalling, rebar buckling, ...

- component failure, tipping, ...

- Consequences

- repair measures (minor to major replacement)

- life safety issues (e.g.,chemical release, falling hazards, etc. )

- functionality (e.g., bridge alignment) 
Damage Measure of Structural Components

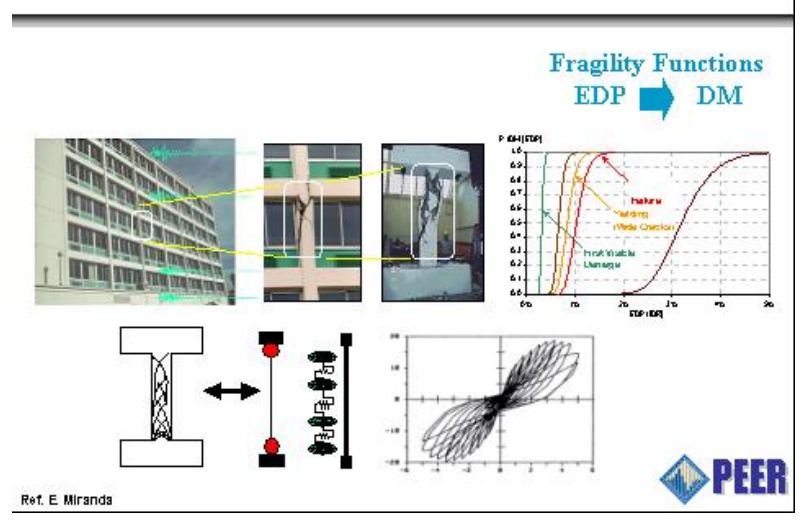

Performance Assessment \& Decision Making

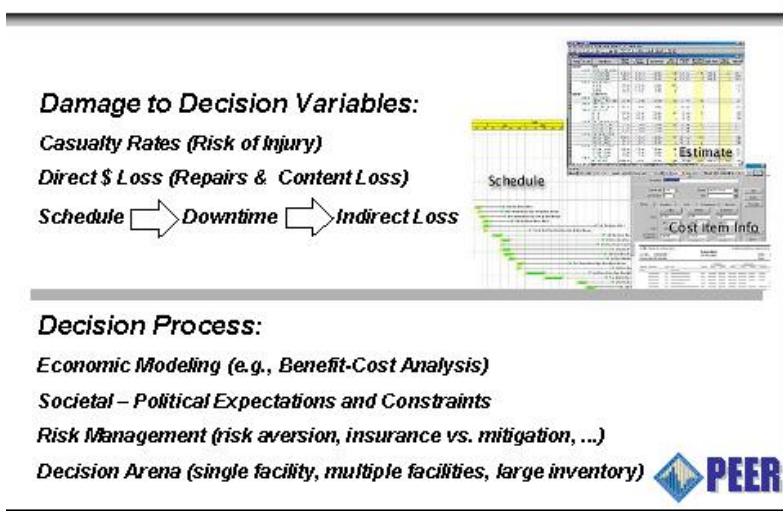

DM of Nonstructural Components

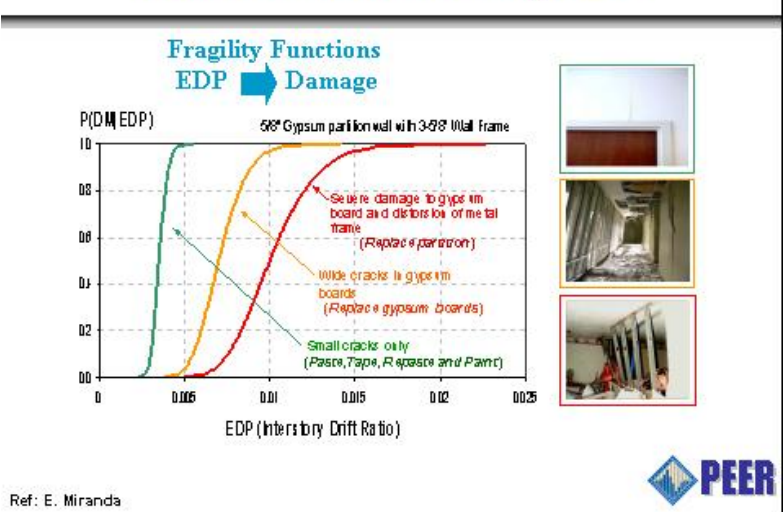

OpenSees - Integrated Simulation Platform

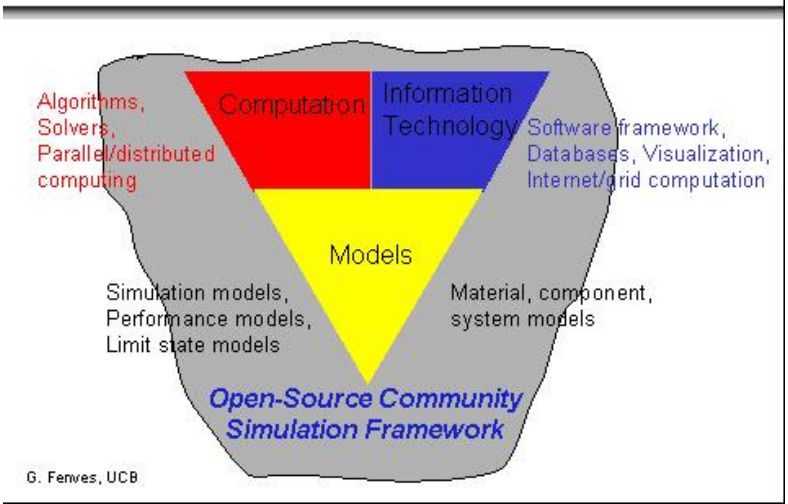

PBFE Methodology Components

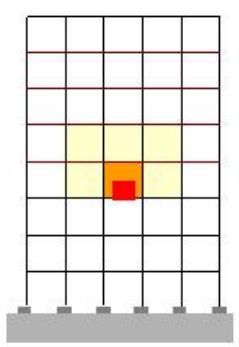

- Decision Variable $\uparrow$

-Damage Measure (condition assessment necessary repairs) 1 1

- Intensity Measure (\$loss, downtime, life-sajety)

- Engrg. Demand Param. (temperature?, deflections?) (Fire Load? Compartment temperature? Material Temperature?

Question: Who is the methodology geared toward-fire modeler, structural engineer, mechanical engineer?

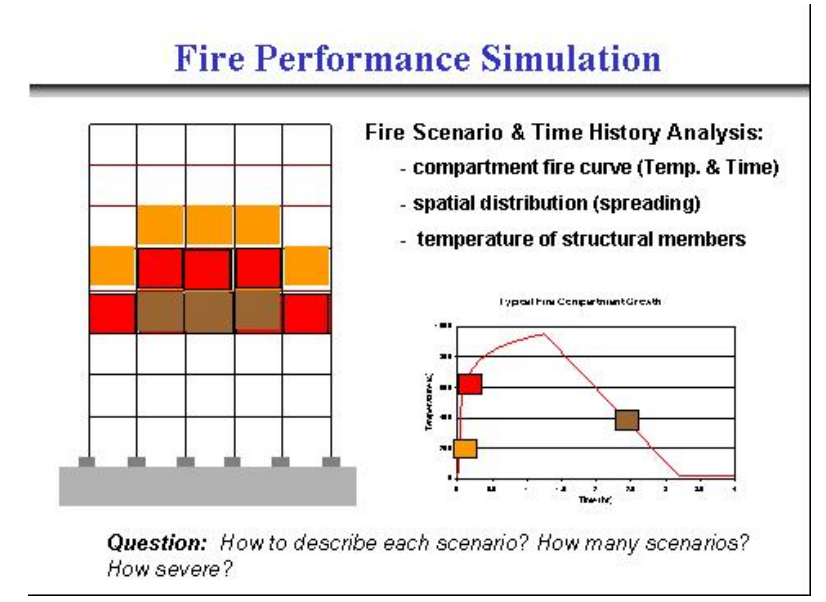




\section{Intensity Measure?}

- Fire Load, Ignition, Growth Parameters?

- Fuel load, ventilation, compartment size, ..

- Compartment Temperature (fire curve)?

- Steel Temperature ?
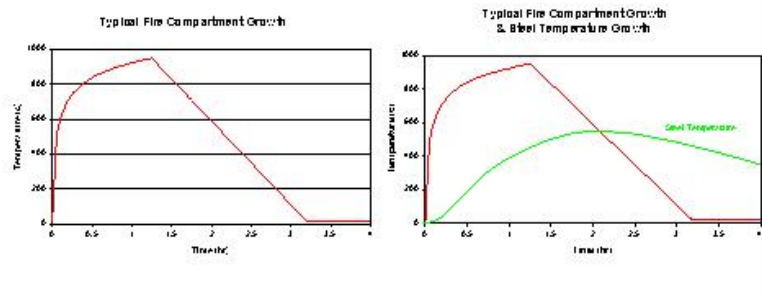

\section{Engineering Demand Parameters?}

- Global Deflections (sag, drift, ...)

- Local Deformations (hinge rotations, strains,...)

- Component Forces

- "Hidden" effects (residual stresses, loss of material integrity, etc.)

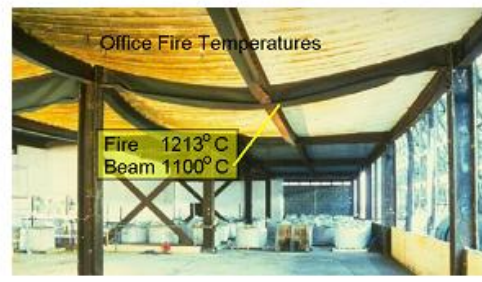

BRF Website, 2001

\section{Structural Simulation (IM to EDP)}

- Material and Geometric NL Response

- member and frame stability

- Temperature Loading Input

- temporal and spatial

- Temperature Effects

- thermal expansion

- material degradation (Fy, E, other ...)

Question: How faithfully can (must?) global analysis model localized degradation (members, connections, composite action, ...)

\section{Damage Measures}

- Safety - Collapse or Partial Collapse

- Repair - member distortion, out of plumb, deck debonding, other loss in strength/stiffness
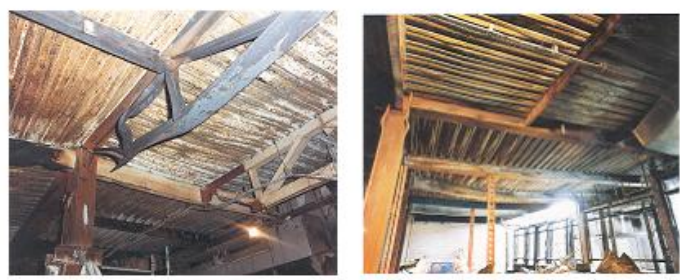
SCI Investigation of Broadzate Phase 8 Frie, 1991

\section{Decision Variables}

- Casualties (injury or death)

- building inhabitants

- emergency responders

- Repair Costs

- contents, nonstructural, structural

- correlations (water/smoke damage, burning, collapse)

- Downtime (repair time)

Big Issue: Risk tolerance (earthquake versus fire) Issues: Minimum protection and benefits of higher performance levels

\section{Issues and Needs}

- Comprehensive Methodology

- consistency with other hazards (earthquake, wind, ...)

- consistent with evolving code provisions (e.g., stability)

- Probabilistic Fire Hazard Assessment

- or scenario (worst case) fire?

- Codification of Acceptance Criteria

- explicit Decision Variables (casualty, \$, downtime rates)

- component strength checks (calibrated)

- survival duration

- Structural Simulation Tools

- Validation (lab tests and field reconnaissance) 


\section{Q. A Consultant's Wish List for a Numerical Model of Structural Response to Fire Conditions Barbara Lane, Arup Fire \\ London, UK}

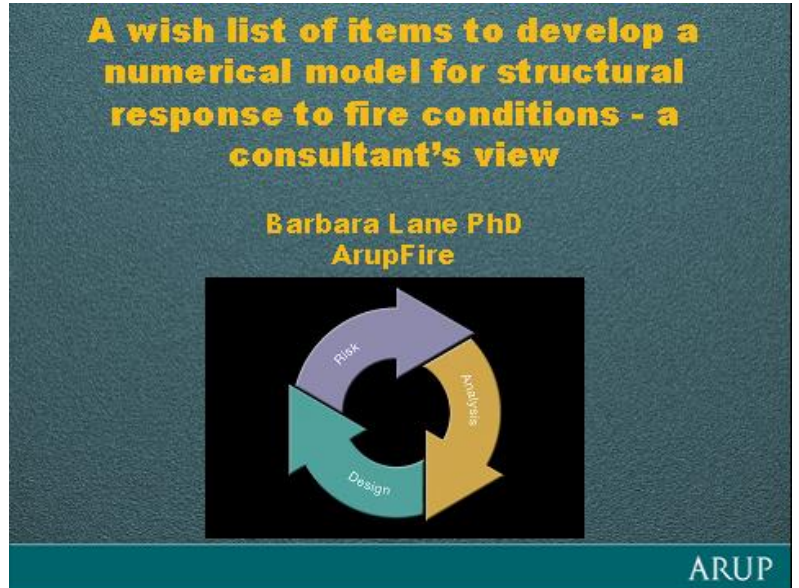

\section{Agreed?}

\section{Concerns with the Standard Test}

> Temperature / time relationship not the same as real fire behavior

$>$ Structural response AND fire protection materials response

- But what about huge body of data existing?

- How can we (Should we??) relate this data to a numerical mode for structures in fire?

> Do we need a new test?

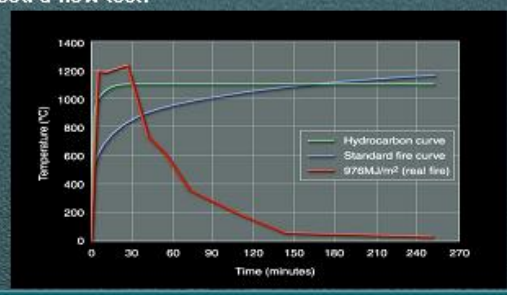

\section{Advanced Calculation Models}

$>$ In Europe principles laid out in, for example

$>$ Eurocode 3 Part 1.2 Structural fire design

$>$ CIB W014 Rational Fire Safety Engineering Approach to Fire Resistance in Buildings

$>\ln$ USA

$>$ Subject of AISC work, ASCEISFPE work, new NIST program of work

\section{Information required}

Reference document for consultants, authorities having juris diction etc

Stating design objectives, means of achieving acceptable results

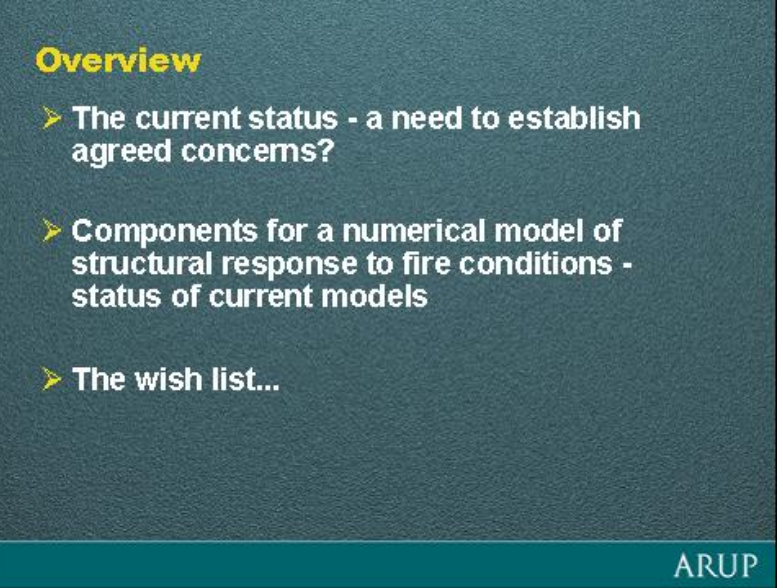

\section{Agreed?}

Mechanical response not addressed

$>$ Single elements tested

$>$ In general single elements "analyzed"

$>$ So real frame behavior ignored

$>$ For example:

> Effects of restrained thermal expansion

> Load transfer through connections to cooler elements

> Slab action identified in the Cardington tests as key to increase in overall strength of composite frames in fire

But what about other assemblies - non Cardington frames?

$>$ Single element analysis cannot capture these responses -is this the case?

$>$ Current FE modeling techniques just beginning to capture complex responses - but not part of "mainstream" design work

\section{Summary of Advanced Method}

1. Thermal Action/Design Fire

Do we:

Create new standard fire resistance test? Use temperature-time relationships from real fire data?

Use Natural/Real fire calculation: fire load, ventilation, boundary properties etc?

\section{Information required:}

Clear guidance on design basis fires 


\section{Summary of Advanced Method}

\section{Thermal Response}

Using defined design fire, calculate heat transfer to structural elements

Results in a temperature field in each structural element Information required:

Have existing heat transfer models been assessed?

Do we need new heat transfer model for current construction materials?

To what detail do we need a temperature profile along the length and through the cross-section of each structural element?

How do we assess protected structural elements?

\section{Summary of Advanced Method}

3. Mechanical Response, as a result of design fire Structural elements losing strength and stiffness

Restraint to thermal expansion produces compression forces

Higher restraint leads to greater deflections

Through depth thermal gradients imposing curvature (bowing)

Combinations of thermal expansion, bowing and restraint conditions can produce large range of deflection and internal force patterns

\section{Summary of Advanced Method}

3. Mechanical Response, as a result of design fire Information required:

What model captures these effects for all construction assemblies?

Is there a means of carrying out a single element analysis that summarises these effects?

Can these models be translated into simple tables for mainstream design?

How can we incorporate the new understanding and future understanding into existing building codes?

\section{Existing Numerical Models}

It is not simple

Intensive work for 10 years in Europe only starting to make progress now

Essential to build on this work rather than start again

Not in format at this time that is useful in a design office

\section{Status of current models}

- Vulcan - University of Sheffielo

- Composite steel framed buildings only

- Validated using Cardington results

- Geometric and material nonlinearities included

- Plate elements used to simulate floor slabs

- Stress resultant issues?

- Shear connectors incopporated using?

- Beam-column element to simulate beams and columns

- Spring elements to simulate steel-to-steel connections

- Reinforcement modelled?

Heat transfer analysis not part of Vulcan - data incorporated from other sources

- Temperature non-uniform through cross-section but not along length for steel? Same for concrete?

- Implicit analysis

\section{Status of current models}

ABAQUS - University of Edinburah

Composite steel framed buildings only

Validated using Cardington results

Geometric and material nonline arities included

Shell elements used to simulate floor slabs

Stress resultant approach to describe behaviour of shells

Shear connectors incorporated using rigid elements

Beam-column element to simulate beams and columns??

Pins used to model steel-to-steel connections

Reinforcement included in slab as a smeared model

Heat transfer analysis part of ABAQUS but not used by Edinburgh Eurocode for Steel, HADAPT for concrete

Temperature non-uniform through cross-section but not along length for steel

Line ar through depth gradient assumed for slab heating?

Implicit analysis. ABAQUS explicit now exists 


\section{Status of current models}

- SAFIR, CTICM models should also be reviewed

- What about explicit models such as LS - DYNA?

- Each elements solved individually - can assess collapse even when some components no langer have stiffness

- Can cope with highly non-linear problems

- More computing power and time required

- Thermal analysis possible in parallel with mechanical analysis

Information required

Capability of each model to date - what it can and cannot do, what aspects of each model holds the advantage?

\section{This wish list....}

- Agree coneernsissues/inaccuracies

- A reference document laying out acceptable principles required for $\mathrm{AHJ}$, consultants etc

- Establish design fire - criteria/data/model/input for codes

- Establish heat transfer analysis capabilities

- Compare and contrast existing 3D FE models

- Further develop these models to address complex behaviours associated with structural response to fire - not just Cardington type frame, not just office fire load, etc

- Develop commercially possible analysis tools - is it possible to reduce time/complexity of analysis once further understanding obtained?

- Develop means of translating results into quantifiable results for Building Codes, into simple design methods 


\section{R. Summary of Red Breakout Session}

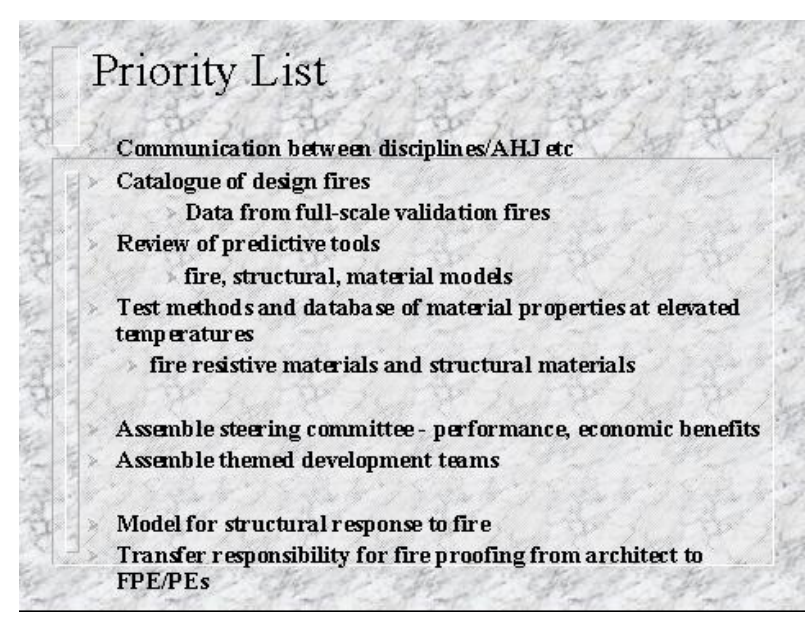

\section{Limitations/research needed}

Installation

assess effects of material variability on installed performance

\section{Test methods}

lack of understanding of science underlying existing methods and use of data derived

Extrapolations of single element test to complex assemblies Many current test methods not well suited to collecting useful data

new fire tests addressing the gaps

using existing tests and current data essential

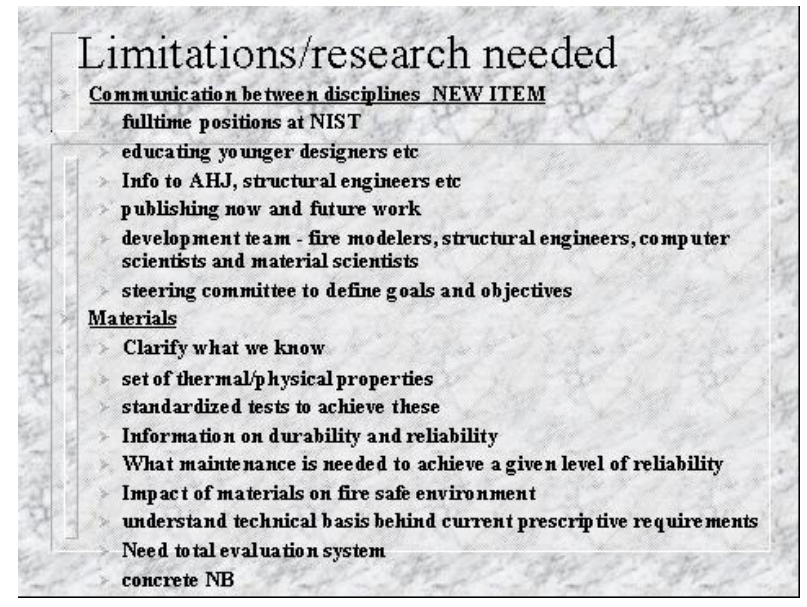

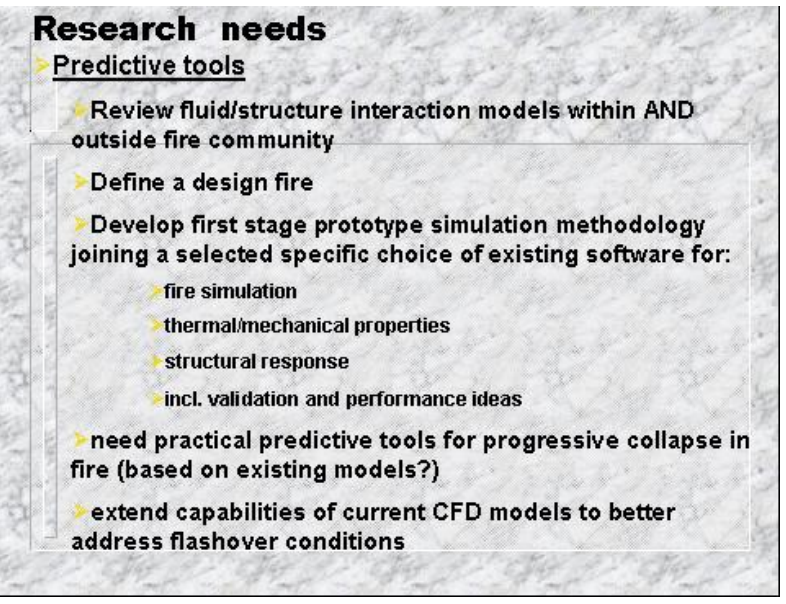

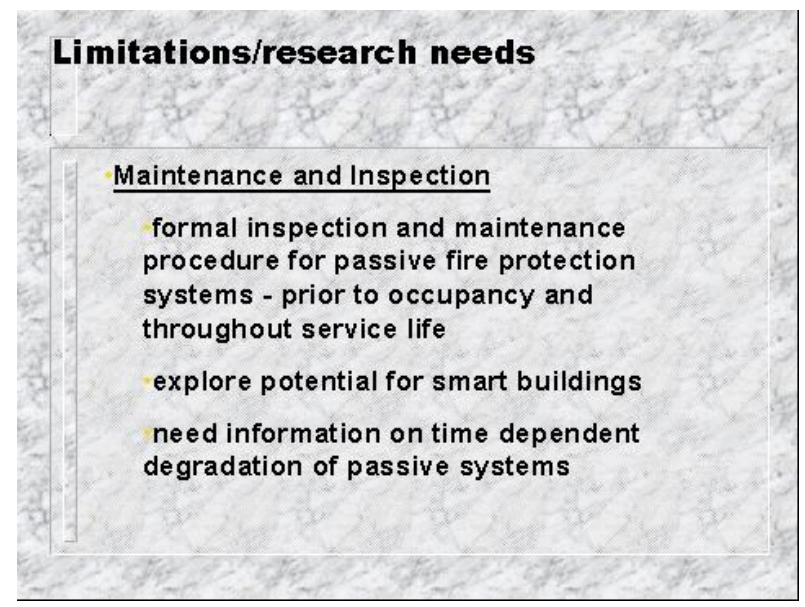




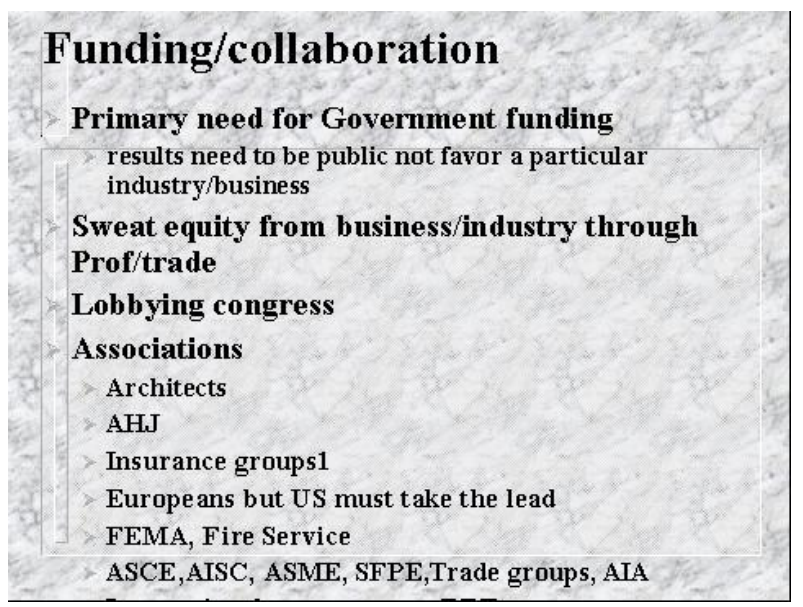




\section{S. Summary of Blue Breakout Session}

\section{End Products}

- Validated Engineering Tools

- Design Framework for new construction

- Design for retrofitting existing construction

- Integration of structural and fire: performance based design

- Education of engineers, designers, AHJs (Make them work together)

\section{Uncertainty/Reliability}

- How much uncertainty is acceptable, i.e. sensitivity of response to the uncertainty - Depends on objective

- Development of a standardized process for uncertainty quantification and analysis techniques

- Integration of fire mitigation strategies

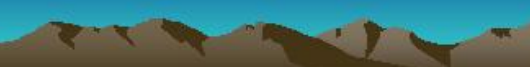

\section{Predictive Tools, cont.}

- Heating of the Structure - Structural Materials

- Thermalimechanical properties as a function of temperature and temperature rise

- Steel: A36 and similar (what are similar, for example HSLA) creep at very high temperature

- Special steel (light gage steel, high strength/performance steels, welds, bolts, rebar, pre-stressing) - all properties

- High Strength Concrete -

- Normal Strength Concrete -

- FRPs, Aluminum, timber, glass etc - all properties

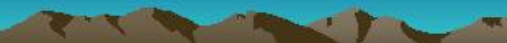

\section{Predictive/Design Tools}

- Fire Growth - we could use approaches such as

- Stick with specified, space independent model

- Use simplified approach (including space/opening effects)

- CFD Model

- Can't be used for direct routine design but can be used to develop design tools and for special design issues

- Bottom line, need to establish and define need based approach
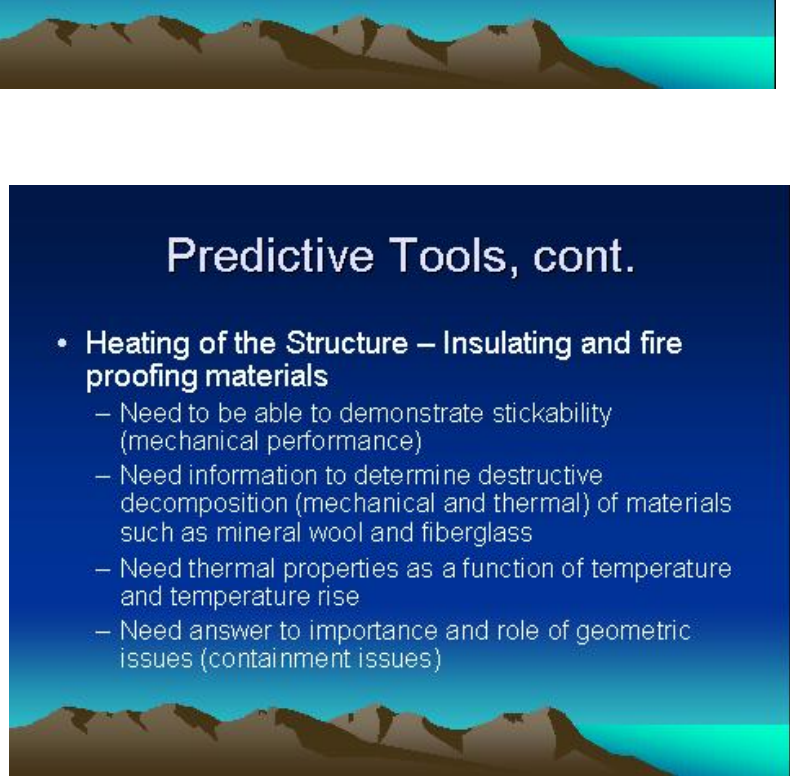

\section{Predictive Tools, cont.}

- Validation of existing structural response tools for assemblies (including connections) and systems under fire conditions (including soot and other fire phenomena effects)

- Development and validation of structural response engineering sub-models for specific fire phenomena

- Fire barrier analysis and design 


\section{Predictive Tools}

- Structural Response

- Need incorporation of high strength concrete behavior in analysis and design

- Need knowledge to develop a simplified model; this then needs to be validated

- Need to know how to apply the "fire load" as a load combination to the entire structure.

- Need to define design limit states (i.e. objectives of design)

\section{Experimental Studies}

- Establish methods for validation

- Develop improved fire measurement technologies, esp. heat transfer

- Evaluate use of existing ASTM standard for fire model validation

- Develop standardized test methods for material property determination

- Develop standardized test methods for structural components such as connections.

\section{Other Objectives}

- Develop performance criteria for insulating materials

- In service issues including impact

- Maintenance and inspection over the life of the structure

- Develop performance criteria for structural materials, products and systems

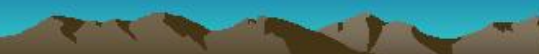

\section{Validation}

- Round Robin testing of models and experiments including material measurements

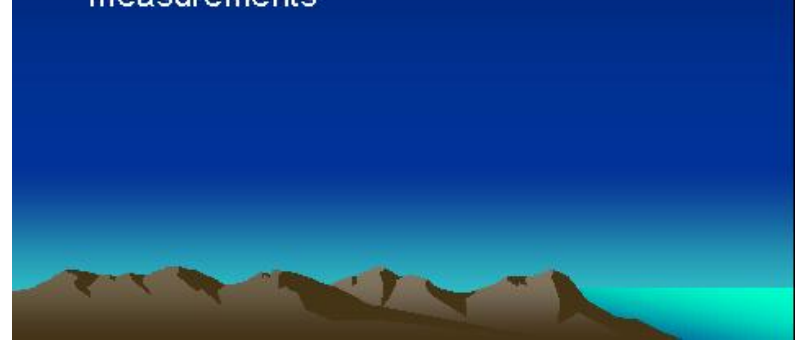




\section{T. Summary of Green Breakout Session}

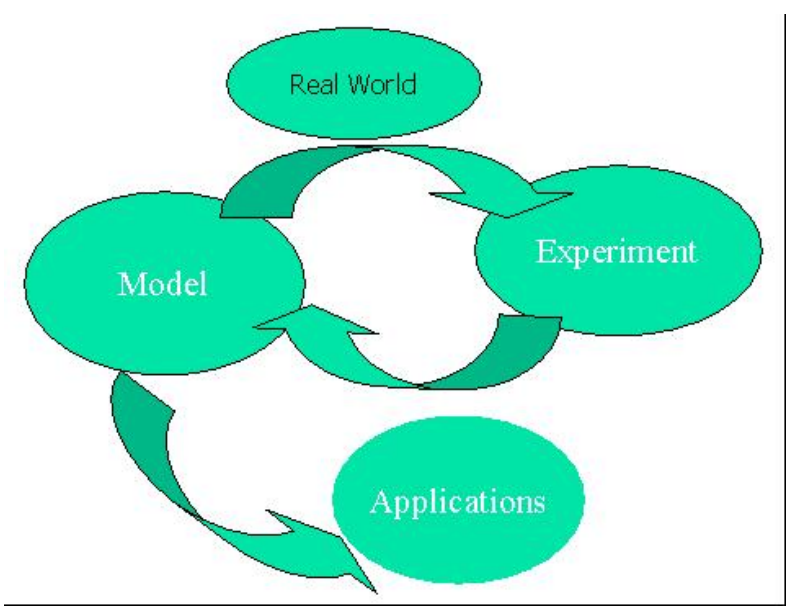

\section{Needs}

- Fire exposure

- Thermal response

- Structural response

- Mitigation strategies

- Redundancy

- Prevention

- Design with fire safety in mind

- Communications

- Engineers

- Consultants

- Regulators

\section{Fire exposure}

- Instrumentation of real fires to obtain better

- Fuel load characterization

- Impact of spatial distribution

- temperature/oxygen histories

- Heat flux

- Products of combustion

- Full cycle (heating and cooling) data

- Model behavior of non-structural elements

\section{Structural response}

- Deflections and stresses

- Connections

- Fire proofing materials

- Heating and cooling cycles

- Coupling fire and structural models

- Zone with frame models

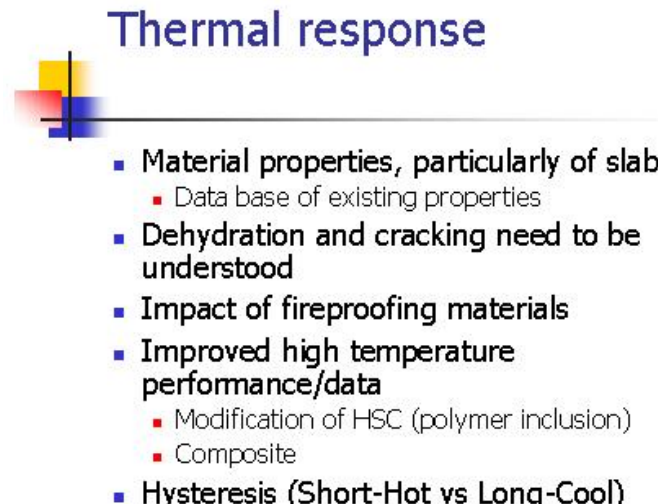

- Hysteresis (Short-Hot vs Long-Cool)

\section{Multiple level of models}

Couple models with experiments validation of models

design of experiments/measurements

Models of fundamental proper ties

Computational chemistry, molecular dynamics, crack development

Models of pyrolyis behavior

Impact of exposure history

Product distribution: heating content, environmental impact Models of behavior under prescribed temperature/oxygen histories Zone models

Need to model non-loading (glazing) as well as load-bearing Detailed CFD/Finites element models 


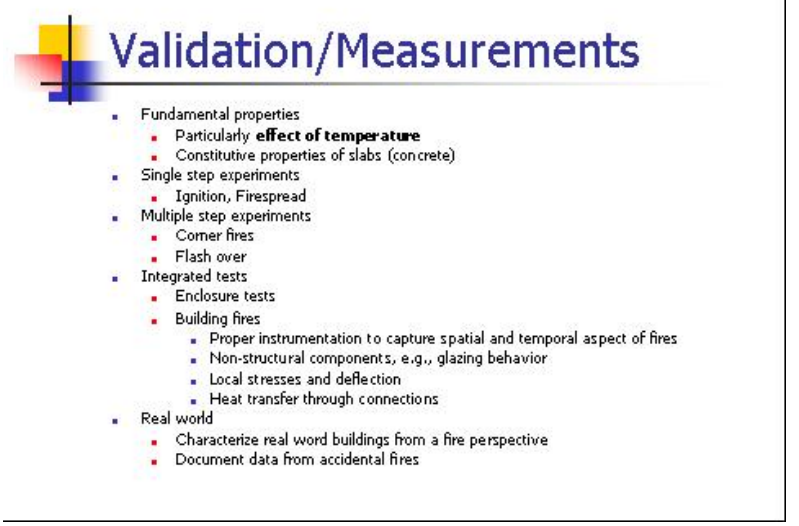

\section{- Performance Objectives}

- Performance prediction

- Test conditions versus real world

- Temperature time curves

- Real world has dimensionality, which has important implication that determines the response

- e.g. plume impacting on the ceiling has not deconvoluted convection and radiation; problems of flash over; impact of air availability

- Need to translate test results into real world situations

- Integrity of fire walls major factor

- Fire test data need to be used to validate models

- There is need of data on more complex strutures

- Need to have data from small, to intermediate, to full scale 


\section{Performance-Based Analytical Prediction of Fireproofing Requirements in Complex Buildings}

\section{By Robert H. Iding}

\section{Wiss, Janney, Elstner Associates, Inc.}

Research Needs for Fire Resistance Determination and Performance Prediction National Institute of Standards and Technology

Gaithersburg, MD

February 19 and 20, 2002 


\section{Analytic Approach to Fire Safety Design}

- Possible fire exposures based on site-specific conditions (fuel load, ventilation, etc.).

- Temperature history during fire calculated by heat conduction computer programs.

- Based on calculated temperatures, fire endurance determined using structural analysis computer programs. 
HARDROCK CONC. FILL $\mathrm{f}_{\mathrm{c}}^{\prime}=20.7 \mathrm{MPa}(3 \mathrm{ksi})$

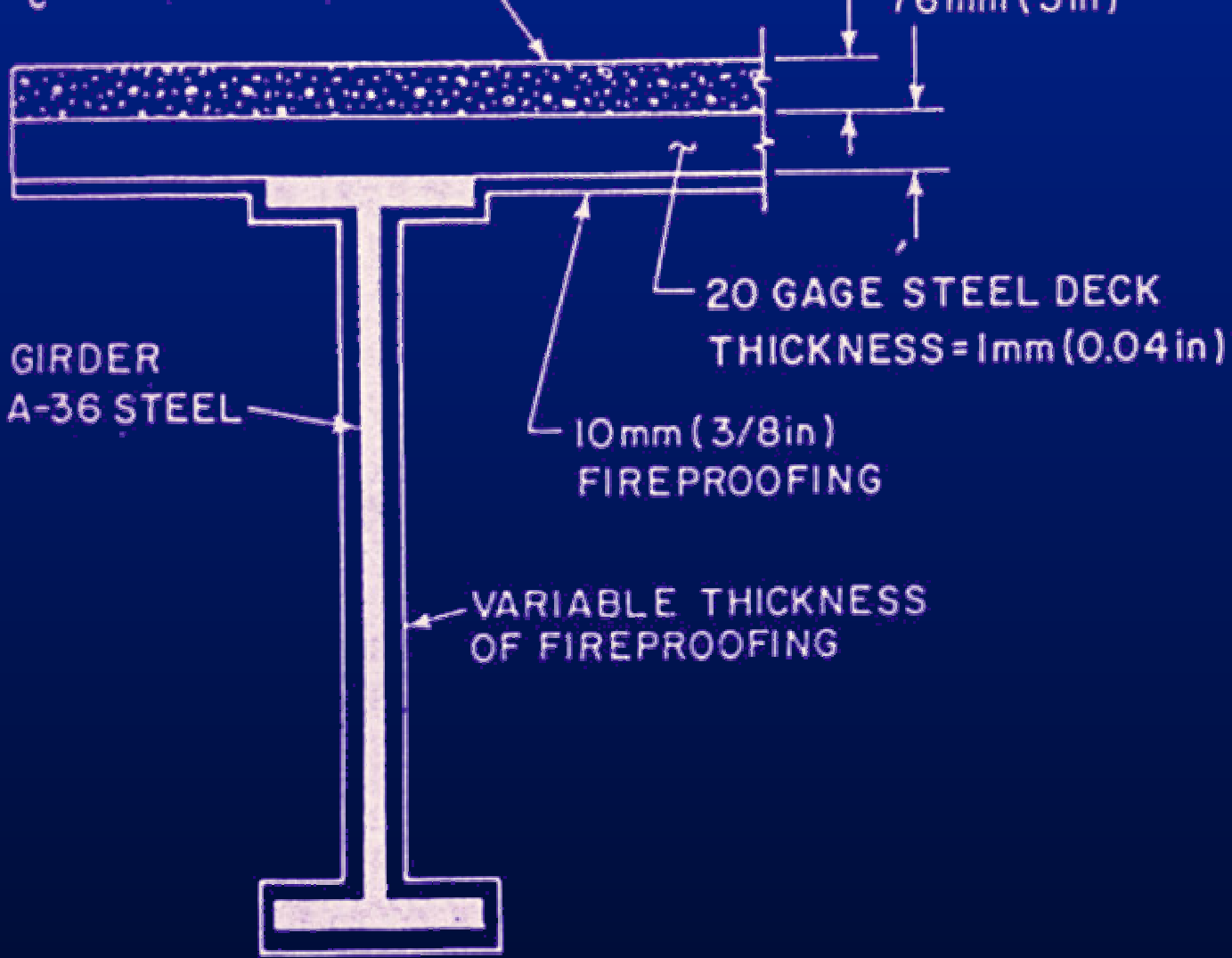

$1 q$

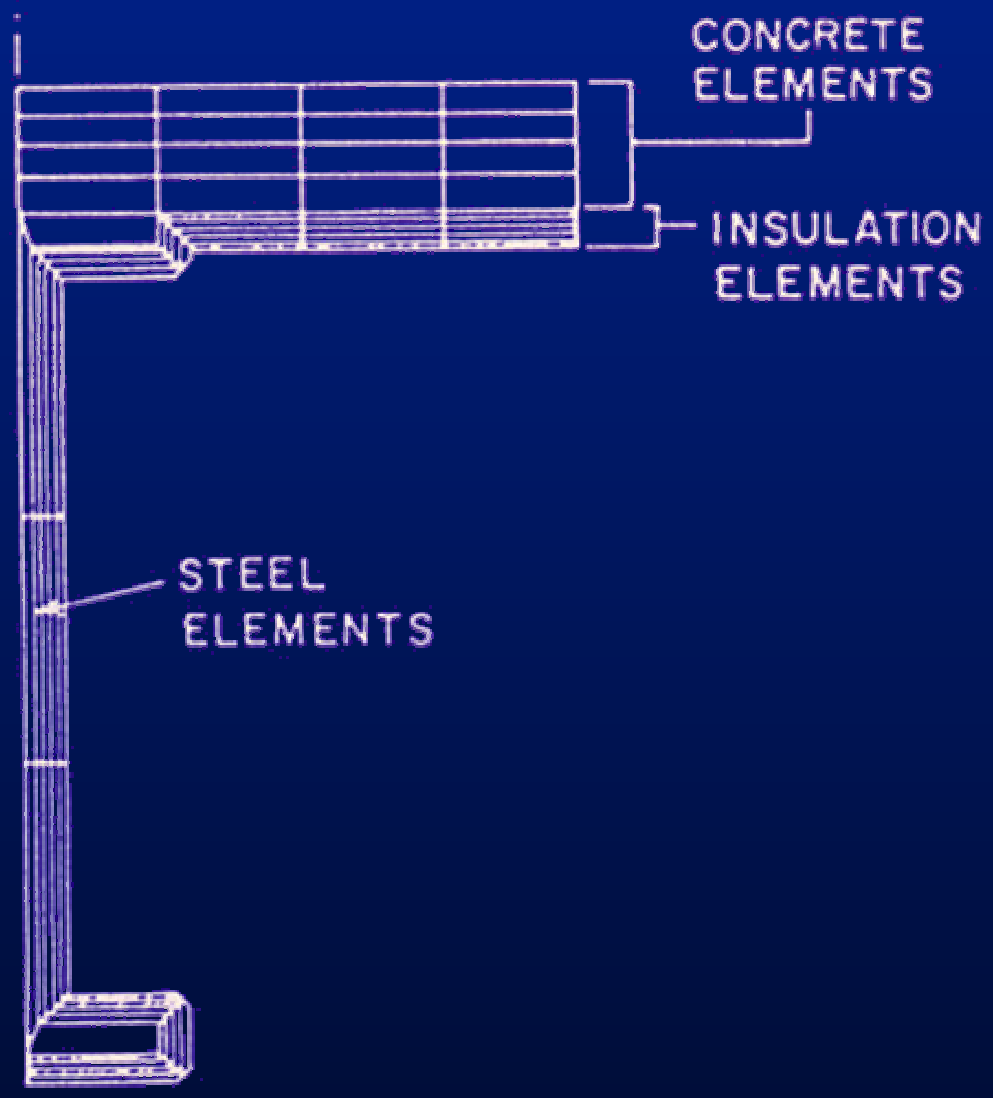




\section{Heat Conduction Equation}

$$
\rho \mathrm{C} \frac{\partial \mathrm{T}}{\partial t}+\mathrm{K} \nabla^{2} \mathrm{~T}=\mathrm{Q}
$$

where

$$
\begin{array}{rll}
\rho & = & \text { density of steel } \\
\mathrm{C} & = & \text { specific heat capacity of steel } \\
\mathrm{T} & = & \text { temperature distribution in column } \\
t & = & \text { time } \\
\mathrm{K} & = & \text { heat conductivity of steel } \\
\mathrm{Q} & = & \text { heat input into column } \\
\nabla^{2}() & = & \frac{\partial^{2}()}{\partial \mathrm{x}^{2}}+\frac{\partial^{2}()}{\partial \mathrm{y}^{2}}+\frac{\partial^{2}()}{\partial \mathrm{z}^{2}}
\end{array}
$$




\section{Fire Boundary Conditions}

$$
\mathrm{Q}=\mathrm{A}\left[\mathrm{C}\left(\mathrm{T}_{\mathrm{f}}-\mathrm{T}_{\mathrm{s}}\right)^{\mathrm{N}}+\mathrm{V} * \sigma\left(\mathrm{a} \varepsilon_{\mathrm{f}} \theta_{\mathrm{f}}^{4}-\varepsilon_{\mathrm{s}} \theta_{\mathrm{s}}{ }_{\mathrm{s}}\right)\right]
$$

where

$$
\begin{array}{lll}
\mathrm{A} & = & \text { surface exposed to fire } \\
\mathrm{C} & = & \text { convection coefficient } \\
\mathrm{N} & = & \text { convection power factor } \\
\mathrm{V} & = & \text { radiation view factor } \\
\sigma & = & \text { Stefan-Boltzmann constant } \\
\mathrm{a} & = & \text { absorption of surface } \\
\varepsilon_{\mathrm{f}} & = & \text { emissivity of the flame associated with fire } \\
\theta_{\mathrm{f}} & = & \text { absolute temperature of fire }\left({ }^{\circ} \mathrm{R}\right) \\
\varepsilon_{\mathrm{s}} & = & \text { surface emissivity } \\
\theta_{\mathrm{s}} & = & \text { absolute temperature of surface }\left({ }^{\circ} \mathrm{R}\right) \\
T_{f} & = & \text { fire exposure temperature }\left({ }^{\circ} \mathrm{R}\right) \\
T_{s} & = & \text { steel temperature }\left({ }^{\circ} \mathrm{R}\right)
\end{array}
$$




\section{Matrix Heat Conduction Equations}

$$
[C]\{T\}+[K]\{T\}=\{Q\}
$$

$[C]=$ Capacity matrix

(temperature-dependent)

$[\mathrm{K}]=$ Conductivity matrix (temperature-dependent)

$\{Q\}=$ External heat flow vector (depends on exothermic reactions and fire boundary conditions)

$\{T\}=$ Temperature vector (time-dependent) 


\section{Fixed Fire Hazards on Ground Floor}

\section{of Healy Power Plant}

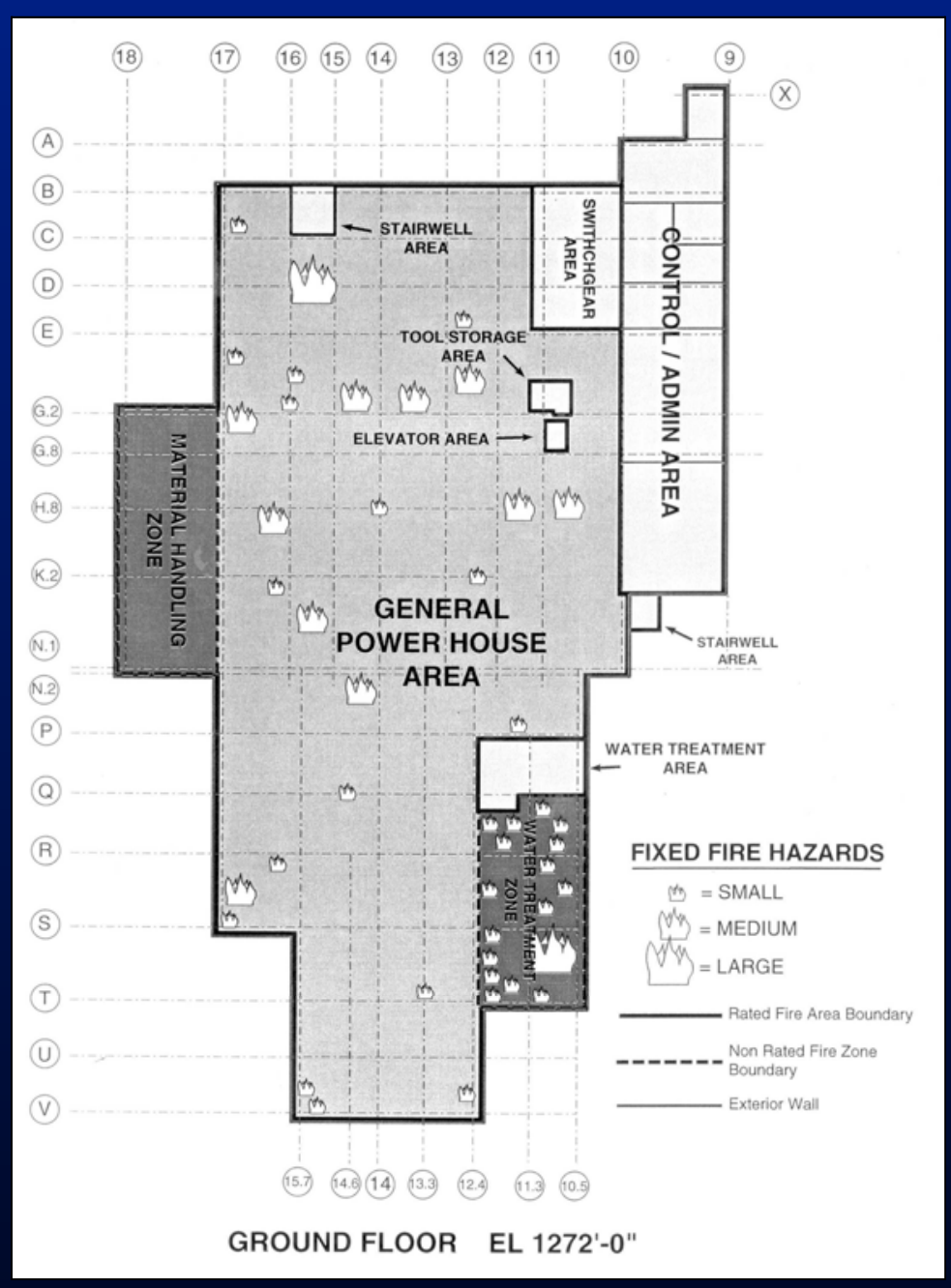




\section{Transportation Fire Hazards on Ground Floor of Healy Power Plant}

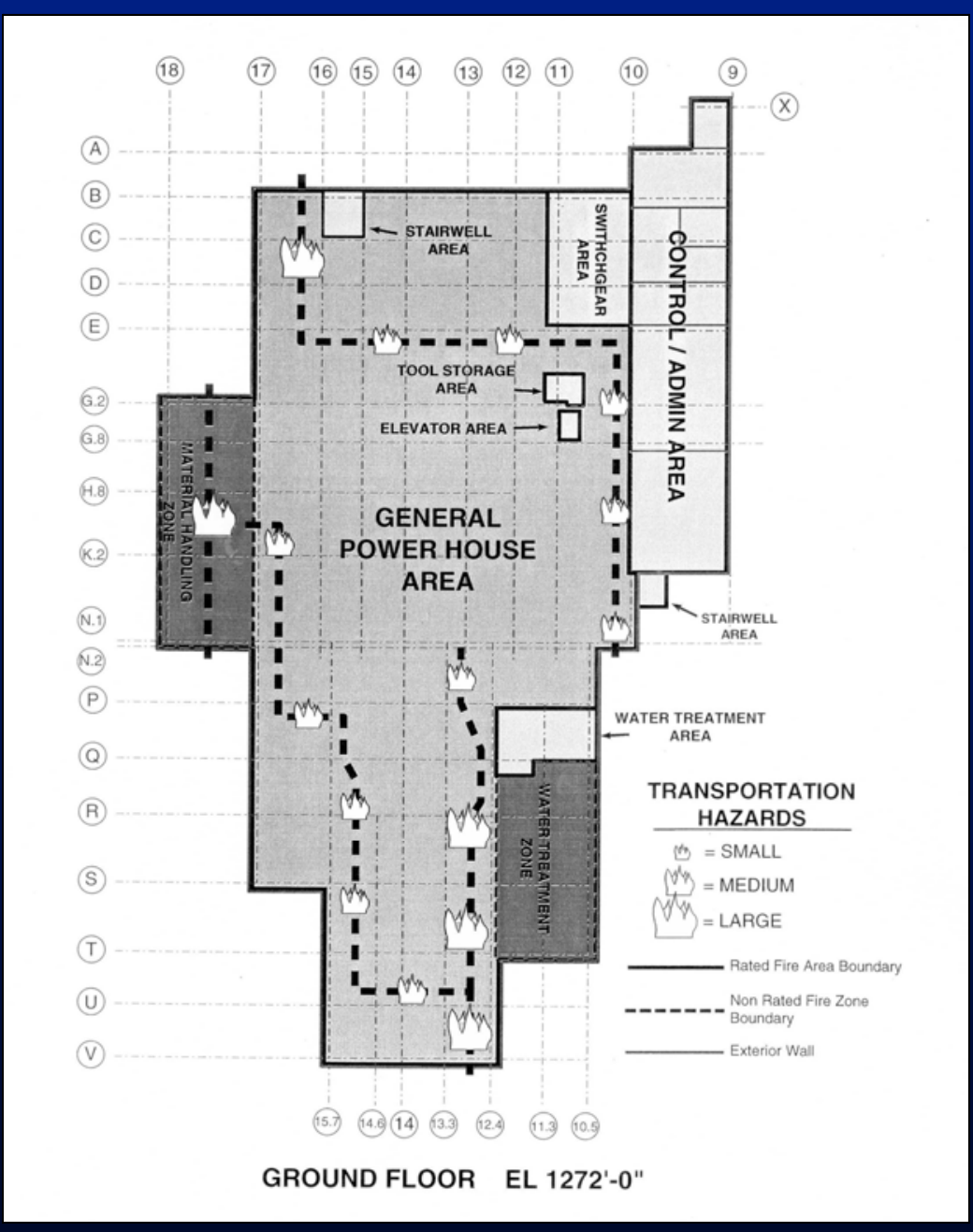




\section{Large Truck Fire Scenario}

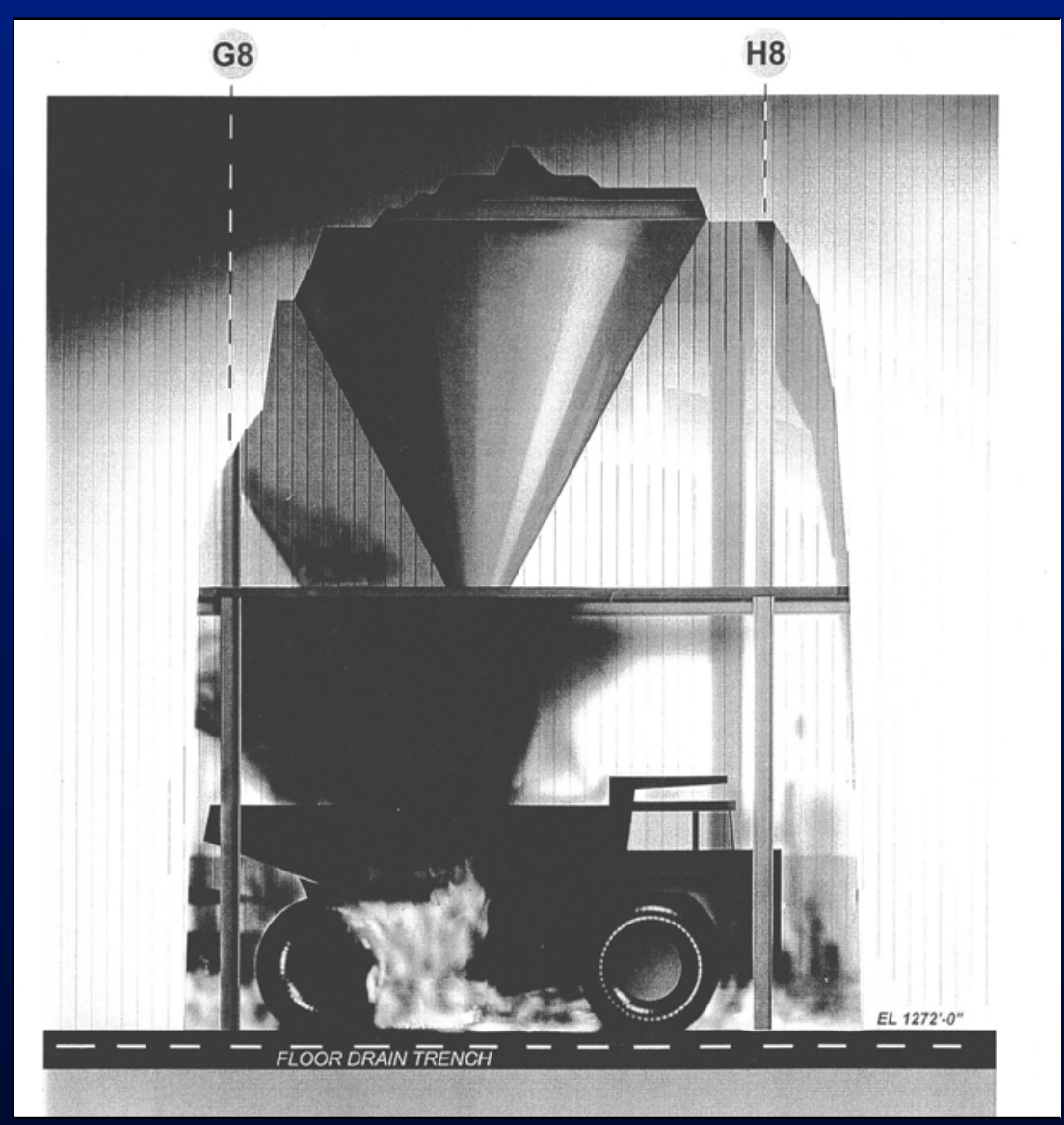




\section{Motor Control Center Fire Scenario}

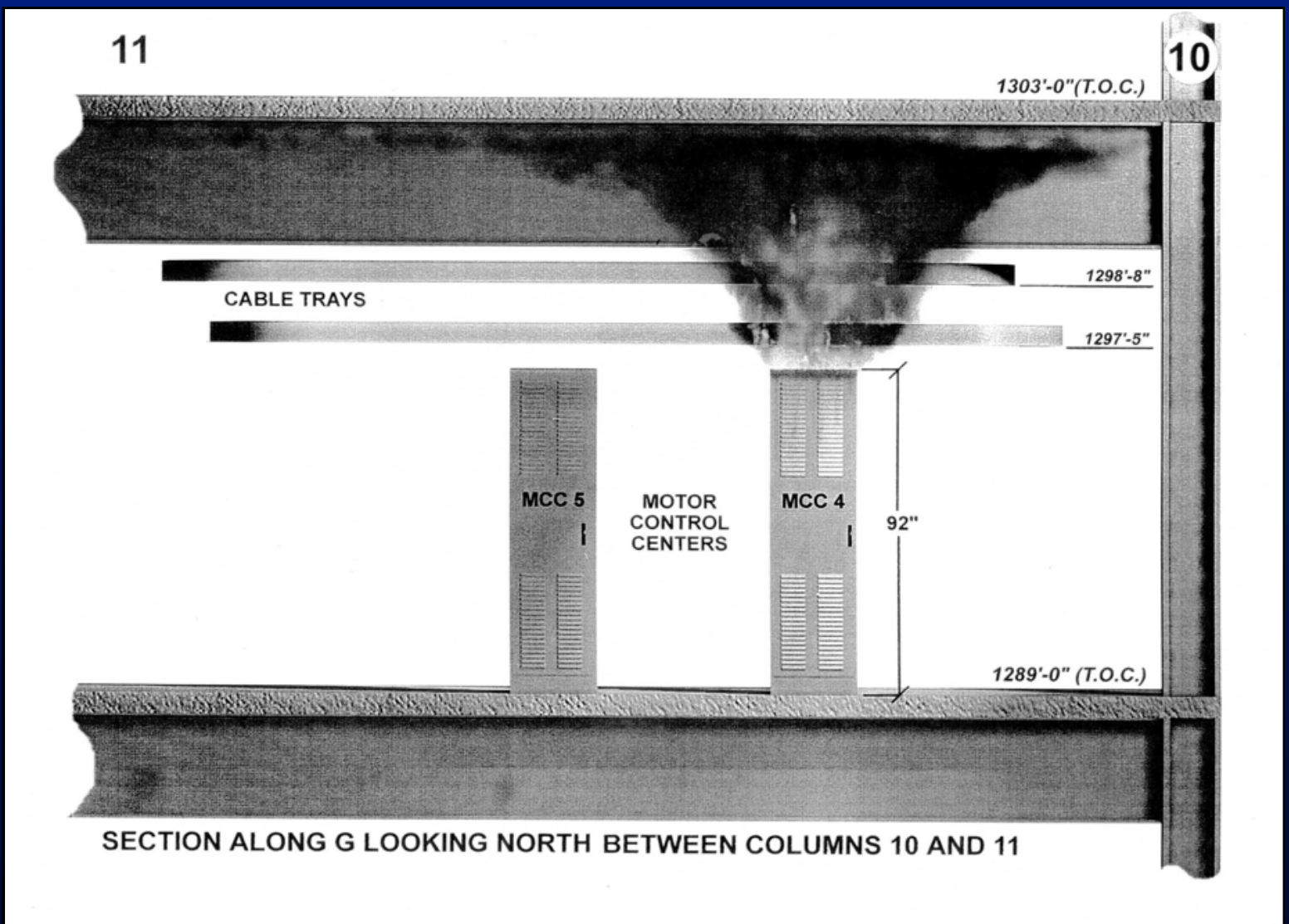




\section{Effect of Temperature on the Ratio}

Between Elevated-Temperature and Room-Temperature Yield Strength of Steel
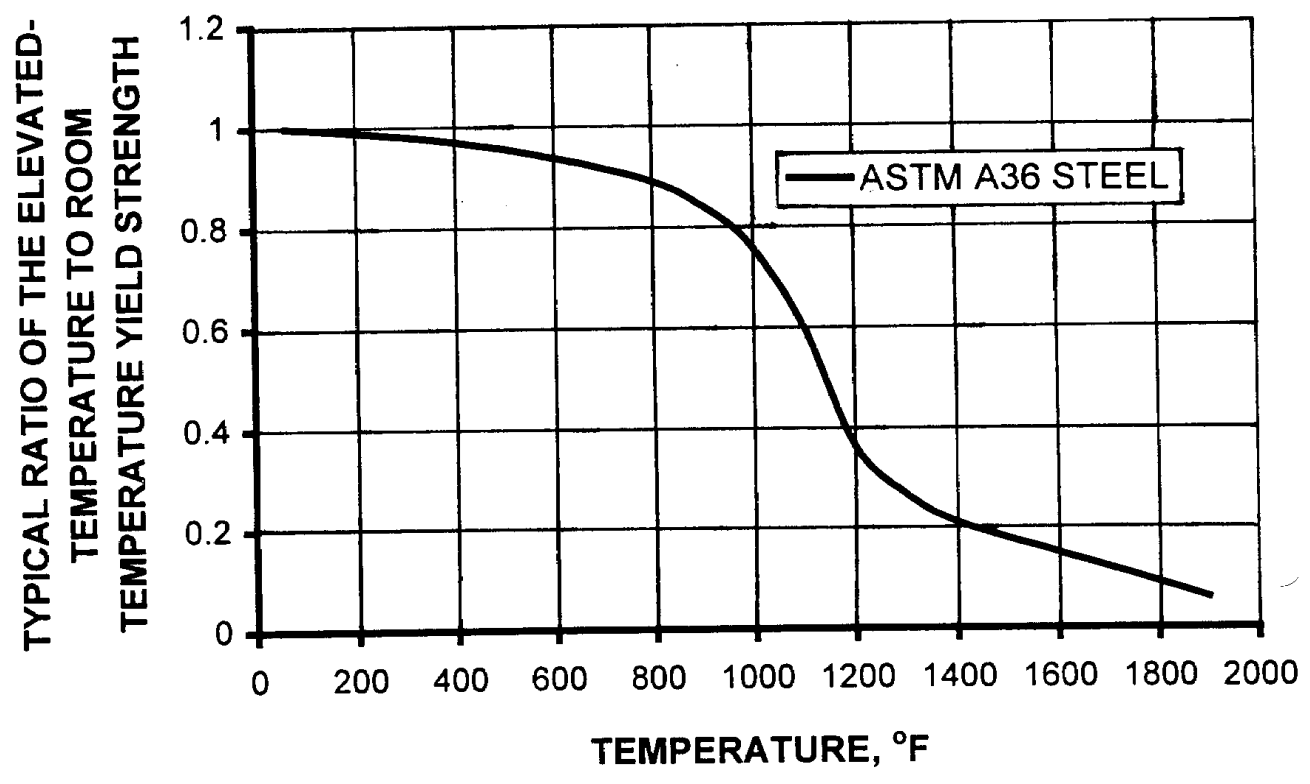


\section{Column Exposure Temperatures from Maintenance Refuse Fire}

\section{Plume Time-Temperature Profile}

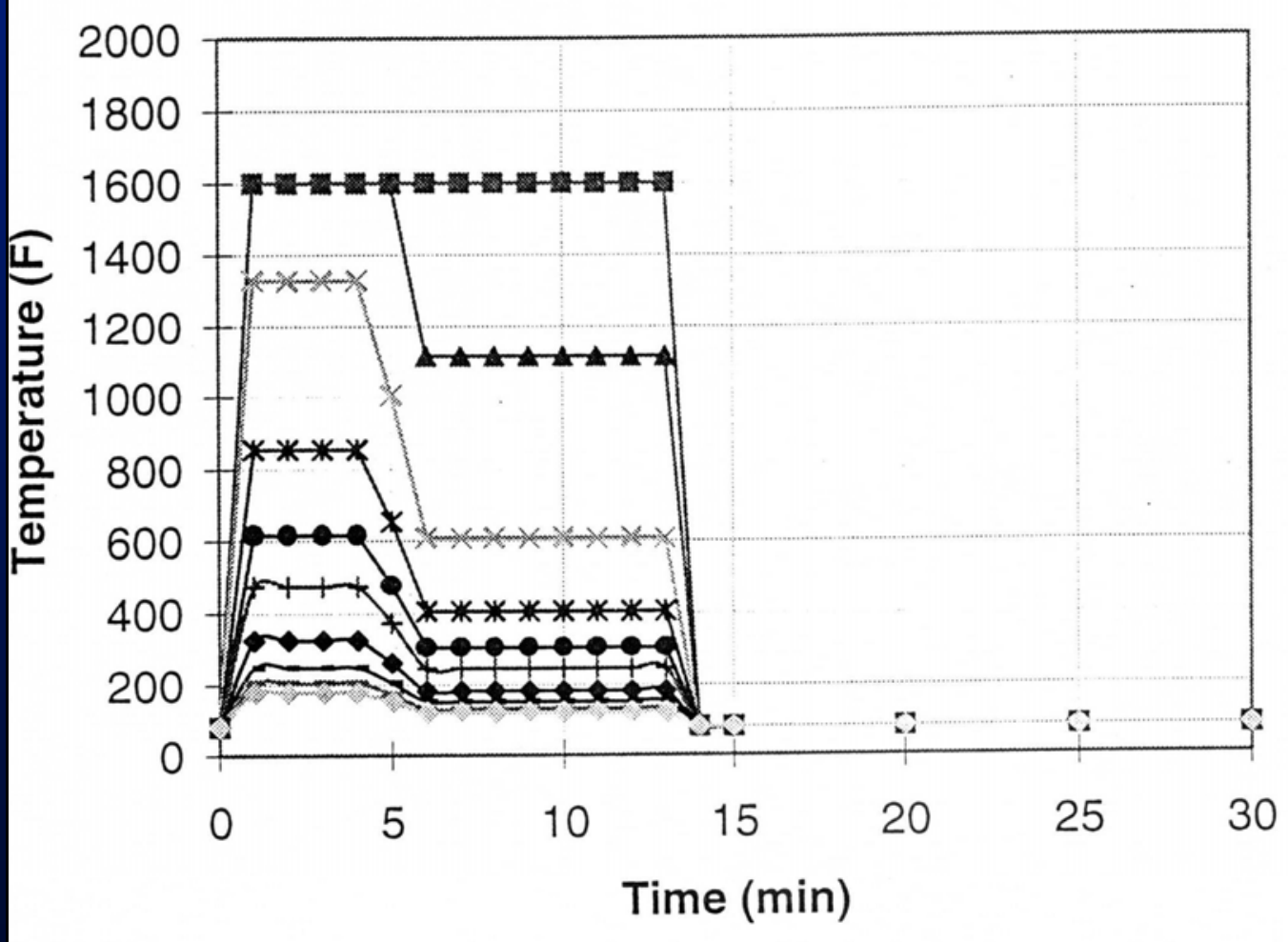

Target

Elevation

$-1 \mathrm{ft}$

$\rightarrow-2 \mathrm{ft}$

$-3 \mathrm{ft}$

$\rightarrow-4 \mathrm{ft}$

$\rightarrow 5 \mathrm{ft}$

$+6 \mathrm{ft}$

$\rightarrow-8 \mathrm{ft}$

$-10 \mathrm{ft}$

$-12 \mathrm{ft}$

$\rightarrow-14 \mathrm{ft}$ 


\section{Column, Adjacent Base Plate and Floor Slab Discretized into Finite Element Mesh}

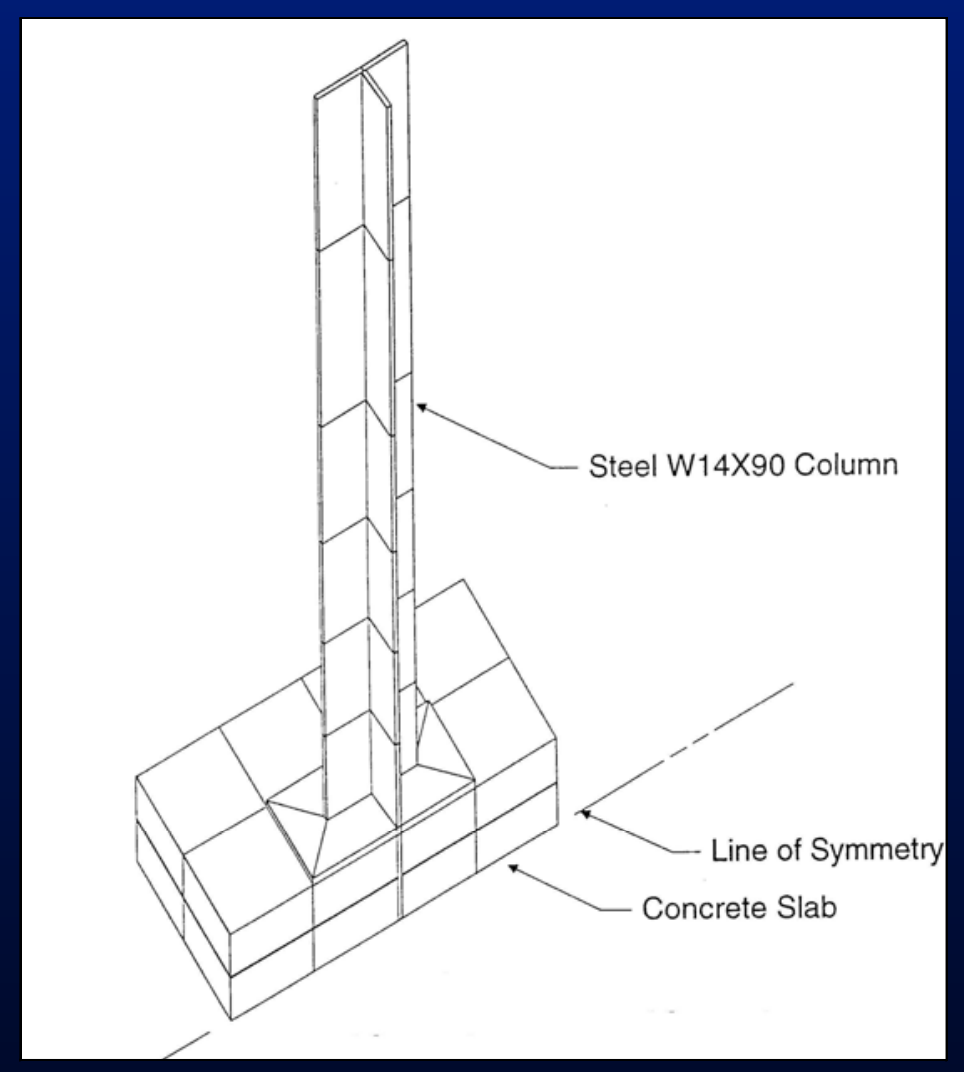




\section{Steel Temperature History for Maintenance Refuse Fire}

Steel Time-Temperature Profile

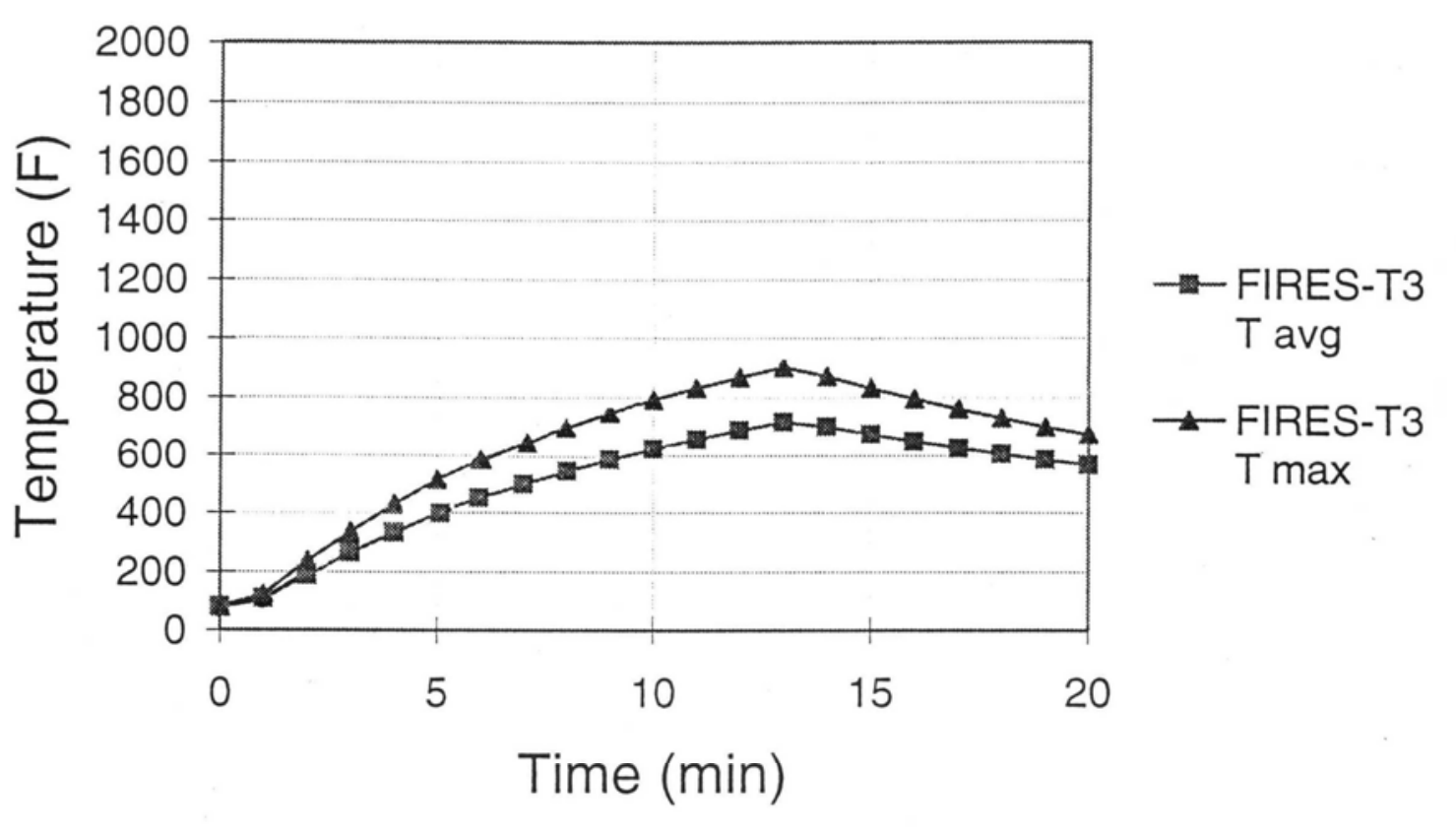




\section{Eiffel Tower II}

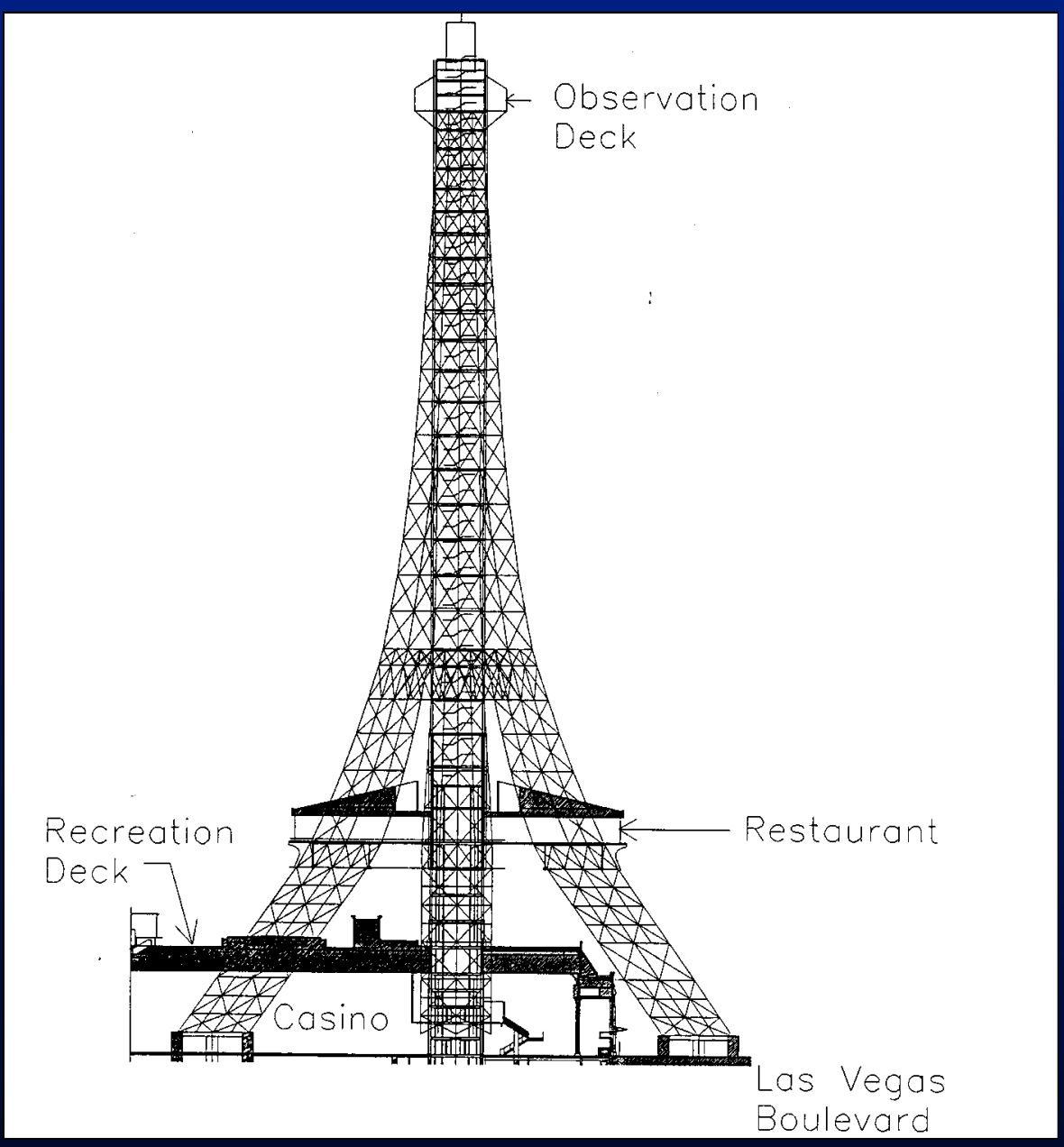




\section{Calculated Steel Temperatures in Eiffel Tower II for Four Fire Scenarios}

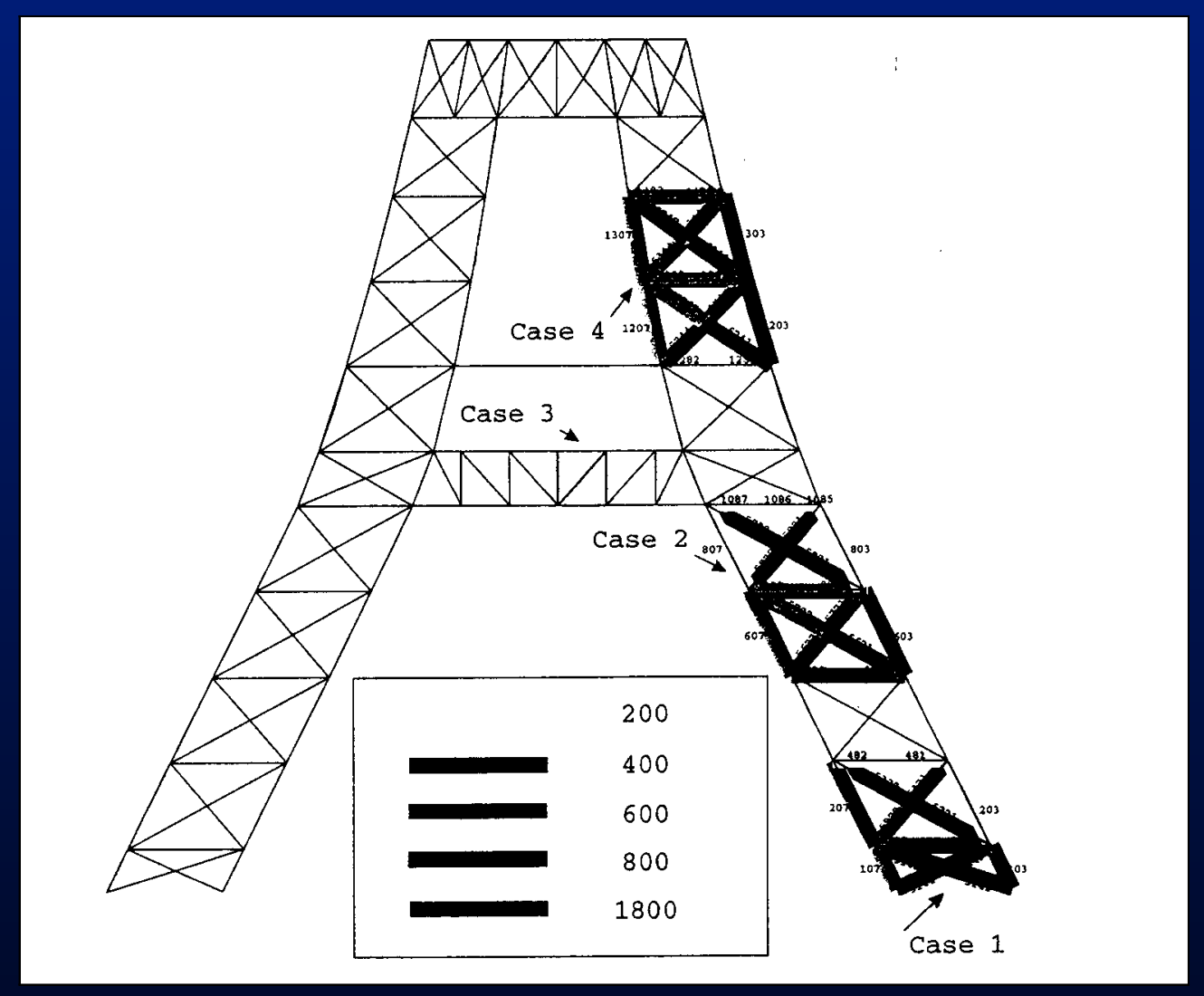




\title{
Behavior of Structures in Extreme Events
}

\author{
James Ricles \\ Department of Civil and Environmental Engineering \\ Lehigh University, Bethlehem, PA
}

NIST Workshop on

Fire Resistance Determination and Performance Prediction

February 19-20, 2002 


\section{Presentation}

- Response of Structures to Severe Earthquakes

- Elevated Temperature Effects on Structural Steel Systems

- Research Needs for Fire Resistance Determination and Performance Prediction 


\section{Response of Structures to Severe Earthquakes}

Damage to Olive View Hospital from 1971 San Fernando EQ

Soft-story Mechanism
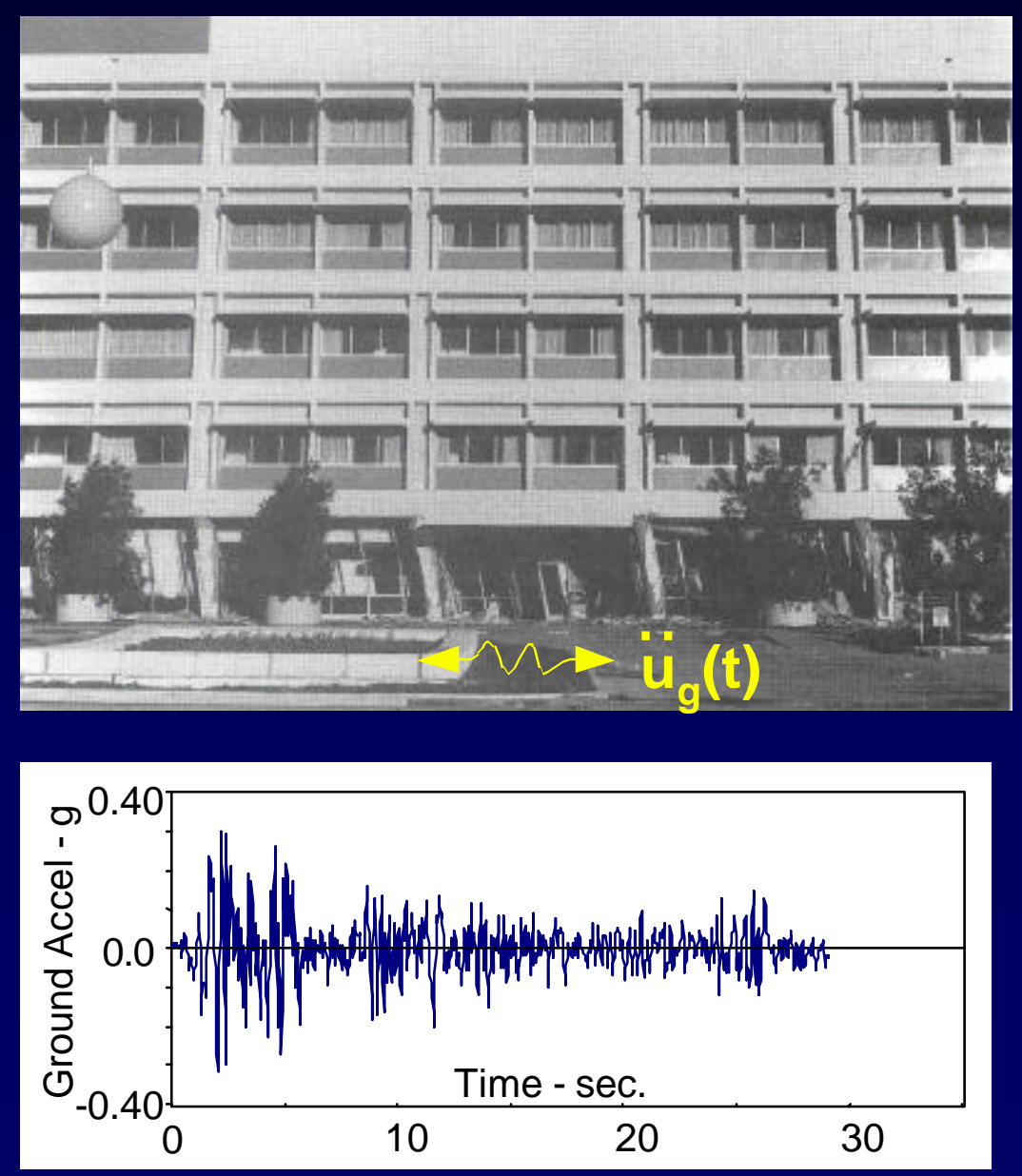

Column Failure

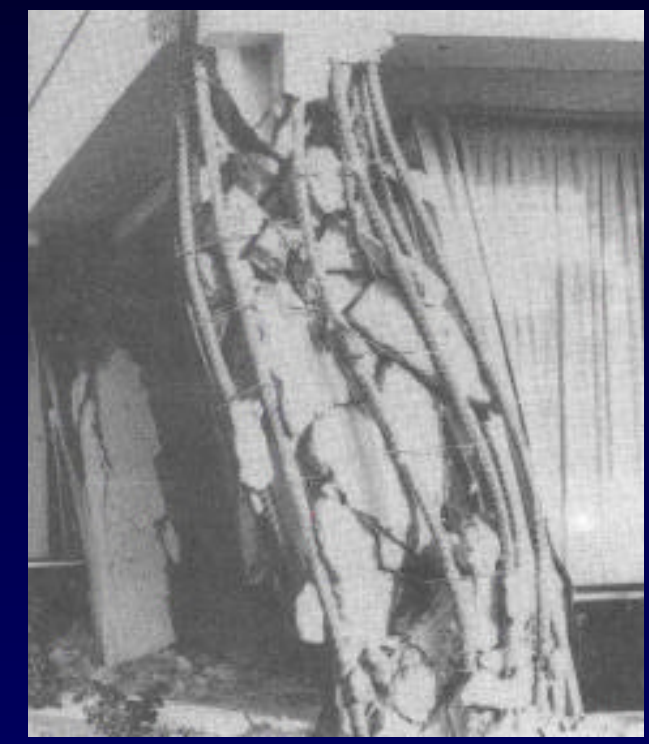

Source: Chopra, 2001 


\section{Structural Response Prediction to Earthquakes}

\section{Analysis}

- Material modeling (non-linearities)

- Cyclic plasticity

- Cyclic degradation of material stiffness and strength

- Fracture

- Geometric non-linearities

- Local buckling

- Global instabilities (P- $\Delta$ effects)

\section{Experimental testing}

- Database on real performance

- Proof of concept

- Calibration of analytical models 


\section{Earthquake Structural Performance Evaluation Experimental Testing}

Shake Table Testing

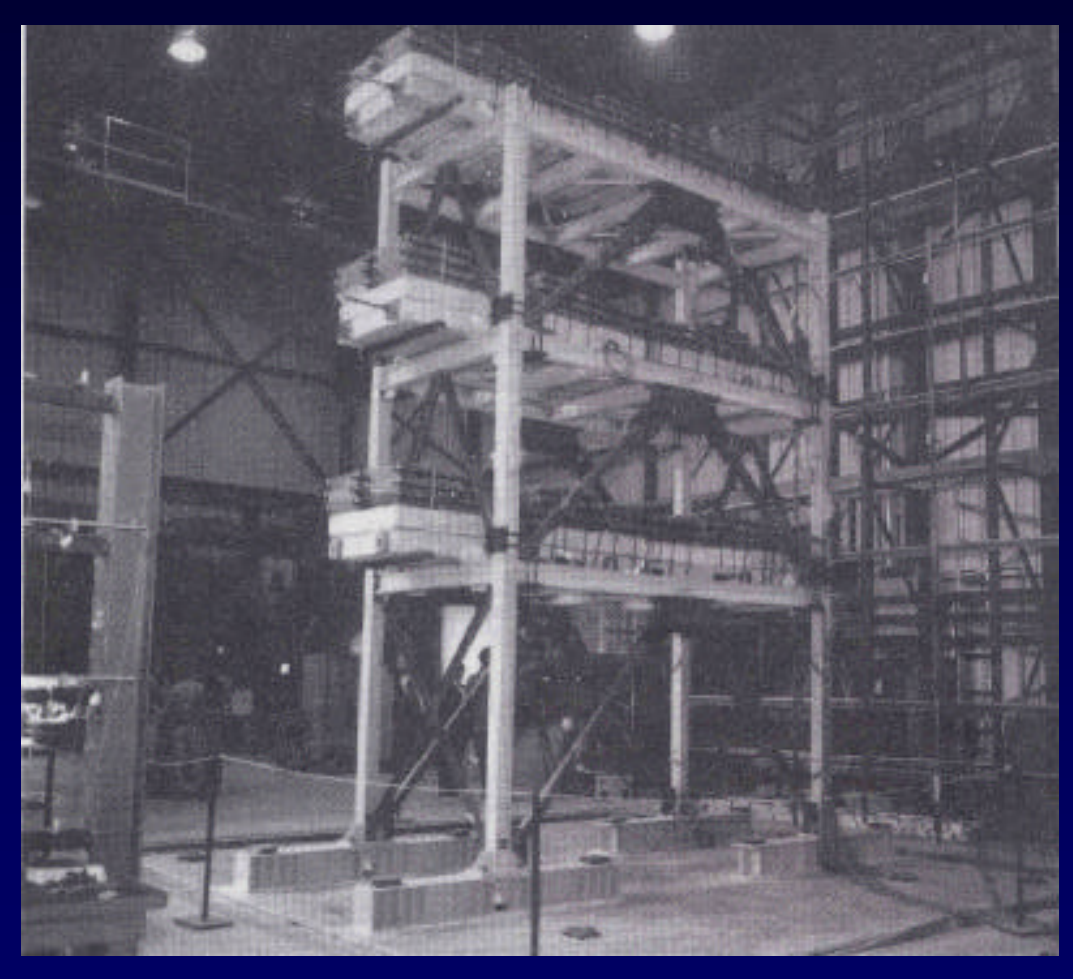

- Real Time

- Limited Specimen Size

University of California, Berkeley

Shake Table (Source: Chopra, 2001) 


\title{
Earthquake Structural Performance Evaluation Experimental Testing
}

\author{
Reaction Wall Testing \\ (Pseudo-Static or Pseudo Dynamic)
}

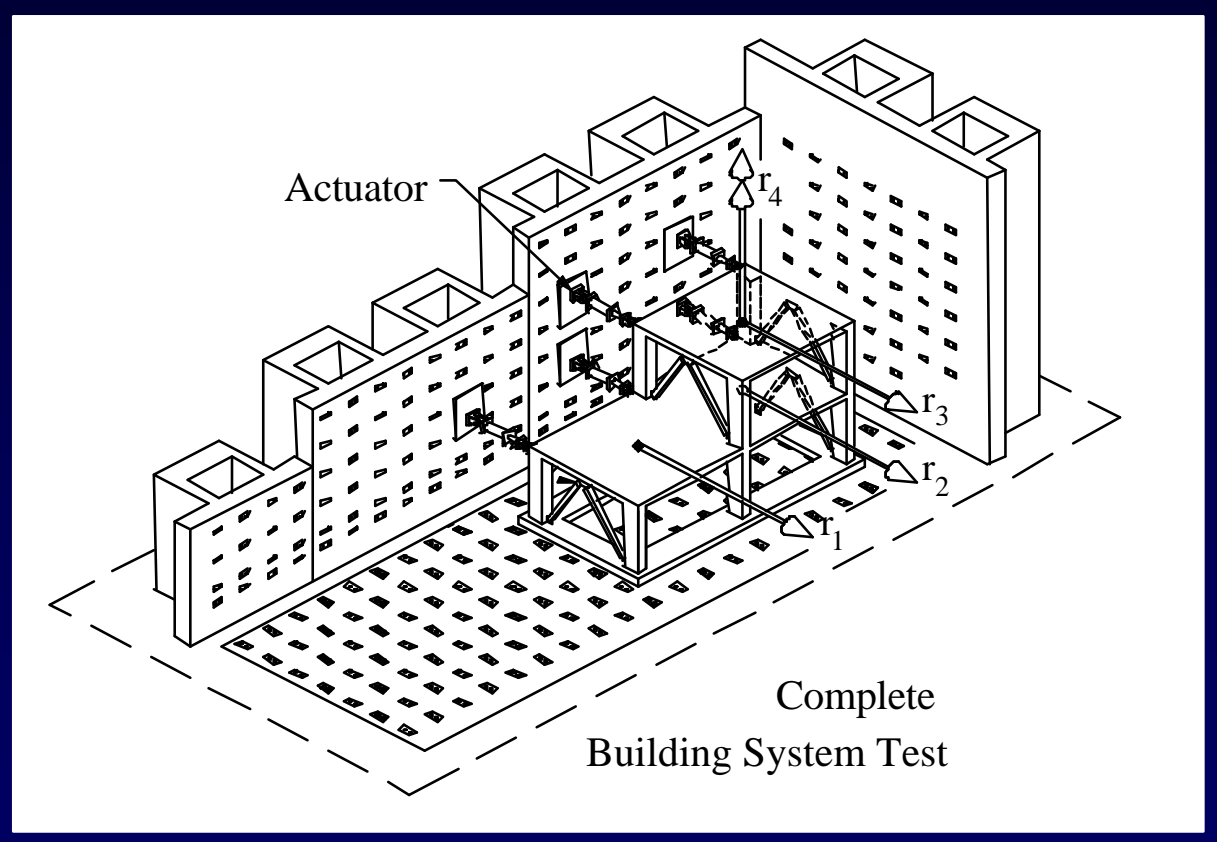

- Not Real Time

- Full-Scale Specimens

Lehigh University Multi-directional Reaction Wall Testing Facility 


\section{Earthquake Structural Performance Evaluation Experimental Testing}

Component Tests

(Pseudo-Static or Pseudo Dynamic)

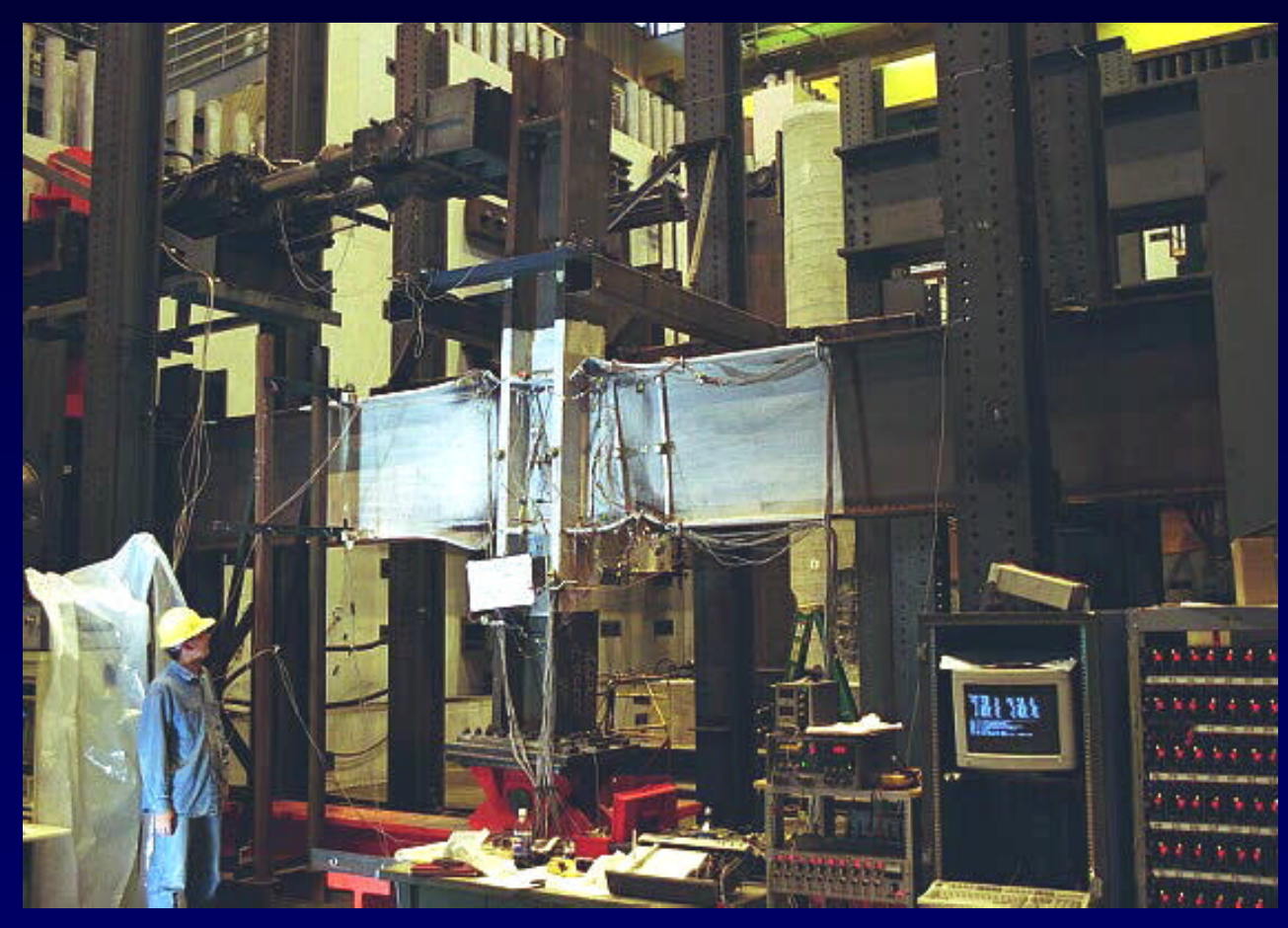

- Not Real Time

- Boundary Condition Effects

- Full-Scale Specimens

Lehigh University Multi-directional Reaction Wall Testing Facility 


\section{Earthquake Structural Performance Evaluation Analysis}

Finite Element Analysis of Welded Connection

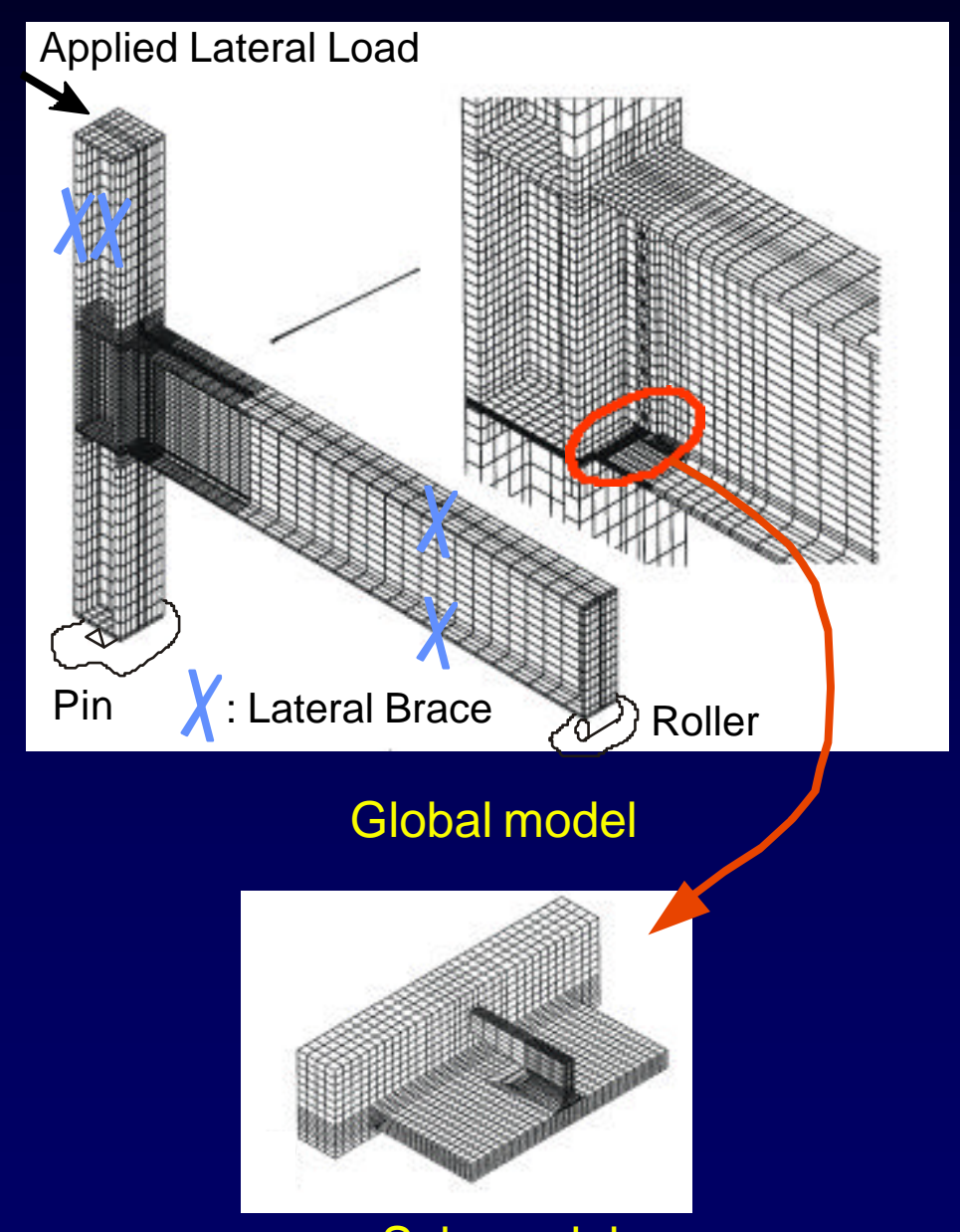

Sub-model
- Material and geometric non-linearities

- Emphasis on local joint region

- Cyclic load analysis

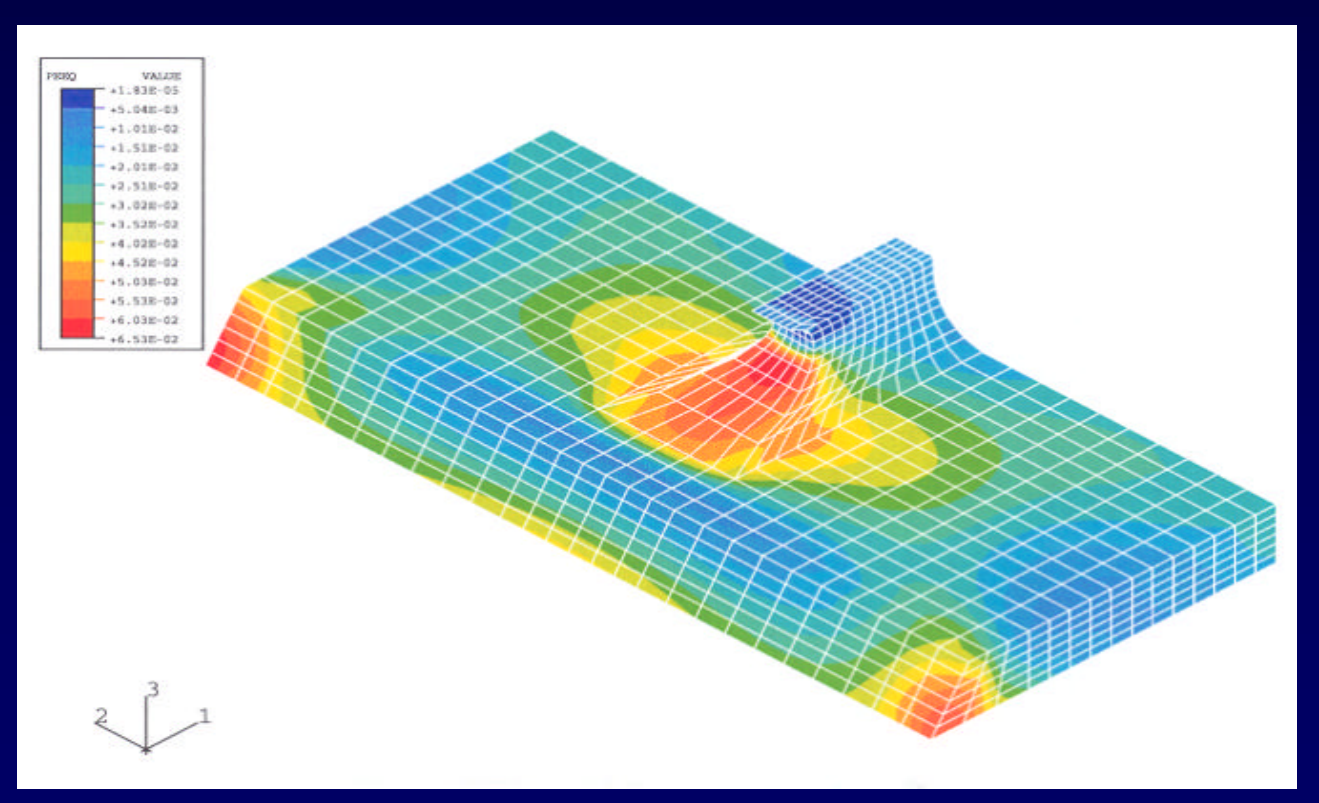

Equivalent Plastic Strain in Weld Access Hole Region 


\section{Earthquake Structural Performance Evaluation Analysis}

Finite Element Analysis of Welded Connection

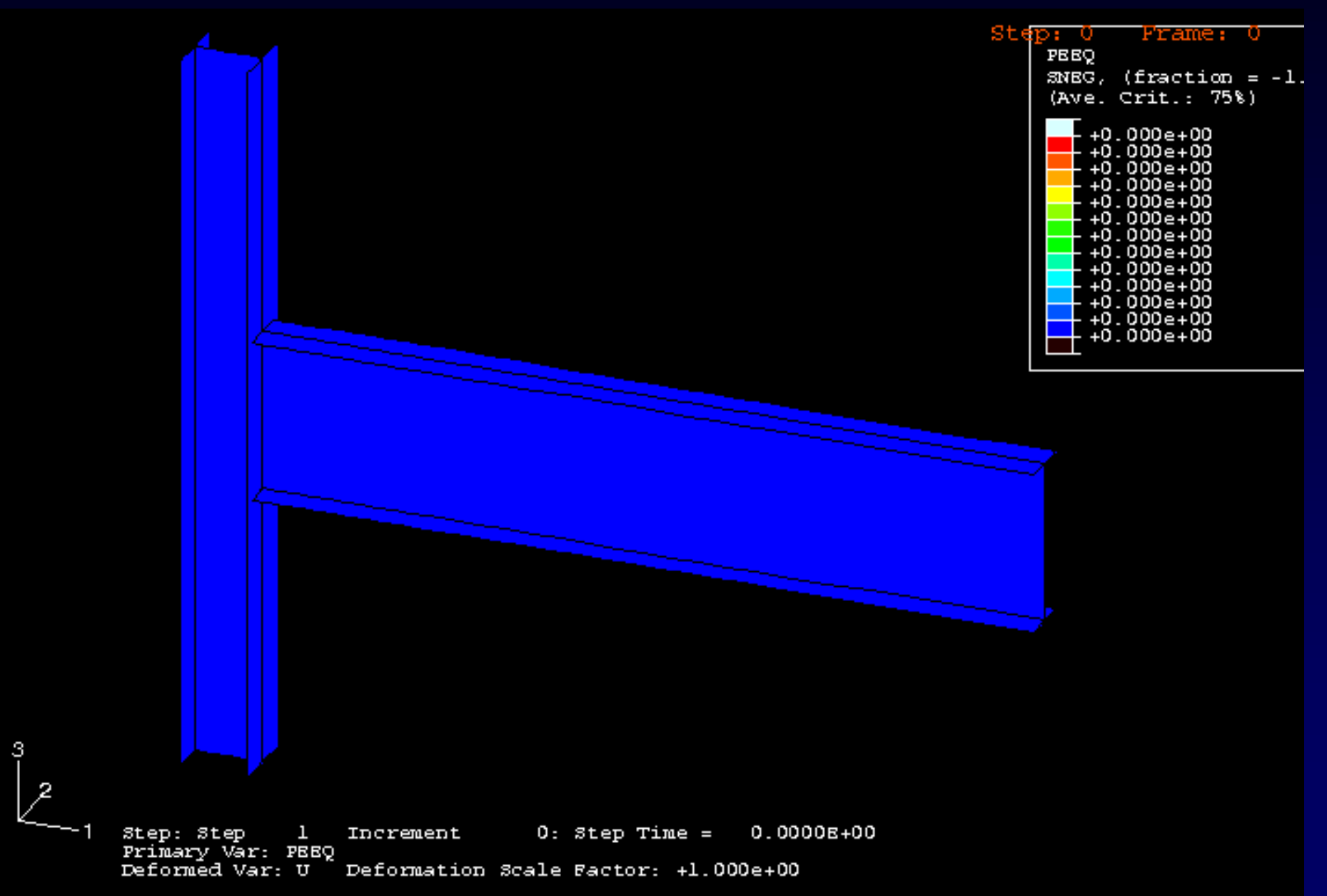

Cyclic Equivalent Plastic Strain 


\section{Earthquake Structural Performance Evaluation Analysis}

Finite Element Analysis of Welded Connection

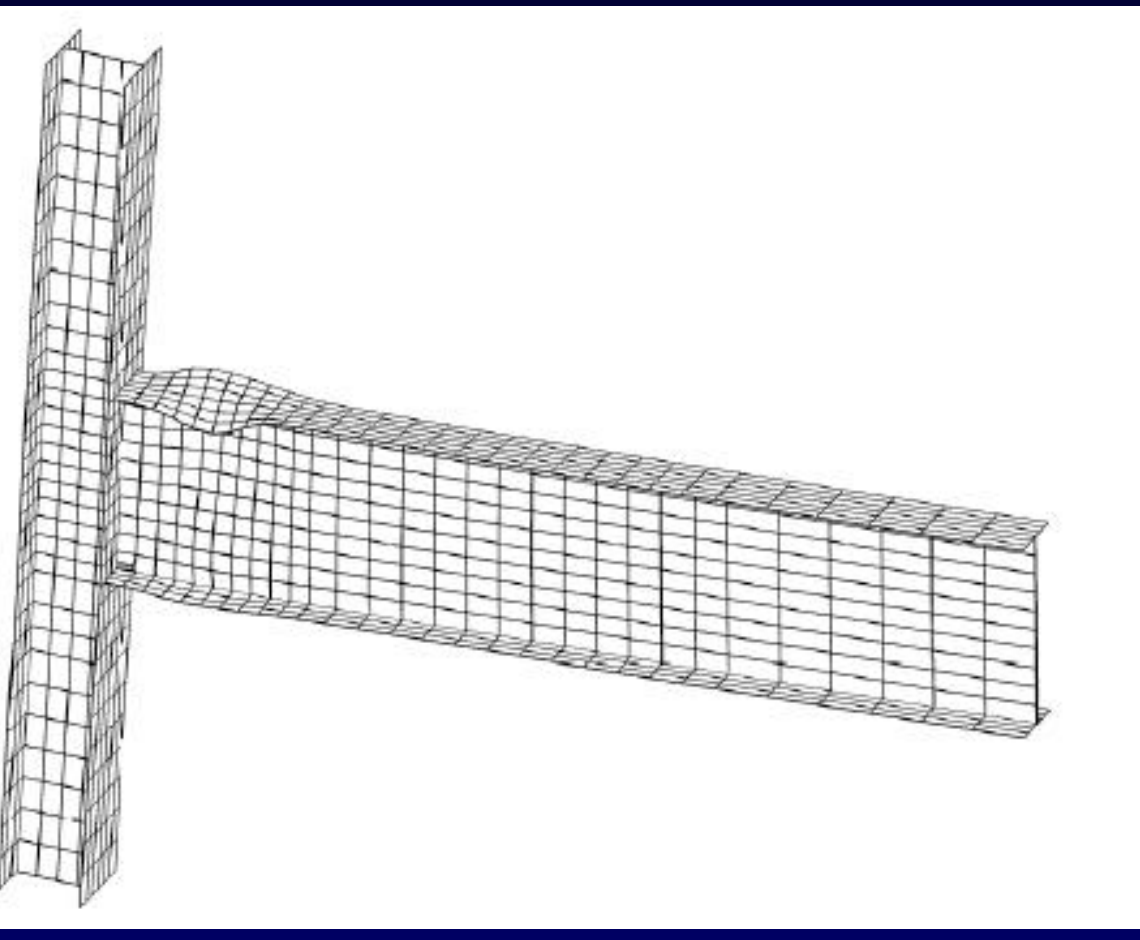

Deformed Shape with Local Buckling

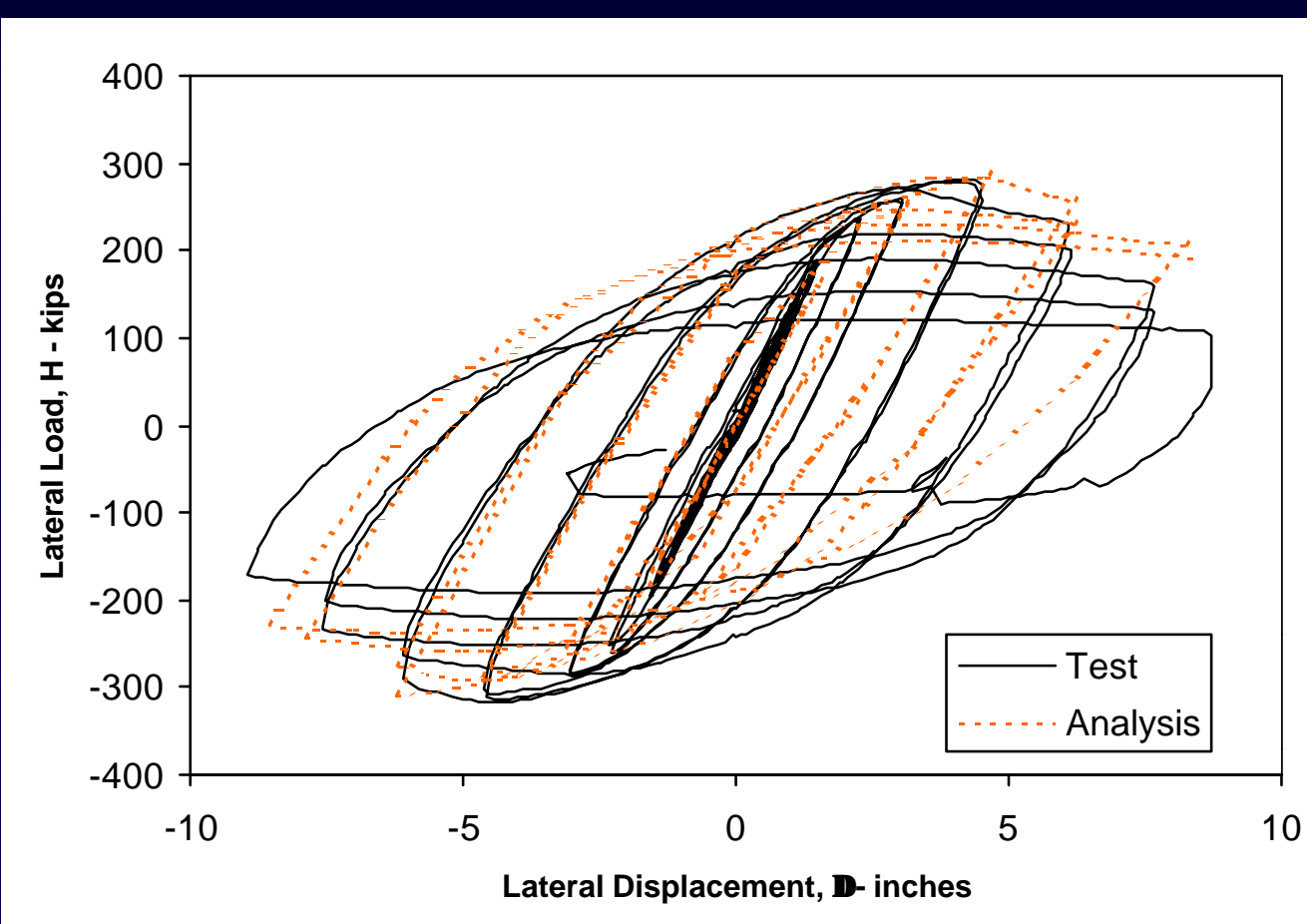

Lateral Load - Displacement Hysteretic Response 


\section{Earthquake Structural Performance Evaluation Analysis}

Nonlinear Structural System Time History Analysis
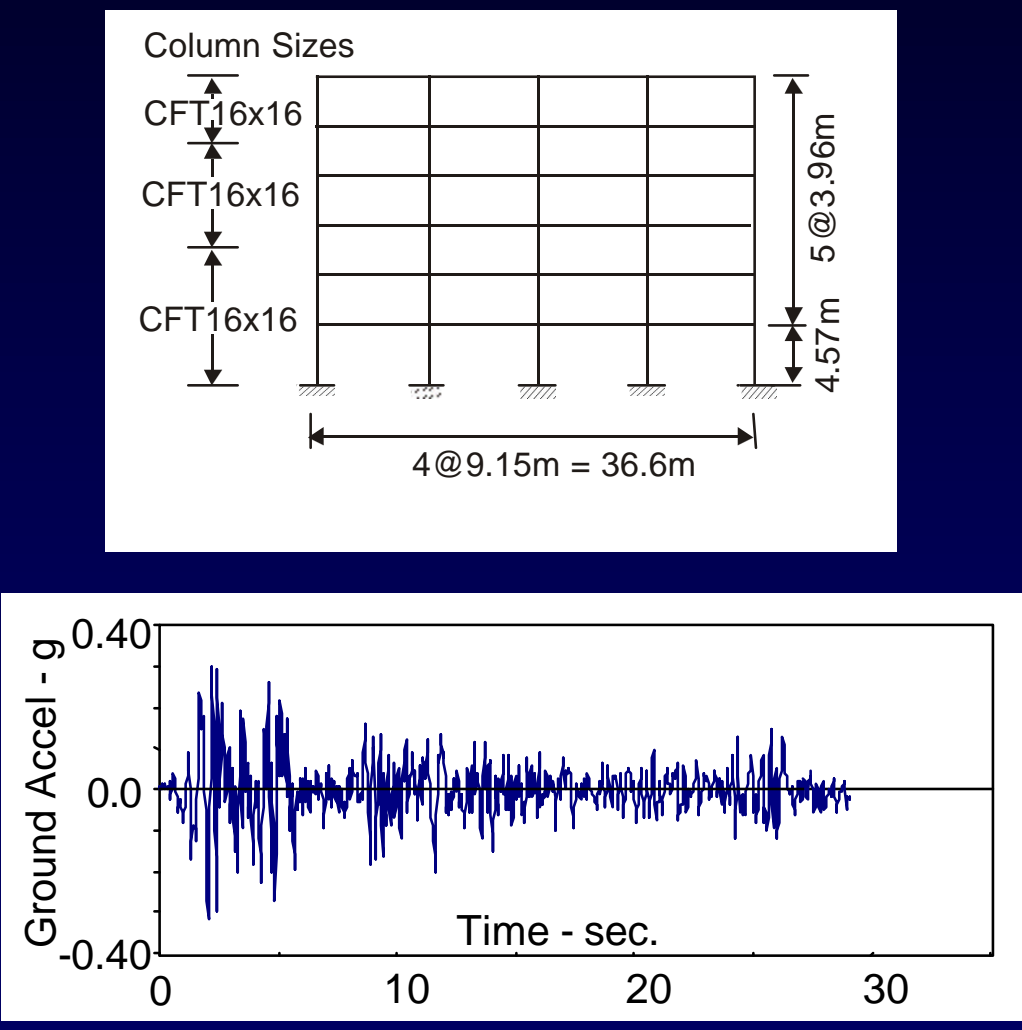
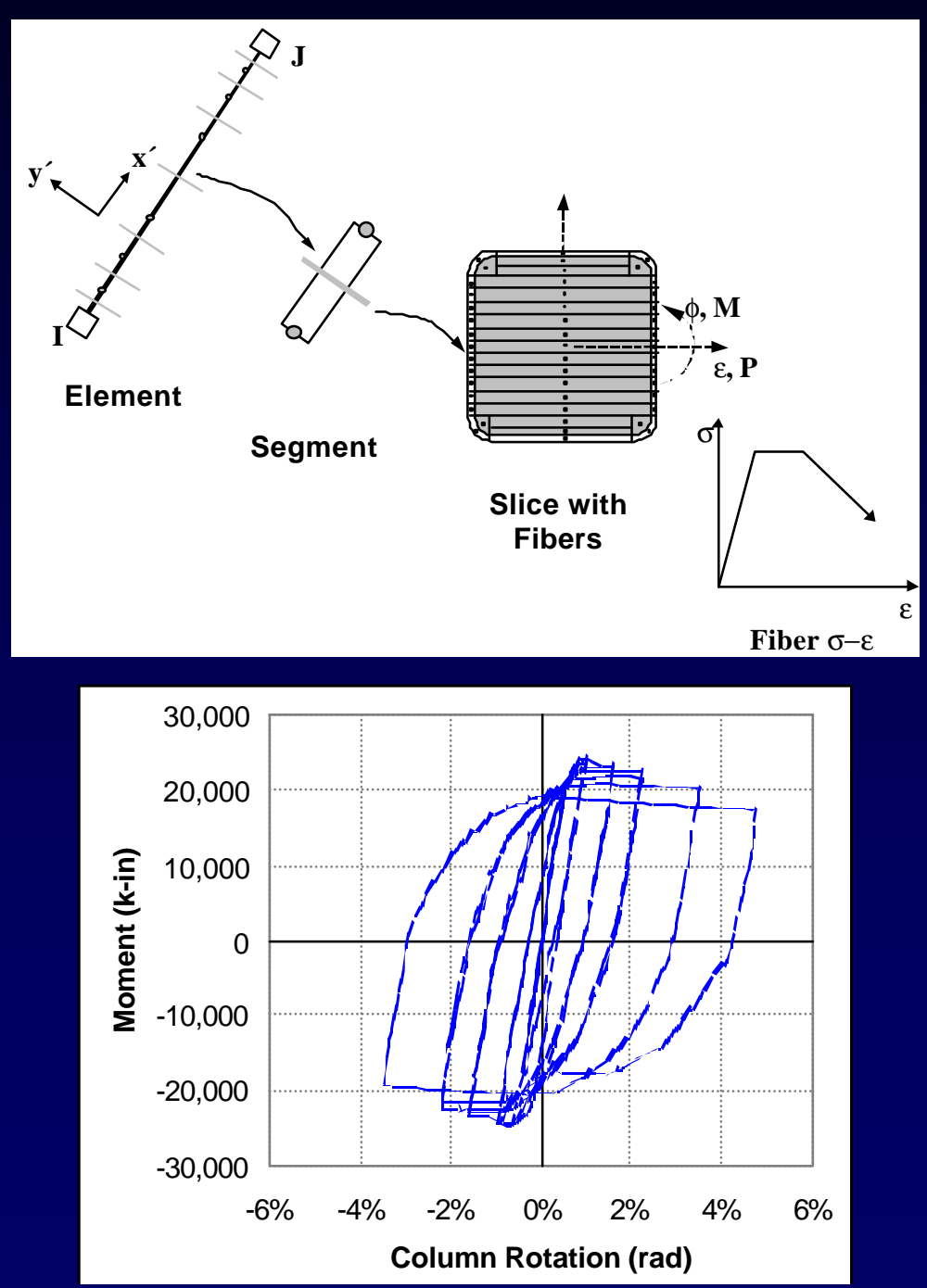


\section{Earthquake Structural Performance Evaluation Analysis}

Nonlinear Structural System Time History Analysis
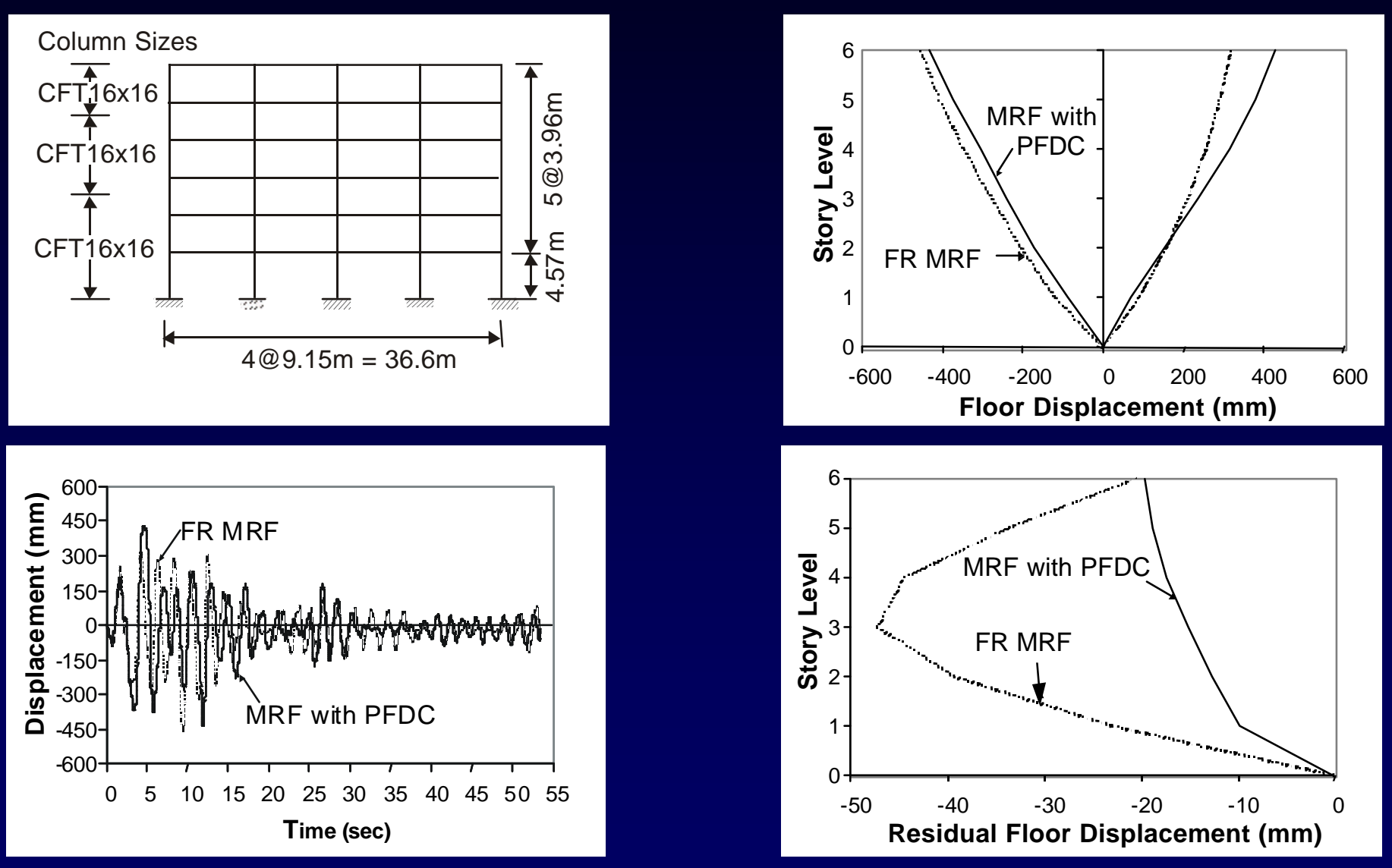


\section{Structural Steel Behavior at Elevated Temperature Steel Production}

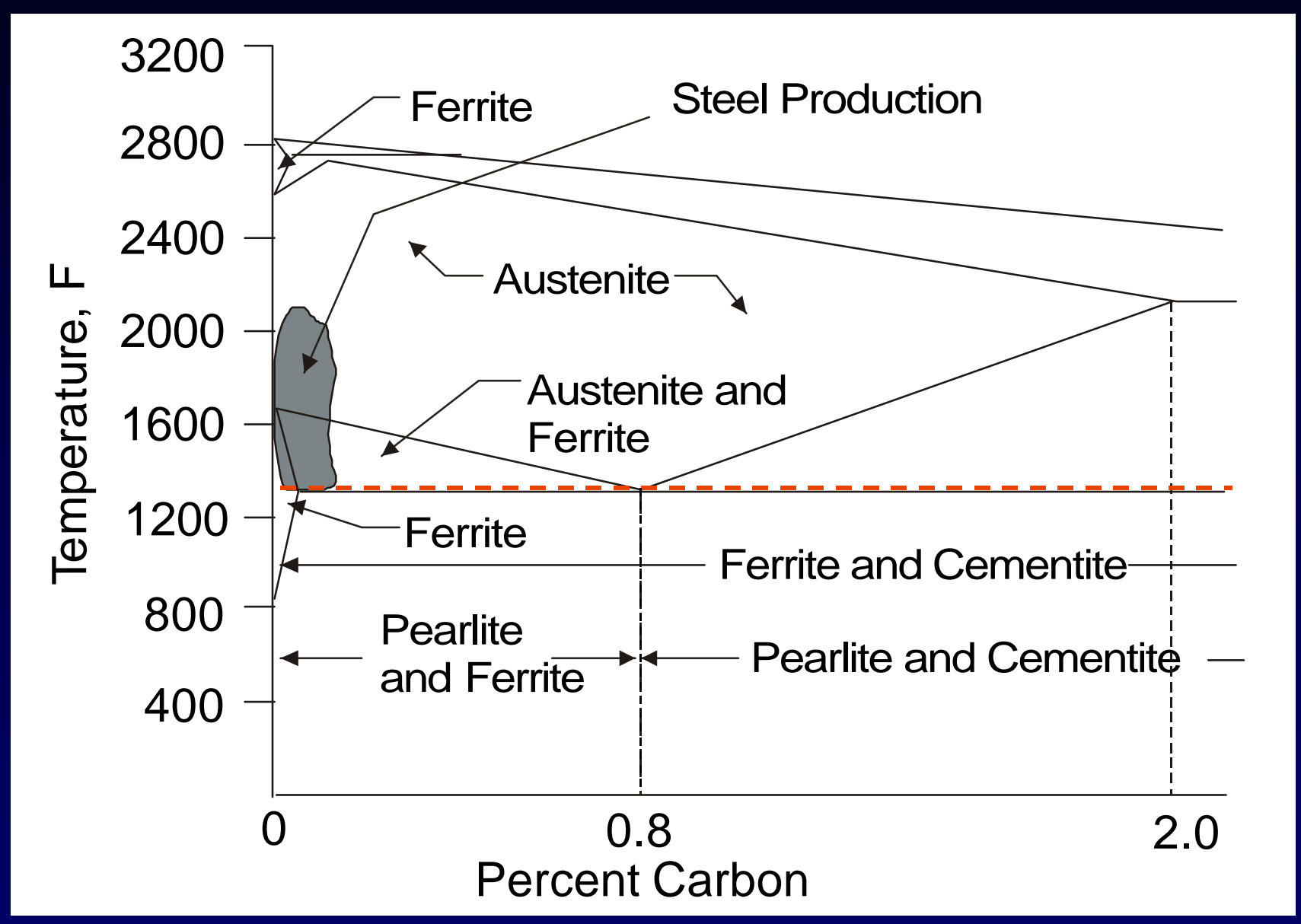

Phase Diagram for Structural Steel 


\section{Structural Steel Behavior at Elevated Temperature Mechanical Properties}
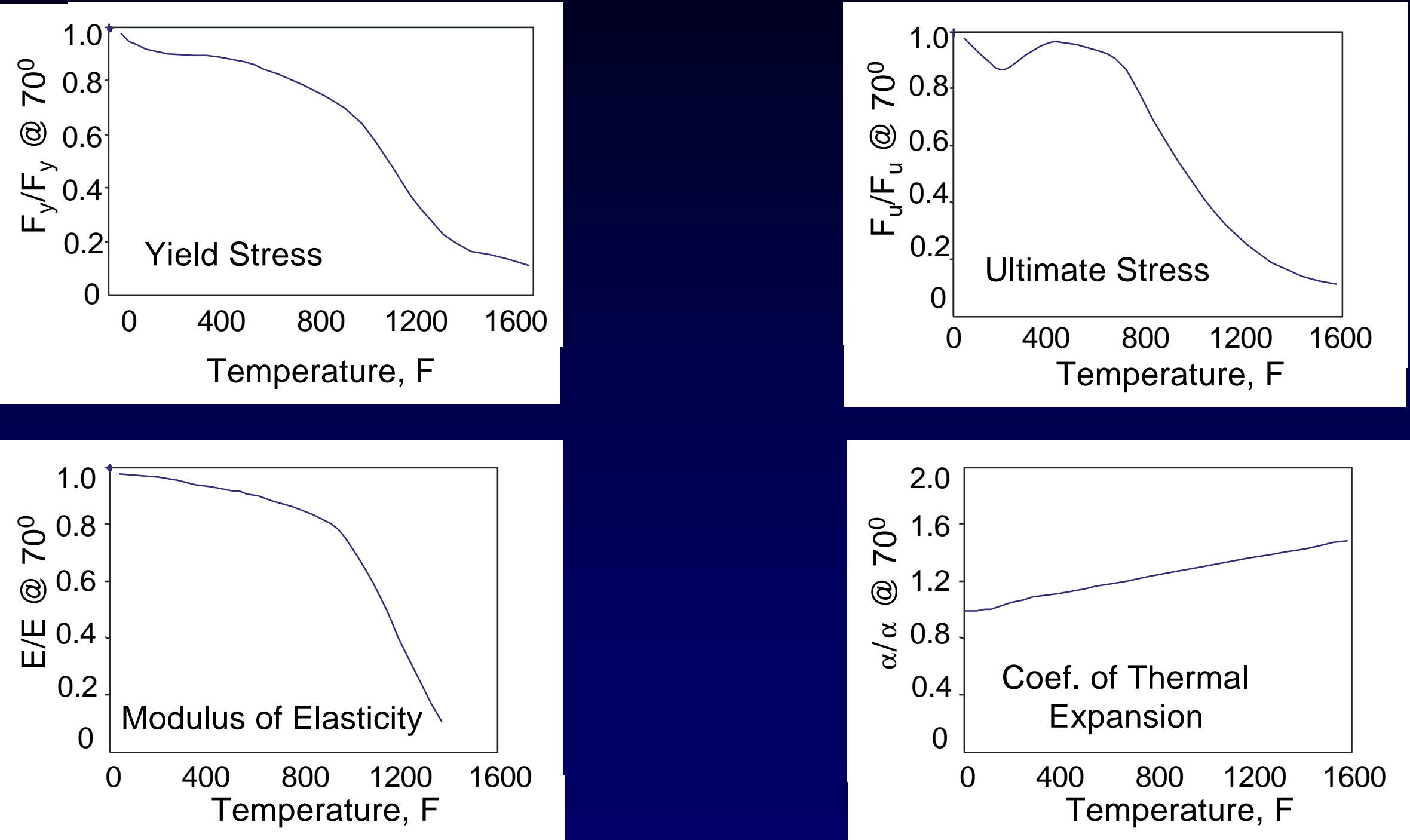


\section{Structural Steel Behavior at Elevated Temperature}

Structural Behavior

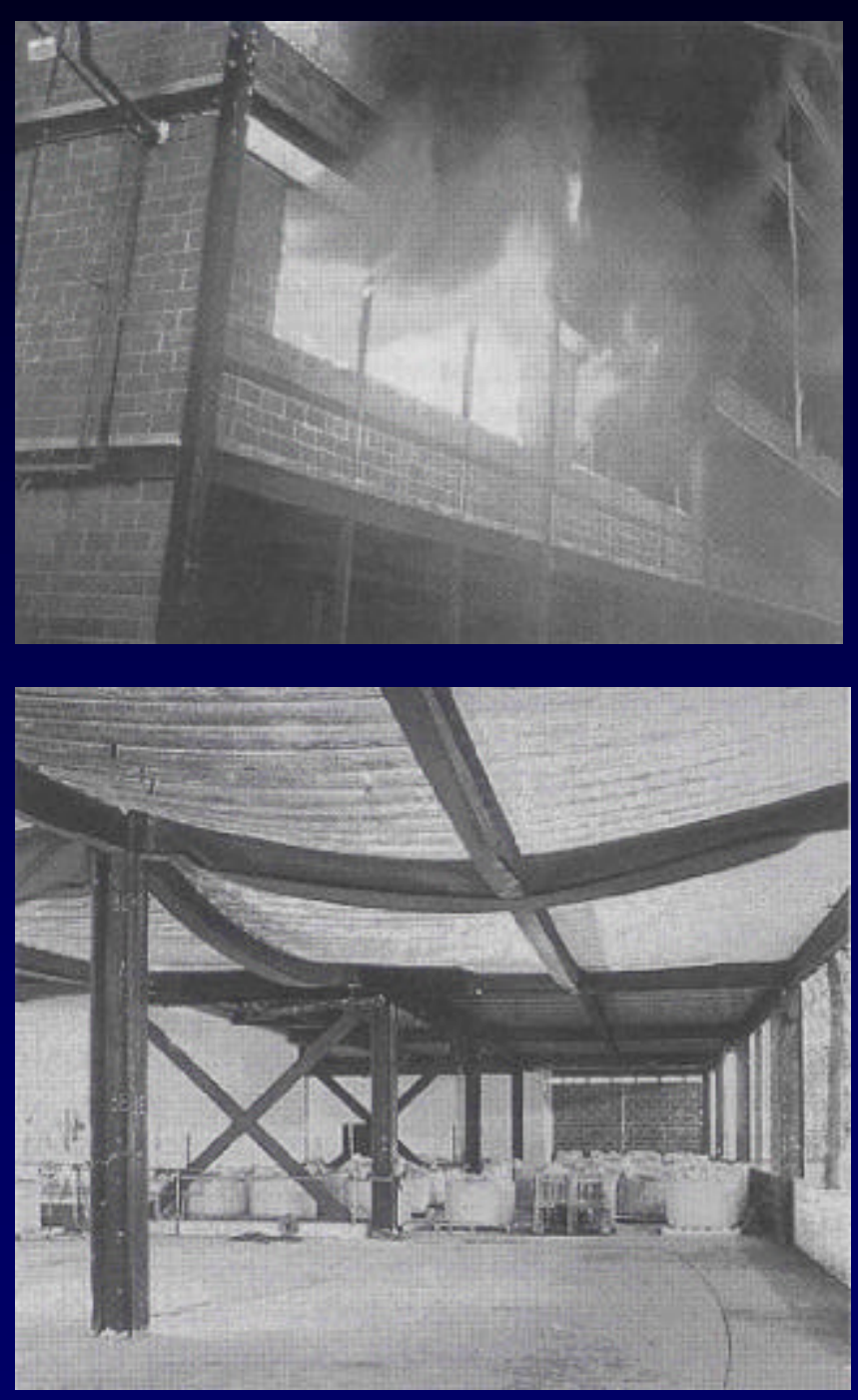

- Temperature Rise and Distribution

- Change in Material Properties

- Thermal Expansion

- Member Restraint

- Large Displacements

- Shifting Load 


\section{Structural Steel Behavior at Elevated Temperature Structural Behavior}

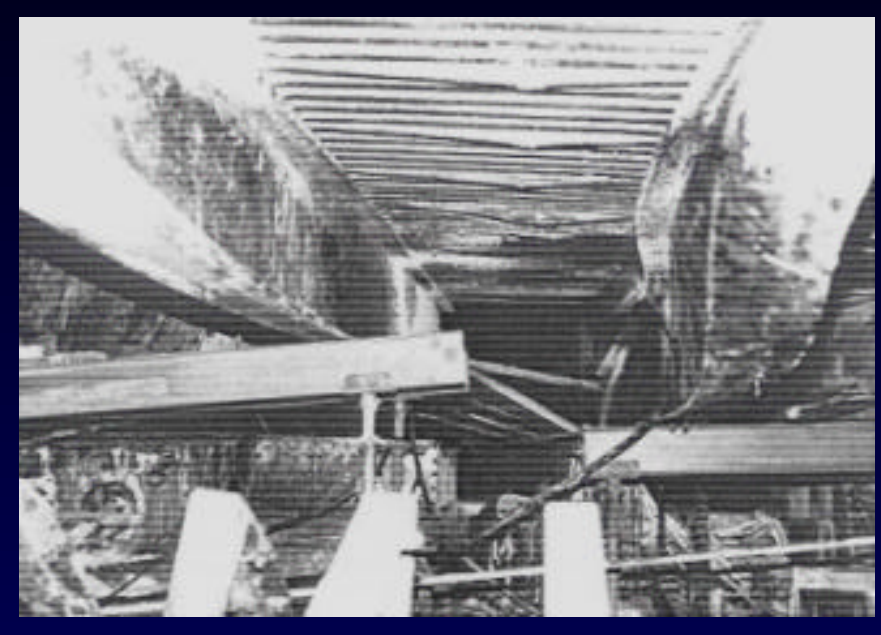

Beam Twisting

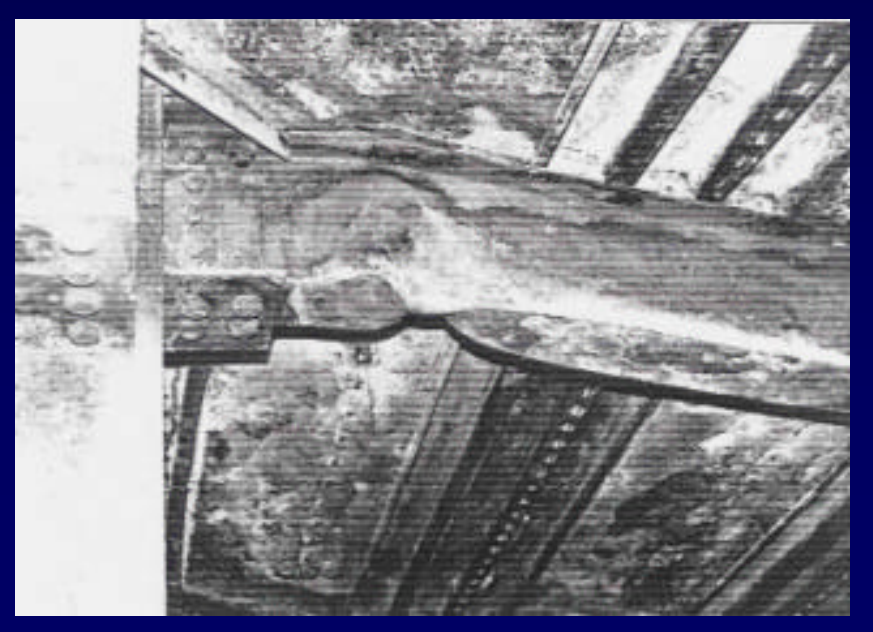

Beam Local Buckling

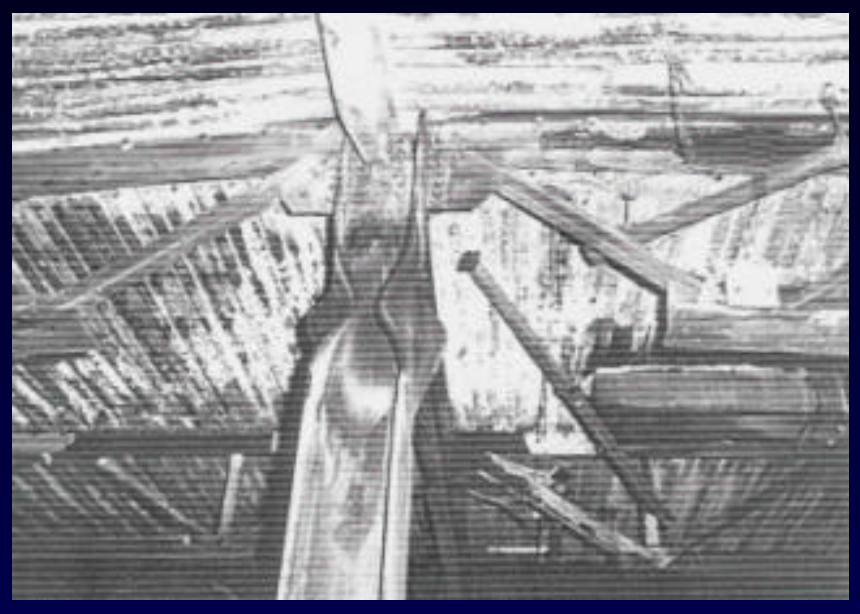

Column Local Buckling

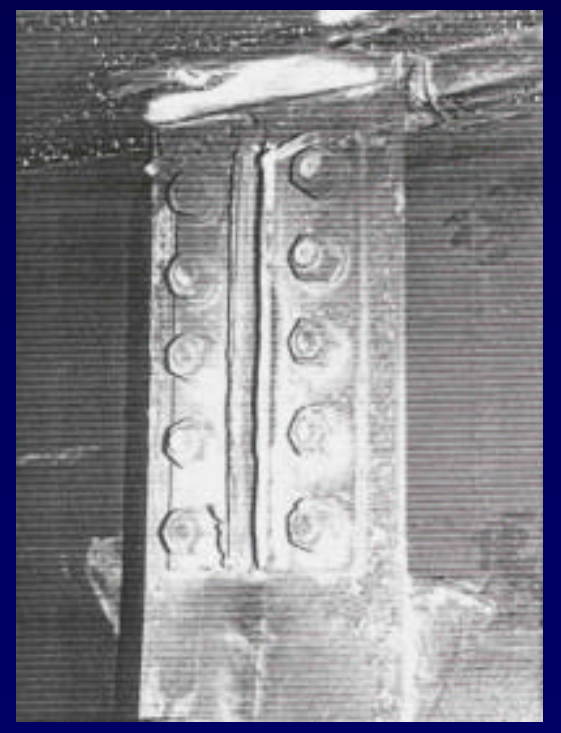

Connection Failure

(Source: Tide, 2000) 


\section{Post-Fire Structural Integrity Evaluation}

\section{Dexter and Lu, 2001}

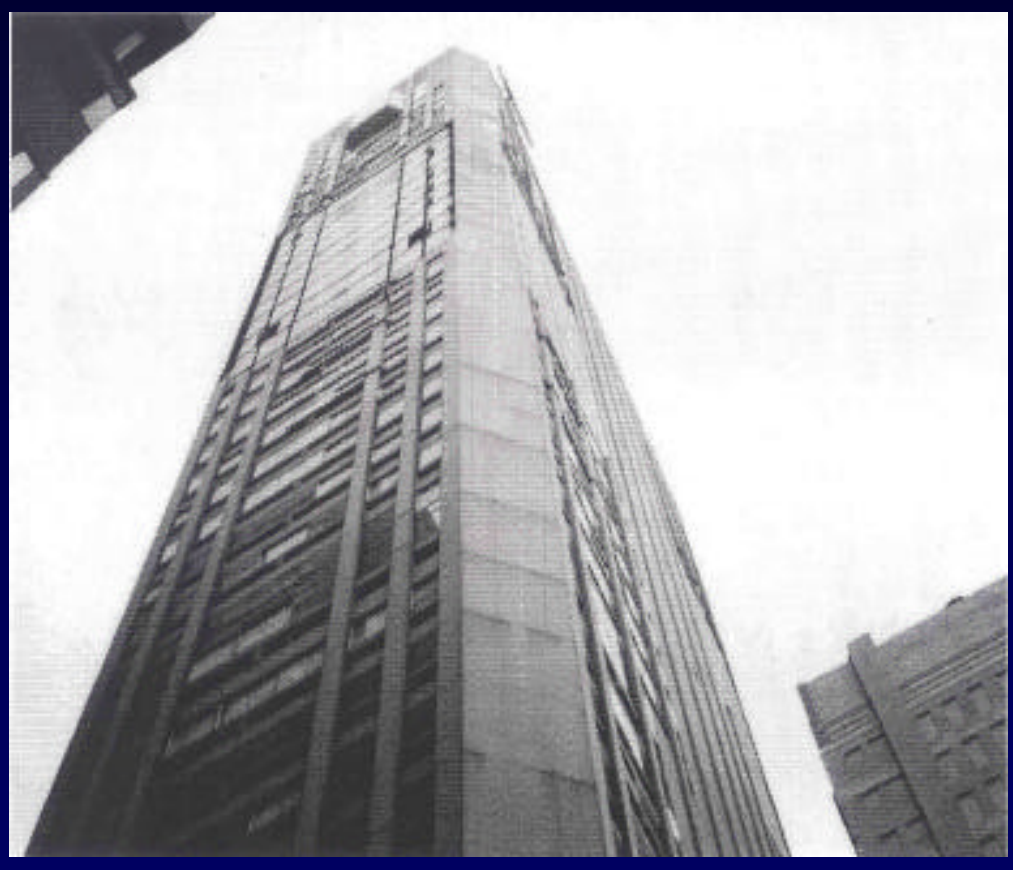

One Meridian Plaza (Phil, PA)

- 38-Story Steel Frame Bldg

- 1991 Fire, 18-hr Duration

- 9 Fire Floors 


\section{Post-Fire Structural Integrity Evaluation}

\section{Dexter and $L u, 2001$}

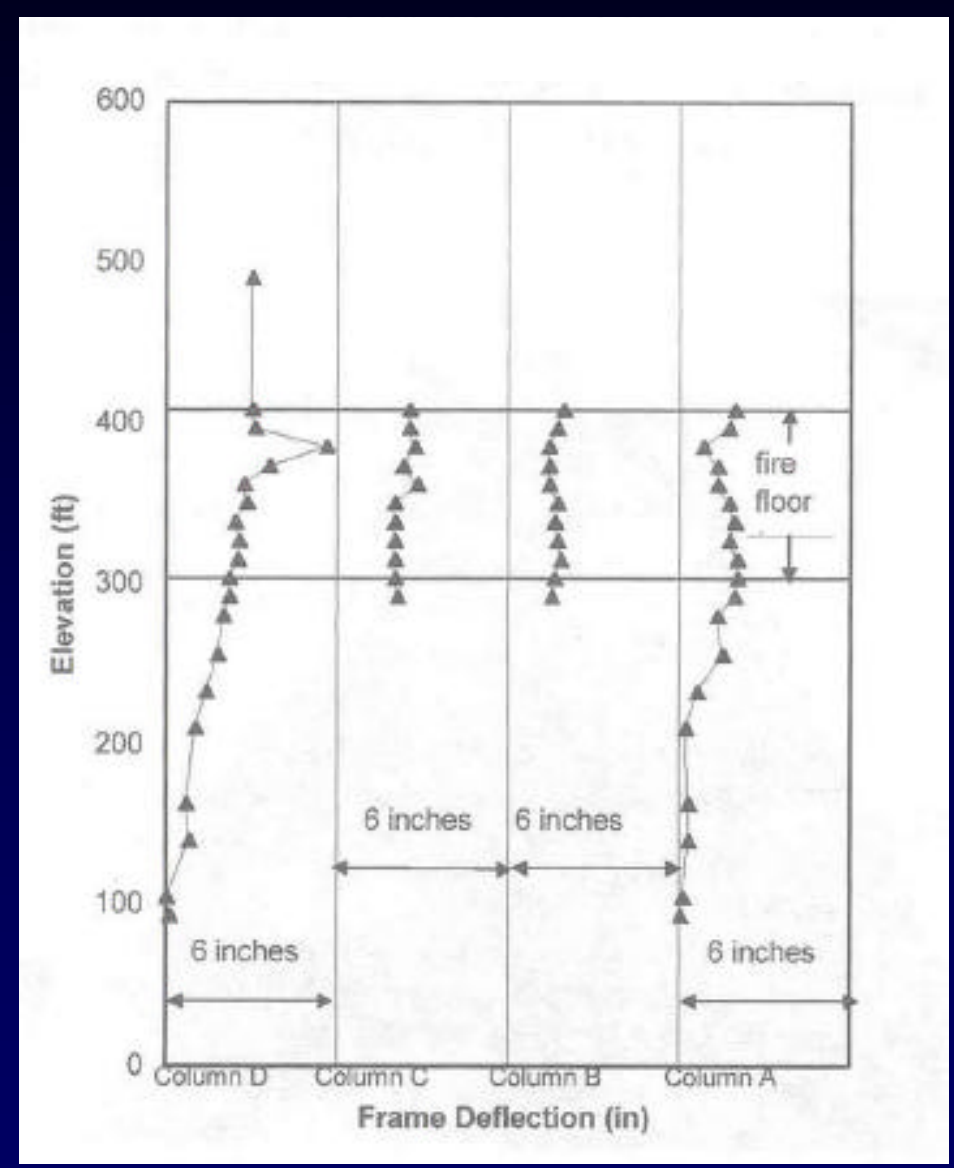

- Inelastic Deformations During Fire

- Changes in Beam Length - Locke in Forces in Members

Building Position After Fire 


\section{Post-Fire Structural Integrity Evaluation}

Dexter and Lu, 2001

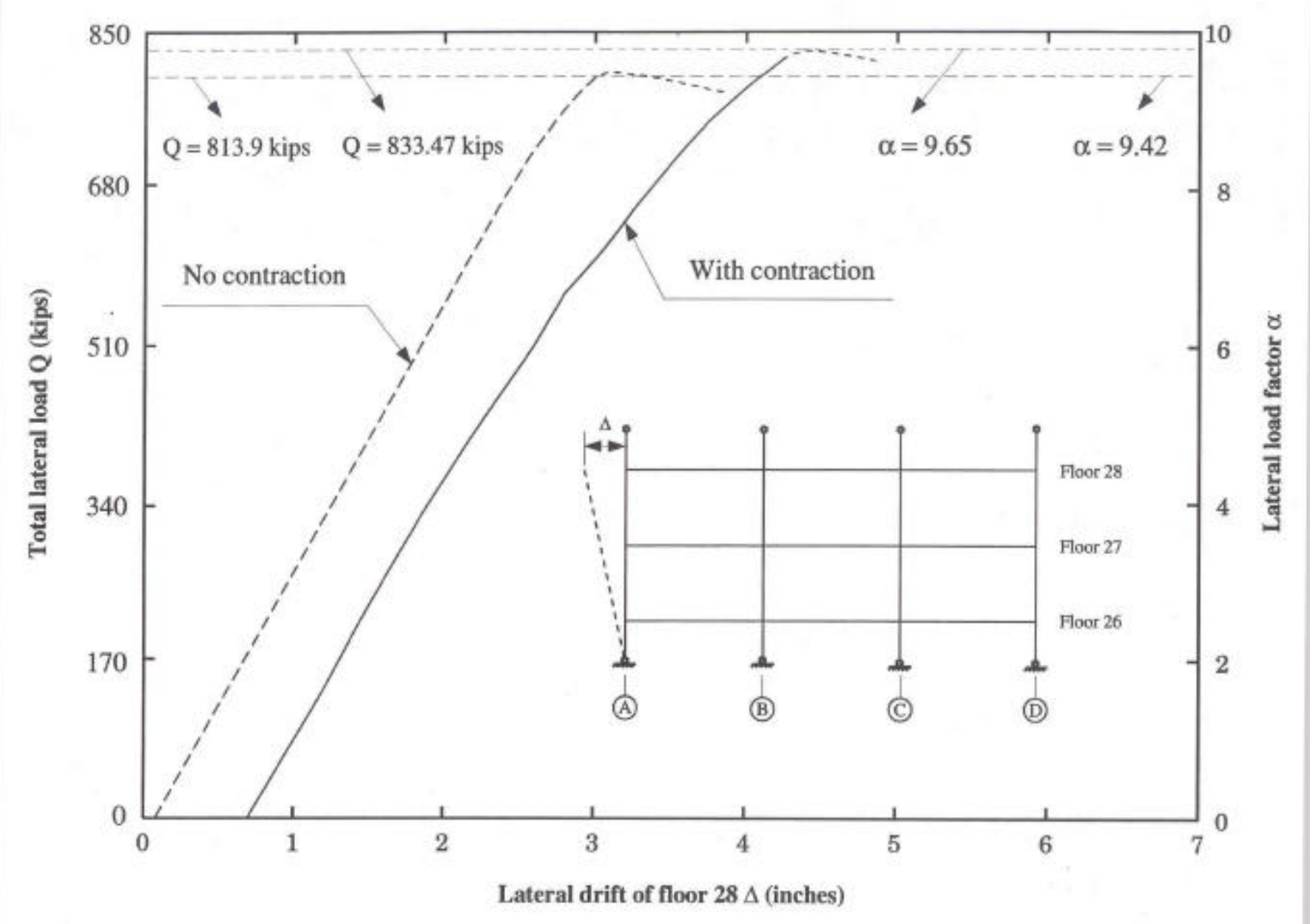

Non-linear Static Pushover Analysis 


\section{Research Issues and Needs}

\section{Testing -}

- Structural component vs. structural system tests (effects of structural redundancy, restraint, connections, non-load bearing elements)

- Thermal input

- Measuring structural response (thermal effect on sensors)

- Test protocol

- Adequate facility for conducting fire testing

\section{Analysis -}

- Calibration of models with test data

- Structural component vs. structural system modeling (effects of structural redundancy, restraint, connections, non-load bearing elements)

- Thermal input

- Time scale

- Non-linearities:

- Change in material properties due to thermal input and loading

- Geometric non-linearities (large displacements; local buckling; load shifting)

- Connection modeling (stiffness and strength deterioration; fracture) 


\section{Summary and Conclusions}

(1) Success has been achieved in predicting the performance of structures to extreme earthquakes

- Sophisticated analytical models

- Experimental testing

(2) Predicting the fire resistance and performance of a structure has several challenges. The complexities involved require sophisticated analytical models, and experimental testing to calibrate these models. 